ENRICO BARNABA FERRI

UMA PROPOSTA DE HEURÍSTICA PARA SOLUÇÃO DO

PROBLEMA DE COBERTURA DE ROTAS

COM CARDINALIDADE RESTRITA

São Paulo

2009 


\section{UMA PROPOSTA DE HEURÍSTICA PARA SOLUÇÃO DO PROBLEMA DE COBERTURA DE ROTAS COM CARDINALIDADE RESTRITA}

Dissertação apresentada à Escola Politécnica da Universidade de São Paulo para obtenção do Título de Mestre em Engenharia.

Área de Concentração:

Engenharia de Produção

Orientador: Prof. Livre-Docente Hugo Tsugunobu Yoshida Yoshizaki 
Este exemplar foi revisado e alterado em relação à versão original, sob responsabilidade única do autor e com a anuência de seu orientados.

São Paulo, de setembro de 2009

Assinatura do autor:

Assinatura do orientador:

FICHA CATALOGRÁFICA

Ferri, Enrico Barnaba

Uma proposta de heurística para solução do problema de cobertura de rotas com cardinalidade restrita / E.B. Ferri. - ed. rev. -- São Paulo, 2009. $162 \mathrm{p}$.

Dissertação (Mestrado) - Escola Politécnica da Universidade de São Paulo. Departamento de Engenharia de Produção.

1.Pesquisa operacional 2. Heurística 3.Logística (Administração de Materiais) I.Universidade de São Paulo. Escola Politécnica. Departamento de Engenharia de Produção II.t. 
"Giudico che la fortuna sia arbitra della metà delle azioni nostre, ma che ce ne lasci governare l'altra metà."

Niccolò Machiavelli 


\section{AGRADECIMENTOS}

Ao Professor Livre Docente Hugo Yoshizaki, meu orientador, pelas preciosas horas de discussão e pela orientação desde a definição do tema deste estudo.

Aos meus pais, Fabio e Mari, e minha irmã Paola pelo apoio e incentivo aos meus estudos.

Aos amigos Pedro Camargo, Celso Hino, Daniel Chebat e Leonardo Maluta pelas valiosas dicas e ajudas durante o desenvolvimento deste estudo.

À Profa. Dra. Özlem Ergun por prover partes dos algoritmos utilizados.

A todos que de alguma forma contribuíram para a realização deste trabalho. 


\section{RESUMO}

A necessidade de redução de custos logísticos tem obrigado as empresas a colaborar entre si. O problema de logística colaborativa aqui enfocado é assim definido: identificar ciclos (ou seja, um percurso fechado) em um conjunto de rotas de carga de lotação (onde o caminhão coleta carga em um ponto e vai diretamente ao local de descarga, pois é completamente preenchido) de vários embarcadores de forma a minimizar o reposicionamento (isto é, viagens sem carga útil) de caminhões, dado que o subconjunto de rotas de um determinado embarcador pode conter rotas que complementam aquelas de outro. Desta maneira, vários embarcadores combinados podem oferecer aos transportadores um conjunto de ciclos com movimentação regular de veículos com carga completa e com mínimo reposicionamento.

Esse problema pode ser modelado como um problema particular de cobertura de conjuntos com restrição de ciclos, o problema de cobertura de rotas com cardinalidade restrita (PCRCR), que é NP-Hard. Este estudo apresenta uma heurística alternativa que obtém resultados, em média, 1,74\% melhores que a literatura existente, além de solucionar instâncias maiores. Ademais, o tempo de execução da heurística cresce de forma polinomial em função do tamanho do problema, ao contrário dos demais métodos aqui avaliados, que possuem comportamento exponencial.

Palavras-chave: Heurística, cobertura de rotas, logística colaborativa. 


\begin{abstract}
Cost and sustainability imperatives are compelling reasons to make companies to collaborate with each other in order to operate more efficiently. The shipper collaboration problem can be defined as how to identify tours (i.e. a closed path) in a set of lanes from various shippers that minimize truck repositioning (deadheads), as the sub-set of routes from a single shipper may have lanes that complement the routes of another shipper. Thus, combined shippers may offer to carriers a set of tours with regularly executed truckload movements (where the truck loads at a point and go directly to the disposal location) with minimum asset repositioning.

This problem can be modeled as a particular case of the set covering formulation with constrained cycles, the cardinality constrained lane covering problem (CCLCP), which is NP-hard. This work resents an alternative heuristic that obtains results about $1.74 \%$ better than the existing literature, and solves larger instances. Besides, the heuristic's execution time presents polynomial growth, unlike other methods that have exponential behavior.
\end{abstract}

Keywords: Heuristic, lane covering, collaborative logistics 


\section{SUMÁRIO}

1 INTRODUÇÃO.......................................................................................1

1.1 Contextualização e Relevância do Problema.............................................

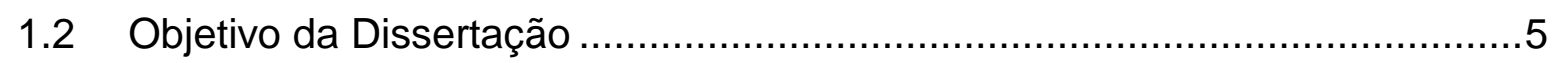

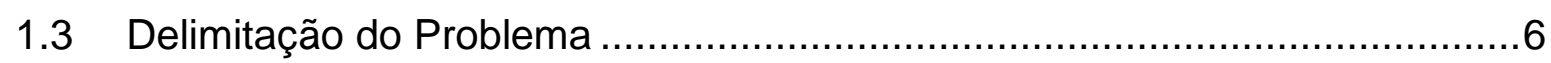

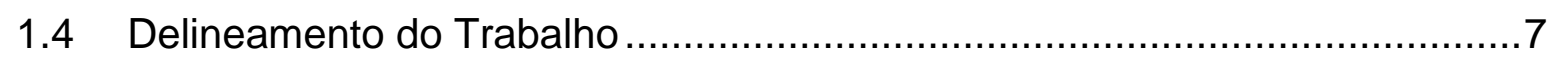

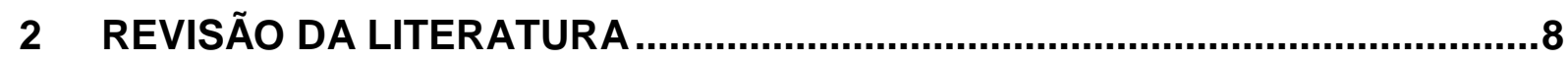

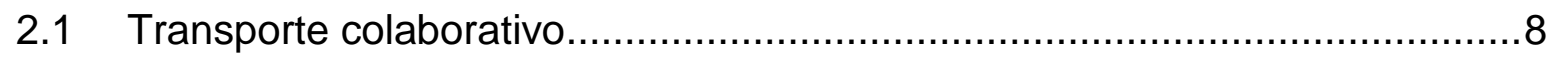

2.2 Problema de cobertura de rotas e suas variações ......................................

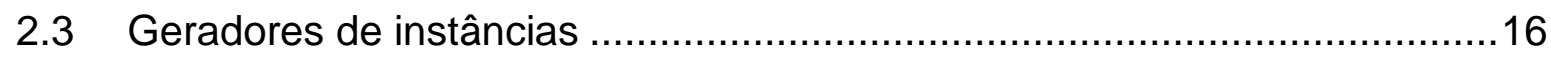

3 METODOLOGIA E MODELAGEM DO PROBLEMA …....................................

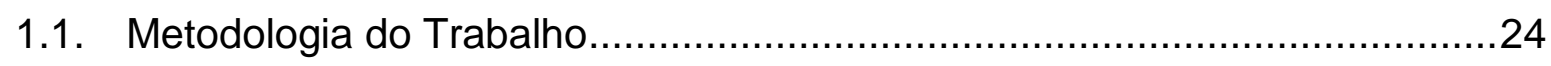

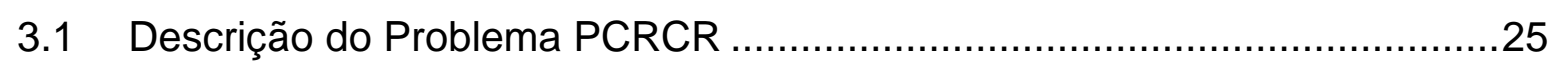

3.1.1 Formulação Matemática - Modelo Básico ................................................................. 25

3.1.2 Formulação Matemática - Modelo de Cobertura de Conjuntos ................................. 28

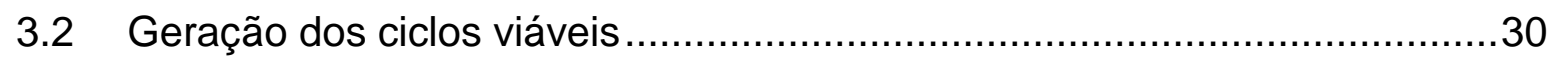

3.2.1 Algoritmo de Busca Posterior .......................................................................... 31

3.2.2 Algoritmo de Busca Anterior .......................................................................... 32

3.2.3 Algoritmo de Geração de Ciclos 1 .................................................................. 33

3.2.4 Algoritmo de Geração de Ciclos 2 …………………………………………….... 34

3.3 Algoritmo Guloso proposto por (ERGUN et al, 2007b) .............................36

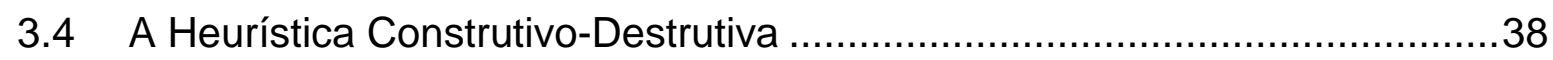

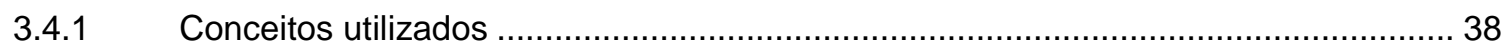

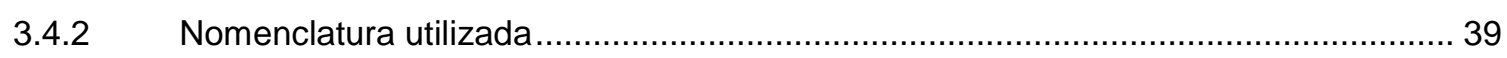

3.4.3 Descrição da Heurística Construtivo-Destrutiva ..................................................... 40

3.4.4 Exemplo de Utilização da Heurística ................................................................... 44

3.5 Gerador de Instâncias ........................................................................5

3.5.1 O gerador de problemas balanceados ................................................................... 56

3.5.2 O gerador de problemas desbalanceados …………………………………….... 58

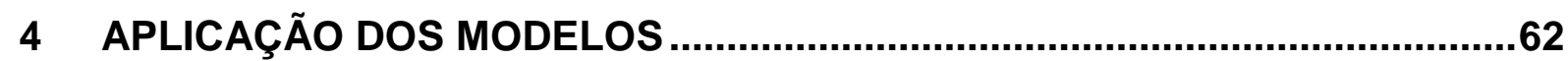

4.1 Escopo e Parâmetros do Caso Teste......................................................62

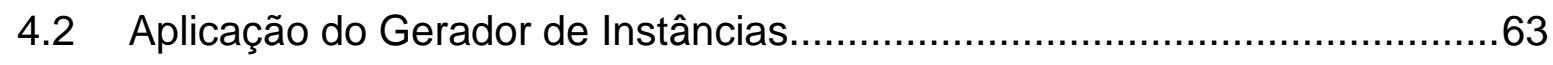

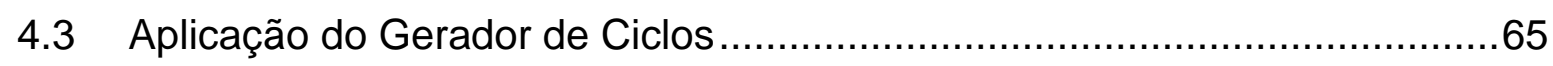

4.4 Aplicação da PLI ....................................................................... 


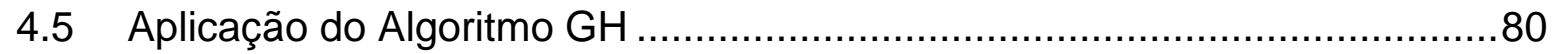

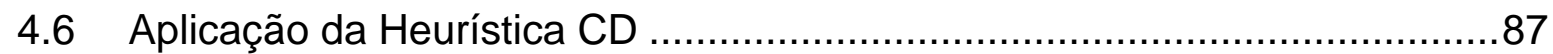

4.6.1 Calibração da Heurística CD para um reposicionamento .......................................... 87

4.6.2 Calibração da Heurística CD para dois reposicionamentos ....................................... 95

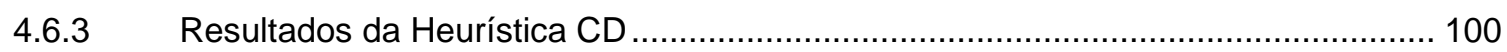

4.7 Comparação e Análise dos resultados.............................................104

4.7.1 Análise dos problemas com um reposicionamento permitido.................................... 104

4.7.2 Análise dos problemas com dois reposicionamentos permitidos ............................. 116

4.8 Análise dos tempos de execução................................................ 128

4.8.1 Regressão para os problemas com um reposicionamento....................................... 128

4.8.2 Regressão para os problemas com dois reposicionamentos .................................. 131

5 CONCLUSÕES E PRÓXIMAS ETAPAS ....................................................136

5.1 Comentários sobre os resultados obtidos ...........................................136

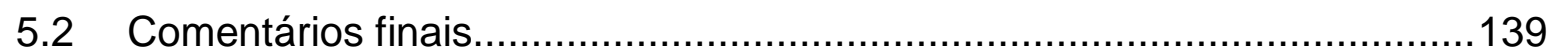

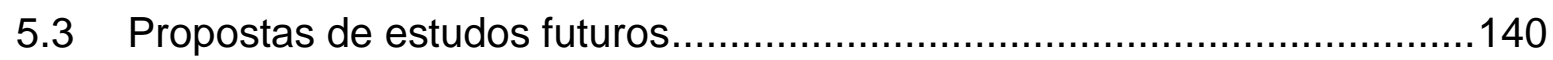

5.4 Propostas de abordagens que não devem ser realizadas .....................141

BIBLIOGRAFIA ............................................................................................ 142

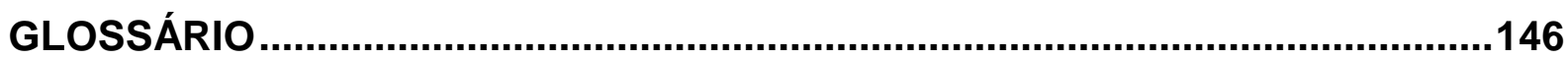

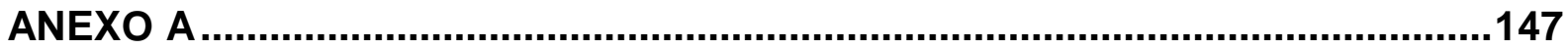

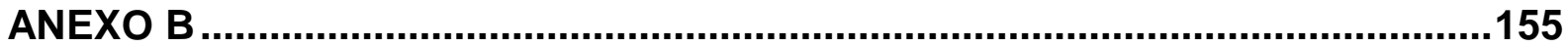




\section{LISTA DE FIGURAS}

Figura 1-1: Exemplo de transporte colaborativo .2

Figura 1-2: Representação do desbalanceamento para a região sudeste do Brasil (em milhões de toneladas). Fonte: FIPE...............................................5

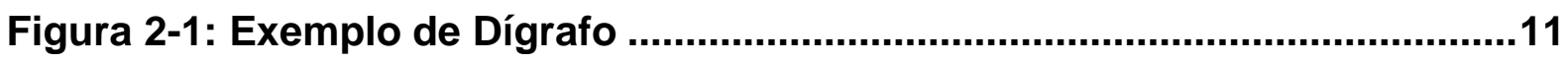

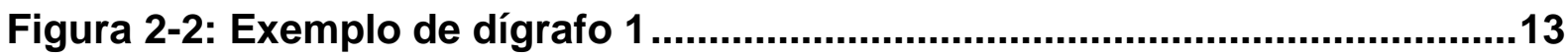

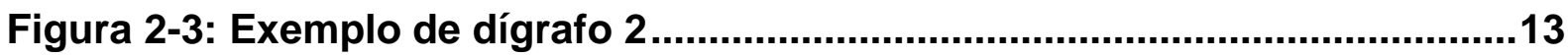

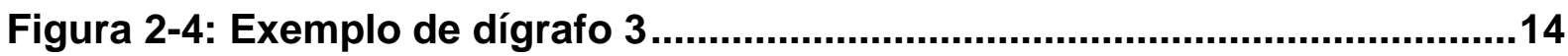

Figura 2-5: Exemplo de ciclos sem reposicionamentos......................................14

Figura 2-6: Exemplo de ciclos com 1 reposicionamento ...................................14

Figura 2-7: Exemplo de ciclos com 2 reposicionamentos.................................15

Figura 2-8: Exemplos de formatos das distribuições aleatórias.........................19

Figura 2-9: Foto noturna do mundo visto do espaço...........................................21

Figura 2-10: Foto noturna da América do Sul vista do espaço...........................21

Figura 2-11: Foto noturna da América do Norte vista do espaço .......................22

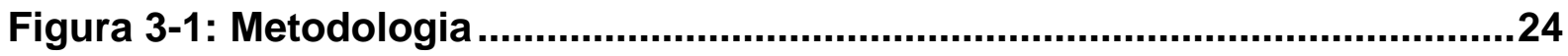

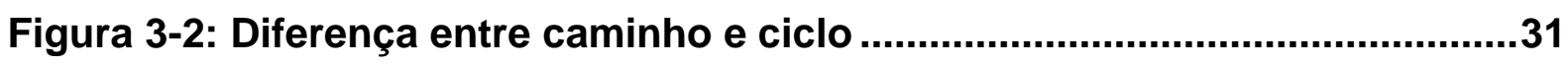

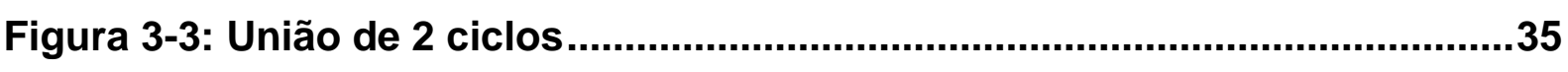

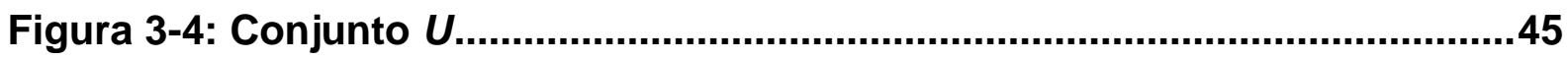

Figura 3-5: Adição da rota base ao ciclo $C_{j}$ (exemplo 1)......................................46

Figura 3-6: Adição da segunda rota ao ciclo $C_{j}$ (exemplo 1) ..............................46

Figura 3-7: Adição da terceira rota ao ciclo $C_{j}$ (exemplo 1)................................47

Figura 3-8: Adição da quarta rota ao ciclo $C_{1}$ (exemplo 1) .................................48

Figura 3-9: Combinações de fechamento dos ciclos $C_{j}$ (exemplo 1)..................48

Figura 3-10: Proporção $p$ por combinação de ciclo $C_{j}$ (exemplo 1) ....................49

Figura 3-11: Fechamento dos ciclos $C_{j}$ (exemplo 1) …..................................49

Figura 3-12: Criação do ciclo candidato $C_{c}$ (exemplo 1)..................................50

Figura 3-13: Ciclo pertencente à solução final (exemplo 1) …............................50

Figura 3-14: Adição da rota base ao ciclo $C_{j}$ (exemplo 2)..................................51

Figura 3-15: Adição da segunda rota ao ciclo $C_{j}$ (exemplo 2) ............................51

Figura 3-16: Adição da terceira rota ao ciclo $C_{j}$ (exemplo 2) ............................52

Figura 3-17: Combinações de fechamento dos ciclos $C_{j}$ (exemplo 2) ................52 
Figura 3-18: Proporção $p$ por combinação de ciclo $C_{j}$ (exemplo 2) ....................53

Figura 3-19: Fechamento dos ciclos $C_{j}$ (exemplo 2) .......................................53

Figura 3-20: Criação do ciclo candidato $C_{c}$ (exemplo 2) ...................................54

Figura 3-21: Exemplo de problemas balanceados e desbalanceados ................55

Figura 4-1: Número de ciclos em função do número de rotas para um reposicionamento para e cada fator de desbalanceamento................................67

Figura 4-2: Número de ciclos em função do número de rotas para dois reposicionamentos e para cada fator de desbalanceamento...............................68

Figura 4-3: Tempos de execução em função do número de rotas para um reposicionamento e para cada fator de desbalanceamento................................70

Figura 4-4: Tempos de execução em função do número de rotas para dois reposicionamentos e para cada fator de desbalanceamento.............................70 Figura 4-5: Tempo de execução de PLI em função do número de ciclos gerados

Figura 4-6: Tempos de execução em função do número de rotas para um reposicionamento e para cada fator de desbalanceamento .77 Figura 4-7: Tempos de execução em função do número de rotas para dois reposicionamentos e para cada fator de desbalanceamento.

Figura 4-8: Tempo de execução do Algoritmo GH em função do número de ciclos gerados

Figura 4-9: Tempos de execução em função do número de rotas para um reposicionamento e para cada fator de desbalanceamento.

Figura 4-10: Tempos de execução em função do número de rotas para dois reposicionamento e para cada fator de desbalanceamento.

Figura 4-11: Número de rotas utilizadas em função do tempo para $p_{\text {mult }}=1$.....91

Figura 4-12: Número de rotas utilizadas em função do tempo para $p_{\text {mult }}=2 \ldots . . .91$

Figura 4-13: Número de rotas utilizadas em função do tempo para $p_{\text {mult }}=3 . . . .92$ Figura 4-14: Resultado em função de $j_{\max }$ para problema de 1500 rotas e dígrafo 1. .93

Figura 4-15: Resultado em função de jmax para problema de 1500 rotas e dígrafo 2 93

Figura 4-16: Resultado em função de $j_{\max }$ para problema de 1500 rotas e dígrafo 3 
Figura 4-17: Tempo de execução em função de $j_{\max }$ para os problemas do dígrafo 1

Figura 4-18: Resultado em função de $j_{\max }$ para problema de 1500 rotas e dígrafo 1

Figura 4-19: Resultado em função de $j_{\max }$ para problema de 1500 rotas e dígrafo 2

Figura 4-20: Resultado em função de $j_{\max }$ para problema de 1500 rotas e dígrafo 3 .98

Figura 4-21: Tempo de execução em função de $j_{\max }$ para os problemas do dígrafo 1

Figura 4-22: Tempos de execução em função do número de rotas para um reposicionamento e para cada fator de desbalanceamento.

Figura 4-23: Tempos de execução em função do número de rotas para dois reposicionamentos e para cada fator de desbalanceamento. 104

Figura 4-24: Gráfico do tempo de execução dos problemas balanceados com um reposicionamento (dígrafo 1 ).

Figura 4-25: Gráfico do tempo de execução dos problemas balanceados com um reposicionamento (dígrafo 3 ).

Figura 4-26: Gráfico do tempo de execução dos problemas desbalanceados (25\%) com um reposicionamento (dígrafo 1 e 3 )

Figura 4-27: Gráfico do tempo de execução dos problemas desbalanceados (50\%) com um reposicionamento (dígrafo 1 e 3 )

Figura 4-28: Gráfico do tempo de execução dos problemas desbalanceados (75\%) com um reposicionamento (dígrafo 1 e 3 )

Figura 4-29: Gráfico do tempo de execução dos problemas balanceados com dois reposicionamentos (dígrafo 1 ).

Figura 4-30: Gráfico do tempo de execução dos problemas balanceados com um reposicionamento (dígrafo 3 ).

Figura 4-31: Gráfico do tempo de execução dos problemas desbalanceados (25\%) com dois reposicionamentos (dígrafo 1 e 3 )

Figura 4-32: Gráfico do tempo de execução dos problemas desbalanceados (50\%) com dois reposicionamentos (dígrafo 1 e 3 )

Figura 4-33: Gráfico do tempo de execução dos problemas desbalanceados (75\%) com dois reposicionamentos (dígrafo 1 e 3 ) 
Figura 4-34: Gráfico do tempo de execução em função do número de rotas dos problemas com um reposicionamento.

Figura 4-35: Gráfico e regressão do tempo de execução em função do número de rotas dos problemas com um reposicionamento para PLI 130

Figura 4-36: Gráfico e regressão do tempo de execução em função do número de rotas dos problemas com um reposicionamento para $\mathrm{GH}$. 130 Figura 4-37: Gráfico e regressão do tempo de execução em função do número de rotas dos problemas com um reposicionamento para CD.

Figura 4-38: Gráfico do tempo de execução em função do número de rotas dos problemas com dois reposicionamentos. 133

Figura 4-39: Gráfico e regressão do tempo de execução em função do número de rotas dos problemas com dois reposicionamentos para PLI 133

Figura 4-40: Gráfico e regressão do tempo de execução em função do número de rotas dos problemas com dois reposicionamentos para $\mathrm{GH}$ 134 Figura 4-41: Gráfico e regressão do tempo de execução em função do número de rotas dos problemas com dois reposicionamentos para CD 134 Figura 5-1: Média dos tempos de execução em função do número de rotas para problemas com um reposicionamento.

Figura 5-2: Média dos tempos de execução em função do número de rotas para problemas com dois reposicionamentos. 138 Figura A-1: Resultado em função de $j_{\max }$ para problema de 100 rotas e dígrafo 1 e um reposicionamento

Figura A-2: Resultado em função de $j_{\max }$ para problema de 100 rotas e dígrafo 2 e um reposicionamento

Figura A-3: Resultado em função de $j_{\max }$ para problema de 100 rotas e dígrafo 3 e um reposicionamento 148

Figura A-4: Resultado em função de $j_{\max }$ para problema de 200 rotas e dígrafo 1 e um reposicionamento 149

Figura A-5: Resultado em função de $j_{\max }$ para problema de 200 rotas e dígrafo 2 e um reposicionamento.

Figura A-6: Resultado em função de $j_{\max }$ para problema de 200 rotas e dígrafo 3 e um reposicionamento 150

Figura A-7: Resultado em função de $j_{\max }$ para problema de 500 rotas e dígrafo 1 e um reposicionamento 150 
Figura A-8: Resultado em função de $j_{\max }$ para problema de 500 rotas e dígrafo 2 e um reposicionamento

Figura A-9: Resultado em função de $j_{\max }$ para problema de 500 rotas e dígrafo 3 e um reposicionamento

Figura A-10: Resultado em função de $j_{\max }$ para problema de 1000 rotas e dígrafo 1 e um reposicionamento 152

Figura A-11: Resultado em função de $j_{\max }$ para problema de 1000 rotas e dígrafo 2 e um reposicionamento

Figura A-12: Resultado em função de $j_{\max }$ para problema de 1000 rotas e dígrafo 3 e um reposicionamento

Figura A-13: Resultado em função de $j_{\max }$ para problema de 1500 rotas e dígrafo 1 e um reposicionamento

Figura A-14: Resultado em função de $j_{\max }$ para problema de 1500 rotas e dígrafo 2 e um reposicionamento

Figura A-15: Resultado em função de $j_{\max }$ para problema de 1500 rotas e dígrafo 3 e um reposicionamento

Figura B-1: Resultado em função de $j_{\max }$ para problema de 100 rotas e dígrafo 1 e dois reposicionamentos 155

Figura B-2: Resultado em função de $j_{\max }$ para problema de 100 rotas e dígrafo 2 e dois reposicionamentos 156

Figura B-3: Resultado em função de $j_{\max }$ para problema de 100 rotas e dígrafo 3 e dois reposicionamentos 156

Figura B-4: Resultado em função de $j_{\max }$ para problema de 200 rotas e dígrafo 1 e dois reposicionamentos 157

Figura B-5: Resultado em função de $j_{\max }$ para problema de 200 rotas e dígrafo 2 e dois reposicionamentos 157

Figura B-6: Resultado em função de $j_{\max }$ para problema de 200 rotas e dígrafo 3 e dois reposicionamentos 158

Figura B-7: Resultado em função de $j_{\max }$ para problema de 500 rotas e dígrafo 1 e dois reposicionamentos 158

Figura B-8: Resultado em função de $j_{\max }$ para problema de 500 rotas e dígrafo 2 e dois reposicionamentos 159

Figura B-9: Resultado em função de $j_{\max }$ para problema de 500 rotas e dígrafo 3 e dois reposicionamentos 
Figura B-10: Resultado em função de $j_{\max }$ para problema de 1000 rotas e dígrafo 1 e dois reposicionamentos

Figura B-11: Resultado em função de $j_{\max }$ para problema de 1000 rotas e dígrafo 2 e dois reposicionamentos

Figura B-12: Resultado em função de $j_{\max }$ para problema de 1000 rotas e dígrafo 3 e dois reposicionamentos

Figura B-13: Resultado em função de $j_{\max }$ para problema de 1500 rotas e dígrafo 1 e dois reposicionamentos

Figura B-14: Resultado em função de $j_{\max }$ para problema de 1500 rotas e dígrafo 2 e dois reposicionamentos

Figura B-15: Resultado em função de $j_{\max }$ para problema de 1500 rotas e dígrafo 3 e dois reposicionamentos 


\section{LISTA DE TABELAS}

Tabela 1-1: Carga movimentada pelo transporte rodoviário entre as regiões brasileiras no ano de 2008 (fonte: FIPE) ..........................................................4

Tabela 2-1: Resumo das características dos geradores de instâncias 20

Tabela 3-1: Permissão para cada tipo de vértice para ser início ou final de rota

Tabela 4-1: Combinações de problemas de teste sem considerar balanceamento

Tabela 4-2: Número de ciclos gerados para problemas com um reposicionamento

Tabela 4-3: Número de ciclos gerados para problemas com dois reposicionamentos

Tabela 4-4: Tempo de execução para problemas com um reposicionamento ..68

Tabela 4-5: Tempo de execução para problemas com dois reposicionamentos

Tabela 4-6: Comparação de número de ciclos gerados e tempos de execução com (ERGUN et al, 2007b) para problemas balanceados

Tabela 4-7: Solução gerada por PLI para problemas com um reposicionamento

Tabela 4-8: Solução gerada por PLI para problemas com dois reposicionamentos

Tabela 4-9: Tempo de execução para problemas com um reposicionamento ..75 Tabela 4-10: Tempo de execução para problemas com dois reposicionamentos

Tabela 4-11: Comparação dos tempos de execução da aplicação de PLI com (ERGUN et al, 2007b) para problemas balanceados

Tabela 4-12: Solução gerada por GH para problemas com um reposicionamento

Tabela 4-13: Solução gerada por PLI para problemas com dois reposicionamentos

Tabela 4-14: Tempo de execução para problemas com um reposicionamento 82 
Tabela 4-15: Tempo de execução para problemas com dois reposicionamentos

Tabela 4-16: Comparação dos tempos de execução da aplicação de GH com (ERGUN et al, 2007b) para problemas balanceados

Tabela 4-17: Resultados da calibração para os problemas com um

reposicionamento 89

Tabela 4-18: $j_{\max }$ por número de rotas por dígrafo 95

Tabela 4-19: Resultados da calibração para os problemas com dois reposicionamentos

Tabela 4-20: $j_{\max }$ por número de rotas por dígrafo

Tabela 4-21: Solução gerada por CD para problemas com um

reposicionamento

Tabela 4-22: Solução gerada por CD para problemas com dois reposicionamentos

Tabela 4-23: Tempo de execução para problemas com um reposicionamento

Tabela 4-24: Tempo de execução para problemas com um reposicionamento

Tabela 4-25: Tempo de execução para problemas com dois reposicionamentos

Tabela 4-26: Comparação das soluções para problemas balanceados e com um reposicionamento

Tabela 4-27: Comparação das soluções para problemas desbalanceados (25\%) e com um reposicionamento

Tabela 4-28: Comparação das soluções para problemas desbalanceados $(50 \%)$ e com um reposicionamento

Tabela 4-29: Comparação das soluções para problemas desbalanceados (75\%) e com um reposicionamento

Tabela 4-30: Comparação dos tempos de execução para problemas

balanceados e com um reposicionamento

Tabela 4-31: Comparação dos tempos de execução para problemas desbalanceados $(25 \%)$ e com um reposicionamento

Tabela 4-32: Comparação dos tempos de execução para problemas desbalanceados $(50 \%)$ e com um reposicionamento 
Tabela 4-33: Comparação dos tempos de execução para problemas desbalanceados ( $75 \%$ ) e com um reposicionamento

Tabela 4-34: Comparação das soluções para problemas balanceados e com dois reposicionamentos

Tabela 4-35: Comparação das soluções para problemas desbalanceados $(25 \%)$ e com dois reposicionamentos

Tabela 4-36: Comparação das soluções para problemas desbalanceados (50\%) e com dois reposicionamentos

Tabela 4-37: Comparação das soluções para problemas desbalanceados (75\%) e com dois reposicionamentos

Tabela 4-38: Comparação dos tempos de execução para problemas

balanceados e com dois reposicionamentos.

Tabela 4-39: Comparação dos tempos de execução para problemas desbalanceados $(25 \%)$ e com dois reposicionamentos

Tabela 4-40: Comparação dos tempos de execução para problemas desbalanceados $(50 \%)$ e com dois reposicionamentos

Tabela 4-41: Comparação dos tempos de execução para problemas desbalanceados $(75 \%)$ e com dois reposicionamentos

Tabela 4-42: Tempos de execução para a regressão dos problemas com um reposicionamento

Tabela 4-43: Tempos de execução para a regressão dos problemas com dois reposicionamentos

Tabela 5-1: Média dos resultados de todos os problemas 136 


\section{LISTA DE ALGORITMOS}

Algoritmo 3-1: Algoritmo de Busca Posterior do gerador de ciclos viáveis......32 Algoritmo 3-3: Algoritmo de Busca Anterior do gerador de ciclos viáveis........33 Algoritmo 3-4: Algoritmo de geração de ciclos 1 do gerador de ciclos viáveis 34 Algoritmo 3-5: Algoritmo de geração de ciclos 2 do gerador de ciclos viáveis 36 Algoritmo 3-6: Algoritmo Guloso proposto por (ERGUN et al, 2007b) ...............37 Algoritmo 3-7: Heurística Construtivo-Destrutiva ...............................................44 Algoritmo 3-8: Gerador de Problemas Balanceados..........................................58 Algoritmo 3-9: Gerador de Problemas Desbalanceados ..................................61 


\section{LISTA DE ABREVIATURAS E SIGLAS}

$\begin{array}{ll}\text { PCR } & \text { Problema de Cobertura de Rotas } \\ \text { PCRCR } & \text { Problema de Cobertura de Rotas com Cardinalidade } \\ & \text { Restrita } \\ \text { PCRER } & \text { Problema de Cobertura de Rotas com Extensão Restrita } \\ \text { PCRJT } & \text { Problema de Cobertura de Rota com Janela de Tempo } \\ \text { PCRMT } & \text { Problema de Cobertura de Rotas com Múltiplos } \\ & \text { Transportadores } \\ \text { CPFR } & \text { Sistema Colaborativo de Planejamento, Previsão e } \\ \text { VICS } & \text { Reabastecimento } \\ & \text { Comitê Voluntário de Padronização do Comércio entre } \\ \text { PLI } & \text { Indústrias } \\ \text { GH } & \text { Programação Linear Inteira } \\ & \text { Algoritmo guloso proposto por (ERGUN et al, 2007b) para } \\ \text { SD } & \text { solucionar o problema PCRCR } \\ & \text { Heurística construtivo-destrutiva proposta por este } \\ \text { trabalho para solucionar o problema PCRCR }\end{array}$




\section{INTRODUÇÃO}

Este capítulo apresenta a contextualização do problema, os objetivos da dissertação, a relevância e as delimitações do estudo, assim como o delineamento do trabalho.

\subsection{Contextualização e Relevância do Problema}

A colaboração logística vem sendo adotada gradativamente pelas empresas a fim de reduzir seus custos logísticos e melhorar o nível de atendimento ao cliente, (BALLOU, 2006). Com o acirramento da concorrência e aumento da exigência do mercado por prazos cada vez menores e preços de produtos mais baixos, várias empresas vêm recorrendo às parcerias colaborativas.

Vieira (2006) define colaboração logística quando duas ou mais empresas trabalham juntas em atender às necessidades dos clientes, por meio de ações conjuntas, compartilhamento de informações e com base na confiança, flexibilidade, reciprocidade e interdependência.

Segundo Vieira (2006), existem vários tipos de colaboração logística possíveis como, por exemplo, compras conjuntas (quando empresas se unem para comprar grandes quantidades de um determinado material obtendo preços mais atrativos devido a um volume maior em um único pedido), serviços compartilhados (de modo que pode-se compartilhar um mesmo centro de distribuição por duas ou mais empresas) e composição de carga (onde empresas podem consolidar suas cargas para obter fretes mais baratos e com melhor ocupação de veículos).

Ballou (2006) cita exemplo de duas empresas americanas (Ace Hardware e Manic) que, utilizando colaboração, conseguiram reduzir seus custos de frete em $14 \%$, no caso da primeira empresa, e $28 \%$ do custo de distribuição para a segunda.

Uma pesquisa apontada por (ERGUN et al, 2007b) mostra que, em média, $18 \%$ das viagens de caminhão executadas nos Estados Unidos são vazias, ou seja, um veículo está se deslocando sem carga e consumindo combustível, pneus, horas 
do motorista, etc. No mercado de transporte de carga rodoviária americano de US\$ 921 bilhões, este desperdício representa, aproximadamente, US\$165,8 bilhões.

Para os problemas de cargas do tipo lotação que, segundo Novaes (2004), são aquelas em que o carregamento do veículo é completo e o caminhão dirige-se da origem ao destino diretamente, sem paradas intermediárias, muitas vezes não é possível eliminar estas viagens vazias. Isso ocorre devido ao fato que nem sempre o ponto de descarga de uma viagem coincide com o local de carregamento da seguinte. Porém, utilizando-se o transporte colaborativo, é possível minimizá-las, como mostrado na Figura 1-1 a seguir.

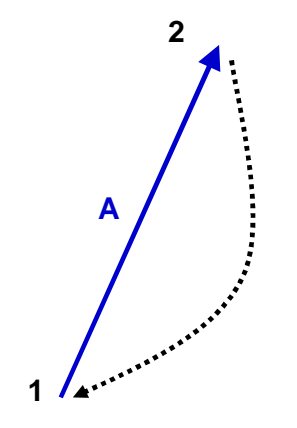

Exemplo 1: Sem colaboração

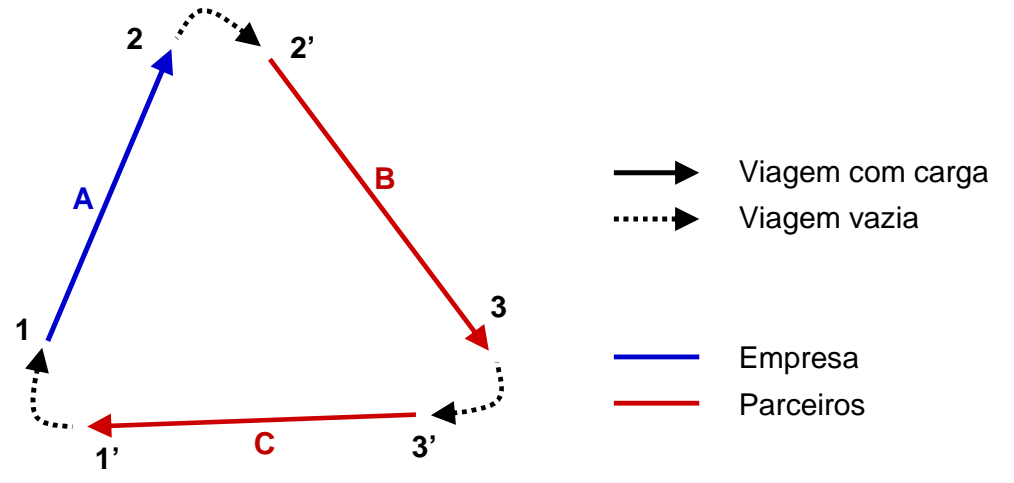

Exemplo 2: Com colaboração

Figura 1-1: Exemplo de transporte colaborativo

A Figura 1-1 ilustra um caso em que a Empresa A (representada pela seta azul) atua sozinha (sem colaboração) e possui uma rota (viagem de carga lotação com freqüência regular) cuja origem é o local 1 e o destino é o local 2 (exemplo 1). Nesse caso, como ela não possui uma rota de 2 para 1, deverá realizá-la sem carga. Vale ressaltar que no preço do frete determinado pelo transportador embutem-se os custos de viagens vazias.

Por outro lado, uma possível estratégia para a Empresa A seria colaborar, oferecendo ao transportador um conjunto de rotas de tal forma que ele consiga combiná-las com rotas de outras empresas de modo a minimizar as viagens vazias. Com isso, será possível oferecer fretes mais baratos (exemplo 2). Neste caso, existem dois parceiros (Empresas $\mathrm{B}$ e $\mathrm{C}$, em vermelho) que possuem rotas de modo que é possível montar um ciclo (percurso fechado feito por um veículo) que minimiza 
todos os reposicionamentos (viagens sem cargas como, por exemplo, de 1 para 1', de 2 para 2' e de 3 para 3'), deixando o custo total de transporte menor se comparado com as três empresas operando sozinhas (sem colaboração). Desta forma, todos os participantes ganham com a colaboração (a Empresa A, os parceiros e a transportadora). Para o ciclo ser possível, é necessário que exista uma compatibilidade de carga e de veículos, ou seja, não é possível ter um ciclo de uma empresa que possui carga refrigerada com outra que transporta grãos, por exemplo.

Dado isso, Ergun et al (2007b) definiram o problema de transporte colaborativo acima como sendo: dado um conjunto de rotas, encontre um conjunto de ciclos que cubram todas as rotas minimizando o reposicionamento dos veículos.

Fundamentado nesses aspectos da logística colaborativa, Ergun et al (2007b) criaram o problema de cobertura de rotas (PCR) que pode ser definido como: encontrar o conjunto de mínimo custo formando ciclos simples que cubram um conjunto de rotas. Além disso, definiram uma variante particular deste problema: o problema de cobertura de rotas com cardinalidade restrita (PCRCR), em que o número de rotas pertencentes ao ciclo é limitado.

Na prática, este problema apresenta caráter estratégico, pois verifica apenas as oportunidades de ciclos entre as empresas. Em seguida seria necessário verificar se as empresas conseguem operacionalmente manter os ciclos e encadear a operação no tempo, ou seja, verificar a compatibilidade dos horários de partida e chegada em cada ponto.

Ergun et al (2007b) demonstraram que este problema de otimização é explosivamente combinatório, fazendo com que mesmo instâncias relativamente pequenas não sejam possíveis de serem resolvidas de forma ótima. Desta forma, os mesmos autores propuseram um algoritmo guloso eficiente que tem bons resultados, porém possui uma limitação que é a dependência da geração prévia de todas as combinações possíveis e viáveis de ciclos. Entretanto o algoritmo foi testado apenas em instâncias que possuem característica de fluxos balanceados entre regiões. Contudo existem muitas economias (como a brasileira) que possuem grande concentração de carga em poucas regiões, concentrando mais destinos ou origens de rotas. 
A Tabela 1-1 a seguir, disponibilizada pela (FIPE, 2009), apresenta o total de carga movimentada pelo transporte rodoviário entre as regiões brasileiras no ano de 2008 em milhões de toneladas. Pode-se utilizá-la como uma aproximação para ilustrar o desbalanceamento entre regiões do país. Apesar de o mais adequado para este estudo ser uma comparação entre as regiões metropolitanas nacionais, não foi possível obter tal informação neste detalhe.

Dado isso, nota-se que existe desbalanceamento de carga significativo entre as regiões. Por exemplo, a região Sudeste envia 19,4 milhões de toneladas para a região Nordeste, porém essa última envia somente 12,2 milhões de toneladas, gerando desbalanceamento. Comparativamente, pode-se comentar que, a cada dez caminhões que saem da região Sudeste e vão para o Nordeste, quatro voltam vazios (o que não é necessariamente verdade uma vez que o caminhão pode sair do Nordeste e ir para outra região).

Tabela 1-1: Carga movimentada pelo transporte rodoviário entre as regiões brasileiras no ano de 2008 (fonte: FIPE)

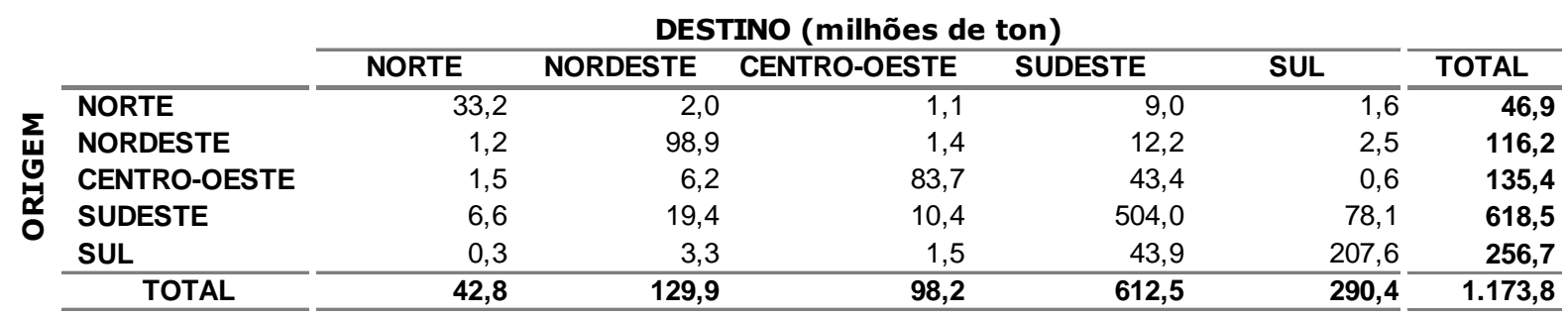

A Figura 1-2 a seguir ilustra o desbalanceamento entre a região Sudeste e as demais regiões. As setas em amarelo são as cargas que se originam na região Sudeste, enquanto as em vermelho são as que possuem destinos para essa região. Os valores estão em milhões de toneladas. Nota-se que todas as regiões são desbalanceadas, comprovando a importância de considerar essa variável neste estudo. 


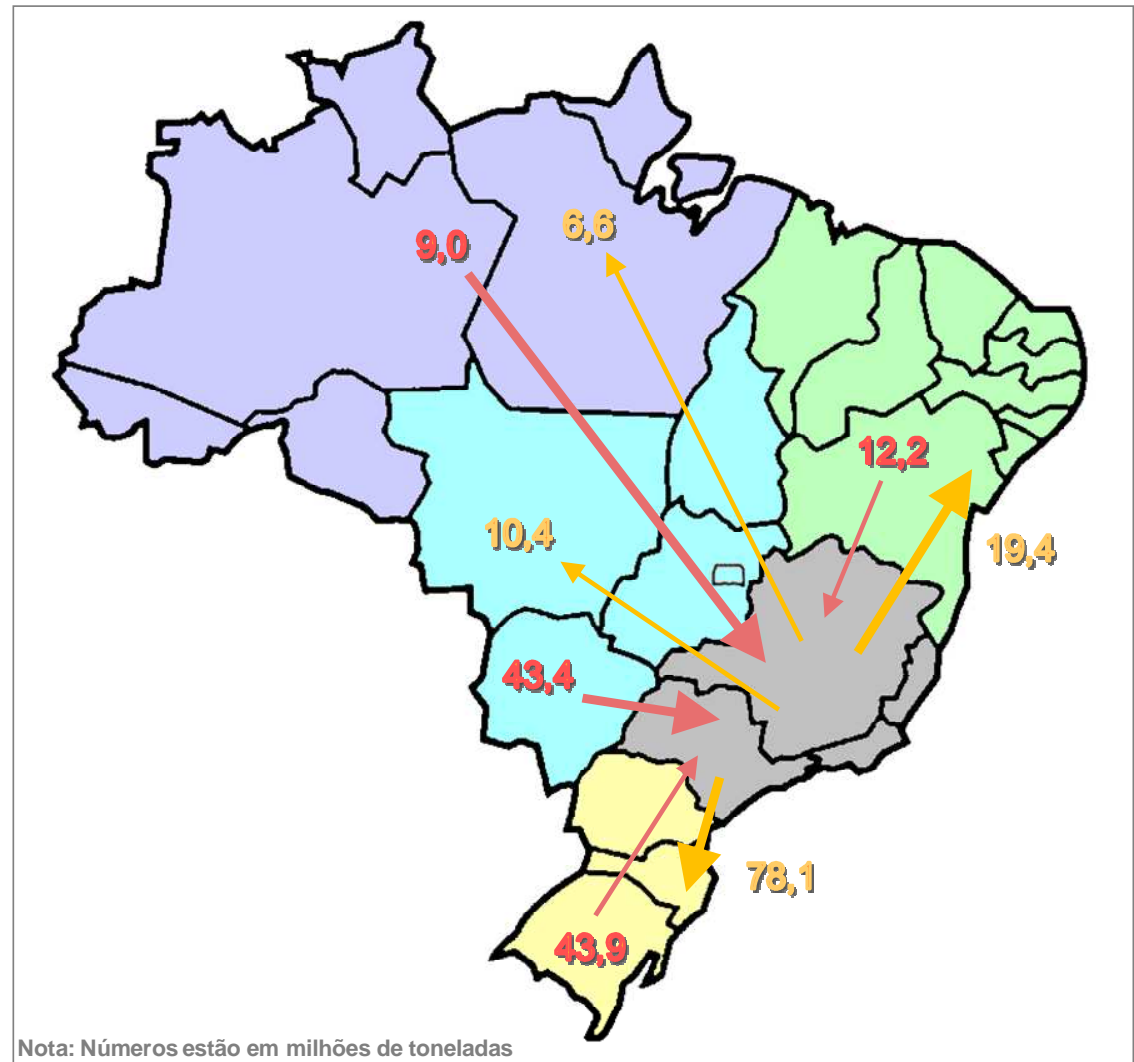

Figura 1-2: Representação do desbalanceamento para a região sudeste do Brasil (em milhões de toneladas). Fonte: FIPE.

\subsection{Objetivo da Dissertação}

O objetivo deste trabalho consiste em desenvolver uma heurística que resolva o problema de cobertura de rotas com cardinalidade restrita sem a dependência da geração de todas as combinações viáveis de ciclos, buscando resolver problemas maiores em tempos semelhantes aos encontrados na literatura.

Os resultados são comparados com um modelo de programação linear inteira (PLI) e com o algoritmo guloso proposto por (ERGUN et al, 2007b). A comparação é feita em um conjunto de instâncias de teste a fim de identificar a qualidade da heurística proposta, utilizando-se o mesmo gerador de instâncias que Ergun et al (2007b). O gerador também foi modificado para gerar problemas com fluxos desbalanceados, ou seja, que possui regiões que concentram mais destinos ou origens de rotas. 


\subsection{Delimitação do Problema}

Será estudado o problema de cobertura de rotas com cardinalidade restrita (PCRCR), cujo objetivo é criar ciclos que englobem um conjunto dado de rotas.

Neste problema, as rotas pertencem aos embarcadores que compram o serviço de transporte de um terceiro. As rotas precisam ser estáticas, ou seja, os embarques precisam ocorrer regularmente.

Da mesma forma que (ERGUN et al, 2007b), serão consideradas somente cargas do tipo lotação. Além disso, assume-se que o agendamento das viagens é flexível de modo que os ciclos gerados sejam viáveis em termo de janelas de tempo das rotas, ou seja, a transportadora pode fazer o atendimento no horário em que chegar no cliente.

A heurística proposta é testada em dois conjuntos de problemas denominados balanceados e desbalanceados. Essa característica refere-se à existência ou não de regiões que concentram maior número de origens ou destino de rotas. Por exemplo, se o problema estudado não apresentar regiões que possuem predominantemente origens ou destinos de rotas, serão chamadas de balanceadas. Caso contrário, serão chamadas de desbalanceadas.

Esta é uma contribuição deste trabalho, pois (ERGUN et al, 2007b) estudou somente problemas balanceados que apresentam características e resultados diferentes dos problemas desbalanceados, que será apresentado nos próximos capítulos. Além do mais, problemas desbalanceados são mais adequados para muitas economias, como, por exemplo, a brasileira, que possui grande desequilíbrio entre suas diversas regiões geográficas.

Por fim, também foram geradas instâncias de problemas maiores que (ERGUN et al, 2007b) para testar o comportamento e viabilidade dos três métodos estudados. 


\subsection{Delineamento do Trabalho}

Esta dissertação está subdividida em cinco capítulos:

- Capítulo 1 - Introdução: Apresenta a contextualização do problema, o objetivo, relevância e delimitação do problema estudado.

- Capítulo 2 - Revisão da literatura: Apresenta e discute os principais conceitos abordados neste estudo.

- Capítulo 3 - Metodologia e modelagem do problema: Descreve detalhadamente o problema, a metodologia empregada, os métodos utilizados para a sua resolução e os conjuntos de problemas que foram utilizados.

- Capítulo 4 - Aplicação e resultados dos modelos: Apresenta a aplicação dos métodos discutidos no capítulo 3 e seus respectivos resultados obtidos nos conjuntos de problemas.

- Capítulo 5 - Conclusões finais: Apresenta uma discussão geral dos resultados obtidos e as conclusões finais. 


\section{REVISÃO DA LITERATURA}

Este capítulo apresenta uma discussão de conhecimentos e trabalhos que são julgados importantes para o desenvolvimento e entendimento das idéias contidas neste estudo. Os tópicos para discussão estão assim divididos:

- Transporte colaborativo

- Problema de cobertura de rotas e suas variações

- Geradores de instâncias

\subsection{Transporte colaborativo}

Botter et al (2006) indicam que o termo "transporte colaborativo" foi instituído como conceito no ano 2000 a partir de uma segmentação e estudo particular do CPFR (Collaboration planning, Forecasting and Replenishment - sistema colaborativo de planejamento, previsão e reabastecimento). O CPFR é um dos comitês do VICS (Voluntary Inter-Industry Commerce Standards Association - comitê voluntário de padronização do comércio entre indústrias), entidade Norte Americana que objetiva criar colaboração entre vendedores e compradores através de cogerenciamento de processos e sistemas de informações (VICS, 2008; CPFR, 2008).

Segundo Browning (2001), o transporte colaborativo ocorre com o compartilhamento de um mesmo equipamento de transporte para formar um ciclo fechado de movimentação de cargas. Para isso, é necessário que os participantes estejam na mesma cadeia logística ou que os embarcadores ofereçam cargas complementares, ou seja, cargas compatíveis com o mesmo equipamento de transporte disponível na rota complementar (por exemplo, uma carga de retorno), formando um ciclo como foi mostrado na Figura 1-1.

Para Figueiredo e Eiras (2007), os principais benefícios do transporte colaborativo são: 
- Redução dos trechos com veículos vazios, devido a uma melhor programação, seqüenciamento e roteirização da frota.

- Aumento da consolidação de carga devido a um melhor aproveitando da capacidade dos veículos.

- Redução dos tempos de espera de carga e descarga devido à melhor organização das áreas de expedição e recebimento ao operar e liberar os veículos mais rapidamente.

- Redução dos prazos de atendimento aos clientes devido à maior pontualidade das entregas.

- Aumento da disponibilidade dos produtos para o cliente, reduzindo a falta de produto ao consumidor e impulsionando as vendas.

Figueiredo e Eiras (2007) destacam o benefício para cada membro da colaboração. No caso dos embarcadores, o benefício está em aumentar a competição entre transportadores e conseguir melhores fretes. No caso dos transportadores, os benefícios estão no aumento dos contatos fazendo com que eleve a sua utilização de capacidade e reduza os trechos com viagens vazias.

Vieira (2006) fez um estudo visando conhecer o estado de colaboração logística na cadeia do varejo supermercadista no Brasil utilizando uma amostra de 125 representantes desta indústria. $O$ autor concluiu que os fatores mais importantes em uma colaboração são: confiança, ações conjuntas entre as empresas, integração de duas áreas funcionais, elaboração de objetivos comuns e metas em conjunto, e relação de reciprocidade. Isso mostra a importância da relação de credibilidade e compartilhamento entre as empresas envolvidas.

\subsection{Problema de cobertura de rotas e suas variações}

Ergun et al (2007b) apresentam o problema de cobertura de rotas que representa o transporte colaborativo entre membros de uma mesma cadeia ou de cadeias diferentes e contribuem com um algoritmo guloso para sua resolução. 
Caplice e Sheffi (2003) classificam os sistemas de transporte de cargas em dois tipos: lotação e fracionado. O transporte de carga lotação normalmente é operado em rotas diretas de uma origem para um único destino sem realizar paradas intermediárias. Por outro lado, a carga fracionada deve ser enviada para centros concentradores onde é feita a consolidação de pequenas cargas a fim de completar um caminhão que as distribuirá para vários destinos.

Segundo Ergun et al (2007b), o problema de cobertura de rotas e suas variações se aplicam apenas ao transporte rodoviário de carga lotação em que os embarcadores oferecem suas rotas para transportadores terceiros formarem ciclos com rotas de outros embarcadores formando um transporte colaborativo. Porém para que isto ocorra de maneira eficiente, é necessário que os embarques pertencentes aos ciclos sejam regulares, ou seja, tenham uma freqüência constante.

Segundo Bang-Jensen e Gutin (2002), um dígrafo $D=(V, A)$ (ou grafo direcionado) consiste em um conjunto finito não vazio $V(D)$ de vértices e em um conjunto finito $A(D)$ de pares ordenados de vértices distintos que são chamados de arcos.

Ergun et al (2007b) classificaram cada tipo de arco de um ciclo: chamam de "rota" o arco que contém uma viagem com carga e "reposicionamento" o arco sem carga que liga o final de uma viagem para o início da próxima.

Ergun et al (2007b) definiram o problema PCR (problema de cobertura de rotas) da seguinte forma: dado um dígrafo direcionado $D=(V, A)$, onde $V$ é o conjunto dos vértices e $A$, o conjunto dos arcos, onde para cada arco há um custo associado $c($ a) para $a \in A$ e um conjunto $L$ de rotas $\subseteq A$, o objetivo é minimizar o custo de cobertura das rotas $L$ utilizando-se ciclos. 


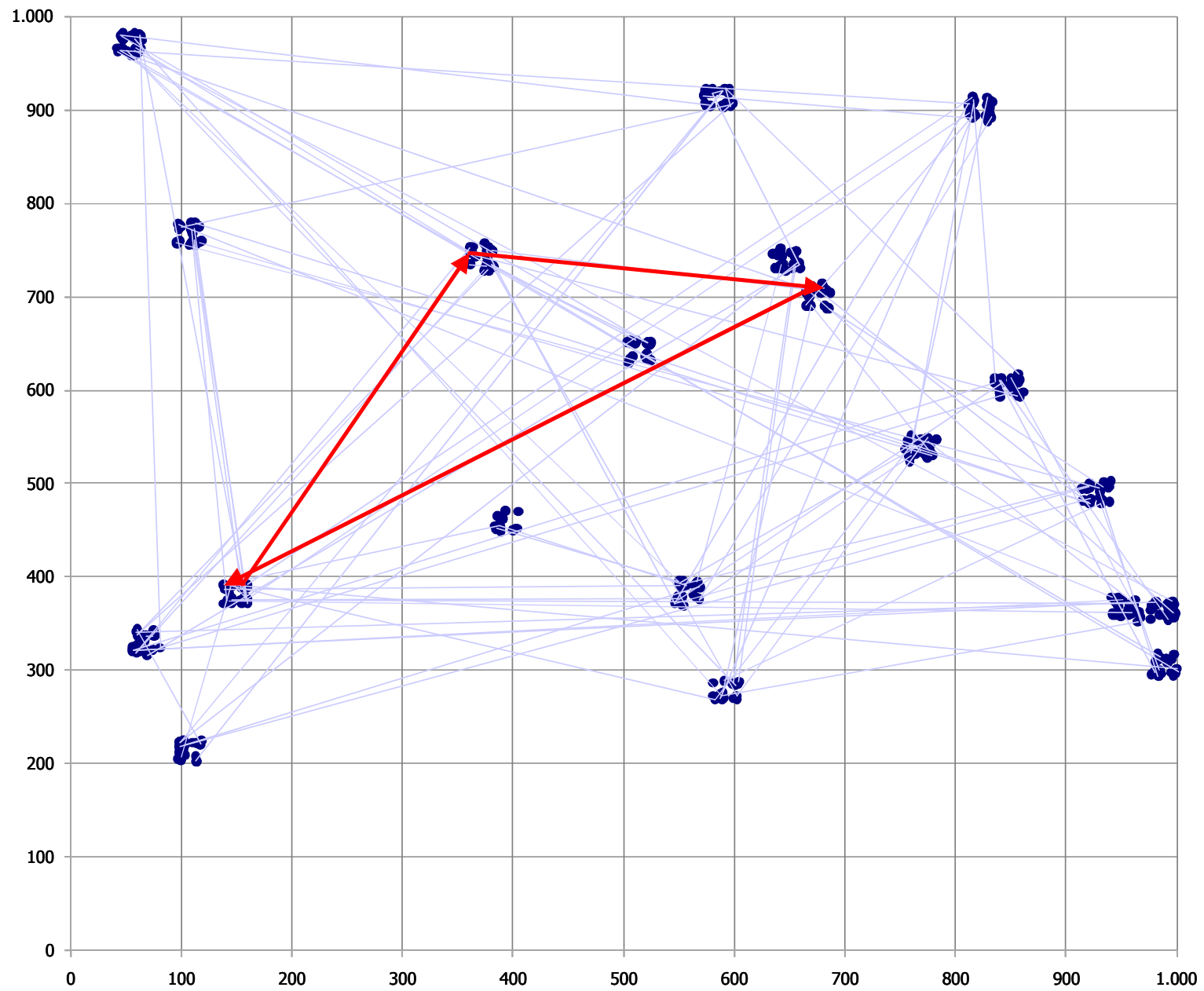

Figura 2-1: Exemplo de Dígrafo

A Figura 2-1 é um exemplo de uma representação de um dígrafo. Os pontos azuis são os vértices que representações os clientes, enquanto as linhas em azul claro são os arcos que representam as rotas. Um exemplo de ciclo foi representado com as linhas destacadas em vermelho. Os agrupamentos de vértices representam as regiões metropolitanas onde os clientes estão inseridos.

A partir deste problema, foram criadas duas variações: o problema de cobertura de rotas com extensão restrita (PCRER) e o problema de cobertura de rotas com cardinalidade restrita (PCRCR). O primeiro caso possui a restrição de que a soma de todos os comprimentos que compõem um ciclo deve ser menor que um dado comprimento $b$. O segundo possui a restrição de que o número de arcos que compõem o ciclo deve ser menor que um dado inteiro $k$. 
Os autores demonstram que, apesar do problema fundamental PCR poder ser resolvido em tempo polinomial, as duas variações comentadas são NP-hard.

Ergun et al (2007b) focaram na solução do PCRCR, formulando o problema e criando um algoritmo guloso para resolvê-lo. Para testar a qualidade de sua solução, criaram um gerador de instâncias e compararam seus resultados e tempos obtidos com a primeira solução viável obtidas com um modelo de PLI, uma vez que, segundo os autores, o tempo de execução para obter a solução ótima era muito elevado. Tanto o gerador como o algoritmo serão explicados detalhadamente no próximo capítulo.

Ao todo foram gerados três dígrafos com características diferentes para testar o comportamento de seu algoritmo guloso em situações distintas. Uma das características mais importantes desses dígrafos é o fato de terem sido considerados agrupamento de vértices. Isso é pode ser observado na Figura 2-1. Dado isso, os dois parâmetros principais utilizados foram: o número de agrupamento de vértices e seus fatores de dispersão. Este último é uma porcentagem que estabelece o tamanho máximo que este agrupamento pode ter em relação ao espaço total que os contém. Por exemplo, se o espaço considerado for um quadrado de dimensões $1000 \mathrm{~km}$ de altura por $1000 \mathrm{~km}$ de largura e o fator de dispersão for $5 \%$, significa que o raio dos agrupamentos será de $50 \mathrm{~km}$.

Os parâmetros considerados nas instâncias de (ERGUN et al, 2007b) estão listados a seguir:

- Dígrafo 1: 20 agrupamentos com fator de dispersão de 5\%.

- Dígrafo 2: 10 agrupamentos com fator de dispersão de 10\%.

- Dígrafo 3: 5 agrupamentos com fator de dispersão de 10\%.

Além disso, todas as instâncias tinham os seguintes parâmetros fixos:

- 500 vértices.

- Ciclos com cardinalidade máxima 5 (ou seja, o número de rotas somadas aos reposicionamentos devem ser menores ou iguais a 5). 
Dado isso, as figuras a seguir representam exemplos dos três dígrafos com as propriedades apresentadas anteriormente:

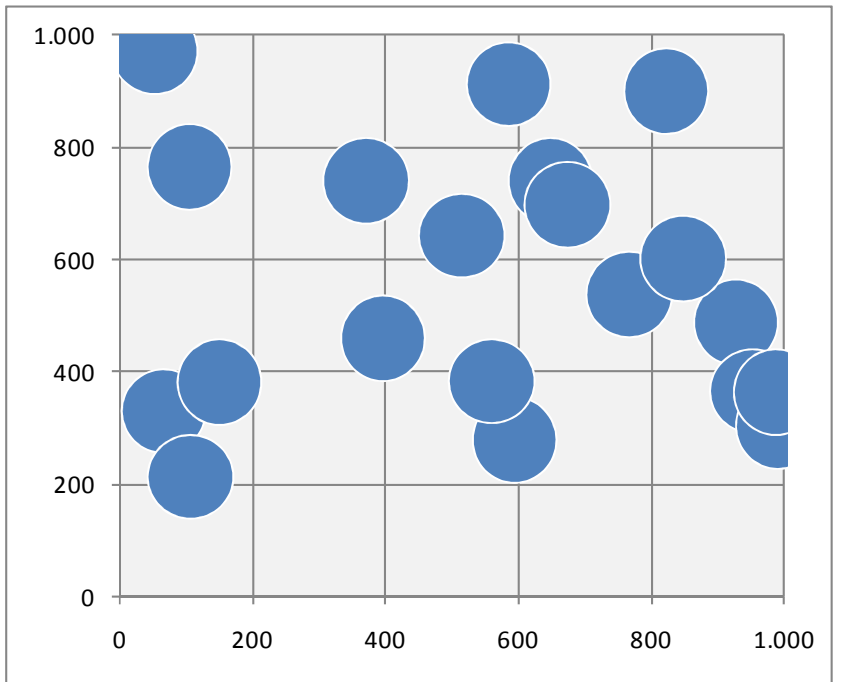

Figura 2-2: Exemplo de dígrafo 1

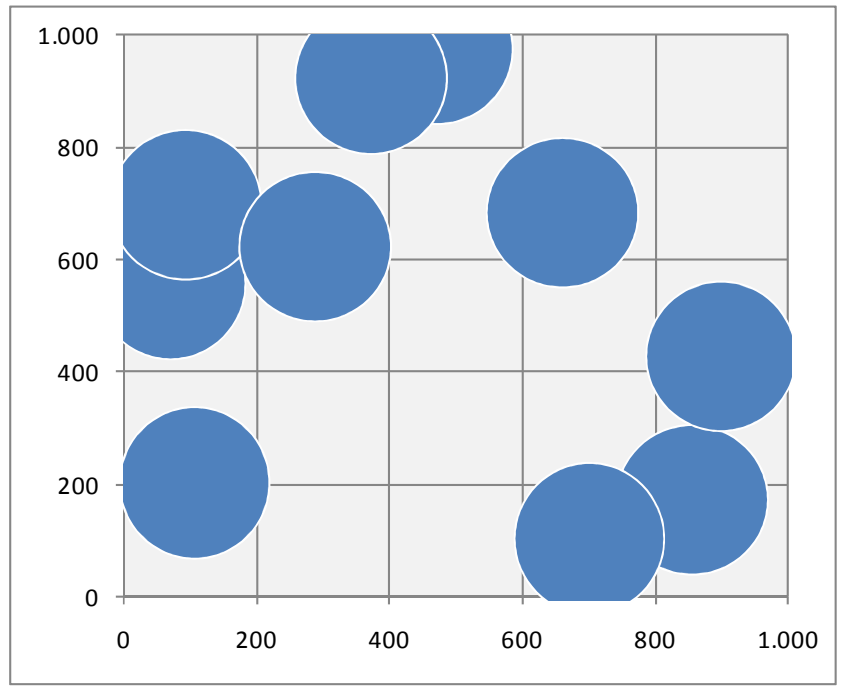

Figura 2-3: Exemplo de dígrafo 2 


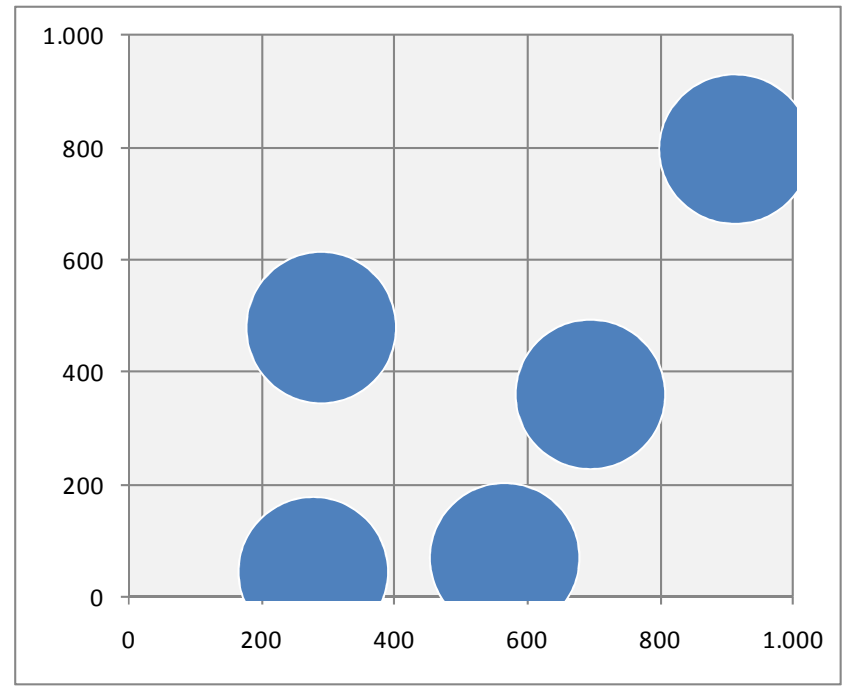

Figura 2-4: Exemplo de dígrafo 3

Para cada dígrafo, foram gerados problemas com 100, 200, 500, 1000 ou 1500 rotas sendo que, para cada um, era permitida a existência de um ou dois reposicionamentos. As figuras a seguir mostram exemplos de ciclos possíveis considerando os reposicionamentos e o limite de cardinalidade 5.
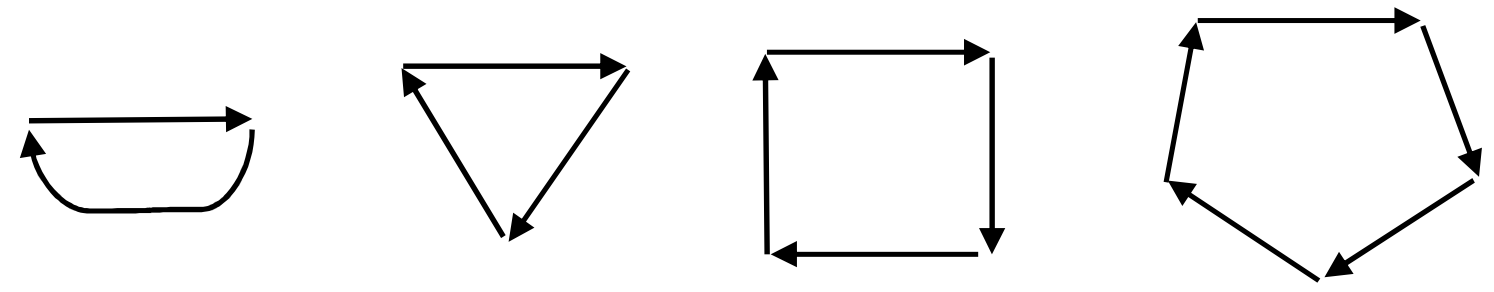

Figura 2-5: Exemplo de ciclos sem reposicionamentos
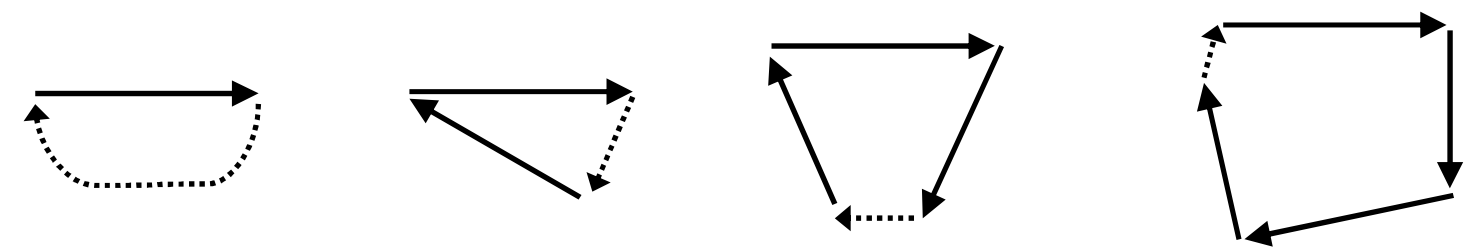

Figura 2-6: Exemplo de ciclos com 1 reposicionamento 

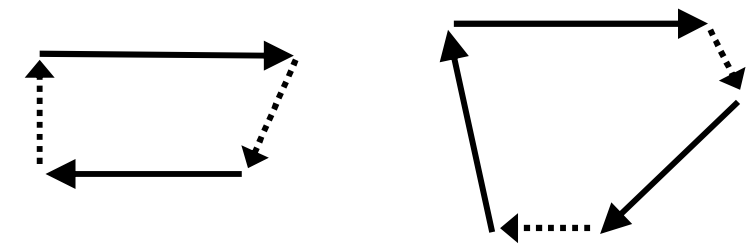

Figura 2-7: Exemplo de ciclos com 2 reposicionamentos

Este mesmo problema também é tratado em (ERGUN et al, 2004) e (SAVELSBERGH et al, 2004), sendo que o primeiro apresenta o mesmo algoritmo que (ERGUN et al, 2007b), porém descrito de forma mais completa e detalhada.

(ERGUN et al, 2007a) e (KUYZU, 2007) descrevem e propõem algoritmos para resolver uma outra variante do problema fundamental PCR que é o problema de cobertura de rota com janela de tempo (PCRJT). Neste problema são consideradas as janelas de tempo em que uma rota pode acontecer, ou seja, a viagem deve iniciar em um determinado intervalo de tempo obrigatoriamente para a solução ser viável.

Outra variação do PCR encontrada em (ÖZENER, 2008) é o problema de cobertura de rotas com múltiplos transportadores (PCRMT). A diferença em relação ao PCR consiste na existência de custos diferentes de transporte para executar uma mesma rota, já que são considerados vários transportadores. O objetivo é cobrir todas as rotas utilizando uma ou mais transportadoras de forma a minimizar o custo total.

(ÖZENER e ERGUN, 2008) propuseram um algoritmo para dividir os ganhos obtidos entre os embarcadores e transportadores de uma relação de transporte colaborativo.

(ITAl et al, 1981), (BERMOND et al, 1983), (ALON e TARSI, 1985), (FRAISSE, 1985), (JACKSON, 1990), (FAN, 1992), (LABBE et al, 1998) e (IMMORLICA, 2005) estudaram o problema de cobertura por ciclos (PCC) e suas variações. O objetivo destes problemas é cobrir os vértices de um dígrafo utilizando ciclos de modo a minimizar o custo total do percurso. A grande diferença é que não existe o conceito de rotas e reposicionamentos. 


\subsection{Geradores de instâncias}

A seguir, serão apresentados os principais conceitos e características utilizados em geradores empregados na criação de problemas relacionados ao transporte rodoviário.

Os geradores de instâncias são comumente utilizados quando se deseja testar um método ou algoritmo para obter e comparar resultados quantitativos.

Eles têm como objetivo gerar problemas que possuam características semelhantes aos enfrentados na prática e que possam ser estudados e testados.

Os geradores apresentam as seguintes propriedades ${ }^{1}$ :

- Criar uma variedade de problemas diferentes que sejam parametrizáveis.

- Criar problemas que possam ser medidos.

- Criar problemas que possam ser replicados a qualquer momento.

- Criar problemas que possam ser resolvidos utilizando métodos diferentes.

(ERGUN et al, 2007b) utilizaram um gerador para criar um conjunto de instâncias teóricas que foram utilizadas para testar o algoritmo guloso proposto e comparar seus resultados com os resultados obtidos por meio de um modelo de programação linear inteiro (PLI). O gerador criado explora basicamente a geografia do problema.

As variáveis utilizadas foram:

- Dimensão do espaço que contém o dígrafo.

- Número de vértices (que representam os clientes).

- Número de agrupamento de vértices (que representam as regiões metropolitanas).

\footnotetext{
${ }^{1}$ Ronconi, D. (Escola Politécnica, USP, Brasil). Notas de aula da disciplina PRO5826: Estudo de Metaheurísticas para Problemas de Produção, 2005.
} 
- Número de rotas.

- Semente aleatória para garantir que seja possível gerar um mesmo problema, caso seja necessário.

- Fator de dispersão do agrupamento (explicado em 2.2).

As instâncias são geradas em duas etapas: na primeira são criados os agrupamentos utilizando uma distribuição aleatória uniforme e seus respectivos vértices utilizando uma distribuição normal. $\mathrm{Na}$ segunda são geradas as rotas tentando cobrir o maior número possível de vértices. A demanda de cada rota é unitária. Além disso, existe uma restrição de número máximos de arcos e de reposicionamentos que podem ser contidos por um ciclo.

O custo das rotas é calculado por meio da distância euclidiana. Dado isso, são considerados unicamente custos variáveis, o que, na prática, não está adequado. Isso se deve ao fato de que, ao não ser considerado o custo fixo, ciclos curtos com reposicionamentos sejam menos custosos do que na realidade e, assim, deveriam ser sempre evitados.

(STRINGHER, 2004) criou um gerador baseado em problema real para testar seu modelo de PLI no problema de otimização relacionado com a designação de rotas de carga lotação para frota própria ou dedicada, visando à minimização dos custos de transporte em uma rede de distribuição. Essas rotas eram agregadas formando ciclos para garantir uma alta eficiência e movimento contínuo para uma frota dedicada.

Seu gerador contém três características importantes:

- Possui restrição da participação de trechos improdutivos (reposicionamentos) do ciclo em relação ao seu custo total. Desta forma, conseguia reduzir 0 número de combinações geradas tornando o problema mais real, já que, na prática, esses ciclos seriam descartados.

- Criou os ciclos de forma que eles nunca se sobrepusessem. Por exemplo, um ciclo formado por três rotas nunca poderia ser uma combinação de outros ciclos. 
- O custeio dos ciclos foi feito utilizando custos fixos e variáveis, diferentemente de Ergun et al (2007b), de modo a penalizar ciclos pequenos.

- Utilizou demanda não unitária.

No caso de carga fracionada, (SOLOMON, 1987) estudou o problema de roteirização de veículos com restrição de janela de entrega e também utilizou gerador de instâncias teóricas. As principais características de seu gerador são:

- Fatores geográficos: utilizou três tipos de agrupamentos de clientes: uniforme, parcialmente agrupados e agrupados. Foi utilizada a distribuição aleatória uniforme.

- Fatores de atendimento ao cliente: utilizou dois tipos de horizonte de programação dada pela capacidade de atendimento, baixo (atendimento a poucos clientes) e alto (atendimento a muitos clientes).

- Fatores de janelas de tempo: utilizou quatro probabilidades para um cliente com possuir restrição de janela de entrega: 25\%, 50\%, 75\% e $100 \%$

Ainda para carga fracionada, (CHRISTOFIDES et al, 1979) criaram um conjunto de catorze problemas teóricos para avaliar duas heurísticas de roteirização de veículos.

Os principais parâmetros utilizados foram:

- Restrição de comprimento máximo dos roteiros

- Variação no tempo de serviço gasto ao visitar cada cliente.

- Restrição de capacidade dos veículos.

- Variação no número de clientes.

- Agrupamento de clientes. 
Os autores utilizaram somente distribuição uniforme para a geração da instância.

Dados os geradores apresentados, criou-se a Tabela 2-1 com um resumo de suas principais características. Nota-se que a principal característica é a geografia do problema, dada basicamente por:

- Número e distribuição aleatória de clientes.

- Agrupamento dos clientes em regiões.

- Número e distribuição aleatória dos agrupamentos de clientes.

Além disso, nota-se que existe uma diferença entre os geradores utilizados para problemas de carga lotação e fracionada: nos problemas de carga fracionada existe uma preocupação maior com o aproveitamento do veículo, fazendo com que a sua capacidade seja um elemento importante para a instância.

Nos casos que utilizaram problemas teóricos, nota-se que todos utilizaram distribuição aleatória uniforme. Somente (ERGUN et al, 2007b) utilizaram uma distribuição normal para alocar os vértices dentro das regiões de agrupamento. $O$ comportamento das distribuições são bem distintos conforme mostrado na Figura 2-8 a seguir.

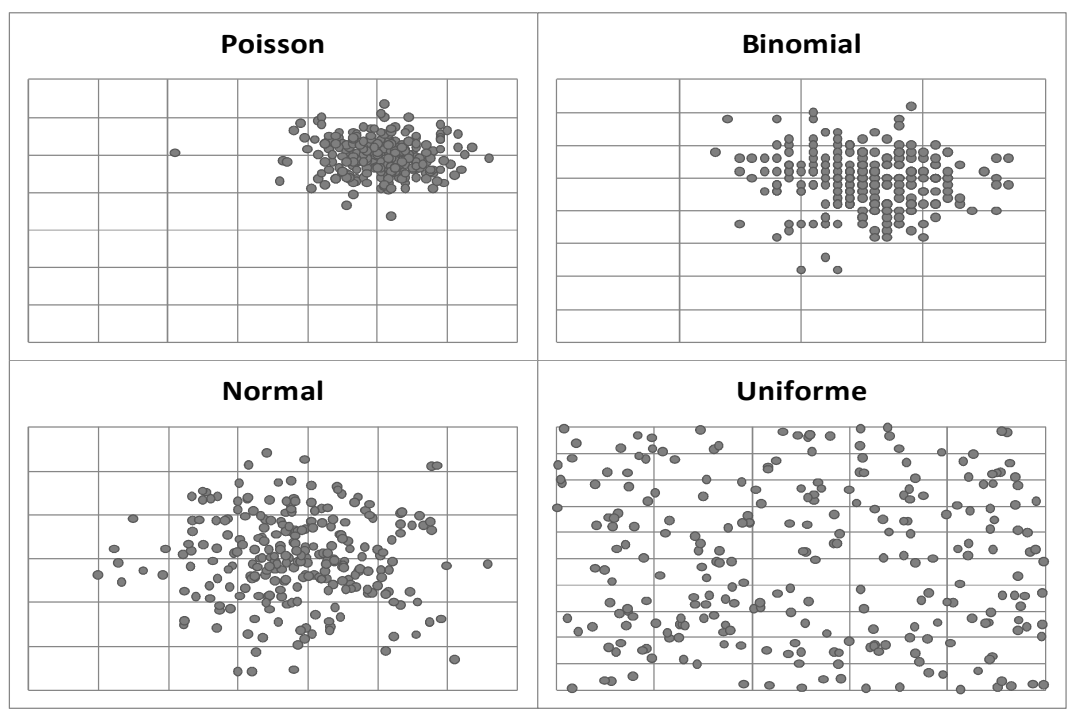

Figura 2-8: Exemplos de formatos das distribuições aleatórias 
Tabela 2-1: Resumo das características dos geradores de instâncias

\begin{tabular}{|c|c|c|c|c|c|}
\hline & (ERGUN et al, 2007b) & (STRINGHER, 2004) & (SOLOMON, 1987) & (CHRISTOFIDES et al, 1979) & (FERRI, 2009) \\
\hline Tipo de instância & $\begin{array}{l}\text { Teórico, utilizando } \\
\text { distribuição aleatória } \\
\text { Uniforme e Normal }\end{array}$ & Baseado em real & $\begin{array}{c}\text { Teórico, utilizando } \\
\text { distribuição aleatória } \\
\text { Uniforme }\end{array}$ & $\begin{array}{c}\text { Teórico, utilizando } \\
\text { distribuição aleatória } \\
\text { Uniforme }\end{array}$ & $\begin{array}{l}\text { Teórico, utilizando } \\
\text { distribuição aleatória } \\
\text { Uniforme e Normal }\end{array}$ \\
\hline Tipo de carga & Lotação & Lotação & Fracionado & Fracionado & Lotação \\
\hline Custos considerandos & Variável & Variável + Fixo & Variável & Variável & Variável \\
\hline Agrupamento de clientes & Sim & Não & Sim & Sim & Sim \\
\hline Restrições do problema & $\begin{array}{l}\text { - Cardinalidade ciclo } \\
\text { - Número de } \\
\text { reposicionamentos }\end{array}$ & $\begin{array}{c}\text { - Distância improdutiva } \\
\text { máxima }\end{array}$ & $\begin{array}{l}\text { - Janela de tempo } \\
\text { - Capacidade de veículo }\end{array}$ & $\begin{array}{l}\text { - Comprimento rota } \\
\text { - Capacidade de Veículo }\end{array}$ & $\begin{array}{l}\text { - Cardinalidade ciclo } \\
\text { - Número de } \\
\text { reposicionamentos } \\
\text { - Desbalanceamento }\end{array}$ \\
\hline Demanda & Unitária & Não-Unitária & Não-Unitária & Não-Unitária & Unitária \\
\hline
\end{tabular}


Ao observar as fotos de satélite registradas a partir do espaço pela (NASA, 2000) mostradas nas figuras a seguir, pode-se concluir que estes parâmetros são importantes. Nota-se a existência de agrupamentos representados pelas regiões metropolitanas.

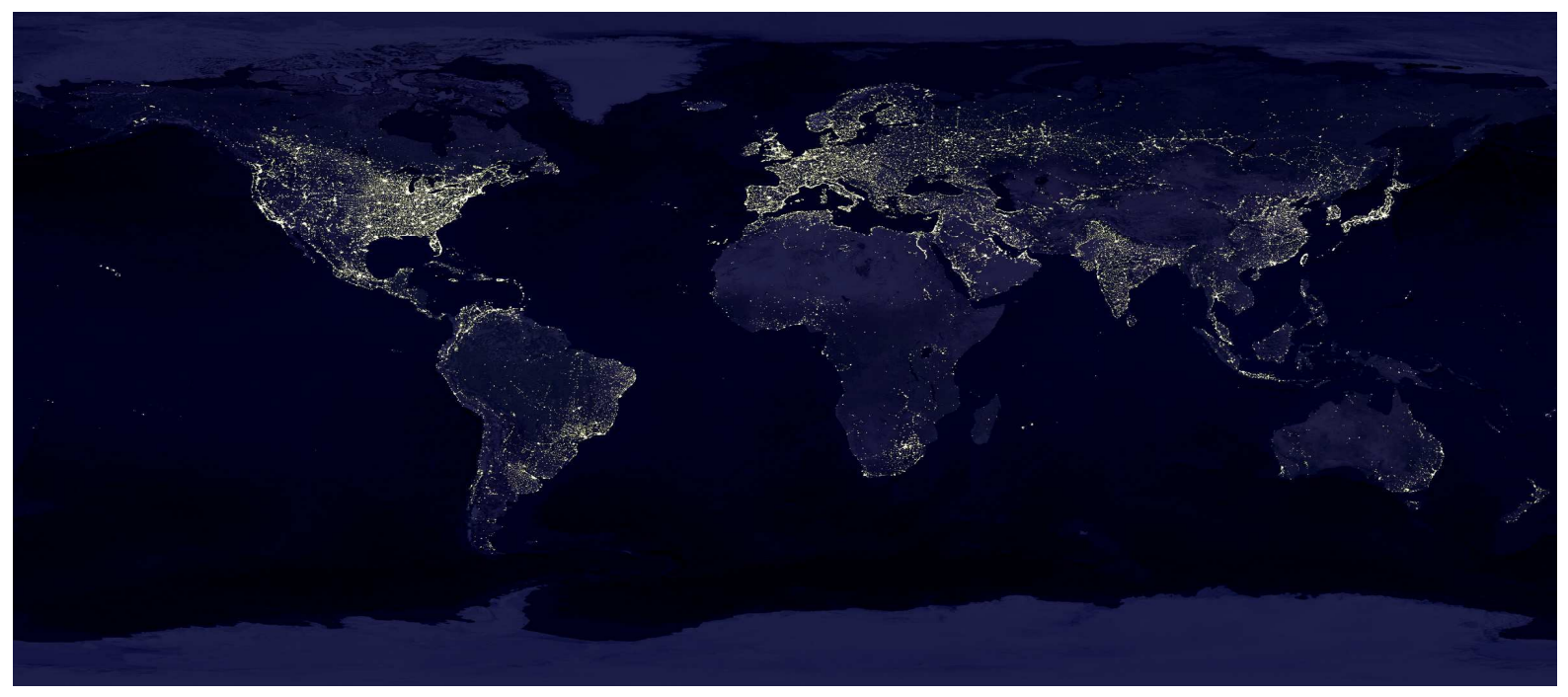

Figura 2-9: Foto noturna do mundo visto do espaço

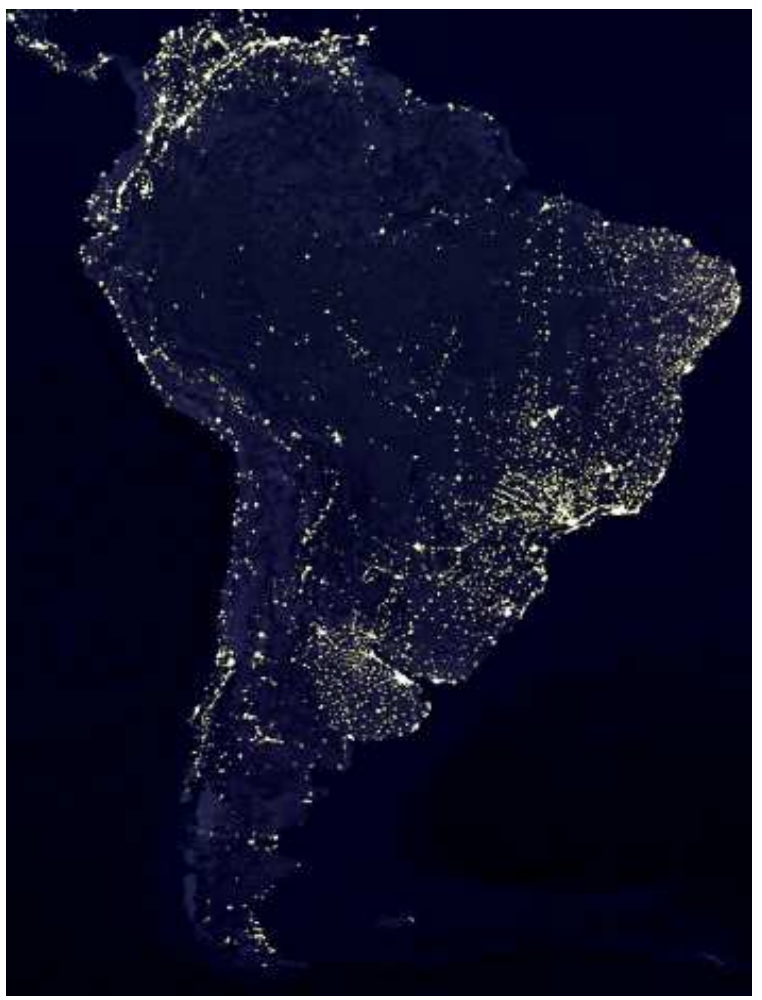

Figura 2-10: Foto noturna da América do Sul vista do espaço 


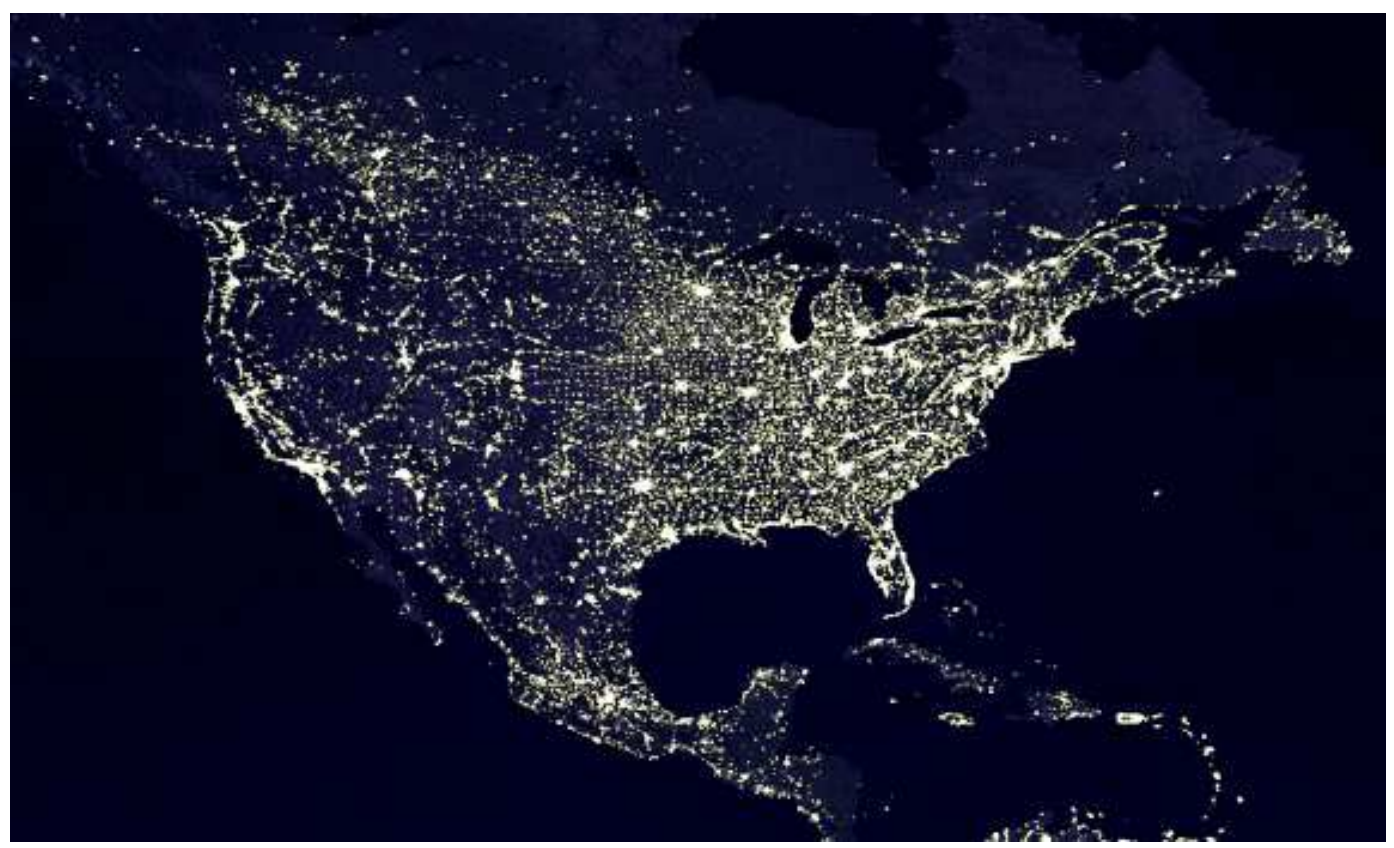

Figura 2-11: Foto noturna da América do Norte vista do espaço

Existem outras características que são importantes, porém não são comumente exploradas. Seguem alguns exemplos:

- Outras distribuições aleatórias poderiam ser avaliadas. Em todos os exemplos citados anteriormente, foram utilizadas apenas a distribuição uniforme e normal. Poderia ser utilizada uma distribuição de Poisson para alocar os clientes (vértices) dentro dos agrupamentos, por exemplo.

- Distância mínima entre os clientes.

- Distância mínima entre os agrupamentos de clientes.

- Velocidade diferente nas rotas que estão situadas entre os agrupamentos e nas rotas que estão dentro do mesmo agrupamento. $\mathrm{Na}$ prática, a velocidade média dentro de um agrupamento normalmente é menor.

- Agrupamentos que possuem predominantemente clientes que demandam carga (possuem um maior número de destinos de rotas) e outros com clientes predominantemente ofertadores de cargas (possuem um maior número de origens de rotas). 
A primeira característica impacta diretamente no formato dos agrupamentos fazendo com que ele fique mais concentrado no centro e mais disperso nas extremidades, por exemplo.

O segundo e terceiro item impactam nas distâncias mínimas e máximas entre os clientes. Dependendo do tipo de problema que se deseja testar, estes parâmetros podem ser relevantes.

O quarto item impacta diretamente no custo dos ciclos fazendo com que rotas entre os agrupamentos tivessem custos diferentes das que estão dentro do mesmo, o que realmente acontece na prática.

Por último e mais importante, a característica do agrupamento pode gerar grandes impactos nos modelos, uma vez que restringe o sentido das rotas entre as regiões (que normalmente são as mais custosas devido às longas distâncias). Existem muitas economias, como é o caso da brasileira, em que existem regiões com maior concentração de carga em pólos mais desenvolvidos gerando desbalanceamento de rotas nessas regiões. Isso faz com que existam regiões com vocação maior de origens de rotas e outras de destinos.

Por este motivo, além de utilizar o mesmo gerador de instâncias de (ERGUN et al, 2007b), que gera somente problemas balanceados, foi feita uma adaptação para gerar também problemas desbalanceados para simular um cenário com características mais semelhantes aos da economia brasileira.

O capítulo seguinte apresenta a metodologia e as modelagens utilizadas para a solução do problema PCRCR utilizando os conceitos abordados neste capítulo. 


\section{METODOLOGIA E MODELAGEM DO PROBLEMA}

Este capítulo descreve a metodologia utilizada neste estudo, bem como a definição do problema de cobertura de rotas com cardinalidade restrita. Além disso, são descritos os geradores de instâncias utilizados, o algoritmo guloso de (ERGUN et al, 2007b) que será chamado de GH, o modelo de programação linear inteira que será chamado de PLI e a heurística construtivo-destrutiva proposta por este trabalho que será chamada de CD.

\subsection{Metodologia do Trabalho}

A metodologia utilizada na solução do problema apresentado está representada na figura a seguir:

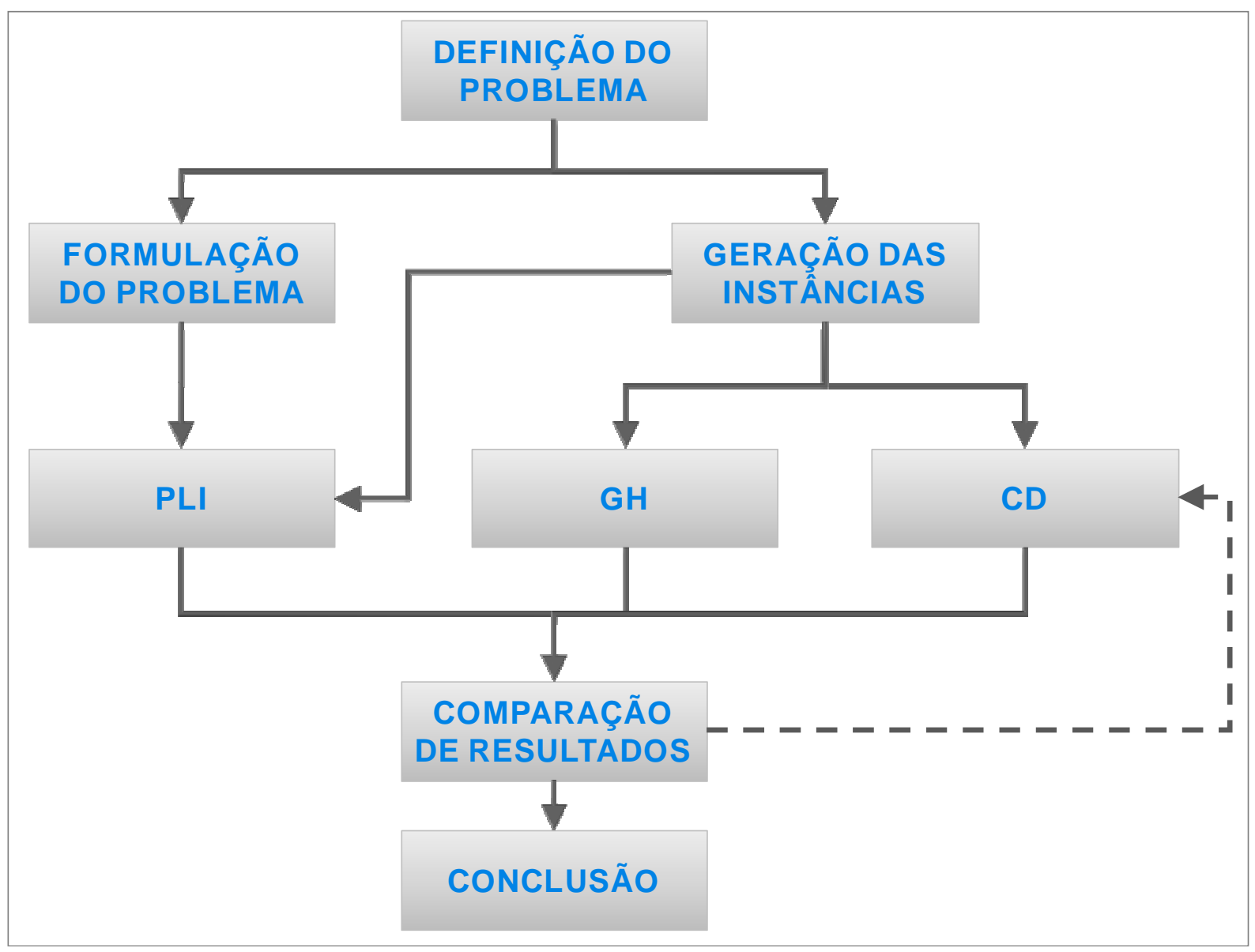

Figura 3-1: Metodologia 
Após a definição do problema, geram-se dois conjuntos de problemas que são chamados de "problemas balanceados" e "problemas desbalanceados". O primeiro é gerado utilizando-se o mesmo gerador de instâncias de (ERGUN et al, 2007b). O segundo é gerado a partir de uma modificação feita no código do primeiro gerador.

A partir disso, cada conjunto de instâncias é resolvido utilizando PLI, GH e $C D$, e é feita uma comparação tanto do valor do custo total gerado por cada método para cada problema, quanto o tempo que cada um utilizou para resolvê-lo.

\subsection{Descrição do Problema PCRCR}

O problema de cobertura de rotas com cardinalidade restrita (PCRCR) foi definido por (ERGUN et al, 2007b) da seguinte forma: dado um dígrafo direcionado $D=(V, A)$, onde $V$ é o conjunto dos vértices e $A$, o conjunto dos arcos, onde para cada arco há um custo não negativo associado $c(a)$ para $a \in A$ e um conjunto $L$ de rotas $\subseteq A$, minimizar o custo de cobertura das rotas $L$ utilizando ciclos $C$ de forma que sua cardinalidade seja menor ou igual a um dado $k$.

Foram encontradas duas formulações matemáticas na literatura: a primeira proposta por (SAVELSBERGH et al, 2004) que será chamada de "modelo básico" e a segunda proposta por (ERGUN et al, 2007b) que utiliza a formulação de cobertura de conjuntos. (SAVELSBERGH et al, 2004) prova que sua formulação é NP-Hard, enquanto que (PELED e SIMEONE 1985) afirmam que a formulação de cobertura de conjuntos é NP-completo.

\subsubsection{Formulação Matemática - Modelo Básico}

Utilizou-se como base a formulação básica de (ERGUN et al, 2004) desenvolvida para o problema PCR. Foram adicionadas as restrições 3.4 a 3.6 para criar a formulação matemática para o modelo básico do problema PCRCR que está descrita a seguir: 


\section{ÍNDICES:}

$i \in V$ : para cada um dos vértices de origem

$j \in V:$ para cada um dos vértices de destino

$c \in C$ : para cada um dos ciclos

\section{PARÂMETROS:}

k: cardinalidade máxima de um ciclo, ou seja, número máximo de arcos (rota ou reposicionamento) que um ciclo pode conter.

$I_{i j:}$ arco entre os vértices $i$ e $j$. Se $l_{i j}=1$, então este arco é uma rota e deve, obrigatoriamente, pertencer a um ciclo $c \in C$. Se $l_{i j}=0$, este arco não é uma rota e não é necessário que pertença a um ciclo.

$\boldsymbol{c}_{i j}$ : custos dos arcos entre os vértices $i$ e $j$.

$\boldsymbol{d h}$ : reposicionamentos permitidos em um ciclo, ou seja, número máximo de $\operatorname{arcos} l_{i j}=0$ que podem pertencer a um ciclo $c \in C$.

\section{VARIÁVEIS:}

$x_{i j}^{c}$ : arco entre os vértices $i$ e $j$ que pertence ao ciclo $c$. Se $x_{i j}^{c}=1$, então existe arco $i j \in c$. Caso contrário, o arco ij $\notin C$.

\section{FUNÇÃO OBJETIVO:}

A função objetivo consiste em minimizar o custo total dos ciclos:

$$
\min \sum_{i} \sum_{j} c_{i j} x_{i j}^{c}
$$




\section{RESTRIÇÕES:}

Restrição que faz com que todas as rotas pertençam a, pelo menos, um ciclo:

$$
\sum_{c} x_{i j}^{c} \geq l_{i j} \quad \text {, para } \forall i \in V, \forall j \in V
$$

Restrição que obriga o ciclo a ser fechado, ou seja, iniciar e terminar em um mesmo vértice:

$$
\sum_{i^{\prime}} x_{i^{\prime} i}^{c}-\sum_{j^{\prime}} x_{i j^{\prime}}^{c}=0 \quad \text {, para } \forall c \in C, \forall i \in V
$$

Restrição de cardinalidade de um ciclo:

$$
\sum_{i} \sum_{j} x_{i j}^{c} \leq k \quad \text {, para } \forall c \in C
$$

Restrição de número máximo de reposicionamentos em um ciclo:

$$
\sum_{i} \sum_{j} x_{i j}^{c}-\sum_{i} \sum_{j} x_{i j}^{c} * l_{i j} \leq d h \quad \text {, para } \forall c \in C
$$

Variável é binária:

$$
x_{i j}^{c} \in\{0,1\} \quad \text {, para } \forall i \in V, \forall j \in V, \forall c \in C
$$

O modelo básico listado acima gera uma quantidade elevada de variáveis para este problema. Por exemplo, no caso do problema que possui 1500 rotas e 500 vértices, haveria aproximadamente 375 milhões de variáveis. No menor problema que contém 100 rotas e 500 vértices, sua dimensão seria de 25 milhões de variáveis. Isso impossibilita sua resolução na prática, pois requisitos de memória de computador, por exemplo, são demasiadamente grandes.

Devido a isso, (ERGUN et al, 2007b) propuseram e utilizaram o modelo de cobertura de conjuntos que será explicado a seguir. 


\subsubsection{Formulação Matemática - Modelo de Cobertura de Conjuntos}

O modelo de cobertura de conjuntos consiste em: dado um conjunto $C_{k}$ gerado previamente de todas as combinações de ciclos (que cobrem pelo menos uma rota respeitando as restrições de cardinalidade $k$ e de número de reposicionamentos permitidos $d h$ ), deve-se escolher um subconjunto de ciclos $c \in C_{k}$ de forma a minimizar o custo total dos ciclos e cobrir todas as rotas de modo que $c \cap L \neq \varnothing$.

\section{ÍNDICES:}

$c \in C_{k}:$ para cada um dos ciclos

\section{PARÂMETROS:}

$\boldsymbol{c}_{c}$ : custo do ciclo $c \in C_{k}$.

$I_{c}$ : rotas que pertencem ao ciclo $c \in C_{k}$. Se $I_{c}=1$, então a rota $I \in L$ pertence a um ciclo $c \in C_{k}$. Se $I_{c}=0$, então a rota $I \in L$ não pertence a um ciclo $c \in C_{k}$.

\section{VARIÁVEIS:}

$x_{c}$ : indica se ciclo $c$ foi selecionado ou não. Se $x_{c}=1$, ciclo $c \in C_{k}$ faz parte da solução. Caso contrário, o ciclo não foi selecionado.

\section{FUNÇÃO OBJETIVO:}

A função objetivo consiste em minimizar o custo total dos ciclos selecionados: 
$\min \sum_{c \in C_{k}} C_{c} x_{c}$

\section{RESTRIÇÕES:}

Restrição que faz com que todas as rotas pertençam a, pelo menos, um ciclo:

$\sum_{c \in C_{k}} l_{c} x_{c} \geq 1 \quad$, para $\forall l \in L$

Variável é binária:

$x_{c} \in\{0,1\}$

, para $\forall c \in C_{k}$

Vale ressaltar que, para gerar o conjunto $C_{k}$, é necessário gerar todos os ciclos viáveis que satisfaçam as restrições de cardinalidade e reposicionamento máximo. Segundo Ergun et al (2007b), o número de combinações geradas por este processo torna-se proibitivamente grande com o aumento do tamanho do problema. Além disso, consome-se uma quantidade significativa de tempo para gerá-las.

Devido a esta limitação, Ergun et al (2007b) resolveram um mesmo problema de duas formas: a primeira, considerando apenas a permissão de um reposicionamento por ciclo, enquanto que a segunda considerando dois reposicionamentos, dada cardinalidade máxima de 5. Desta forma, o primeiro caso gera uma quantidade de ciclos viáveis significativamente menor, de modo que seja possível resolver problemas maiores que o segundo caso. Foi feito isso com o objetivo de comparar e analisar as diferenças de tempos e combinações geradas por cada um dos dois casos. 


\subsection{Geração dos ciclos viáveis}

Tanto o algoritmo GH quanto o PLI utilizam a formulação de cobertura de conjuntos e isso faz com que seja necessário gerar todas as combinações viáveis de ciclos que respeitam as restrições de cardinalidade e número máximo de reposicionamentos. Para isso, foram utilizados os algoritmos disponíveis em (ERGUN et al, 2004).

Os algoritmos são funções recursivas muito eficientes que estão dividas em duas etapas: primeiramente são geradas todas as combinações de ciclos que possuem nenhum ou somente um reposicionamento. Posteriormente são gerados os ciclos com dois reposicionamentos por meio de combinações entre os que foram gerados anteriormente.

A primeira parte da geração de ciclos é dividida em três algoritmos, sendo um é o algoritmo principal, que será chamado de "Algoritmo de Geração de Ciclos 1". Ele utiliza outros dois para construir os ciclos, que serão chamados de "Algoritmo de Busca Posterior" e "Algoritmo de Busca Anterior".

Esses últimos possuem o objetivo de gerar caminhos $P$ que são uma seqüência de uma ou mais rotas sem reposicionamento entre elas de modo que o vértice de início da primeira rota não coincida com o vértice final da última, ou seja, sem formar um ciclo. O vértice inicial do caminho $P$ será chamado de início $(P)$, enquanto o vértice final de $P$ será chamado de $f i m(P)$.

Dessa forma, um caminho com um reposicionamento entre $f i m(P)$ e início $(P)$ é um ciclo, conforme mostrado na Figura 3-2 a seguir: 


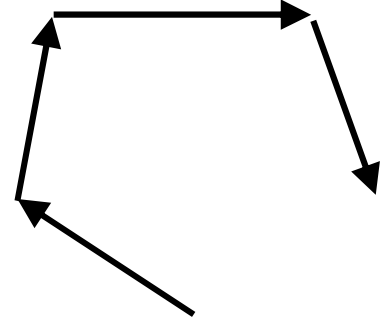

Caminho

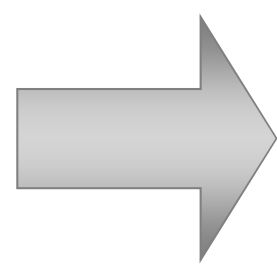

Ciclo

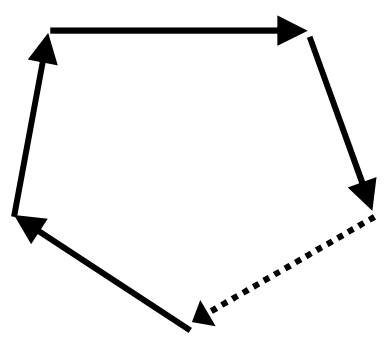

Figura 3-2: Diferença entre caminho e ciclo

Segundo Ergun et al (2004), os algoritmos de busca apresentam, respectivamente, as seguintes características:

1. Gerar todos os ciclos que contenham o arco que cubra uma rota específica, apagando-a do conjunto das rotas até que esse esteja vazio.

2. Gerar todos os ciclos que contenham o arco que cubra uma rota específica de modo que seja o primeiro arco de um caminho que cobre rotas. Repete-se para todas as rotas do conjunto.

\subsubsection{Algoritmo de Busca Posterior}

O Algoritmo de Busca Posterior recebe como entrada um caminho $P$ cuja cardinalidade deve ser menor ou igual a $K-1$, sendo que $K$ é a cardinalidade máxima permitida. Primeiramente, é criado um ciclo fechando-se o caminho $P$ com um reposicionamento (ligando-se as extremidades de $P$ ).

A seguir, se o caminho $P$ tiver cardinalidade menor que $K-1$, adiciona-se uma rota ao final dele, porém somente se o vértice inicial desta rota coincidir com 0 $f i m(P)$ e se o vértice final da rota não for igual a nenhum outro vértice pertencente a $P$. Após isso, o algoritmo é executado recursivamente.

Este algoritmo consegue gerar somente ciclos que possuem um único reposicionamento. 
O Algoritmo de Busca Posterior é descrito a seguir:

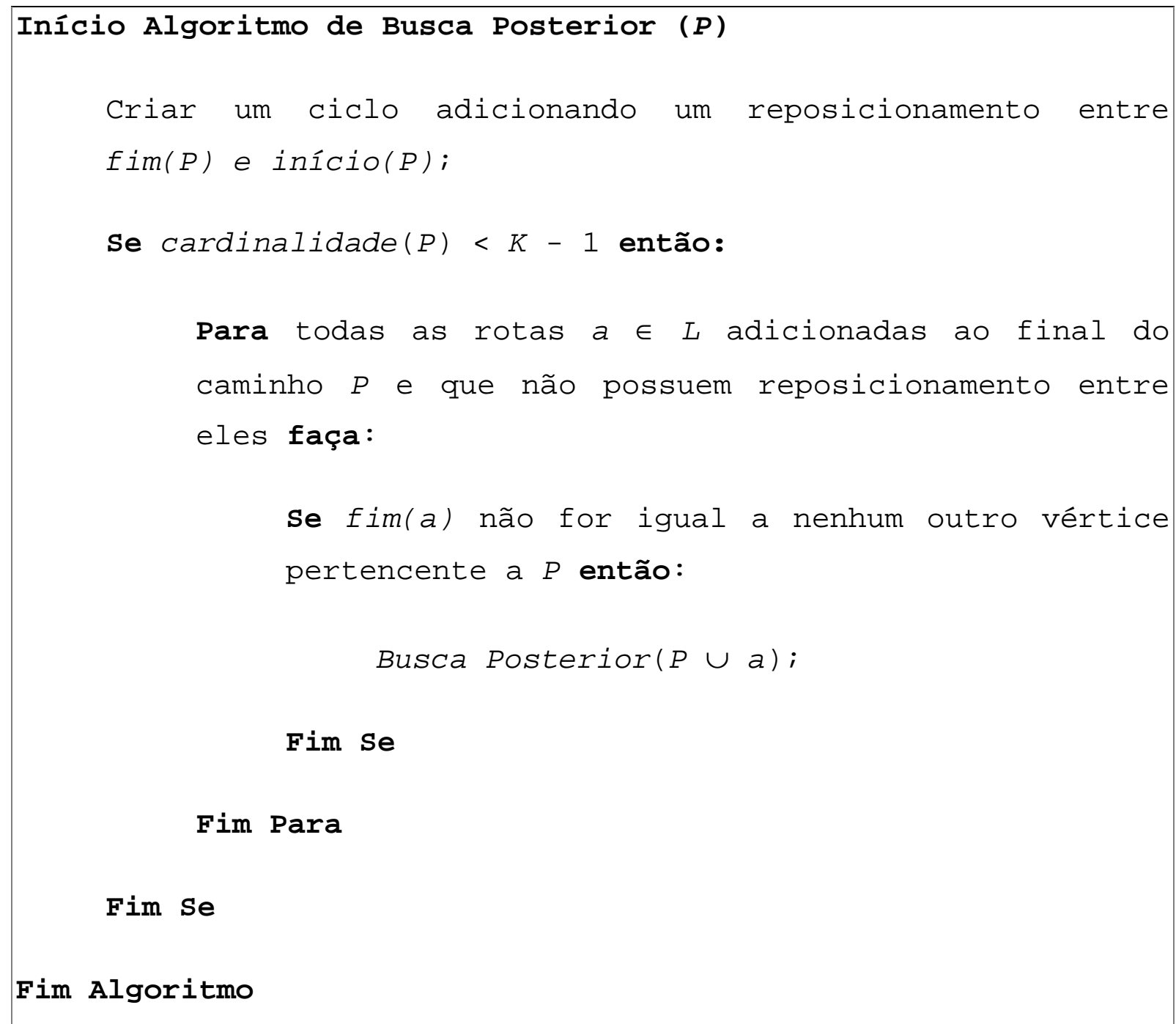

Algoritmo 3-1: Algoritmo de Busca Posterior do gerador de ciclos viáveis

\subsubsection{Algoritmo de Busca Anterior}

O Algoritmo de Busca Anterior recebe como entrada um caminho $P$ cuja cardinalidade deve ser menor ou igual a $K-1$. Primeiramente, adiciona-se uma rota ao início dele, porém somente se o vértice final desta rota coincidir com o início $(P)$ e se o vértice inicial da rota coincidir com o vértice final de $P$, criando, assim, um ciclo sem reposicionamento. Caso contrário, se a cardinalidade de $P$ for menor que $K$ - 1 e se o vértice inicial da rota não for igual a nenhum outro vértice pertencente a $P$, os algoritmos de Busca Posterior e de Busca Anterior são executados recursivamente. 
Este algoritmo consegue gerar somente ciclos que não possuem nenhum reposicionamento.

O Algoritmo de Busca Anterior é descrito a seguir:

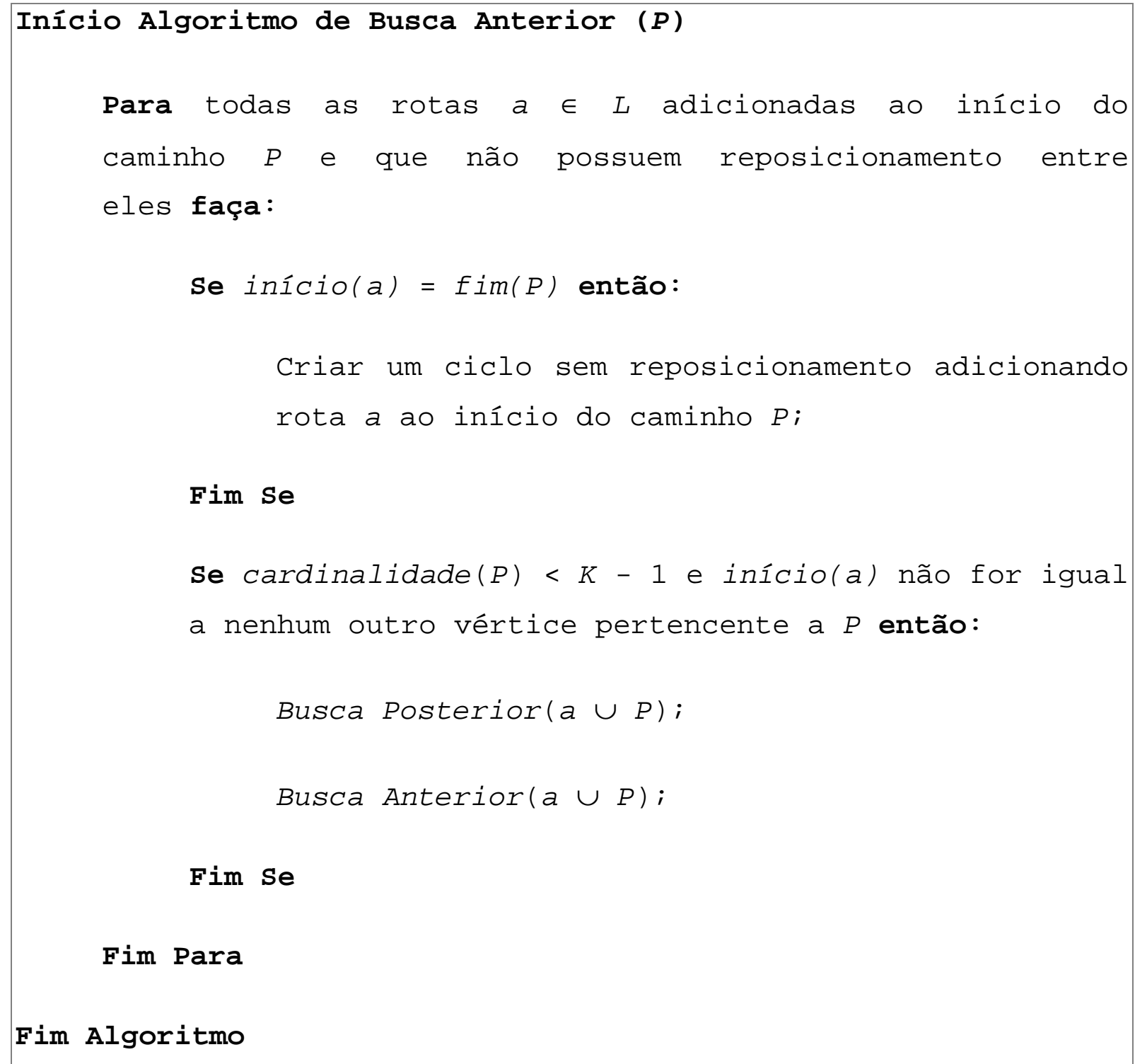

Algoritmo 3-2: Algoritmo de Busca Anterior do gerador de ciclos viáveis

\subsubsection{Algoritmo de Geração de Ciclos 1}

A partir destes dois algoritmos de busca o Algoritmo Principal de Geração de Ciclos 1 os executa para cada rota $/ \in L$. Em seguida, remove / do conjunto até que este esteja vazio. 
O Algoritmo Principal de Geração de Ciclos 1 é descrito a seguir:

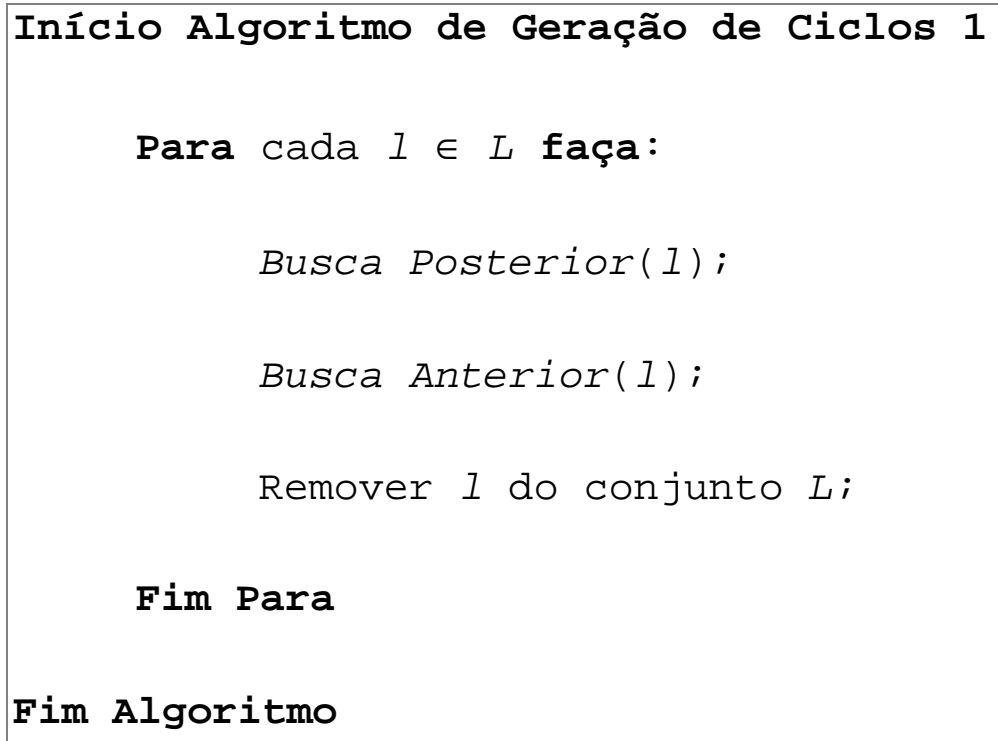

Fim Algoritmo

Algoritmo 3-3: Algoritmo de geração de ciclos 1 do gerador de ciclos viáveis

Este algoritmo consegue evitar a geração de ciclos que são iguais, mas que estão em ordem diferente. Por exemplo, seja um ciclo com as seguintes rotas A-B-C (em que a rota $A$ envia para a $B$ que envia para a $C$ que por fim retorna para a $A$ ). Esse ciclo é o mesmo de B-C-A e C-A-B, porém estão em ordens diferentes. Dessa forma, o número total de ciclos gerados é reduzido.

\subsubsection{Algoritmo de Geração de Ciclos 2}

A segunda parte do gerador de ciclos (que será chamada de "Algoritmo de Geração de Ciclos 2") utiliza uma heurística para unir dois ciclos com um reposicionamento com o objetivo de criar um ciclo com dois reposicionamentos.

Sejam, por exemplos, dois ciclos $C_{1} \in C_{k}$ e $C_{2} \in C_{k}$ formados pelos caminhos $P_{1}$ e $P_{2}$, respectivamente, com um reposicionamento ligando suas extremidades de modo que: $C_{1}=P_{1} \cup\left(f i m\left(P_{1}\right)\right.$, início $\left.\left(P_{1}\right)\right)$ e $C_{2}=P_{2} \cup\left(f i m\left(P_{2}\right)\right.$, início $\left.\left(P_{2}\right)\right)$. A heurística é utilizada para unir $C_{1}$ e $C_{2}$ para formar $C_{12}$, que será um ciclo com dois reposicionamentos. 
Este algoritmo funciona da seguinte forma: removem-se os dois arcos de reposicionamento $\left(f i m\left(P_{1}\right)\right.$, início $\left.\left(P_{1}\right)\right)$ e $\left(f i m\left(P_{2}\right)\right.$, início $\left.\left(P_{2}\right)\right)$ e adicionam-se os arcos $\left(f i m\left(P_{1}\right)\right.$, início $\left.\left(P_{2}\right)\right)$ e $\left(f i m\left(P_{2}\right)\right.$, início $\left.\left(P_{1}\right)\right)$ entre os caminhos $P_{1}$ e $P_{2}$, formando dois reposicionamentos como é mostrado na Figura 3-3 a seguir:

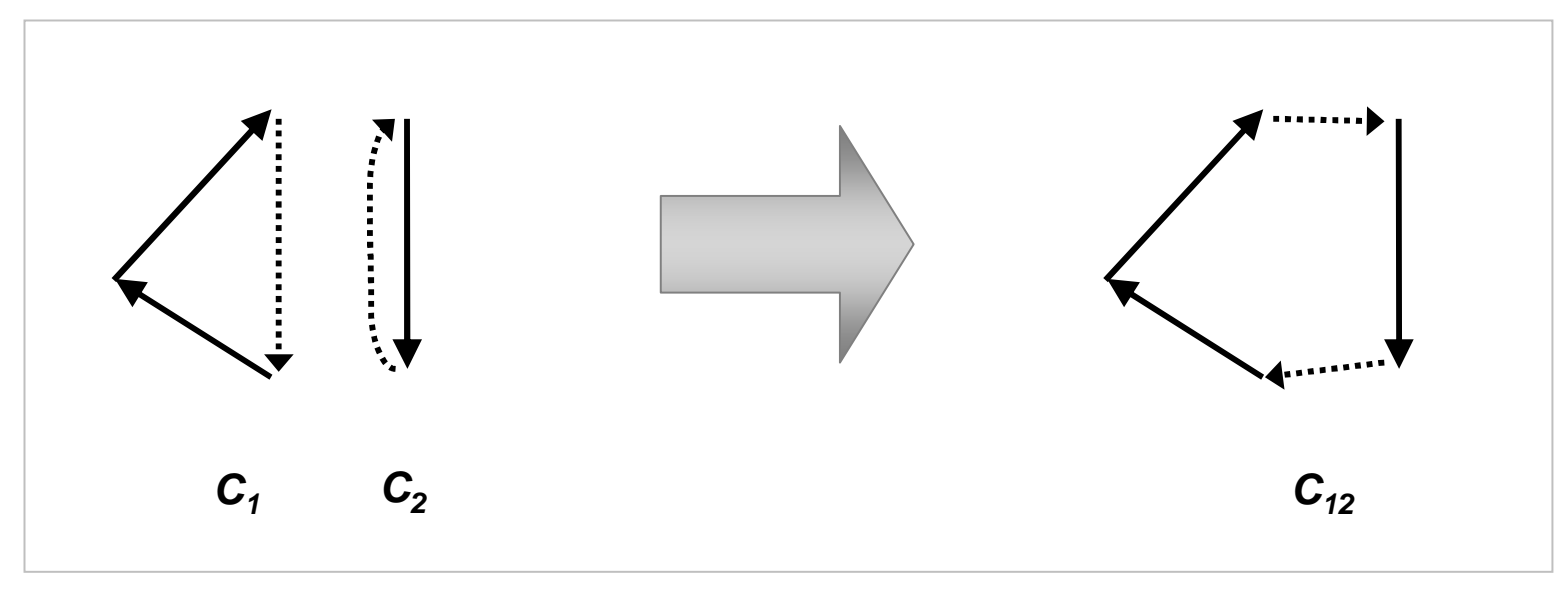

Figura 3-3: União de 2 ciclos

Para reduzir significativamente o número de combinações geradas por este algoritmo, a união dos ciclos só será permitida se a soma dos custos dos reposicionamentos dos ciclos individuais for maior do que a soma dos custos dos reposicionamentos do novo ciclo, representado a seguir:

- $\operatorname{Custo}\left(f i m\left(P_{1}\right)\right.$, início $\left.\left(P_{1}\right)\right)+\operatorname{Custo}\left(f i m\left(P_{2}\right)\right.$, início $\left.\left(P_{2}\right)\right)>\operatorname{Custo}\left(f i m\left(P_{1}\right)\right.$, início $\left.\left(P_{2}\right)\right)+$ Custo $\left(f i m\left(P_{2}\right)\right.$, início $\left.\left(P_{1}\right)\right)$

Dada essa propriedade, Ergun et al (2004) provam que pelo menos uma das as inequações a seguir são verdadeiras:

- $\operatorname{Custo}\left(f i m\left(P_{1}\right), \operatorname{início}\left(P_{1}\right)\right)>\operatorname{Custo}\left(f i m\left(P_{1}\right), \operatorname{início}\left(P_{2}\right)\right)$

- $\operatorname{Custo}\left(f i m\left(P_{2}\right)\right.$, início $\left.\left(P_{2}\right)\right)>\operatorname{Custo}\left(f i m\left(P_{2}\right), \operatorname{início}\left(P_{1}\right)\right)$

Dado isso, seja o conjunto $\hat{C}$ dos ciclos formados pelo Algoritmo de Geração de Ciclos $1, c(C)$ o custo do ciclo $C \in \hat{C}$ e as inequações listadas, o Algoritmo de Geração de Ciclos 2 é descrito a seguir: 


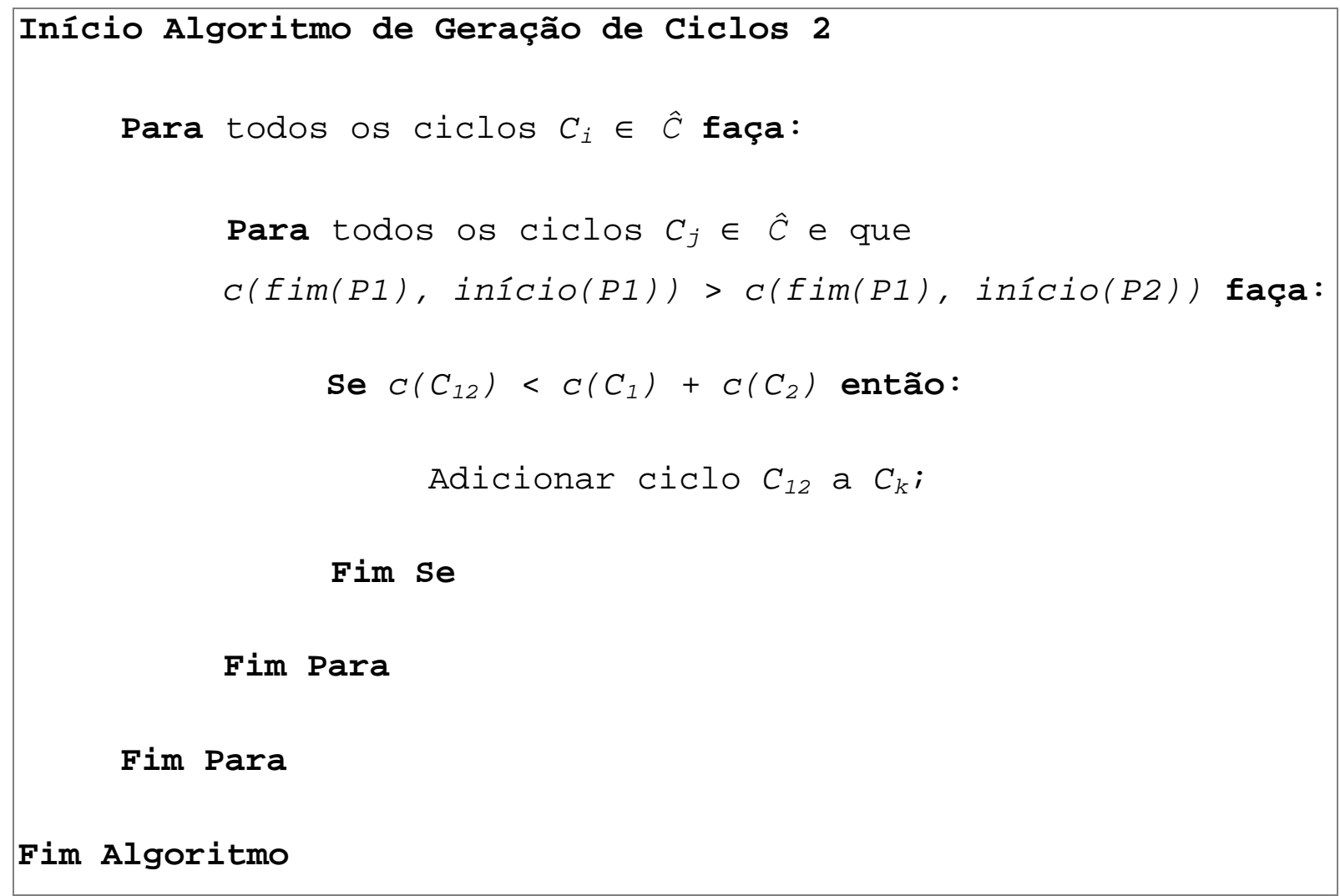

Algoritmo 3-4: Algoritmo de geração de ciclos 2 do gerador de ciclos viáveis

Apesar de estes artifícios conseguirem reduzirem o número de ciclos, com o aumento do problema (tanto em cardinalidade, quanto no número de rotas e reposicionamentos permitidos), o número de ciclos gerados cresce exponencialmente, tornando proibitiva a sua geração e, conseqüentemente, a sua resolução posterior.

\subsection{Algoritmo Guloso proposto por (ERGUN et al, 2007b)}

O algoritmo guloso proposto por (ERGUN et al, 2007b) utiliza a formulação de cobertura de conjuntos apresentado anteriormente neste capítulo.

A partir de todas as combinações de ciclos viáveis, é calculado um fator $f$ para cada ciclo da seguinte forma: $f$ é dado pela divisão entre o custo total do ciclo sem considerar os reposicionamentos pelo custo total do ciclo considerando os reposicionamentos. 
A partir disso, seleciona-se o ciclo deste conjunto que possui o maior fator $f$ de modo que $C \cap U \neq \varnothing$, sendo que $U$ é uma cópia de $L$, conjunto das rotas. Em seguida, removem-se as rotas deste ciclo do conjunto $U$. Repetem-se estes últimos passos selecionando ciclos e removendo as rotas até que o conjunto $U$ esteja vazio.

O algoritmo é representado da seguinte forma:

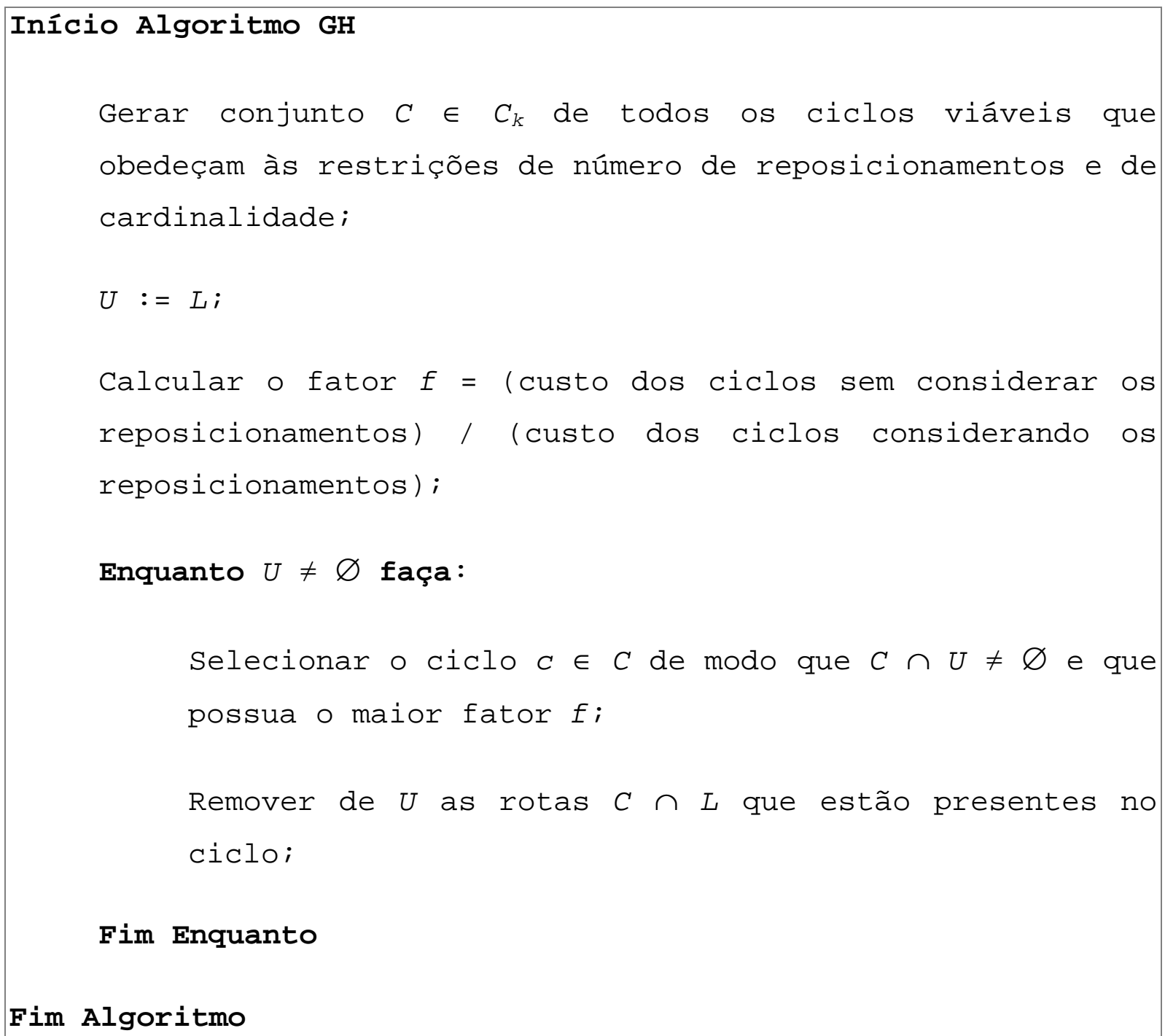

Fim Enquanto

Fim Algoritmo

Algoritmo 3-5: Algoritmo Guloso proposto por (ERGUN et al, 2007b)

É importante ressaltar que só é possível executar este algoritmo se todos os ciclos viáveis forem gerados anteriormente. 


\subsection{A Heurística Construtivo-Destrutiva}

A descrição da heurística será dividida em quatro partes a fim de tornar mais simples o entendimento:

- Na primeira parte serão explicados os conceitos-chave utilizados na sua criação.

- Na segunda parte será apresentada a nomenclatura utilizada.

- Na terceira parte será explicado detalhadamente o algoritmo.

- Na última parte será mostrado um exemplo de sua aplicação buscando abordar todas as partes do algoritmo.

\subsubsection{Conceitos utilizados}

A heurística proposta neste estudo tem o objetivo de ser uma alternativa ao GH e PLI. Além disso, buscou-se criar um algoritmo que fosse independente da necessidade de geração de todas as combinações de ciclos viáveis e que tivesse desempenho comparável aos outros métodos (tanto em tempo, quanto no valor da solução), porém que conseguisse solucionar problemas muito maiores.

Foram utilizados quatro conceitos principais na criação da heurística, conforme listado a seguir:

- Durante o início da construção dos ciclos, as rotas mais longas têm prioridade para serem alocadas.

- A construção é dada adicionando-se a rota mais próxima a uma das extremidades do ciclo em construção.

- A fim de reduzir a "miopia" da heurística, devem-se construir ciclos em paralelo e ao final do processo de construção, selecionar o que apresenta melhor "qualidade" (este conceito será explicado mais adiante). 
- Após a construção de um ciclo, esse deve ser destruído caso não atenda a um limite de "qualidade" mínima. Esse limite de "qualidade" não deve ser fixo. Deve ser muito rigoroso no início e ir reduzindo à medida que novos ciclos são construídos.

O conceito utilizado de "qualidade" de um ciclo refere-se à proporção do custo dos reposicionamentos em relação ao custo total desse. Essa proporção será chamada de $p$. Dessa forma, quanto menor for $p$ de um ciclo, mais "qualidade" ele terá.

\subsubsection{Nomenclatura utilizada}

Sejam os seguintes parâmetros que são utilizados pela heurística CD com suas respectivas descrições:

- Lé o conjunto das rotas.

- $U$ é dado por $U=L$, é o conjunto das rotas que estão ordenadas em ordem decrescente de comprimento.

- $I_{\max }$ é o número de rotas contidas em $L$.

- $I_{1}$ é o índice atrelado ao conjunto $U$ de modo que $I_{1}=[1 ; \operatorname{lmax}]$. Dado isso, quando $I_{1}=1$ refere-se à rota de maior comprimento de $U$ e $I_{1}=I_{\max }$ referese à de menor comprimento. Ao final da criação de um ciclo, este índice é sempre incrementado.

- $\quad p$ é o fator de "qualidade" do ciclo dado pela proporção entre o custo do reposicionamento e o custo total de um determinado ciclo.

- $p_{\min }$ é a menor proporção $p$ que o ciclo deve ter para não ser destruído. $p_{\min }=[0 ; 1]$.

- $p_{\text {incr }}$ é o quanto a proporção $p_{\min }$ será incrementada após todas as rotas forem inspecionadas. $p_{\text {incr }}=[0 ; 1]$. 
- Č é o conjunto dos ciclos criados pela heurística (solução final).

- Ç é o conjunto dos ciclos que estão sendo criados em paralelo e ainda não foram selecionados para a solução final.

- $C_{c}$ é o ciclo candidato a ser considerado na solução final $C \check{\text {. }}$

- $j$ é o índice utilizado para os ciclos $C_{j} \in C$.

- $j_{\max }$ é o número máximo de ciclos que serão construídos em paralelo.

- $I_{\min }$ é a proporção mínima de rotas que devem ser alocadas em ciclo antes de $p_{\min }$ ser incrementado. $I_{\min }=[0 ; 1]$.

- $P_{\text {mult }}$ é o multiplicador que será aplicado a $p_{\text {incr, }}$ caso a proporção mínima de rotas $I_{\min }$ não seja atingida. Este parâmetro é utilizado para deixar a heurística mais rápida.

\subsubsection{Descrição da Heurística Construtivo-Destrutiva}

Dadas as nomenclaturas e os conceitos explicados anteriormente é possível iniciar a descrição da heurística.

Primeiramente, deve-se criar o conjunto $U$ de modo que $U=L$ e que contém as rotas $I \in U$ em ordem decrescente de comprimento atrelando-se o índice $I_{1}$ a esse conjunto. Em seguida, escolhe-se $l_{1}=1$ para iniciar a construção dos ciclos $C_{j} \in C$. A primeira rota do ciclo será chamada de rota base.

Para todos os passos a seguir, sempre que um ciclo atingir as restrições de número máximo de reposicionamento e/ou cardinalidade, sua construção é concluída. Além disso, sempre que uma rota $I \in U$ for selecionada, é removida de $U$.

Os ciclos $C_{j} \in \mathcal{C}$ serão construídos em paralelo e ao final do processo somente aquele que apresentar a menor proporção $p$ será um candidato ao conjunto Č. A construção desses ciclos se dá adicionando-se ao final do ciclo a j-ésima rota que possui seu vértice inicial mais próximo do vértice final da rota base. Por 
exemplo, para criar o ciclo $C_{1}$, será inserida a primeira rota mais próxima, para o $C_{2}$, a segunda mais próxima e assim por diante até a $j_{m a x}$-ésima rota.

É importante enfatizar que o processo de construção de ciclos em paralelo é feito de modo que a construção de um ciclo não afete a de outro. Por exemplo, se um ciclo utilizar uma determinada rota, essa estará disponível para ser utilizada para os outros ciclos em construção.

A seguir, adiciona-se ao início do ciclo em construção a rota $I \in U$ que possui seu vértice final mais próximo do vértice inicial da rota base do ciclo $C_{j}$.

Para concluir a construção, adiciona-se ao final de $C_{j}$ a rota $I \in U$ que possui seu vértice inicial mais próximo do vértice da extremidade final de $C_{j}$. Repete-se este passo até que a restrição de cardinalidade e/ou reposicionamento sejam atingidas.

Após a construção dos ciclos $C_{j}$, verifica-se, para cada um, todas as combinações possíveis e viáveis de fechamento do ciclo de modo que todas elas contenham a rota base e calcula-se o fator $p$ para cada combinação. Escolhe-se, para cada ciclo $C_{j}$, a combinação com o menor $p$ eliminando as rotas desnecessárias de cada ciclo. Por exemplo, se um ciclo $C_{1}$ for composto por apenas duas rotas, existem duas formas de fechamento: a primeira é com as duas rotas e a segunda é com somente a rota base. Se a segunda opção tiver o menor $p$, o ciclo será fechado com uma rota e a outra é devolvida ao conjunto $U$.

A seguir, escolhe-se o ciclo $\mathrm{C}_{\mathrm{c}} \in C_{j}$ que é aquele que possui o menor valor $p$. Esse é o ciclo candidato para fazer parte da solução. Os demais j-1 ciclos $C_{j}$ são descartados.

Se o ciclo candidato tiver $p$ maior que $p_{\min }$, então ele será descartado. Caso contrário é adicionado a Č.

Por último, devem-se atualizar os parâmetros. $I_{1}$ é incrementado até que a primeira rota $I \in U$ esteja disponível.

Se $I_{1}$ for maior que $I_{\max }$, então $I_{1}$ é igual ao menor índice disponível em $U$ e ainda, caso a proporção de rotas alocadas aos ciclos Č em relação ao total de rotas 
disponíveis $\left(I_{\max }\right)$ for menor que $I_{\min }$, então $p_{\min }$ será multiplicado por $\left(1+p_{\text {incr }}{ }^{*} p_{\text {mult }}\right)$, caso contrário, será multiplicado apenas por $\left(1+p_{\text {incr }}\right)$.

Os fatores $I_{\text {min e }} p_{\text {mult }}$ são utilizados quando o número de ciclos gerados é muito baixo devido ao fator $p_{\min }$ estar rejeitando a maior parte dos ciclos $C_{c}$. Entretanto a utilização desses parâmetros é opcional, porém utilizá-los reduz o tempo de execução da heurística sem afetar o significativamente o resultado.

Inicia-se a construção do próximo ciclo selecionando-se a rota base até que o conjunto $U$ esteja vazio.

A heurística CD é representada da seguinte forma:

\section{Início Heurística Construtivo-Destrutiva (CD)}

$$
U:=L_{i}
$$

Ordenar rotas $I \in U$ em ordem decrescente de comprimento utilizando 0 índice $I_{1}$;

$I_{1}:=1$

\section{Enquanto $U \neq \varnothing$ faça:}

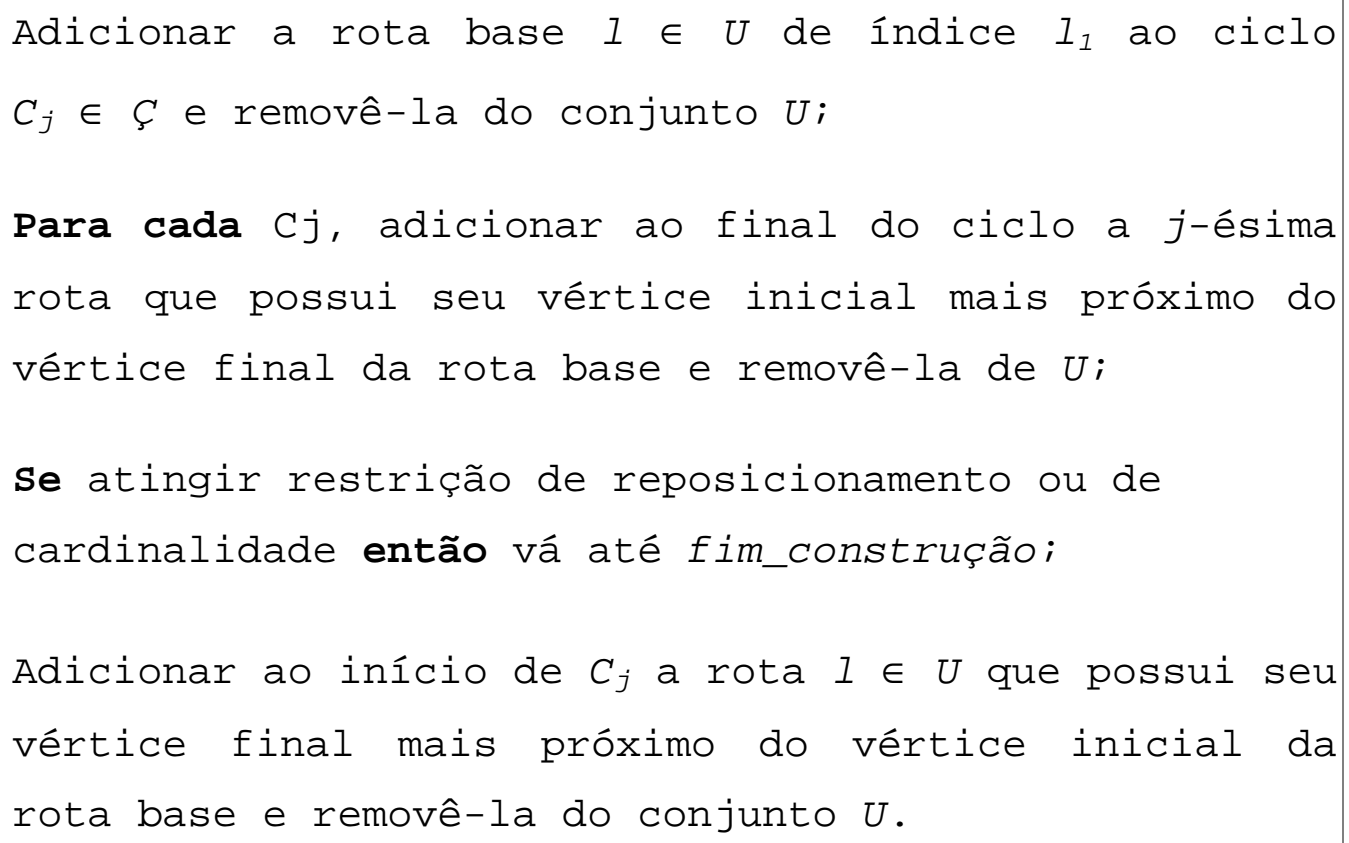


Enquanto não atingir restrição de reposicionamento ou de cardinalidade faça:

Adicionar ao final de $C_{j}$ a rota $l \in U$ que possui seu vértice inicial mais próximo do vértice da extremidade final de $C_{j}$ e removê-la de $U$.

\section{Fim Enquanto}

fim_constr:

Para cada $C_{j}$, verificar todas as combinações viáveis de fechamento de ciclo que contenham a rota base;

Para cada combinação de $C_{j}$, calcular a proporção $p$;

Para cada combinação de $C_{j}$, escolher a combinação que possua o menor $p$ e devolver rotas não usadas ao conjunto $U$;

Escolhe-se o ciclo $C_{c} \in C_{j}$ que possui o menor valor $p$ e descartar os demais $C_{j}$ de modo que $\zeta=\varnothing$;

Se $C_{C}$ tiver $p>p_{\text {min }}$, então $C_{C}$ é descartado;

$$
\text { caso contrário, } \check{C}:=\check{C} \cup C_{C} \text {; }
$$

$I_{1}$ é incrementado até que a próxima rota $I \in U$ esteja disponível.

Se $I_{1}>I_{\max r}$ então:

$I_{1}$ é igual ao menor índice disponível em $U$;

Se (número de rotas alocadas a $\check{C}$ ) / $I_{\max }<I_{\min }$ então:

$$
p_{\text {min }}=p_{\text {min }} *\left(1+p_{\text {incr }} * p_{\text {mult }}\right) ;
$$


Caso contrário:

$$
p_{\text {min }}=p_{\text {min }} *\left(1+p_{\text {incr }}\right) ;
$$

\section{Fim Se}

\section{Fim Se}

\section{Fim Enquanto}

Fim Algoritmo

\section{Algoritmo 3-6: Heurística Construtivo-Destrutiva}

\subsubsection{Exemplo de Utilização da Heurística}

A seguir será apresentado um exemplo fictício e simplificado de um problema que possui um conjunto $L$ que contém 100 rotas com o objetivo de ilustrar a heurística CD.

Neste exemplo, buscou-se explicar de maneira simples, omitindo-se alguns cálculos considerados pouco relevantes e enfatizando as passagens mais complexas empregando ilustrações.

Será gerado somente um ciclo, pois a construção dos demais é dada pelos mesmos passos. Além disso, utilizou-se um problema que abrange todo o algoritmo da heurística CD.

Os parâmetros utilizados neste problema são os seguintes:

- Número de reposicionamentos permitidos: 2 reposicionamentos.

- Cardinalidade: 5 arcos permitidos no ciclo.

- $I_{\max }=100$ rotas.

- $p_{\min }=10 \%$. 
- $p_{\text {incr }}=20 \%$.

- $j_{\max }=2$ ciclos.

- $I_{\min }=10 \%$.

- $\quad p_{\text {mult }}=2$ vezes

A partir desses parâmetros, inicia-se a heurística CD:

Criar o conjunto $U$ de modo que $U=L$ onde as rotas estejam em ordem decrescente de comprimento utilizando o índice $l_{1}$, conforme demonstrado na Figura 3-4 a seguir:

$\boldsymbol{U}=\left(\begin{array}{cc}I_{1} & \text { Comprimento } \\ 1 & 542,24 \\ 2 & 541,39 \\ 3 & 520,14 \\ 4 & 498,27 \\ \vdots & \vdots \\ 98 & 2,51 \\ 99 & 1,95 \\ 100 & 1,36\end{array}\right)$

Figura 3-4: Conjunto $U$

Atribui-se $I_{1}=1$.

Dá-se o início à construção do ciclo. Como $j_{\max }=2$, serão construídos dois ciclos $C_{j} \in C$ simultaneamente.

Adicionar a rota de índice $I_{1}$ aos ciclos $C_{j}$. Essa será a rota base para cada um deles. 


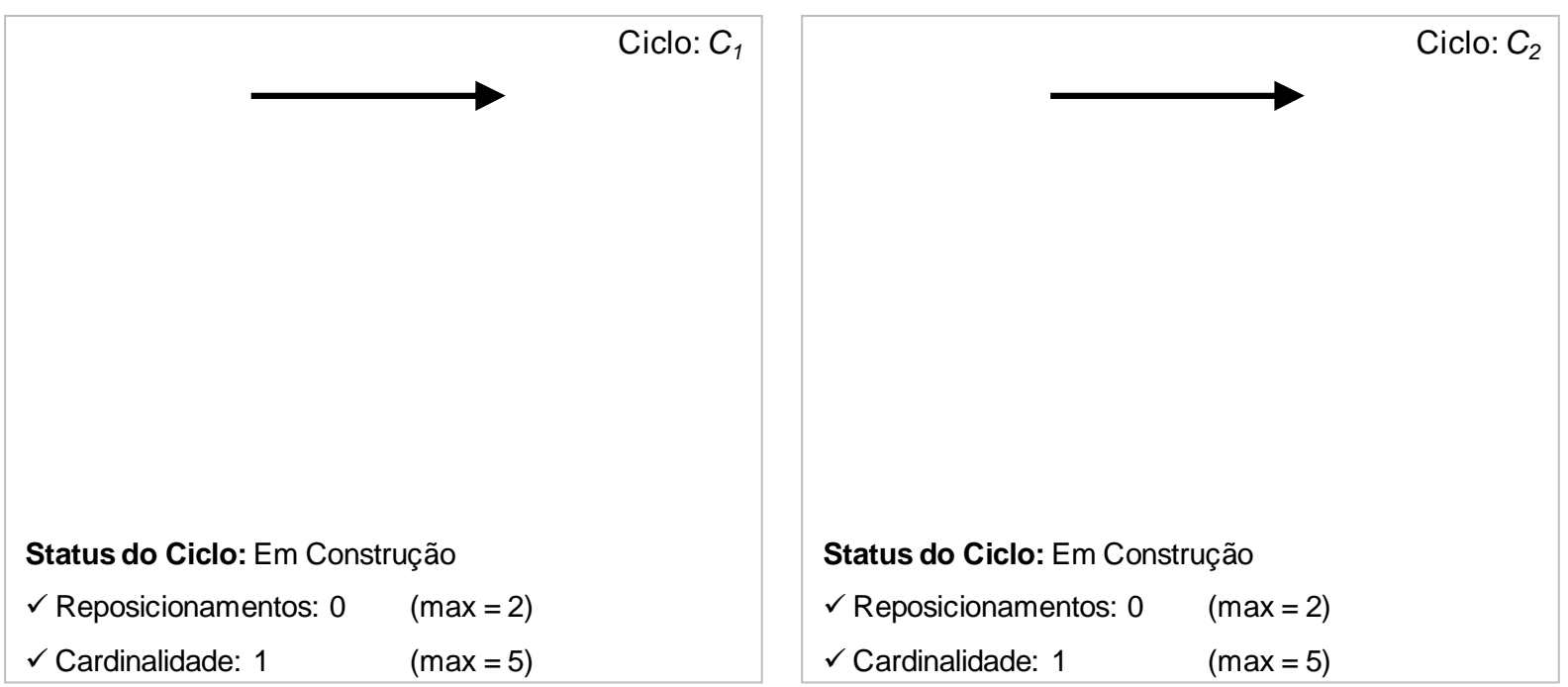

Figura 3-5: Adição da rota base ao ciclo $C_{j}$ (exemplo 1)

Remover a rota base do conjunto $U$.

Adicionar ao final do ciclo a j-ésima rota que possui vértice inicial mais próximo do vértice final de $C_{j}$. Desta forma, será adicionada ao $C_{1}$ a primeira rota mais próxima da rota base, e ao $C_{2}$, a segunda.

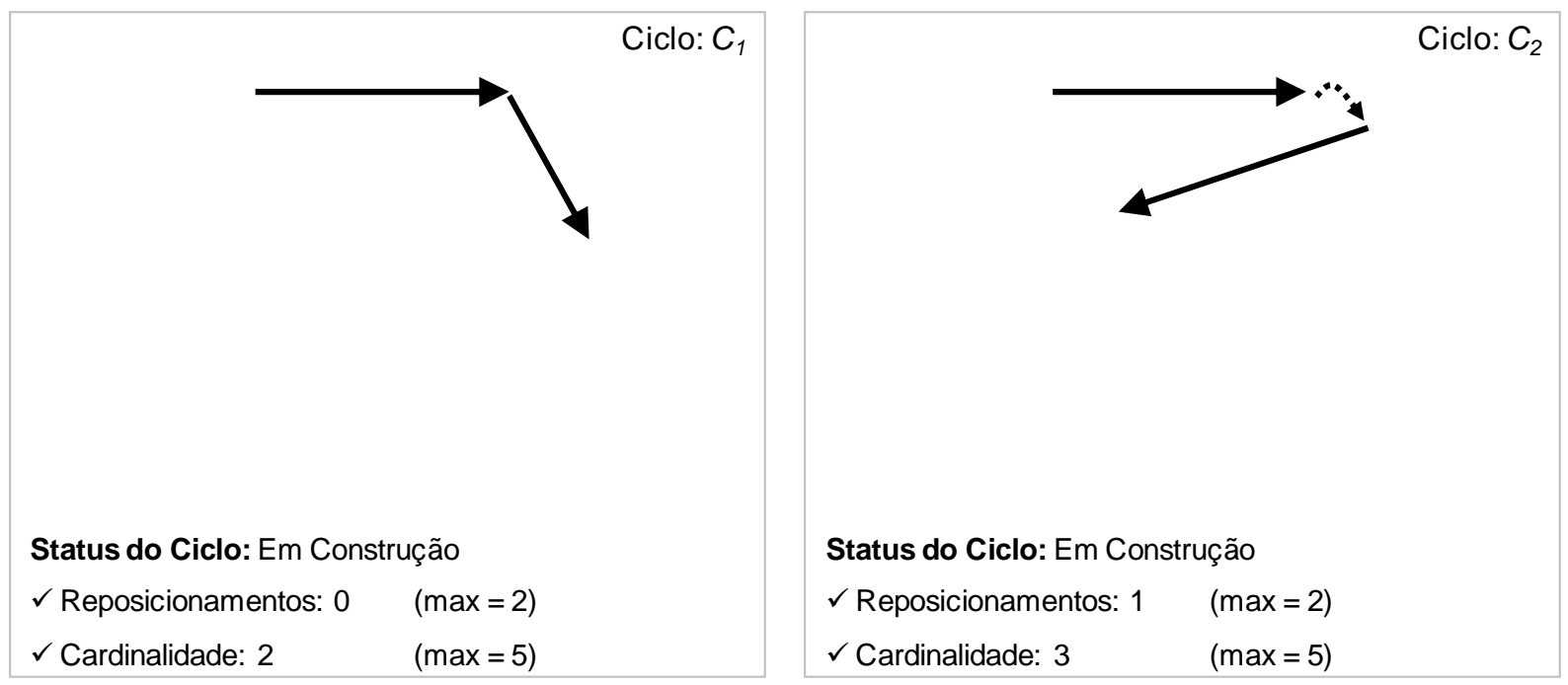

Figura 3-6: Adição da segunda rota ao ciclo $C_{j}$ (exemplo 1)

Observando-se a Figura 3-6 nota-se que no caso do ciclo $C_{1}$, a segunda rota foi adicionada sem que houvesse um reposicionamento. Por outro lado, em $C_{2}$ foi adicionada uma rota com um reposicionamento. 
Demover do conjunto $U$ as rotas adicionadas.

$>$ Como os dois ciclos em construção não atingiram as restrições de reposicionamento e de cardinalidade, ambos prosseguem com a construção.

Adicionar ao início do ciclo a rota que possui vértice final mais próximo do vértice inicial de $C_{j}$.
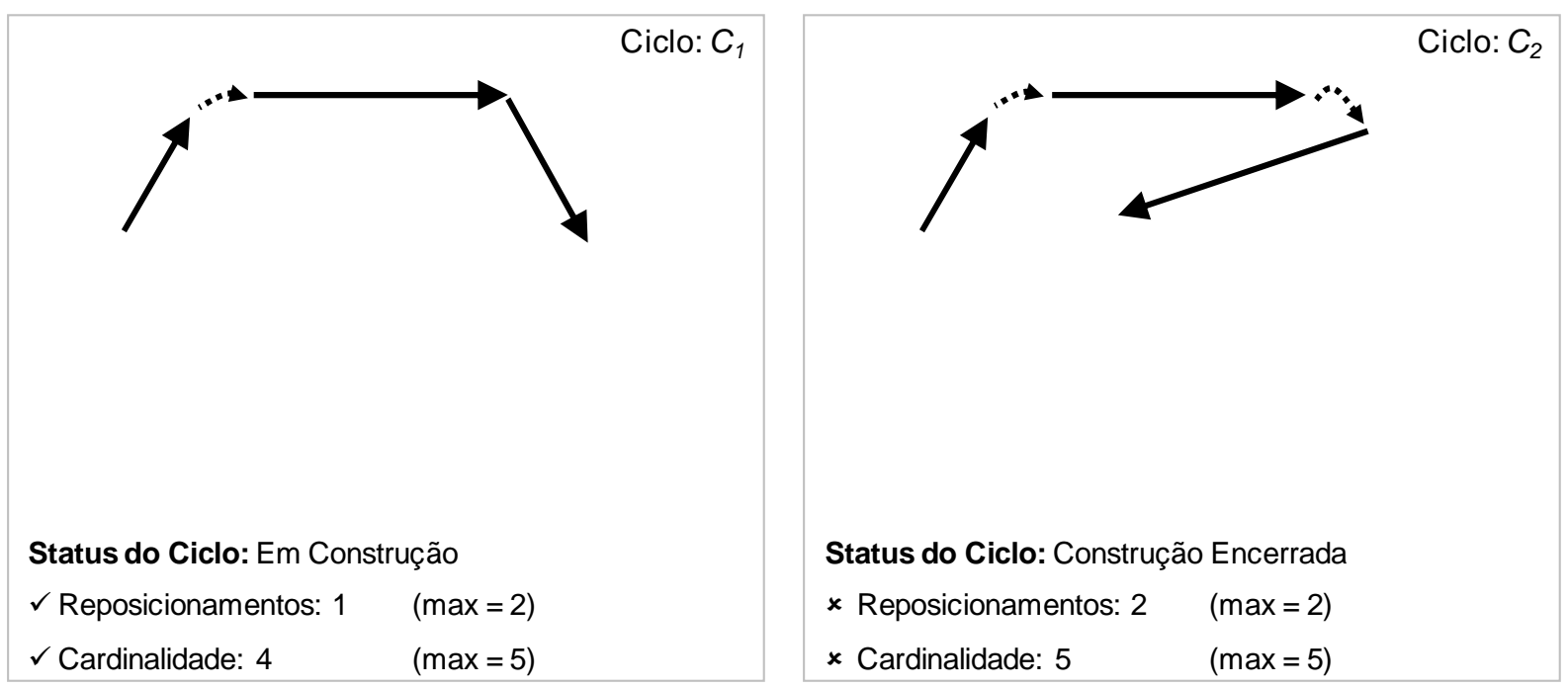

Figura 3-7: Adição da terceira rota ao ciclo $C_{j}$ (exemplo 1)

Observando-se a Figura 3-7 nota-se que em ambos os ciclos ocorreu um reposicionamento ao adicionar a terceira rota.

Remover do conjunto $U$ as rotas adicionadas.

> Como o ciclo $C_{2}$ atingiu o número máximo de reposicionamentos e cardinalidade, sua construção é encerrada. $C_{1}$ continua normalmente com a construção.

Somente para $C_{1}$, adicionar ao final do ciclo a rota que possui vértice final mais próximo do vértice inicial de $C_{j}$. 

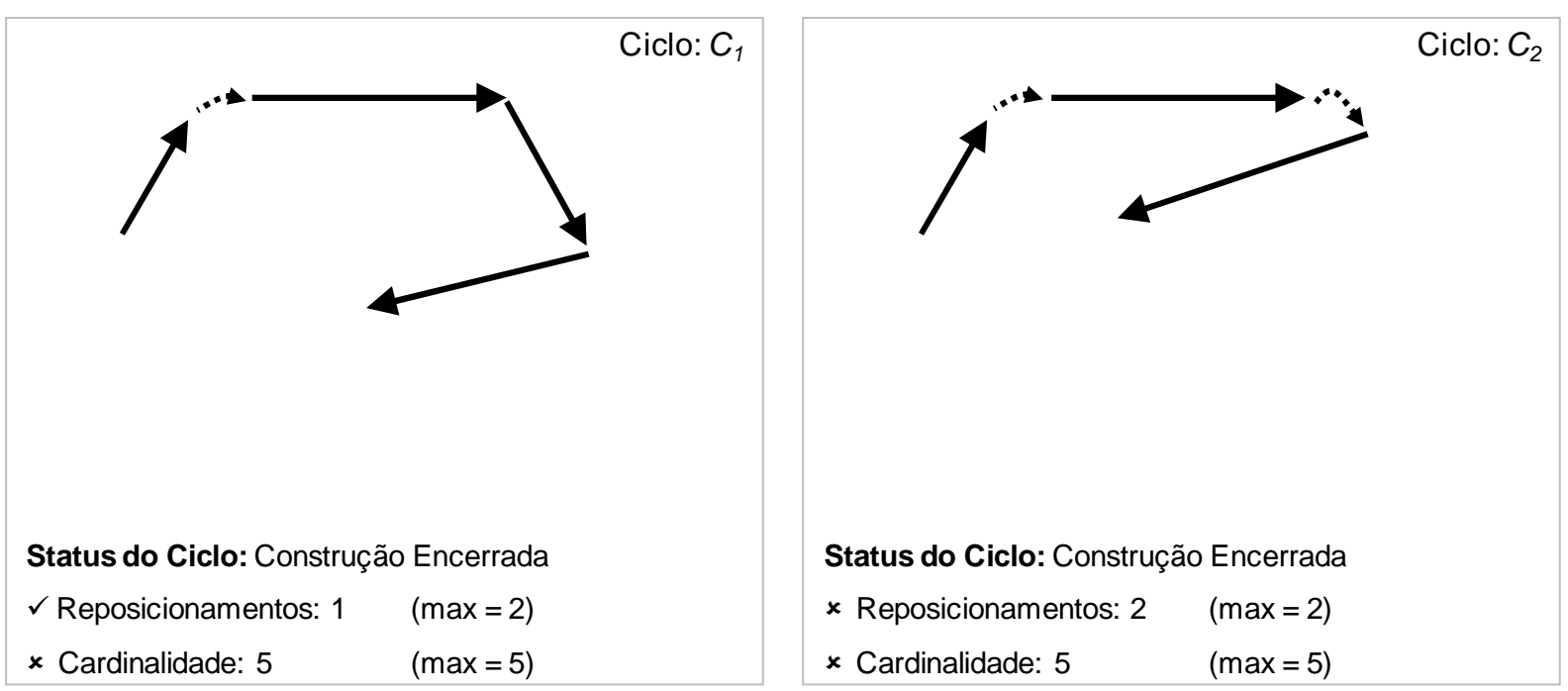

Figura 3-8: Adição da quarta rota ao ciclo $C_{1}$ (exemplo 1)

Observando-se a Figura 3-8 nota-se que em $C_{1}$ não ocorreu um reposicionamento ao adicionar a quarta rota, porém a cardinalidade máxima foi atingida.

Remover do conjunto $U$ as rotas adicionadas.

Como $C_{1}$ atingiu a cardinalidade máxima, sua construção é encerrada.

Para cada ciclo $C_{j}$, devem ser verificadas todas as combinações viáveis (que contenha a rota base e que obedecem as restrições de reposicionamento e cardinalidade) de seu fechamento. Fazendo isso, reduz-se a "miopia" da heurística.

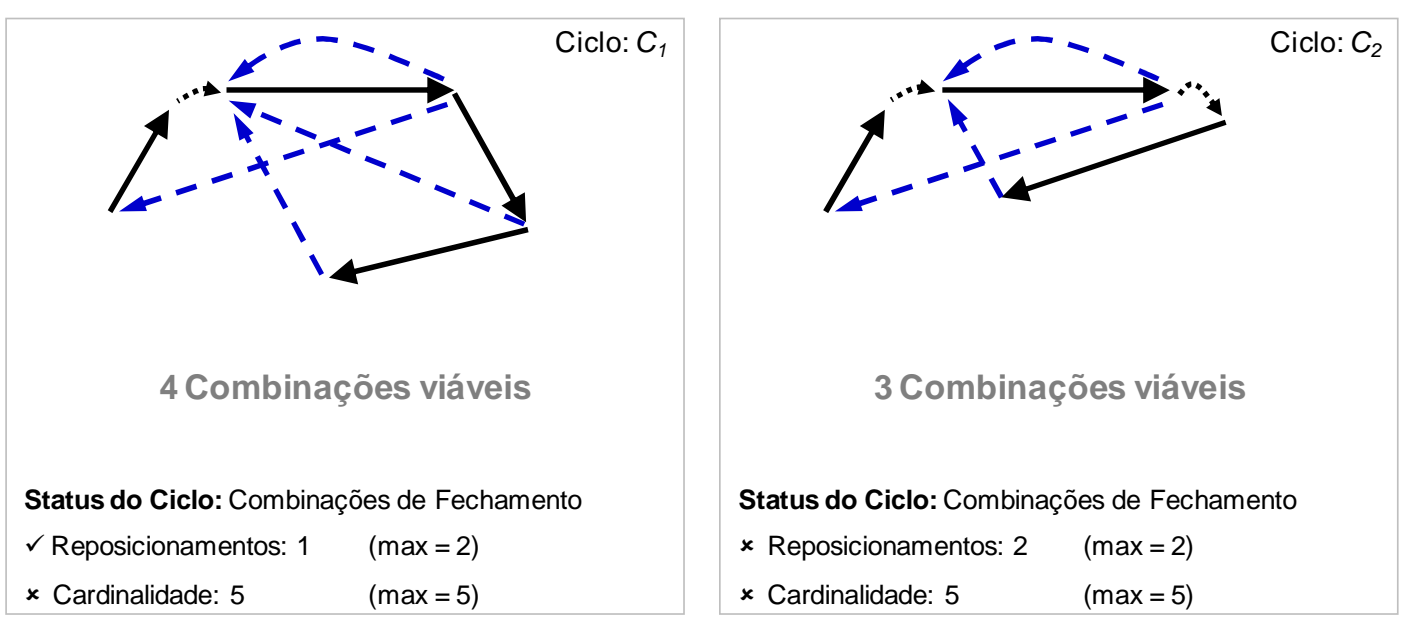

Figura 3-9: Combinações de fechamento dos ciclos $C_{j}$ (exemplo 1) 
O ciclo $C_{1}$ gerou quatro combinações diferentes de ciclos viáveis enquanto que $C_{2}$ gerou apenas três.

Calcular a proporção $p$ de cada combinação dos ciclos $C_{j}$. O fator $p$ é dado pela divisão entre o custo dos reposicionamentos e o custo total do ciclo. Na Figura 3-10 a seguir, as combinações de ciclos serão separadas para facilitar a visualização.
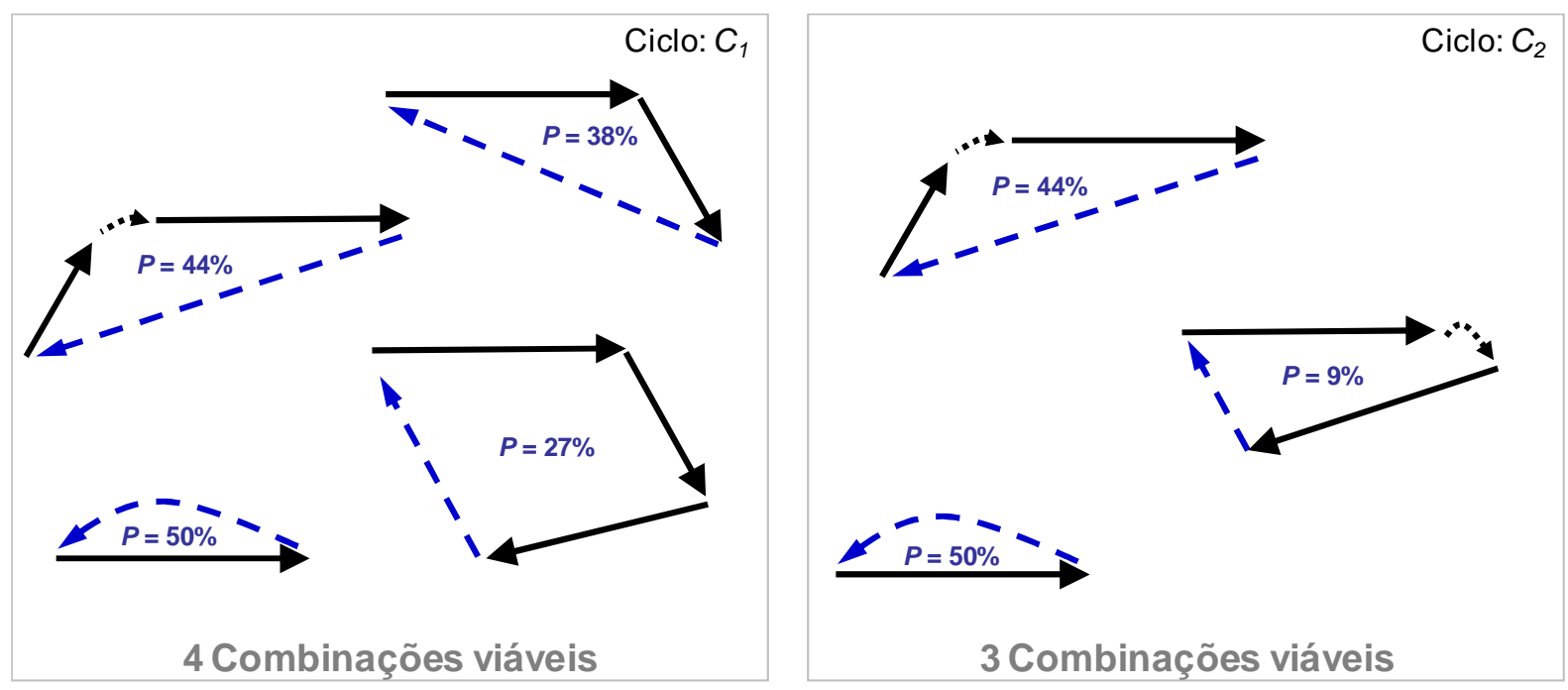

Figura 3-10: Proporção $p$ por combinação de ciclo $C_{j}$ (exemplo 1)

Para cada ciclo $C_{j}$, selecionar a combinação que possui a menor proporção $p$ devolvendo as rotas não utilizadas ao conjunto $U$.

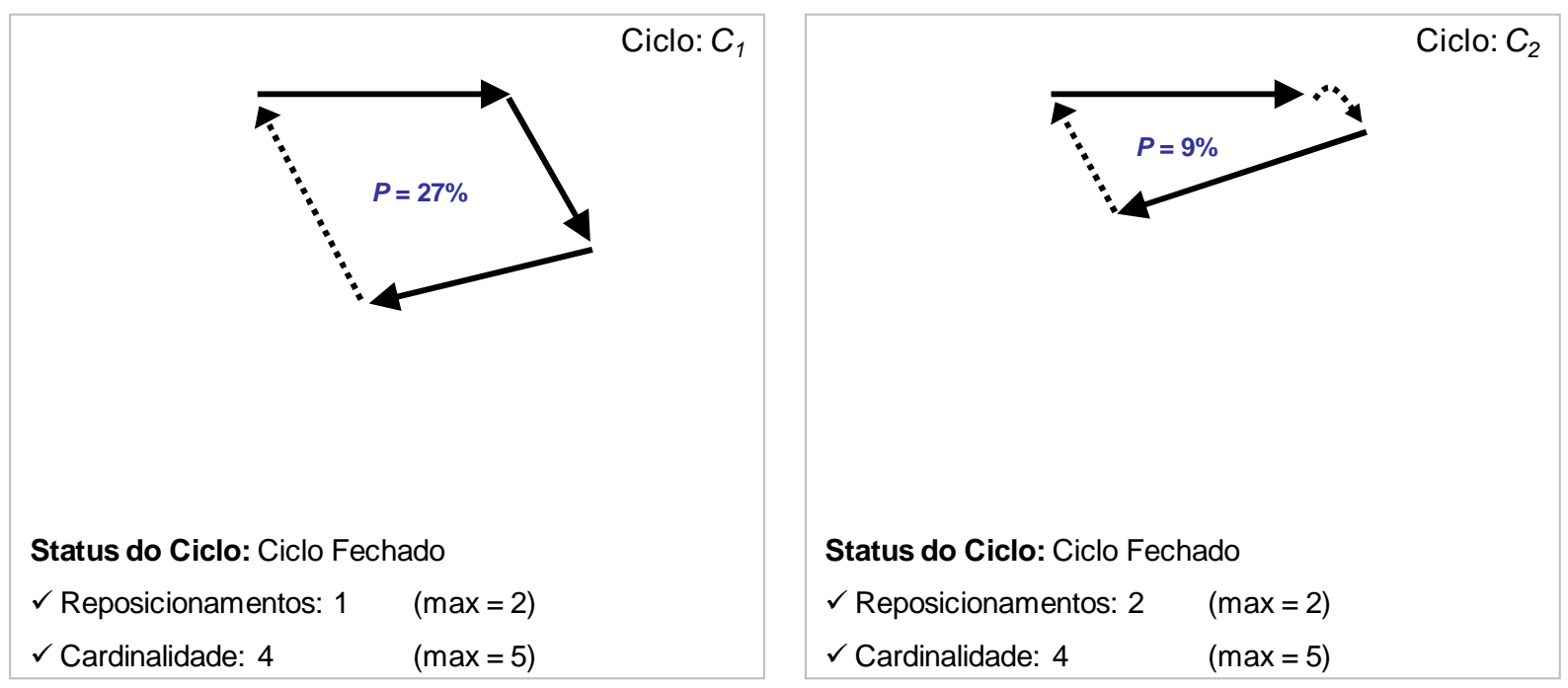

Figura 3-11: Fechamento dos ciclos $C_{j}$ (exemplo 1) 
Para o ciclo $C_{1}$ foi selecionada a combinação com 3 rotas e um reposicionamento gerando $p=27 \%$. Para $C_{2}$ foi selecionada a que possui 2 rotas e $p=9 \%$.

Selecionar o ciclo $C_{c} \in C_{j}$ que tenha a menor proporção $p$ descartando os demais ciclos $C_{j}$ de modo que $C_{3}=\varnothing$.
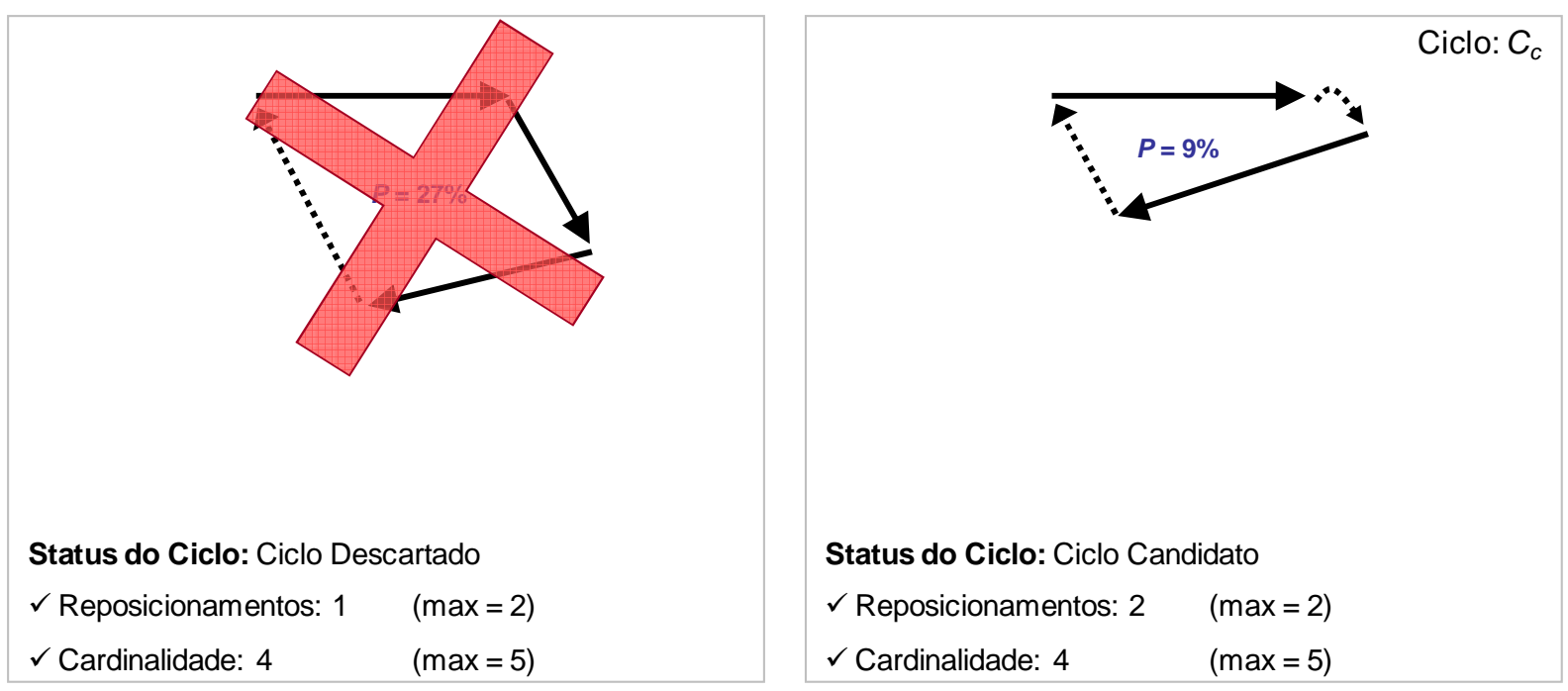

Figura 3-12: Criação do ciclo candidato $C_{c}$ (exemplo 1)

O ciclo candidato selecionado foi $C_{2}$, pois possui menor valor $p$. $C_{1}$ foi descartado e suas rotas devolvidas ao conjunto $U$.

$>$ Como o ciclo $C_{c}$ possuir valor de $p$ menor que $p_{\min }$, será aceito como solução e adicionado ao conjunto $\check{C}$.

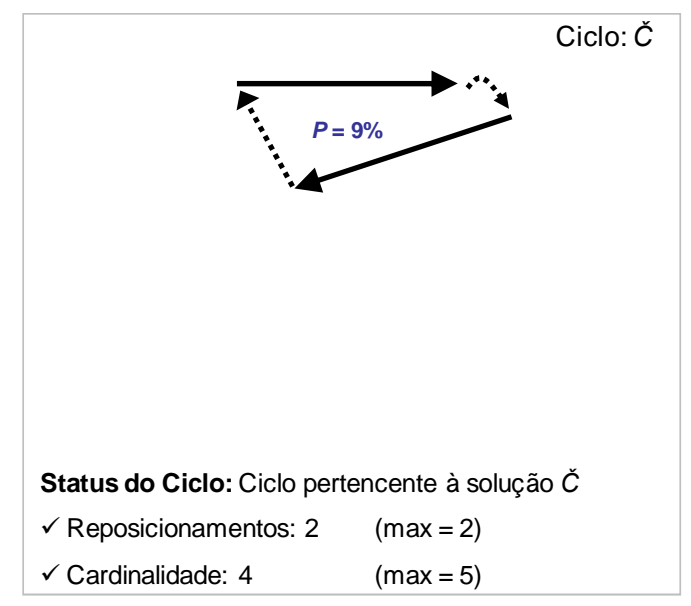

Figura 3-13: Ciclo pertencente à solução final (exemplo 1) 
- Incrementa-se $I_{1}$ até a próxima rota disponível $I \in U$ e retorna-se ao primeiro passo para a seleção da rota base do próximo ciclo $C_{j}$. Se $I_{1}=2$ estivesse disponível no conjunto $U$, ela seria selecionado.

Os mesmos passos seriam seguidos na construção deste novo ciclo até a decisão de aceitá-lo ou não como solução. A seguir, será ilustrado mais um exemplo, porém de forma resumida.

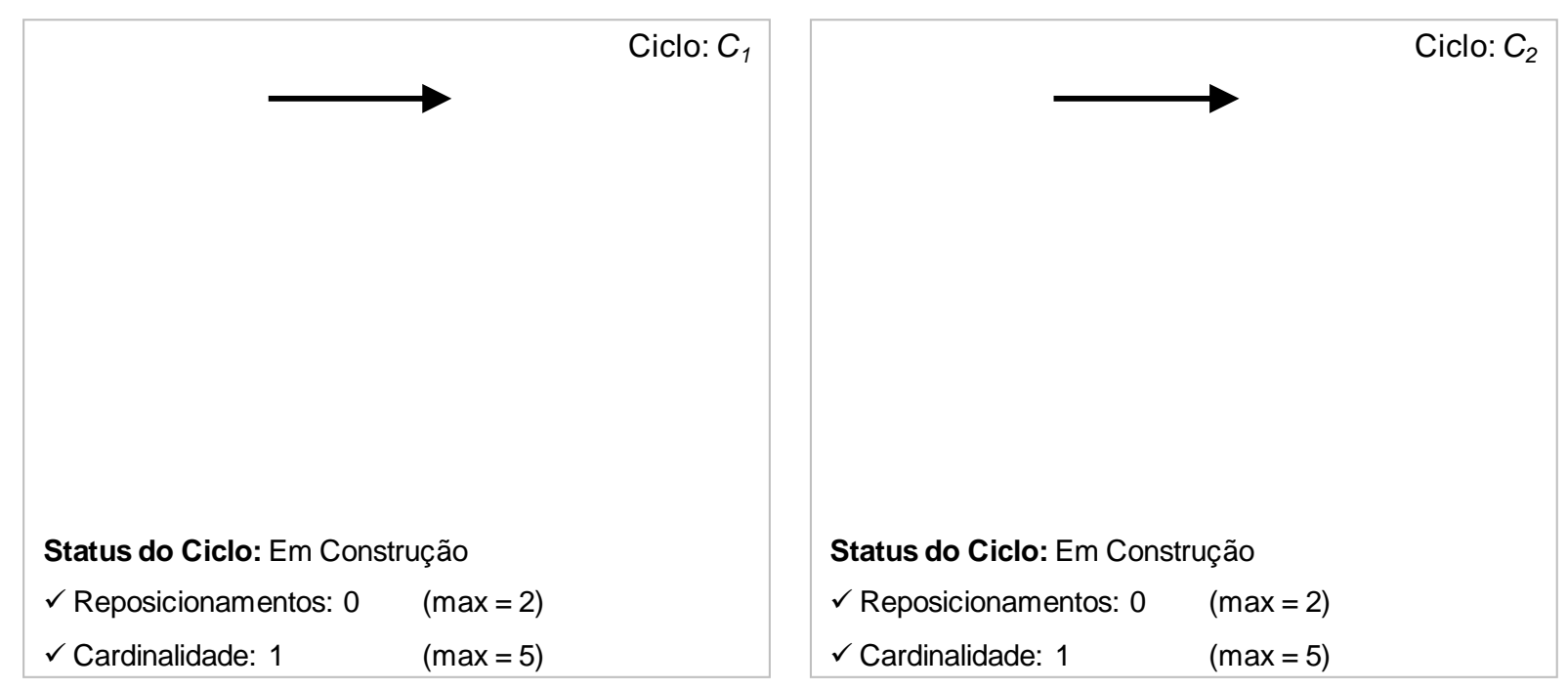

Figura 3-14: Adição da rota base ao ciclo $C_{j}$ (exemplo 2)

Adicionar ao final do ciclo a j-ésima rota que possui vértice inicial mais próximo do vértice final de $C_{j}$.

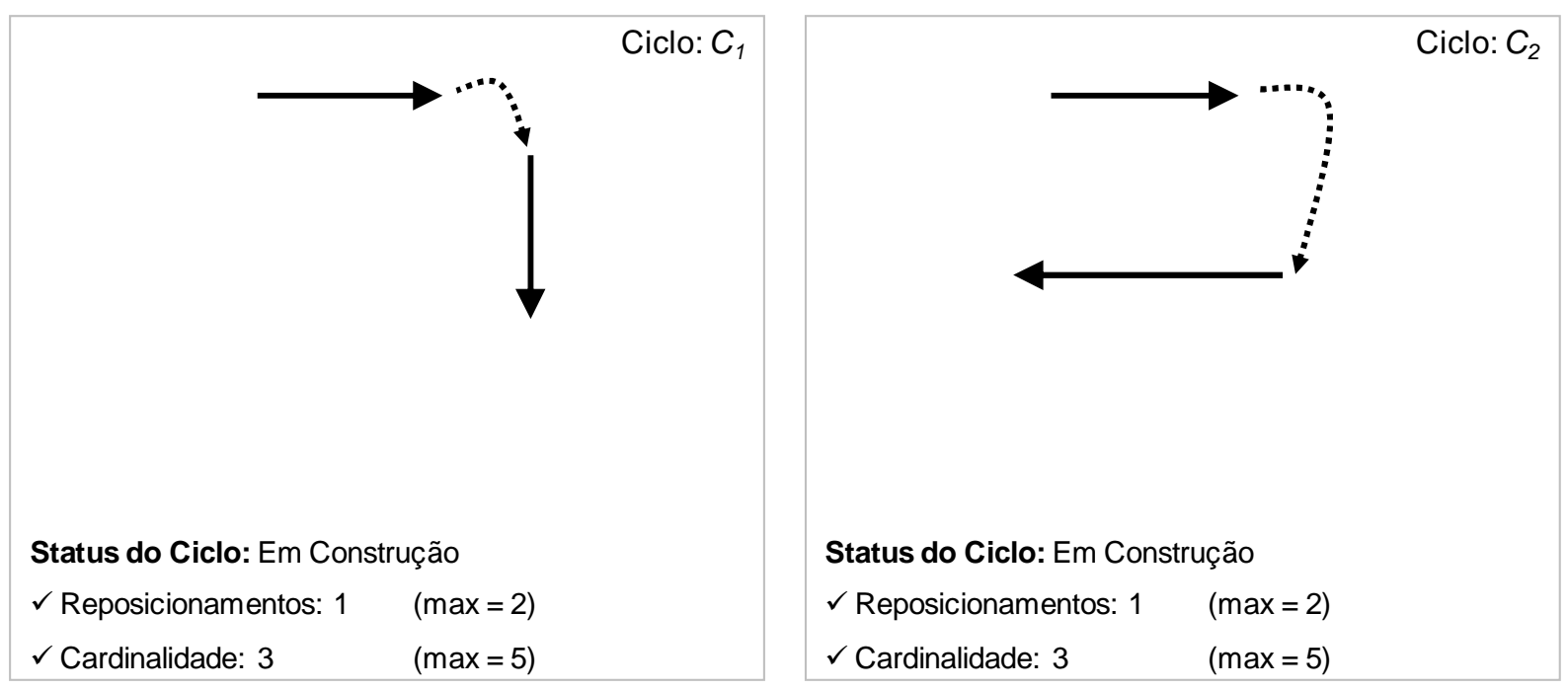

Figura 3-15: Adição da segunda rota ao ciclo $C_{j}$ (exemplo 2) 
Adicionar ao início do ciclo a rota que possui vértice final mais próximo do vértice inicial de $C_{j}$.

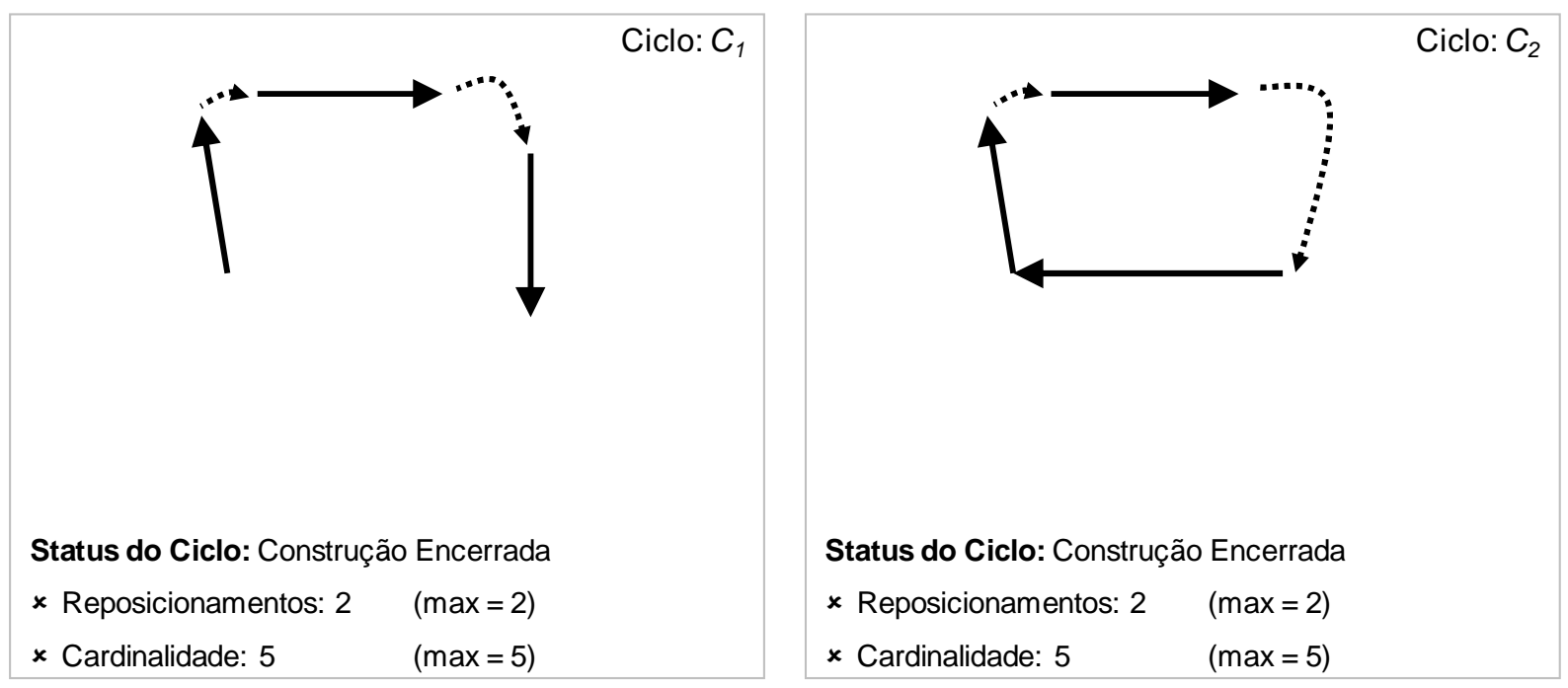

Figura 3-16: Adição da terceira rota ao ciclo $C_{j}$ (exemplo 2)

Como $C_{1}$ e $C_{2}$ atingiram a restrição de cardinalidade e número máximo de reposicionamentos permitidos, a construção de ambos é encerrada e verifica-se todas as combinações viáveis de seu fechamento que contenham a rota base.
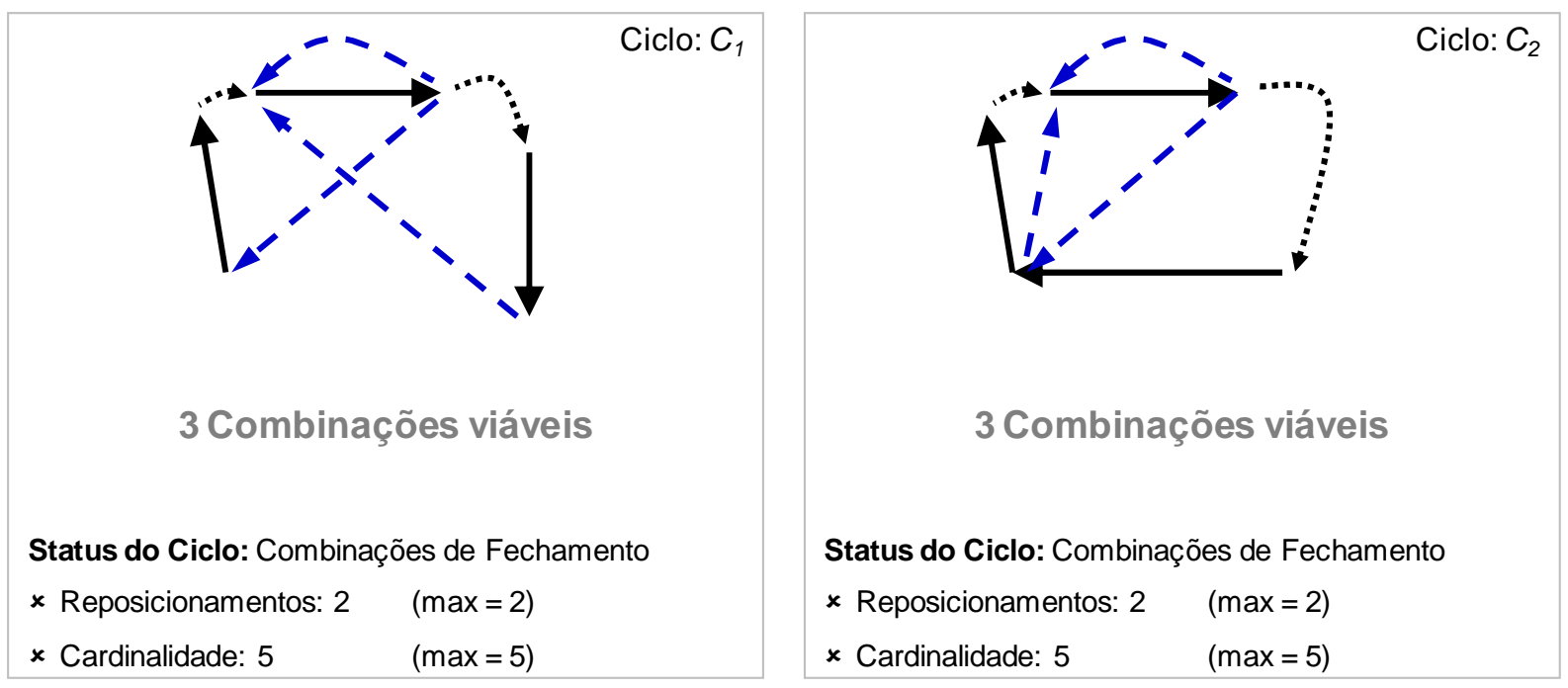

Figura 3-17: Combinações de fechamento dos ciclos $C_{j}$ (exemplo 2)

Calcular a proporção $p$ de cada combinação dos ciclos $C_{j}$. 

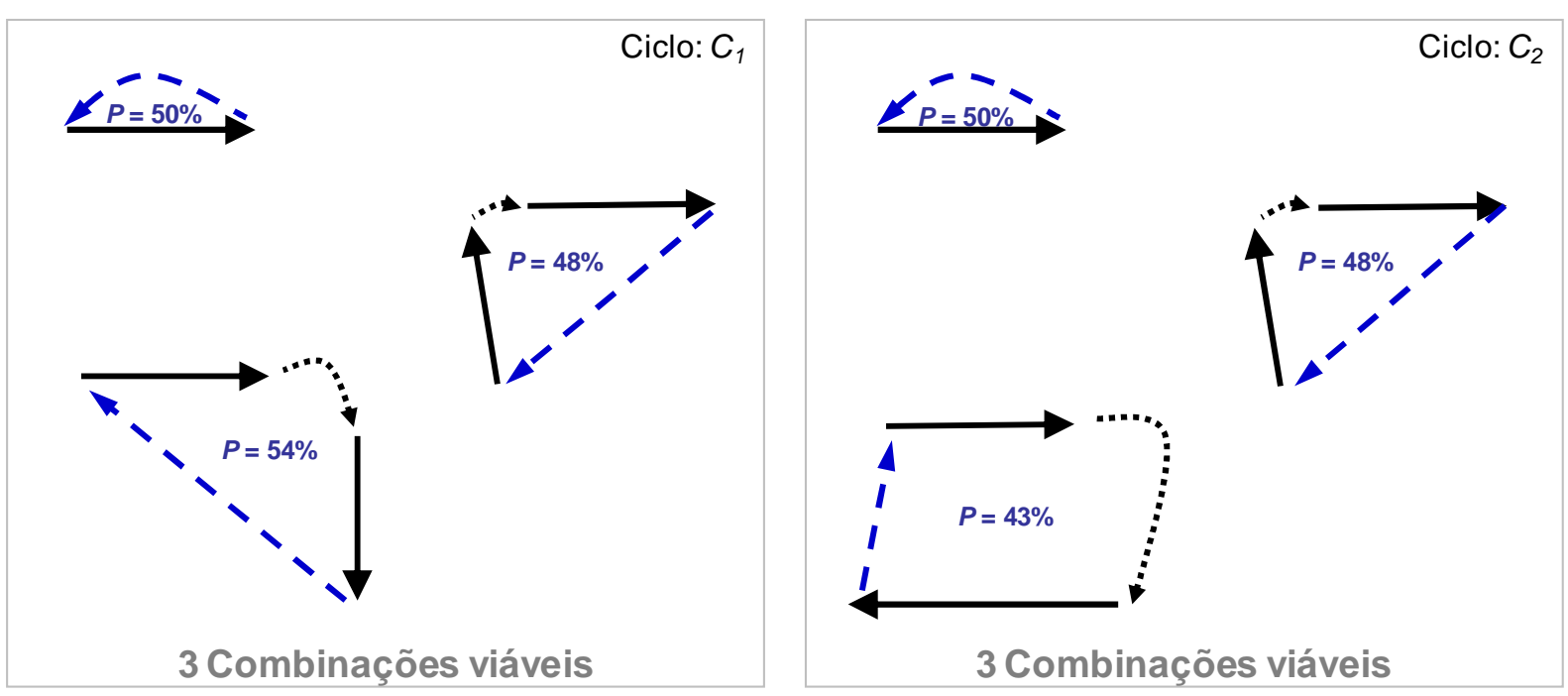

Figura 3-18: Proporção $p$ por combinação de ciclo $C_{j}$ (exemplo 2)

Para cada ciclo $C_{j}$, selecionar a combinação que possui a menor proporção $p$ devolvendo as rotas não utilizadas ao conjunto $U$.
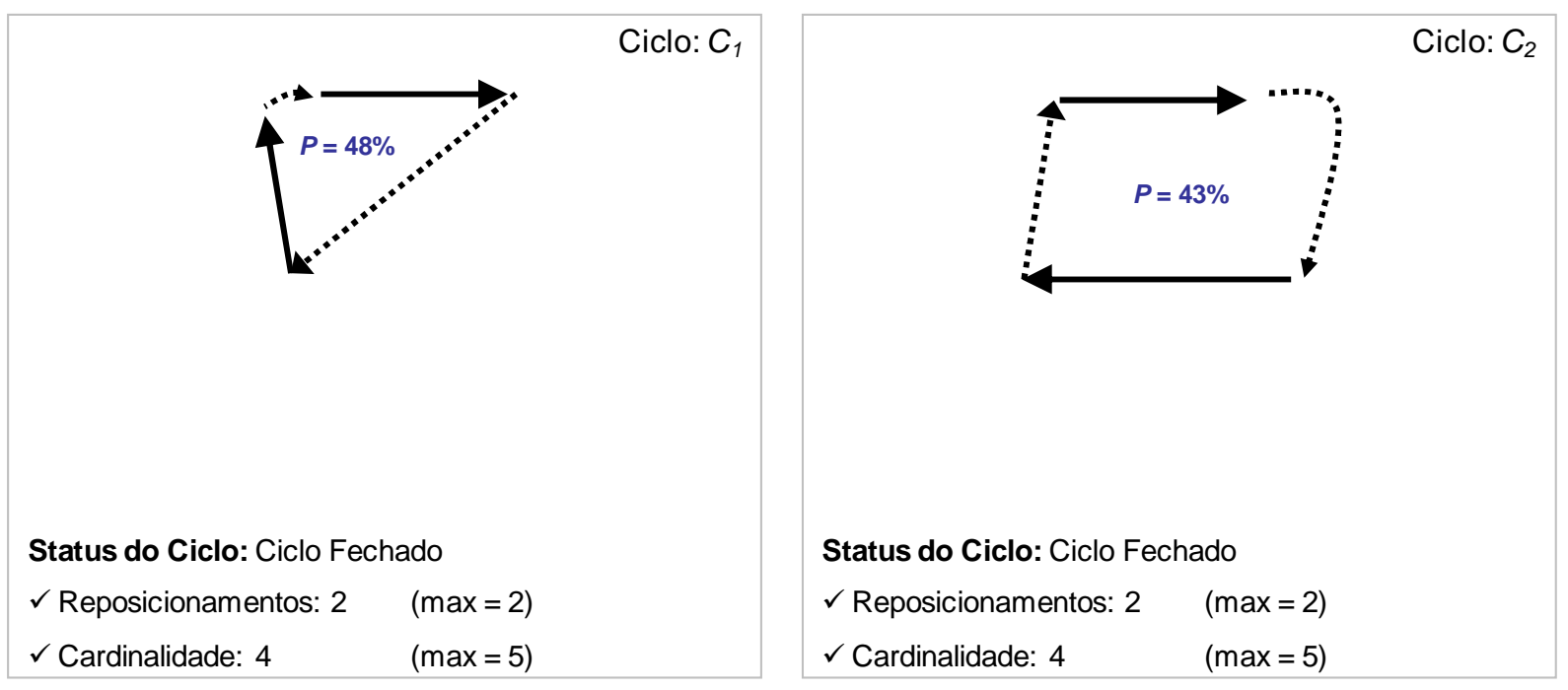

Figura 3-19: Fechamento dos ciclos $C_{j}$ (exemplo 2)

A melhor combinação para o ciclo $C_{1}$ possui $p=48 \%$, enquanto que $C_{2}$ possui $p=43 \%$.

Como os dois ciclo gerados possuem valor de $p$ maior que $p_{\text {min, então }}$ ambos serão descartados e suas rotas são devolvidas ao conjunto $U$. Nenhum ciclo foi aceito como solução e não foram adicionados ao conjunto $\check{C}$ 

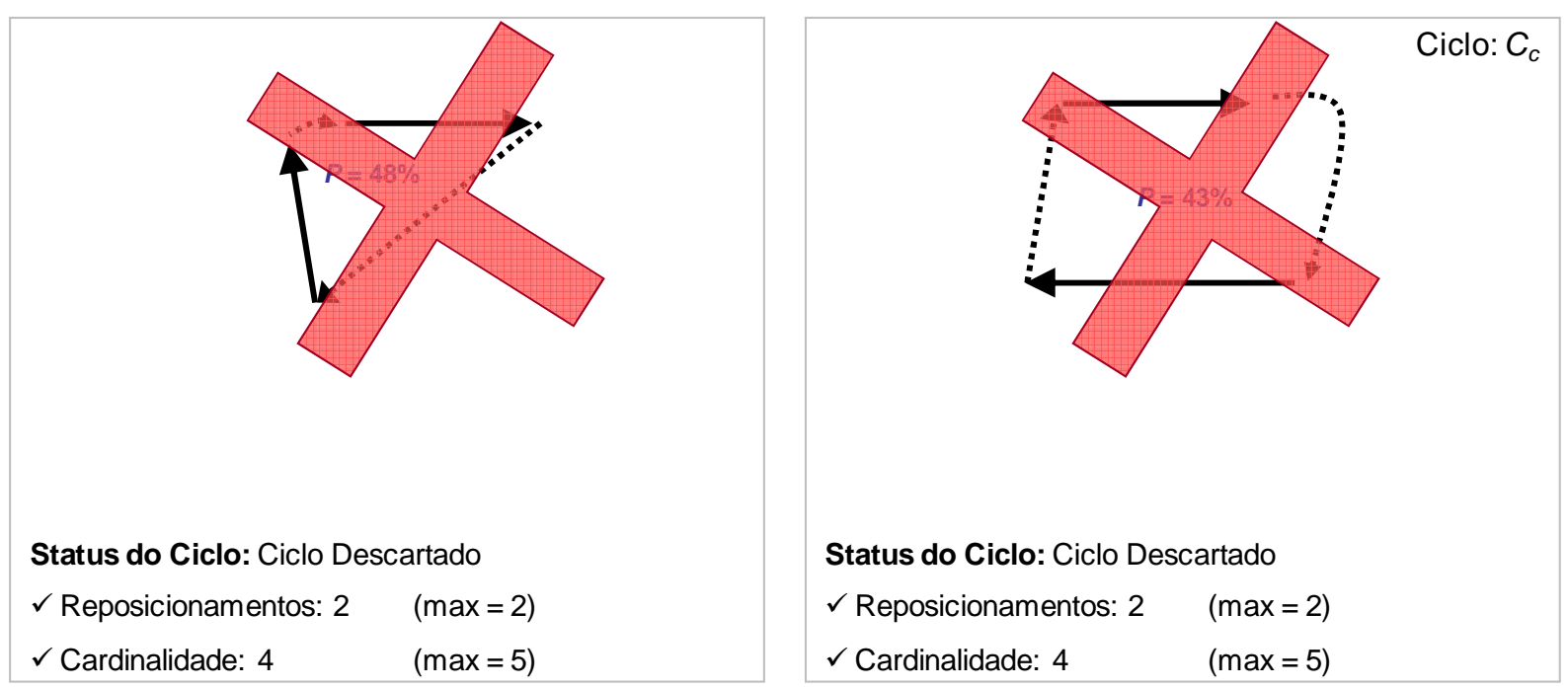

Figura 3-20: Criação do ciclo candidato $C_{c}$ (exemplo 2)

> Volta-se novamente ao primeiro passo e incrementa-se $l_{1}$. Porém, se $I_{1}$ fosse maior que $I_{\max }$, alguns passos adicionais deveriam ser executados.

$>$ Dado isso, suponhamos que $I_{1}>I_{\max }$ para ilustrar como seriam os próximos passos.

> Primeiramente, $I_{1}$ voltaria ao índice da primeira rota disponível $I \in U$.

$>$ Em seguida o valor $p_{\min }$ deveria ser incrementado, contudo depende de uma condição.

Se a proporção entre o número de rotas alocadas aos ciclos $\check{C}$ até este momento dividido pelo número de rotas que estavam disponíveis $\left(I_{\max }\right)$ for menor que $I_{\min }$ (neste caso, $\left.10 \%\right)$ então $p_{\text {incr }}$ será multiplicado por $\left(1+p_{\text {incr }}\right.$ * $\left.p_{\text {mult }}\right)$, caso contrário, será multiplicado apenas por $\left(1+p_{\text {incr }}\right)$.

A heurística CD é encerrada quando o conjunto $U$ estiver vazio, ou seja, todas as rotas foram alocadas aos ciclos. 


\subsection{Gerador de Instâncias}

Para avaliar o desempenho dos três métodos (PLI, algoritmo GH e heurística CD) na solução do problema PCRCR, criaram-se diversas instâncias de problemas controlados. A principal característica dos geradores utilizados é a possibilidade de criar tanto problemas "balanceados" como "desbalanceados".

O balanceamento refere-se à existência ou não de regiões que concentram um número maior de origens ou destino de rotas. Por exemplo, se o problema apresentar regiões que possuem predominantemente origens ou destinos de rotas, será chamado de desbalanceado. Caso contrário, será balanceado. A Figura 3-21 a seguir mostra dois exemplos de problemas, um balanceado e outro desbalanceado. Ambos possuem dois agrupamentos representados pelos círculos.

No problema balanceado, existe um equilíbrio das rotas que se originam e que chegam aos agrupamentos. No outro problema, ocorre o contrário.
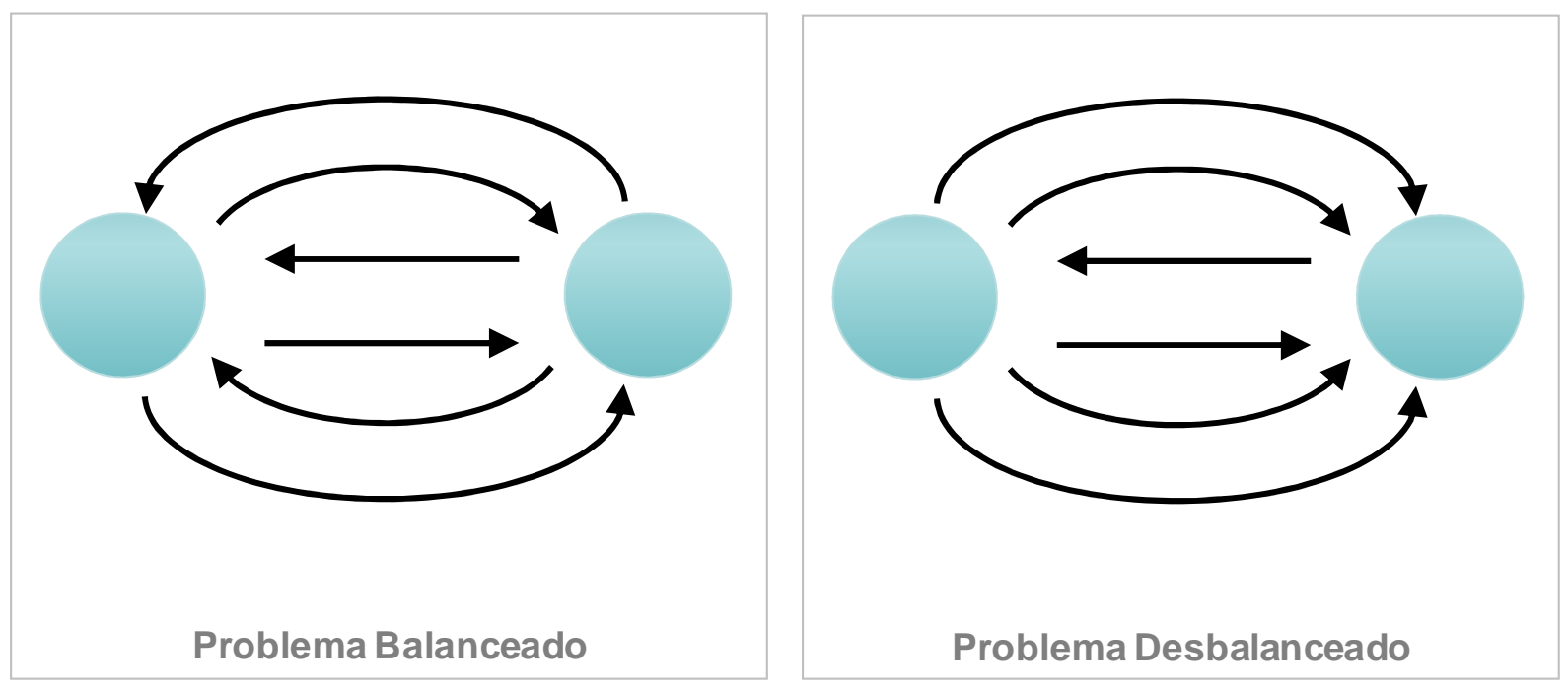

Figura 3-21: Exemplo de problemas balanceados e desbalanceados

O código-fonte do gerador de problemas balanceados foi fornecido pelos autores de (ERGUN et al , 2007b). O gerador de problemas desbalanceados foi desenvolvido modificando-se o primeiro. 


\subsubsection{O gerador de problemas balanceados}

O gerador de problemas balanceados é utilizado para criar os dígrafos das instâncias. É um processo simples que pode ser dividido basicamente em três grandes passos:

- Criação das regiões de agrupamentos

- Criação dos vértices seguida da suas alocações aos agrupamentos

- Criação das rotas (que são os arcos direcionados dos dígrafos)

Para isso são utilizados os seguintes parâmetros de entrada na configuração do problema:

- $H_{\max }$ e $V_{\max }$ são as dimensões do espaço que contém o dígrafo

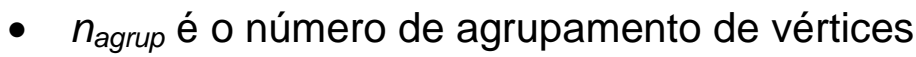

- $f_{\text {agrup }}$ é o fator de dispersão do agrupamento (explicado em 2.2)

- $n_{v}$ é o número de vértices do problema

- $\quad n_{l}$ é o número de rotas

Além disso, como o gerador utiliza diversas distribuições de números aleatórios é possível entrar com uma semente aleatória para garantir que seja possível gerar um mesmo problema, caso seja necessário.

Dado isso, o primeiro passo é gerar os agrupamentos dentro do espaço definido $\left(H_{\max } \times V_{\max }\right)$ utilizando-se uma distribuição aleatória uniforme. Porém caso se deseje criar somente um agrupamento $\left(n_{\text {agrup }}=1\right)$, esse é alocado ao centro do espaço.

Em seguida, antes de gerar as coordenadas dos vértices do dígrafo, esses são alocados aos agrupamentos utilizando distribuição aleatória uniforme, ou seja, determinam-se a que agrupamentos esses vértices irão pertencer. Para gerar suas coordenadas, utiliza-se uma distribuição aleatória normal truncada de modo que seja 
gerado um valor entre $[-1,1]$ que, em seguida, é multiplicado pelo fator de dispersão $\left(f_{\text {agrup }}\right)$ e somado à coordenada do respectivo agrupamento.

Por último, são geradas as rotas cuja criação é dividida em dois momentos. Para as primeiras $n_{v}$ rotas, a geração é feita de modo que o seu vértice inicial seja seqüencial (ou seja, na construção da primeira rota utiliza-se o primeiro vértice, para a segunda utiliza-se o vértice seguinte e assim por diante) e seu vértice final seja gerado utilizando-se distribuição aleatória uniforme. Para as demais rotas, tanto o vértice inicial quanto o final são gerados utilizando-se distribuição uniforme. Em uma rota, seus vértices de início e fim devem ser distintos.

Esse primeiro caso da geração das rotas existe para garantir que se utilize o maior número possível de vértices distintos. Além disso, quando são gerados problemas com um número pequeno de rotas, o dígrafo gerado é bem disperso, ou seja, não possui nenhuma região com concentração de rotas.

Dada essa propriedade e o fato de utilizar-se distribuição aleatória uniforme para a geração das rotas é que faz com que o problema seja balanceado.

O gerador de problemas balanceados é representado pelo algoritmo a seguir:

\section{Início Gerador de Problemas Balanceados}

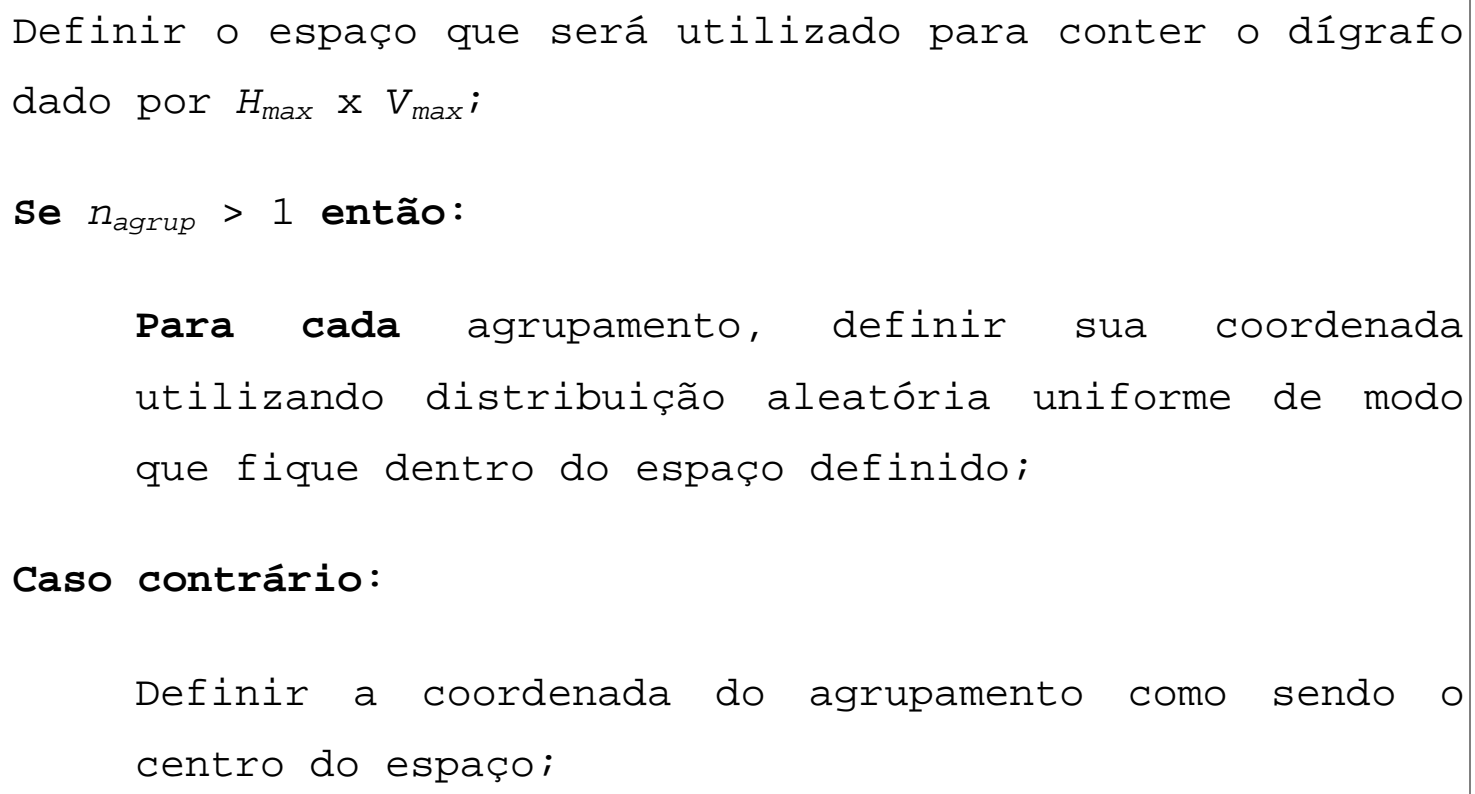


Para cada vértice, alocá-lo a um agrupamento utilizando distribuição aleatória uniforme;

Para cada vértice, gerar sua coordenada utilizando distribuição aleatória normal truncada entre [-1, 1] multiplicando esse valor ao $f_{\text {agrup }}$ e somando a coordenada de seu respectivo agrupamento;

Para cada rota, faça:

Se número de rotas geradas $\leq n_{V}$ então:

O vértice inicial da rota é escolhido seqüencialmente;

O vértice final da rota é escolhido utilizando distribuição aleatória uniforme;

Caso contrário:

Tanto $\circ$ vértice inicial quanto 0 final são escolhidos utilizando distribuição aleatória uniforme;

Fim Se

Fim Para

Fim Algoritmo

Algoritmo 3-7: Gerador de Problemas Balanceados

\subsubsection{O gerador de problemas desbalanceados}

A fim de garantir que os resultados dos problemas desbalanceados fossem comparáveis com os dos balanceados, este novo gerador foi criado com as mesmas características que o original, porém foram acrescentadas somente as propriedades de desbalanceamento que serão explicadas a seguir. 
Tanto a geração dos agrupamentos como a dos vértices foram mantidos iguais ao gerador anterior. Porém a cada um foram atribuídas algumas propriedades atreladas ao desbalanceamento.

Definiu-se que existem dois tipos de agrupamentos: aqueles que possuem vocação de origem de rotas e outros com vocação de destino. Dado isso, utilizou-se uma distribuição aleatória uniforme para atribuir, a cada agrupamento, essa propriedade. Foram dadas chances iguais para um agrupamento ser uma origem ou um destino.

Definiu-se que existem três tipos de vértices: aqueles que são exclusivamente origens de rota, aqueles que são exclusivamente destinos e aqueles que podem ser tanto uma origem como um destino. Esse último vértice foi chamado de balanceado. Dado isso, foi criado um parâmetro de entrada $p_{\text {desb }}$ que indica a probabilidade de um determinado vértice ser desbalanceado que é dada da seguinte forma: o vértice possui probabilidade $p_{\text {desb }}$ de ter a mesma propriedade de seu agrupamento e (1 $\left.p_{\text {desb }}\right)$ de ser balanceado. Por exemplo, suponhamos que $p_{\text {desb }}=25 \%$ e que o vértice está dentro de um agrupamento com característica de "origem", então o vértice possui $25 \%$ de probabilidade de ser uma origem exclusiva (desse modo, ele nunca poderá ser um destino de rota) e $75 \%$ de probabilidade de ser balanceado (podendo ser tanto uma origem como um destino de rota). Dessa forma, quanto maior o fator de balanceamento $p_{\text {desb }}$, maior será o desbalanceamento do problema.

Por fim, as rotas são geradas da mesma forma que o gerador original, porém respeitando as propriedades dos vértices conforme mostrado na Tabela 3-1 a seguir que mostra para cada tipo de vértice se pode ser início ou final de rota:

Tabela 3-1: Permissão para cada tipo de vértice para ser início ou final de rota

\begin{tabular}{|l|c|c|c|}
\hline \multicolumn{1}{|c|}{} & Origem & Destino & Balanceado \\
\hline Vértice Inicial da Rota & $\checkmark$ & $\times$ & $\checkmark$ \\
\hline Vértice Final da Rota & $x$ & $\checkmark$ & $\checkmark$ \\
\hline
\end{tabular}


O gerador de problemas desbalanceados é representado pelo algoritmo a seguir:

\section{Início Gerador de Problemas Desbalanceados \\ Definir o espaço que será utilizado para conter o dígrafo dado por $H_{\max } \times V_{\max }$; \\ Se $n_{\text {agrup }}>1$ então: \\ Para cada agrupamento, definir sua coordenada utilizando distribuição aleatória uniforme de modo que fique dentro do espaço definido; \\ Caso contrário:}

Definir a coordenada do agrupamento como sendo o centro do espaço;

\section{Fim Se}

Para cada agrupamento, atribuir a propriedade de "origem" ou "destino" utilizando distribuição aleatória uniforme.

Para cada vértice, alocá-lo a um agrupamento utilizando distribuição aleatória uniforme;

Para cada vértice, gerar sua coordenada utilizando distribuição aleatória normal truncada entre [-1, 1] multiplicando esse valor ao $f_{\text {agrup }} e$ somando a coordenada de seu respectivo agrupamento;

Para cada vértice, utilizando distribuição aleatória uniforme, faça:

Vértice tem probabilidade $p_{\text {desb }}$ de ter a mesma propriedade de balanceamento que o seu respectivo agrupamento ("origem" ou "destino"); 
Vértice tem probabilidade (1 - $\left.p_{\text {desb }}\right)$ de ser balanceado;

\section{Fim Para}

Para cada rota, respeitando as propriedades dos vértices, faça:

Se número de rotas geradas $\leq n_{V}$ então:

o vértice inicial da rota é escolhido seqüencialmente;

o vértice final da rota é escolhido utilizando distribuição aleatória uniforme;

Caso contrário:

Tanto $\circ$ vértice inicial quanto 0 final são escolhidos utilizando distribuição aleatória uniforme;

Fim Se

Fim Para

Fim Algoritmo

Algoritmo 3-8: Gerador de Problemas Desbalanceados

$\mathrm{Na}$ prática, o gerador de problemas desbalanceados consegue gerar os mesmos problemas do gerador original caso o fator $p_{\text {desb }}=0 \%$. Desta forma, todos os vértices serão "balanceados".

O capítulo seguinte apresenta a aplicação dos modelos e seus respectivos resultados e análises. 


\section{APLICAÇÃO DOS MODELOS}

Este capítulo apresenta a aplicação dos modelos apresentados no anterior, a calibração da Heurística CD, os resultados obtidos e suas respectivas análises.

\subsection{Escopo e Parâmetros do Caso Teste}

Para validar a metodologia e os métodos propostos no capítulo anterior, foi utilizado um conjunto de problemas de teste que representam situações reais.

Serão utilizadas como base as mesmas instâncias que Ergun et al (2007b), porém também foram adicionadas instâncias maiores. Essas apresentam as seguintes características:

- Conjunto de 500 vértices

- Número de rotas: $100,200,500,1000,1500,3000$ ou 5000

- 3 dígrafos que se diferenciam pelo o número de agrupamentos e seus respectivos fatores de dispersão

- Cardinalidade máxima de 5 arcos por ciclo em todos os problemas

- Permissão de um ou dois reposicionamentos

- Problemas com proporção de desbalanceamento de $0 \%$ (balanceado), $25 \%, 50 \%$ ou $75 \%$ (desbalanceados)

Foram criados dois conjuntos de problemas. O primeiro é composto por cinco instâncias distintas por tipo que foram utilizadas para calibrar os parâmetros da heurística CD. O segundo conjunto é composto por outras cinco instâncias diferentes que foram utilizadas para avaliar os três métodos.

As cinco instâncias por tipo de problema foram criadas trocando-se apenas a semente aleatória do gerador de instâncias de modo a criar problemas com dígrafos diferentes, porém com as mesmas características. 
Utilizaram-se cinco instâncias de problemas da mesma forma que (ERGUN et al, 2004) para reduzir o impacto das distribuições aleatórias. Elas podem fazer com que, para um mesmo problema, o desempenho de uma instância seja muito bom e para outra, muito ruim devido à aleatoriedade envolvida na criação dos mesmos. Desta forma, após rodá-las, faz-se a média de seus resultados e de seus tempos de execução.

O gerador de instância, gerador de ciclos, algoritmo GH e heurística CD foram implementados utilizando o compilador Microsoft ${ }^{\circledR}$ Visual C++ $2008^{\circledR}$ 64bits. A PLI foi implementada utilizando-se como linguagem de manipulação algébrica GAMS ${ }^{\circledR} 23.0$ e o ILOG CPLEX ${ }^{\circledR} 11.0$ para 64 bits como solver.

O computador utilizado possui um processador Intel Core 2 Quad $^{\circledR}$ de 2,33 $\mathrm{GHz}$ com 8 GB de memória RAM rodando no sistema operacional Microsoft Vista 64 bits $^{\circledR}$.

\subsection{Aplicação do Gerador de Instâncias}

O gerador de instâncias foi utilizado e foram gerados 210 problemas que foram utilizados para a calibração da Heurística CD e 840 problemas que foram utilizados como conjunto de teste para os métodos PLI, Algoritmo GH e Heurística CD.

No primeiro conjunto foram geradas cinco instâncias diferentes para cada combinação de problemas que variam de acordo com as seguintes características: número de reposicionamentos permitidos, tipo de dígrafo e número de rotas do problema. A Tabela 4-1 a seguir, apresenta todas essas combinações geradas.

No segundo conjunto foram gerados problemas da mesma forma que o primeiro, porém para cada grupo diferente de balanceamento (problemas com fatores de desbalanceamento $0 \%, 25 \%, 50 \%$ e $75 \%$ ). Dessa forma, esse grupo possui quatro vezes mais instâncias a serem avaliadas. 
Tabela 4-1: Combinações de problemas de teste sem considerar balanceamento

\begin{tabular}{|c|c|c|c|}
\hline REPOSICIONAMENTOS & DÍGRAFO & ROTAS & NÚM. INSTÂNCIAS \\
\hline 1 & 1 & 100 & 5 \\
\hline 1 & 1 & 200 & 5 \\
\hline 1 & 1 & 500 & 5 \\
\hline 1 & 1 & 1000 & 5 \\
\hline 1 & 1 & 1500 & 5 \\
\hline 1 & 1 & 3000 & 5 \\
\hline 1 & 1 & 5000 & 5 \\
\hline 1 & 2 & 100 & 5 \\
\hline 1 & 2 & 200 & 5 \\
\hline 1 & 2 & 500 & 5 \\
\hline 1 & 2 & 1000 & 5 \\
\hline 1 & 2 & 1500 & 5 \\
\hline 1 & 2 & 3000 & 5 \\
\hline 1 & 2 & 5000 & 5 \\
\hline 1 & 3 & 100 & 5 \\
\hline 1 & 3 & 200 & 5 \\
\hline 1 & 3 & 500 & 5 \\
\hline 1 & 3 & 1000 & 5 \\
\hline 1 & 3 & 1500 & 5 \\
\hline 1 & 3 & 3000 & 5 \\
\hline 1 & 3 & 5000 & 5 \\
\hline 2 & 1 & 100 & 5 \\
\hline 2 & 1 & 200 & 5 \\
\hline 2 & 1 & 500 & 5 \\
\hline 2 & 1 & 1000 & 5 \\
\hline 2 & 1 & 1500 & 5 \\
\hline 2 & 1 & 3000 & 5 \\
\hline 2 & 1 & 5000 & 5 \\
\hline 2 & 2 & 100 & 5 \\
\hline 2 & 2 & 200 & 5 \\
\hline 2 & 2 & 500 & 5 \\
\hline 2 & 2 & 1000 & 5 \\
\hline 2 & 2 & 1500 & 5 \\
\hline 2 & 2 & 3000 & 5 \\
\hline 2 & 2 & 5000 & 5 \\
\hline 2 & 3 & 100 & 5 \\
\hline 2 & 3 & 200 & 5 \\
\hline 2 & 3 & 500 & 5 \\
\hline 2 & 3 & 1000 & 5 \\
\hline 2 & 3 & 1500 & 5 \\
\hline 2 & 3 & 3000 & 5 \\
\hline 2 & 3 & 5000 & 5 \\
\hline
\end{tabular}




\subsection{Aplicação do Gerador de Ciclos}

O gerador de ciclos foi utilizado para gerar o conjunto $C_{k}$ que deve ser utilizado para PLI e Algoritmo GH. Para cada instância, foram gerados todos os ciclos viáveis que respeitem as restrições de cardinalidade e número de reposicionamento máximo.

A Tabela 4-2 a seguir mostra o resultado para cada um dos dígrafos gerados para os problemas de 100, 200, 500, 1000, 1500, 3000 e 5000 rotas e fator de desbalanceamento de $0 \%, 25 \%, 50 \%$ e $75 \%$ sendo permitido somente um reposicionamento. Os valores exibidos são uma média simples do número de ciclos gerados por cada instância.

Tabela 4-2: Número de ciclos gerados para problemas com um reposicionamento

NÚMERO DE CICLOS VIÁVEIS GERADOS (\#)

\begin{tabular}{|c|c|c|c|c|c|c|}
\hline \multirow[b]{2}{*}{ REPOS. } & \multirow[b]{2}{*}{ DÍGRAFO } & \multirow[b]{2}{*}{ ROTAS } & \multicolumn{4}{|c|}{ FATOR DESBALANCEAMENTO } \\
\hline & & & $0 \%$ & $25 \%$ & $50 \%$ & $75 \%$ \\
\hline 1 & 1 & 100 & 125 & 122 & 119 & 117 \\
\hline 1 & 1 & 200 & 327 & 302 & 301 & 268 \\
\hline 1 & 1 & 500 & 1.989 & 1.958 & 1.648 & 1.094 \\
\hline 1 & 1 & 1000 & 13.992 & 14.086 & 10.452 & 5.200 \\
\hline 1 & 1 & 1500 & 56.040 & 53.945 & 40.386 & 18.653 \\
\hline 1 & 1 & 3000 & 689.255 & 655.707 & 468.794 & 191.219 \\
\hline 1 & 1 & 5000 & 4.879 .843 & 4.583 .479 & 3.377 .313 & 1.311 .222 \\
\hline 1 & 2 & 100 & 122 & 125 & 124 & 114 \\
\hline 1 & 2 & 200 & 331 & 319 & 301 & 271 \\
\hline 1 & 2 & 500 & 1.997 & 1.949 & 1.659 & 1.162 \\
\hline 1 & 2 & 1000 & 15.069 & 13.586 & 11.754 & 5.826 \\
\hline 1 & 2 & 1500 & 56.050 & 51.858 & 42.227 & 19.198 \\
\hline 1 & 2 & 3000 & 695.591 & 645.334 & 507.669 & 229.189 \\
\hline 1 & 2 & 5000 & 4.880 .386 & 4.482 .625 & 3.493 .912 & 1.434 .795 \\
\hline 1 & 3 & 100 & 128 & 132 & 124 & 116 \\
\hline 1 & 3 & 200 & 321 & 308 & 306 & 273 \\
\hline 1 & 3 & 500 & 1.984 & 2.012 & 1.627 & 1.315 \\
\hline 1 & 3 & 1000 & 14.530 & 13.203 & 11.291 & 6.788 \\
\hline 1 & 3 & 1500 & 54.337 & 52.693 & 40.794 & 22.354 \\
\hline 1 & 3 & 3000 & 684.772 & 662.054 & 472.588 & 255.214 \\
\hline 1 & 3 & 5000 & 4.874 .611 & 4.594.271 & 3.348.078 & 1.746 .700 \\
\hline
\end{tabular}


Nota-se que a quantidade de ciclos gerados aumenta exponencialmente com o aumento do número de rotas. Além disso, para um mesmo número de rotas, o número de ciclos gerados diminui com o aumento do desbalanceamento do problema. Esse comportamento era esperado, pois com 0 aumento do desbalanceamento, existe uma concentração de rotas com um único sentido entre os agrupamentos fazendo com que seja mais difícil criar uma rota, uma vez que o número de reposicionamentos permitidos é limitado. Comparando-se os dígrafos, não existe diferença significativa para um mesmo problema.

A Tabela 4-3 a seguir mostra o número de ciclos gerados, da mesma forma que a primeira, porém para problemas com dois reposicionamentos permitidos.

Tabela 4-3: Número de ciclos gerados para problemas com dois reposicionamentos

NÚMERO DE CICLOS VIÁVEIS GERADOS (\#)

\begin{tabular}{|c|c|c|c|c|c|c|}
\hline \multirow[b]{2}{*}{ REPOS. } & \multirow[b]{2}{*}{ DÍGRAFO } & \multirow[b]{2}{*}{ ROTAS } & \multicolumn{4}{|c|}{ FATOR DESBALANCEAMENTO } \\
\hline & & & $0 \%$ & $25 \%$ & $50 \%$ & $75 \%$ \\
\hline 2 & 1 & 100 & 3.495 & 3.432 & 3.407 & 3.328 \\
\hline 2 & 1 & 200 & 18.405 & 17.482 & 17.578 & 15.278 \\
\hline 2 & 1 & 500 & 186.574 & 188.586 & 172.759 & 136.107 \\
\hline 2 & 1 & 1000 & 1.221 .101 & 1.210 .506 & 1.118 .794 & 877.957 \\
\hline 2 & 1 & 1500 & 3.832 .040 & 3.821 .340 & 3.520 .823 & 2.600 .039 \\
\hline 2 & 1 & 3000 & & & & \\
\hline 2 & 1 & 5000 & & & & \\
\hline 2 & 2 & 100 & 3.531 & 3.432 & 3.550 & 3.043 \\
\hline 2 & 2 & 200 & 18.240 & 17.054 & 17.378 & 14.741 \\
\hline 2 & 2 & 500 & 190.080 & 179.662 & 170.473 & 144.243 \\
\hline 2 & 2 & 1000 & 1.249 .333 & 1.197 .141 & 1.114 .678 & 882.927 \\
\hline 2 & 2 & 1500 & 3.842 .495 & 3.779 .409 & 3.451 .688 & 2.746 .605 \\
\hline 2 & 2 & 3000 & & & & \\
\hline 2 & 2 & 5000 & & & & \\
\hline 2 & 3 & 100 & 3.798 & 3.470 & 3.345 & 3.157 \\
\hline 2 & 3 & 200 & 18.025 & 17.450 & 16.912 & 15.036 \\
\hline 2 & 3 & 500 & 186.687 & 182.006 & 173.795 & 149.177 \\
\hline 2 & 3 & 1000 & 1.235 .299 & 1.182 .626 & 1.124 .804 & 927.354 \\
\hline 2 & 3 & 1500 & 3.817 .899 & 3.703 .350 & 3.436 .052 & 2.790 .123 \\
\hline 2 & 3 & 3000 & & & & \\
\hline 2 & 3 & 5000 & & & & \\
\hline
\end{tabular}


Não foi possível executar os problemas de 3000 e 5000 rotas devido à restrição de memória do computador em função do número de combinações geradas.

Da mesma forma que os problemas com um reposicionamento, o aumento do número de ciclos também aumenta exponencialmente com o aumento do número de rotas, porém isso ocorre a uma taxa de crescimento muito maior. Além disso, também notou-se que o número de ciclos é reduzido com o aumento do desbalanceamento, porém a uma taxa menor do que o primeiro caso. Do mesmo modo, a diferença entre os dígrafos não se mostrou significativa.

A Figura 4-1 e a Figura 4-2 mostram a taxa de crescimento do número de ciclos gerados por fator de desbalanceamento em função do número rotas para os problemas de um e dois reposicionamentos, respectivamente. Utilizou-se o dígrafo 1 como exemplo.

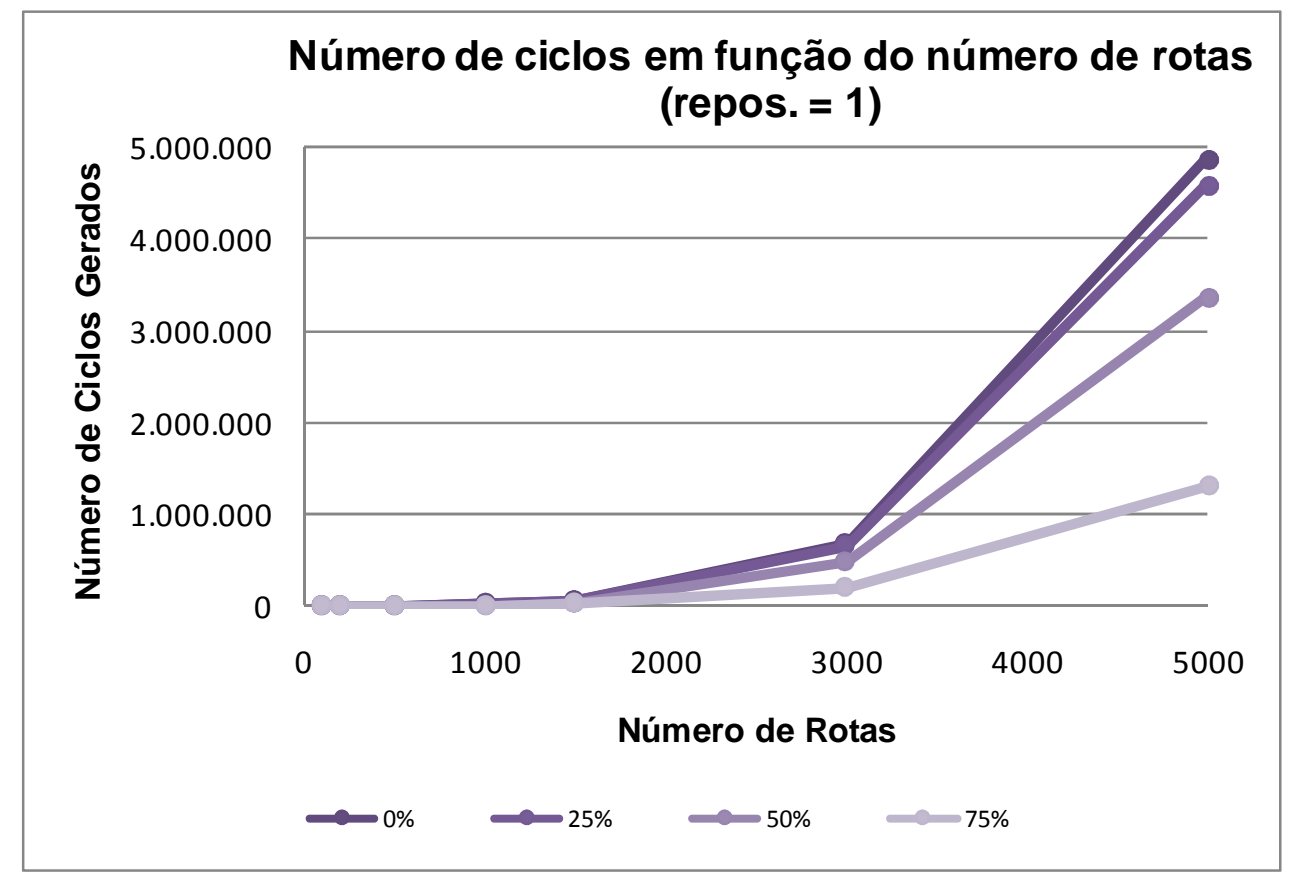

Figura 4-1: Número de ciclos em função do número de rotas para um reposicionamento para e cada fator de desbalanceamento

A Tabela 4-4 e a Tabela 4-5 a seguir mostram os tempos de execução para gerar os ciclos viáveis para os problemas com um e dois reposicionamentos, respectivamente. Da mesma forma que para o número de ciclos gerados, também foi feita uma média dos tempos das instâncias. 


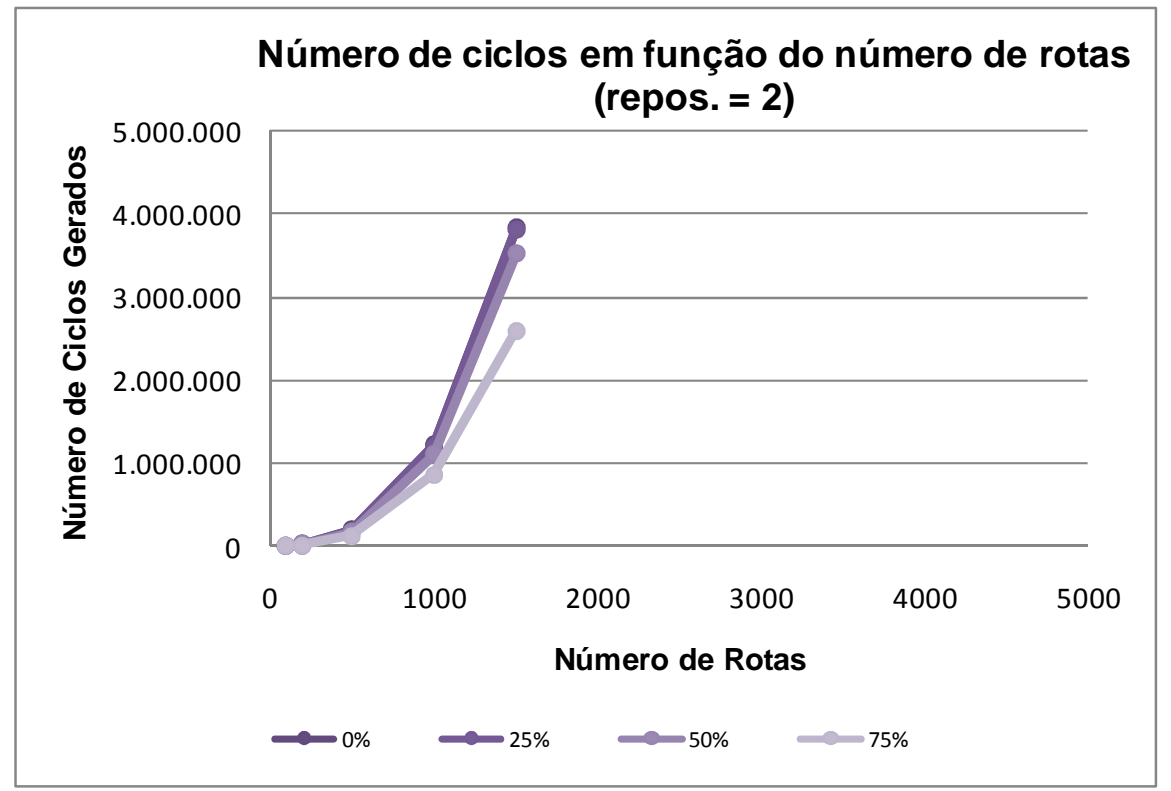

Figura 4-2: Número de ciclos em função do número de rotas para dois reposicionamentos e para cada fator de desbalanceamento

Tabela 4-4: Tempo de execução para problemas com um reposicionamento

TEMPO DE EXECUÇÃO (s)

\begin{tabular}{|c|c|c|c|c|c|c|}
\hline \multirow[b]{2}{*}{ REPOS. } & \multirow[b]{2}{*}{ DÍGRAFO } & \multirow[b]{2}{*}{ ROTAS } & \multicolumn{4}{|c|}{ FATOR DESBALANCEAMENTO } \\
\hline & & & $0 \%$ & $25 \%$ & $50 \%$ & $75 \%$ \\
\hline 1 & 1 & 100 & 0,00 & 0,00 & 0,00 & 0,00 \\
\hline 1 & 1 & 200 & 0,00 & 0,00 & 0,00 & 0,00 \\
\hline 1 & 1 & 500 & 0,00 & 0,01 & 0,01 & 0,00 \\
\hline 1 & 1 & 1000 & 0,07 & 0,08 & 0,06 & 0,03 \\
\hline 1 & 1 & 1500 & 0,34 & 0,34 & 0,25 & 0,14 \\
\hline 1 & 1 & 3000 & 5,35 & 5,14 & 3,83 & 1,78 \\
\hline 1 & 1 & 5000 & 48,50 & 45,86 & 34,83 & 14,94 \\
\hline 1 & 2 & 100 & 0,00 & 0,00 & 0,00 & 0,00 \\
\hline 1 & 2 & 200 & 0,00 & 0,00 & 0,00 & 0,00 \\
\hline 1 & 2 & 500 & 0,02 & 0,01 & 0,01 & 0,01 \\
\hline 1 & 2 & 1000 & 0,08 & 0,08 & 0,07 & 0,03 \\
\hline 1 & 2 & 1500 & 0,33 & 0,31 & 0,27 & 0,14 \\
\hline 1 & 2 & 3000 & 5,39 & 5,16 & 4,07 & 2,06 \\
\hline 1 & 2 & 5000 & 48,47 & 44,97 & 35,81 & 16,14 \\
\hline 1 & 3 & 100 & 0,00 & 0,00 & 0,00 & 0,00 \\
\hline 1 & 3 & 200 & 0,00 & 0,00 & 0,00 & 0,00 \\
\hline 1 & 3 & 500 & 0,01 & 0,01 & 0,01 & 0,00 \\
\hline 1 & 3 & 1000 & 0,07 & 0,07 & 0,06 & 0,04 \\
\hline 1 & 3 & 1500 & 0,33 & 0,32 & 0,27 & 0,16 \\
\hline 1 & 3 & 3000 & 5,34 & 5,17 & 3,83 & 2,24 \\
\hline 1 & 3 & 5000 & 48,45 & 45,90 & 34,34 & 19,13 \\
\hline
\end{tabular}


Tabela 4-5: Tempo de execução para problemas com dois reposicionamentos

TEMPO DE EXECUÇÃO (s)

\begin{tabular}{|c|c|c|c|c|c|c|}
\hline \multirow[b]{2}{*}{ REPOS. } & \multirow[b]{2}{*}{ DÍGRAFO } & \multirow[b]{2}{*}{ ROTAS } & \multicolumn{4}{|c|}{ FATOR DESBALANCEAMENTO } \\
\hline & & & $0 \%$ & $25 \%$ & $50 \%$ & $75 \%$ \\
\hline 2 & 1 & 100 & 0,01 & 0,01 & 0,01 & 0,01 \\
\hline 2 & 1 & 200 & 0,04 & 0,03 & 0,03 & 0,03 \\
\hline 2 & 1 & 500 & 0,46 & 0,47 & 0,42 & 0,33 \\
\hline 2 & 1 & 1000 & 3,52 & 3,49 & 3,15 & 2,40 \\
\hline 2 & 1 & 1500 & 12,15 & 12,05 & 10,92 & 7,65 \\
\hline 2 & 1 & 3000 & & & & \\
\hline 2 & 1 & 5000 & & & & \\
\hline 2 & 2 & 100 & 0,01 & 0,00 & 0,01 & 0,01 \\
\hline 2 & 2 & 200 & 0,04 & 0,04 & 0,04 & 0,03 \\
\hline 2 & 2 & 500 & 0,47 & 0,45 & 0,43 & 0,34 \\
\hline 2 & 2 & 1000 & 3,60 & 3,42 & 3,14 & 2,42 \\
\hline 2 & 2 & 1500 & 12,17 & 11,96 & 10,64 & 8,30 \\
\hline 2 & 2 & 3000 & & & & \\
\hline 2 & 2 & 5000 & & & & \\
\hline 2 & 3 & 100 & 0,01 & 0,00 & 0,01 & 0,01 \\
\hline 2 & 3 & 200 & 0,04 & 0,04 & 0,04 & 0,03 \\
\hline 2 & 3 & 500 & 0,48 & 0,46 & 0,44 & 0,36 \\
\hline 2 & 3 & 1000 & 3,54 & 3,38 & 3,16 & 2,54 \\
\hline 2 & 3 & 1500 & 12,24 & 11,64 & 10,64 & 8,36 \\
\hline 2 & 3 & 3000 & & & & \\
\hline 2 & 3 & 5000 & & & & \\
\hline
\end{tabular}

O tempo de execução possui o mesmo comportamento que o número de ciclos gerados aumentando proporcionalmente ao número de rotas e inversamente proporcional ao aumento do desbalanceamento do problema.

A Figura 4-3 e a Figura 4-4 mostram a taxa de crescimento do tempo de execução por fator de desbalanceamento em função do número rotas para os problemas de um e dois reposicionamentos, respectivamente. Utilizou-se o dígrafo 1 como exemplo. 


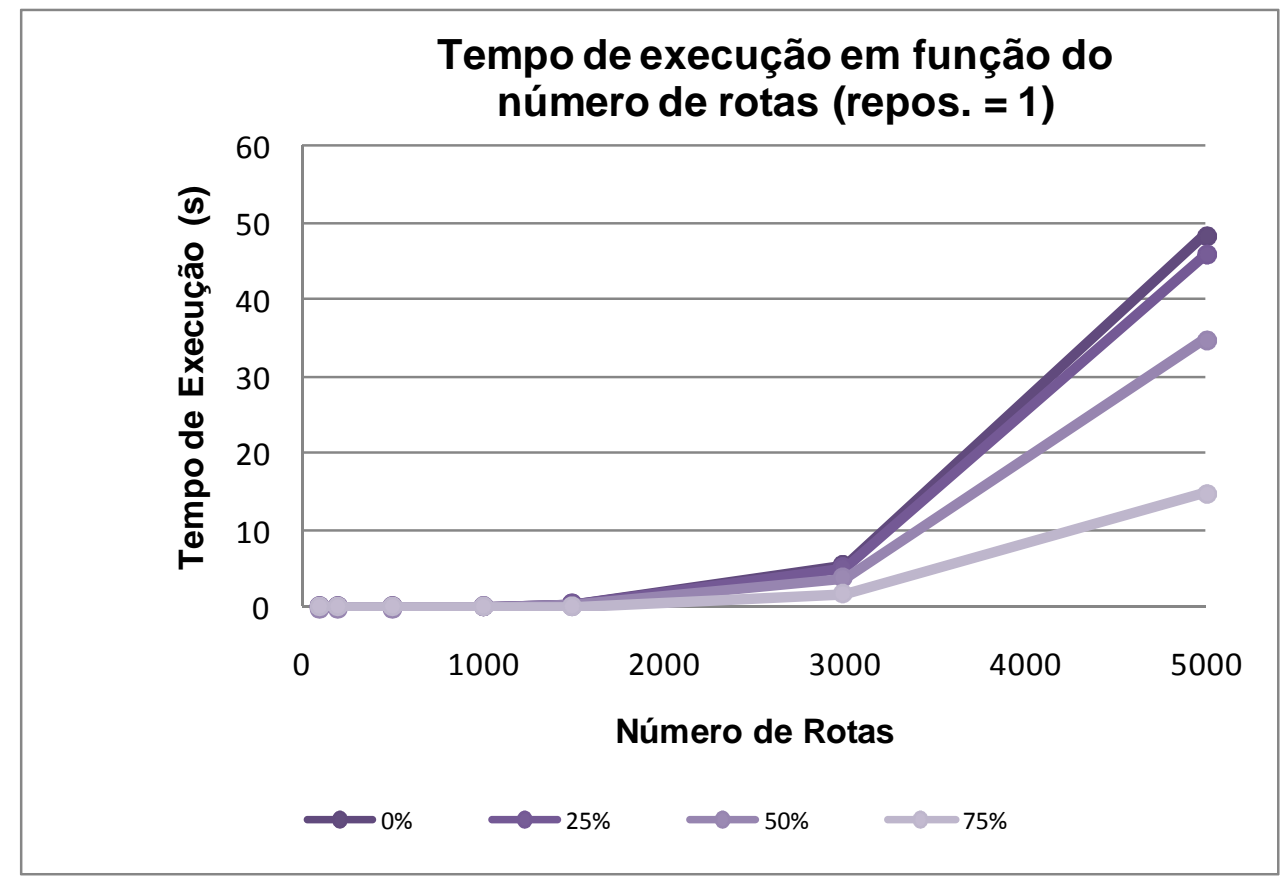

Figura 4-3: Tempos de execução em função do número de rotas para um reposicionamento e para cada fator de desbalanceamento

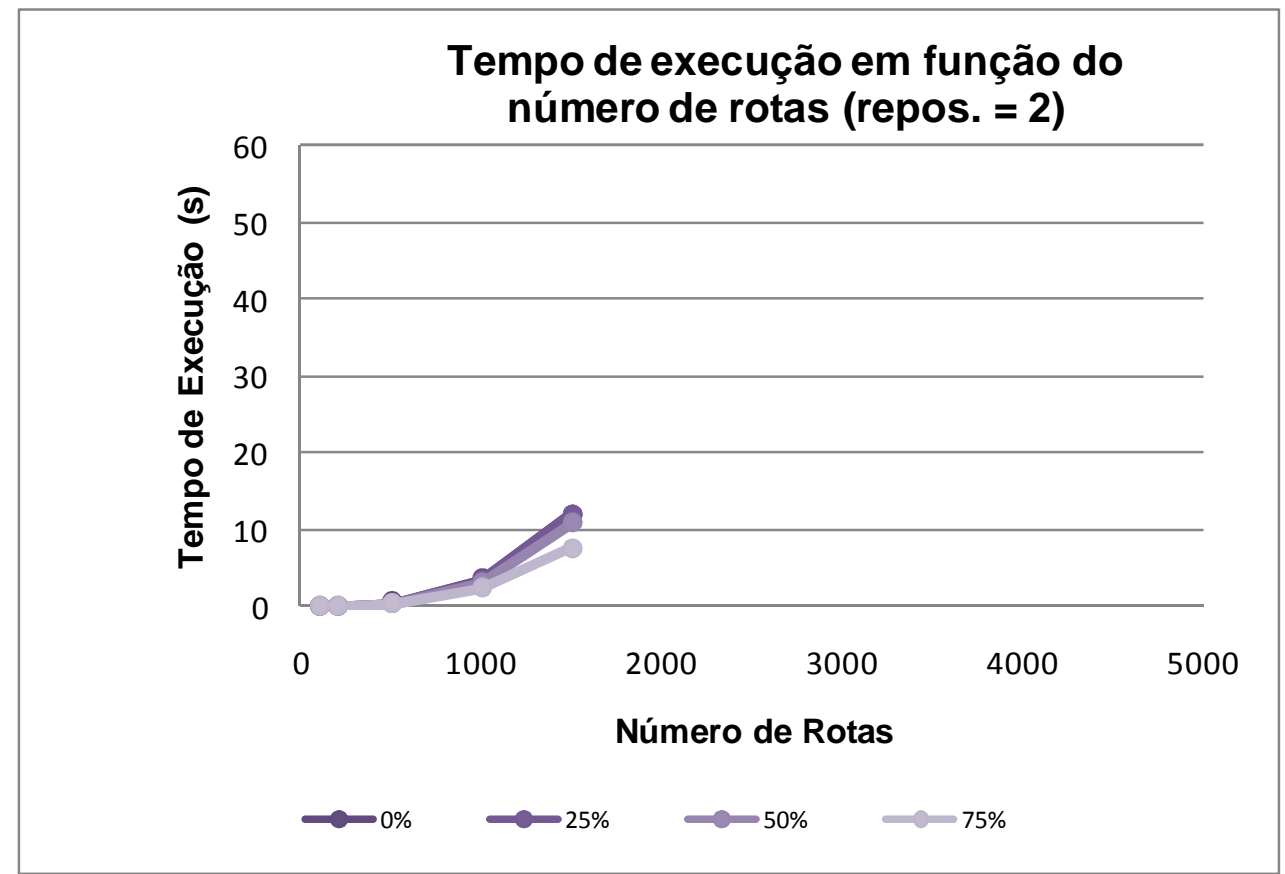

Figura 4-4: Tempos de execução em função do número de rotas para dois reposicionamentos e para cada fator de desbalanceamento

Comparando-se o número de ciclos gerado para os problemas balanceados com os resultados obtidos por (ERGUN et al, 2007b) na Tabela 4-6, observa-se que 
para aqueles com um único reposicionamento existe uma diferença significativa. $\mathrm{O}$ número de ciclos gerados por (ERGUN et al, 2007b) é sempre menor e sua diferença aumenta com o número de rotas atingindo, aproximadamente, - $-70 \%$ para os problemas de 1500 rotas. Por outro lado, o tempo de execução apresenta aproximadamente a mesma ordem de grandeza, considerando-se que os computadores utilizados para a geração são diferentes.

Tabela 4-6: Comparação de número de ciclos gerados e tempos de execução com (ERGUN et al, 2007b) para problemas balanceados

COMPARAÇÃO DA GERAÇÃO DE CICLOS VIÁVEIS - PROBLEMAS BALANCEADOS

\begin{tabular}{|c|c|c|c|c|c|c|}
\hline \multirow[b]{2}{*}{ REPOS. } & \multirow[b]{2}{*}{ DÍGRAFO } & \multirow[b]{2}{*}{ ROTAS } & \multicolumn{2}{|c|}{ (ERGUN et al, 2007b) } & \multicolumn{2}{|c|}{ (FERRI, 2009) } \\
\hline & & & NÚM. CICLO (\#) & $\begin{array}{c}\text { TEMPO } \\
\text { EXECUÇÃO (s) }\end{array}$ & NÚM. CICLO (\#) & $\begin{array}{c}\text { TEMPO } \\
\text { EXECUÇÃO (s) }\end{array}$ \\
\hline 1 & 1 & 100 & 119 & 0,00 & 125 & 0,00 \\
\hline 1 & 1 & 200 & 270 & 0,00 & 327 & 0,00 \\
\hline 1 & 1 & 500 & 1.123 & 0,00 & 1.989 & 0,00 \\
\hline 1 & 1 & 1000 & 4.966 & 0,01 & 13.992 & 0,07 \\
\hline 1 & 1 & 1500 & 15.977 & 0,05 & 56.040 & 0,34 \\
\hline 1 & 2 & 100 & 114 & 0,00 & 122 & 0,00 \\
\hline 1 & 2 & 200 & 275 & 0,00 & 331 & 0,00 \\
\hline 1 & 2 & 500 & 1.179 & 0,00 & 1.997 & 0,02 \\
\hline 1 & 2 & 1000 & 5.507 & 0,01 & 15.069 & 0,08 \\
\hline 1 & 2 & 1500 & 17.502 & 0,05 & 56.050 & 0,33 \\
\hline 1 & 3 & 100 & 122 & 0,00 & 128 & 0,00 \\
\hline 1 & 3 & 200 & 275 & 0,00 & 321 & 0,00 \\
\hline 1 & 3 & 500 & 1.021 & 0,00 & 1.984 & 0,01 \\
\hline 1 & 3 & 1000 & 4.310 & 0,01 & 14.530 & 0,07 \\
\hline 1 & 3 & 1500 & 14.041 & 0,03 & 54.337 & 0,33 \\
\hline 2 & 1 & 100 & 4.124 & 0,01 & 3.495 & 0,01 \\
\hline 2 & 1 & 200 & 19.712 & 0,06 & 18.405 & 0,04 \\
\hline 2 & 1 & 500 & 219.468 & 3,80 & 186.574 & 0,46 \\
\hline 2 & 1 & 1000 & 1.380 .971 & 155,59 & 1.221 .101 & 3,52 \\
\hline 2 & 1 & 1500 & 4.426 .539 & $1.654,99$ & 3.832 .040 & 12,15 \\
\hline 2 & 2 & 100 & 4.032 & 0,01 & 3.531 & 0,01 \\
\hline 2 & 2 & 200 & 21.082 & 0,06 & 18.240 & 0,04 \\
\hline 2 & 2 & 500 & 220.506 & 3,48 & 190.080 & 0,47 \\
\hline 2 & 2 & 1000 & 1.493 .193 & 177,75 & 1.249 .333 & 3,60 \\
\hline 2 & 2 & 1500 & 4.653.239 & $1.812,84$ & 3.842 .495 & 12,17 \\
\hline 2 & 3 & 100 & 4.491 & 0,01 & 3.798 & 0,01 \\
\hline 2 & 3 & 200 & 20.914 & 0,06 & 18.025 & 0,04 \\
\hline 2 & 3 & 500 & 194.061 & 2,73 & 186.687 & 0,48 \\
\hline 2 & 3 & 1000 & 1.283 .701 & 131,48 & 1.235 .299 & 3,54 \\
\hline 2 & 3 & 1500 & 4.246 .370 & $1.494,28$ & 3.817 .899 & 12,24 \\
\hline
\end{tabular}


Para os problemas com dois reposicionamentos, também foi observada uma diferença significativa, entretanto o número gerado por (ERGUN et al, 2007b) é sempre maior e aproximadamente constante entre $10 \%$ e $20 \%$. Os tempos de execução para esse caso apresentam uma diferença muito grande com o aumento do número de rotas. Para os problemas de 1500 rotas, os autores obtiveram tempos aproximados entre 1400 s e 1800 s enquanto que para os mesmos problemas obtevese uma média de 12s, aproximadamente. É provável que (ERGUN et al, 2007b) tenham utilizado alguns critérios adicionais na geração dos ciclos viáveis que não estão mencionados em suas publicações.

\subsection{Aplicação da PLI}

A aplicação da PLI foi feita utilizando-se a formulação de cobertura de conjuntos. O GAMS/CPLEX foi configurado com as seguintes características:

- Configurou-se para encerrar o processo de otimização ao encontrar a primeira solução viável que atenda a todas as restrições do modelo da mesma forma que foi feito por (ERGUN et al, 2007b).

- Permitiu-se que o GAMS/CPLEX utilizasse os quatro núcleos do processador para realizar otimização em paralelo com o objetivo de se chegar mais rápido à solução do problema.

- Configurou-se para priorizar a obtenção da primeira solução viável ao invés da solução global.

- Utilizou-se como limite superior para a primeira solução viável, a resposta dada pelo Algoritmo GH. Sem esse limite, verificou-se que a solução gerada não era adequada, pois, em média, o seu valor era $70 \%$ maior que os outros métodos.

- Configurou-se um tempo limite de execução de 8 horas.

A Tabela 4-7 e a Tabela 4-8 a seguir mostram os resultados para cada um dos dígrafos gerados para os problemas de 100, 200, 500, 1000, 1500, 3000 e 5000 
rotas e fator de desbalanceamento de $0 \%, 25 \%, 50 \%$ e $75 \%$ sendo permitido um ou dois reposicionamentos, respectivamente. Os valores exibidos são uma média simples das soluções geradas por cada instância.

Tabela 4-7: Solução gerada por PLI para problemas com um reposicionamento

SOLUÇÃO GERADA POR PLI (\#)

\begin{tabular}{|c|c|c|c|c|c|c|}
\hline \multirow[b]{2}{*}{ REPOS. } & \multirow[b]{2}{*}{ DÍGRAFO } & \multirow[b]{2}{*}{ ROTAS } & \multicolumn{4}{|c|}{ FATOR DESBALANCEAMENTO } \\
\hline & & & $0 \%$ & $25 \%$ & $50 \%$ & $75 \%$ \\
\hline 1 & 1 & 100 & 96.872 & 96.089 & 98.522 & 96.044 \\
\hline 1 & 1 & 200 & 169.443 & 172.256 & 175.179 & 183.478 \\
\hline 1 & 1 & 500 & 338.856 & 337.753 & 393.514 & 449.747 \\
\hline 1 & 1 & 1000 & 621.360 & 619.282 & 732.749 & 804.720 \\
\hline 1 & 1 & 1500 & 828.852 & 923.947 & 1.001 .654 & 1.238 .229 \\
\hline 1 & 1 & 3000 & 1.603 .193 & 1.753 .018 & 1.888 .528 & 2.412 .726 \\
\hline 1 & 1 & 5000 & & & & \\
\hline 1 & 2 & 100 & 94.154 & 84.564 & 102.192 & 103.158 \\
\hline 1 & 2 & 200 & 157.752 & 156.558 & 165.210 & 184.440 \\
\hline 1 & 2 & 500 & 309.631 & 323.818 & 342.358 & 430.667 \\
\hline 1 & 2 & 1000 & 546.414 & 586.106 & 657.095 & 822.531 \\
\hline 1 & 2 & 1500 & 789.016 & 796.548 & 1.043 .284 & 1.172 .948 \\
\hline 1 & 2 & 3000 & 1.654 .983 & 1.632 .003 & 1.836 .831 & 2.422 .985 \\
\hline 1 & 2 & 5000 & & & & \\
\hline 1 & 3 & 100 & 81.018 & 71.774 & 73.418 & 91.426 \\
\hline 1 & 3 & 200 & 150.131 & 147.864 & 137.100 & 158.353 \\
\hline 1 & 3 & 500 & 314.159 & 289.424 & 323.130 & 374.737 \\
\hline 1 & 3 & 1000 & 479.838 & 552.270 & 623.185 & 746.580 \\
\hline 1 & 3 & 1500 & 738.953 & 784.490 & 863.018 & 1.094 .551 \\
\hline 1 & 3 & 3000 & 1.339 .474 & 1.371 .506 & 1.717 .238 & 2.216 .556 \\
\hline 1 & 3 & 5000 & & & & \\
\hline
\end{tabular}


Tabela 4-8: Solução gerada por PLI para problemas com dois reposicionamentos

SOLUÇÃO GERADA POR PLI (\#)

\begin{tabular}{|c|c|c|c|c|c|c|}
\hline \multirow[b]{2}{*}{ REPOS. } & \multirow[b]{2}{*}{ DÍGRAFO } & \multirow[b]{2}{*}{ ROTAS } & \multicolumn{4}{|c|}{ FATOR DESBALANCEAMENTO } \\
\hline & & & $0 \%$ & $25 \%$ & $50 \%$ & $75 \%$ \\
\hline 2 & 1 & 100 & 59.751 & 58.980 & 66.006 & 69.259 \\
\hline 2 & 1 & 200 & 114.034 & 125.250 & 126.835 & 138.828 \\
\hline 2 & 1 & 500 & 257.593 & 271.828 & 312.875 & 342.942 \\
\hline 2 & 1 & 1000 & & & & \\
\hline 2 & 1 & 1500 & & & & \\
\hline 2 & 1 & 3000 & & & & \\
\hline 2 & 1 & 5000 & & & & \\
\hline 2 & 2 & 100 & 56.052 & 59.693 & 60.348 & 73.147 \\
\hline 2 & 2 & 200 & 100.764 & 103.758 & 125.662 & 137.755 \\
\hline 2 & 2 & 500 & 254.205 & 258.835 & 314.886 & 355.388 \\
\hline 2 & 2 & 1000 & & & & \\
\hline 2 & 2 & 1500 & & & & \\
\hline 2 & 2 & 3000 & & & & \\
\hline 2 & 2 & 5000 & & & & \\
\hline 2 & 3 & 100 & 52.854 & 45.424 & 54.572 & 61.212 \\
\hline 2 & 3 & 200 & 98.424 & 91.602 & 115.919 & 138.848 \\
\hline 2 & 3 & 500 & 251.237 & 230.619 & 296.691 & 318.656 \\
\hline 2 & 3 & 1000 & & & & \\
\hline 2 & 3 & 1500 & & & & \\
\hline 2 & 3 & 3000 & & & & \\
\hline 2 & 3 & 5000 & & & & \\
\hline
\end{tabular}

Não foi possível executar os problemas de 5000 rotas com um reposicionamento e os problemas com mais de 1000 rotas com dois reposicionamentos devido à restrição de memória do computador.

Nota-se que o valor da solução cresce com o aumento do número de rotas. Isso também ocorre com o aumento do desbalanceamento do problema. Por outro lado, o valor da solução, na média diminui para os dígrafos mais concentrados (como é o caso do dígrafo 3 que possui apenas cinco agrupamentos).

O número de reposicionamentos permitidos também influencia muito na solução. $O$ fato de ser permitido um reposicionamento adicional na geração do ciclo 
(em relação ao primeiro caso) faz com que o valor da solução se reduza, aproximadamente, de $10 \%$ a $40 \%$.

A Tabela 4-9 e a Tabela 4-10 a seguir mostram os tempos de execução para gerar a primeira solução viável para os problemas com um e dois reposicionamento, respectivamente. Esses tempos não possuem os tempos de geração de ciclos viáveis somados. Da mesma forma que para o número de ciclos gerados, também foi feita uma média dos tempos das instâncias.

Tabela 4-9: Tempo de execução para problemas com um reposicionamento

TEMPO DE EXECUÇÃO (s)

\begin{tabular}{|c|c|c|c|c|c|c|}
\hline \multirow[b]{2}{*}{ REPOS. } & \multirow[b]{2}{*}{ DÍGRAFO } & \multirow[b]{2}{*}{ ROTAS } & \multicolumn{4}{|c|}{ FATOR DESBALANCEAMENTO } \\
\hline & & & $0 \%$ & $25 \%$ & $50 \%$ & $75 \%$ \\
\hline 1 & 1 & 100 & 0,02 & 0,02 & 0,02 & 0,02 \\
\hline 1 & 1 & 200 & 0,02 & 0,03 & 0,03 & 0,02 \\
\hline 1 & 1 & 500 & 0,05 & 0,04 & 0,04 & 0,03 \\
\hline 1 & 1 & 1000 & 0,38 & 0,31 & 0,18 & 0,08 \\
\hline 1 & 1 & 1500 & 9,66 & 4,81 & 1,34 & 0,31 \\
\hline 1 & 1 & 3000 & $4.502,21$ & $1.402,45$ & 197,58 & 7,65 \\
\hline 1 & 1 & 5000 & & & & \\
\hline 1 & 2 & 100 & 0,02 & 0,03 & 0,02 & 0,03 \\
\hline 1 & 2 & 200 & 0,03 & 0,02 & 0,03 & 0,02 \\
\hline 1 & 2 & 500 & 0,04 & 0,04 & 0,04 & 0,03 \\
\hline 1 & 2 & 1000 & 0,41 & 0,27 & 0,20 & 0,09 \\
\hline 1 & 2 & 1500 & 9,63 & 3,51 & 1,09 & 0,29 \\
\hline 1 & 2 & 3000 & $4.817,76$ & $1.189,81$ & 192,08 & 7,69 \\
\hline 1 & 2 & 5000 & & & & \\
\hline 1 & 3 & 100 & 0,02 & 0,02 & 0,02 & 0,02 \\
\hline 1 & 3 & 200 & 0,02 & 0,03 & 0,02 & 0,02 \\
\hline 1 & 3 & 500 & 0,04 & 0,05 & 0,04 & 0,04 \\
\hline 1 & 3 & 1000 & 0,37 & 0,25 & 0,17 & 0,10 \\
\hline 1 & 3 & 1500 & 8,18 & 3,87 & 0,78 & 0,33 \\
\hline 1 & 3 & 3000 & $4.351,39$ & $1.570,84$ & 127,67 & 7,48 \\
\hline 1 & 3 & 5000 & & & & \\
\hline
\end{tabular}


Tabela 4-10: Tempo de execução para problemas com dois reposicionamentos

TEMPO DE EXECUÇÃO (s)

\begin{tabular}{|c|c|c|c|c|c|c|}
\hline \multirow[b]{2}{*}{ REPOS. } & \multirow[b]{2}{*}{ DÍGRAFO } & \multirow[b]{2}{*}{ ROTAS } & \multicolumn{4}{|c|}{ FATOR DESBALANCEAMENTO } \\
\hline & & & $0 \%$ & $25 \%$ & $50 \%$ & $75 \%$ \\
\hline 2 & 1 & 100 & 0,06 & 0,05 & 0,08 & 0,05 \\
\hline 2 & 1 & 200 & 0,26 & 0,23 & 0,23 & 0,18 \\
\hline 2 & 1 & 500 & 17,91 & 17,50 & 11,60 & 4,56 \\
\hline 2 & 1 & 1000 & & & & \\
\hline 2 & 1 & 1500 & & & & \\
\hline 2 & 1 & 3000 & & & & \\
\hline 2 & 1 & 5000 & & & & \\
\hline 2 & 2 & 100 & 0,06 & 0,06 & 0,06 & 0,05 \\
\hline 2 & 2 & 200 & 0,24 & 0,26 & 0,36 & 0,18 \\
\hline 2 & 2 & 500 & 17,20 & 14,06 & 12,82 & 4,47 \\
\hline 2 & 2 & 1000 & & & & \\
\hline 2 & 2 & 1500 & & & & \\
\hline 2 & 2 & 3000 & & & & \\
\hline 2 & 2 & 5000 & & & & \\
\hline 2 & 3 & 100 & 0,06 & 0,05 & 0,05 & 0,05 \\
\hline 2 & 3 & 200 & 0,33 & 0,22 & 0,22 & 0,18 \\
\hline 2 & 3 & 500 & 17,25 & 14,74 & 15,53 & 4,28 \\
\hline 2 & 3 & 1000 & & & & \\
\hline 2 & 3 & 1500 & & & & \\
\hline 2 & 3 & 3000 & & & & \\
\hline 2 & 3 & 5000 & & & & \\
\hline
\end{tabular}

O tempo de execução aumenta com o número de rotas. O crescimento é explosivo para os problemas com um reposicionamento e 3000 rotas, sendo necessário mais de uma hora para sua conclusão, principalmente para os problemas balanceados. Nota-se também que o tempo decresce com o aumento do desbalanceamento. Por outro lado, não existe diferença significativa ou tendência de tempo entre os dígrafos para um mesmo problema.

Comparando-se os tempos de execução de PLI com o número de ciclos gerados pelos problemas, nota-se que são diretamente proporcionais. A Figura 4-5 a seguir mostra um gráfico do tempo de solução de PLI em função do número de ciclos viáveis. Adicionou-se uma curva de tendência exponencial e observou-se uma correlação muito forte. $O R^{2}$ da regressão ficou em $89,9 \%$. Nota-se que a PLI não consegue executar problemas com mais de 700.000 ciclos viáveis. 


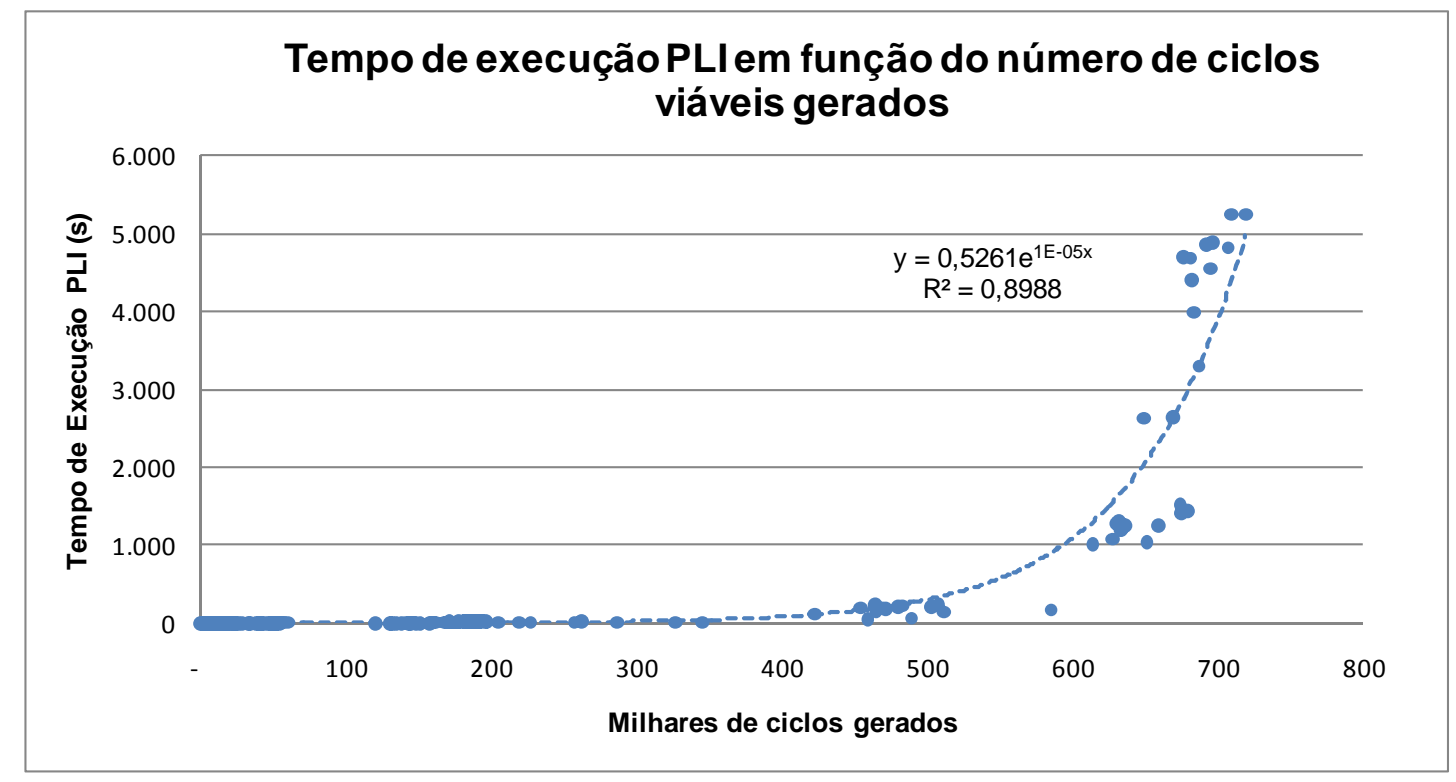

Figura 4-5: Tempo de execução de PLI em função do número de ciclos gerados

A Figura 4-6 e a Figura 4-7 mostram a taxa de crescimento do tempo de execução por fator de desbalanceamento em função do número rotas para os problemas de um e dois reposicionamentos, respectivamente. Utilizou-se o dígrafo 1 como exemplo. É importante ressaltar que a escala da segunda figura é diferente da primeira para facilitar a visualização.

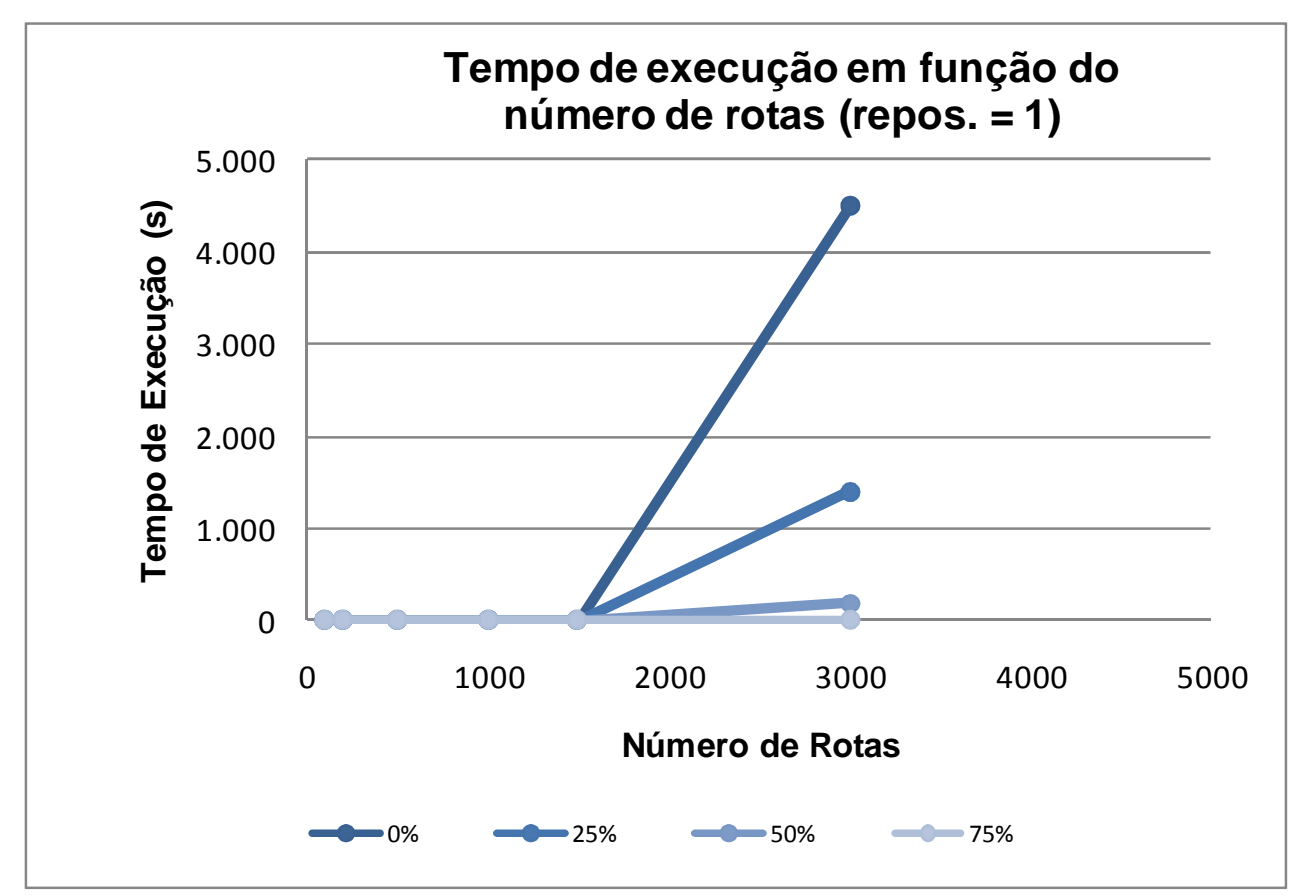

Figura 4-6: Tempos de execução em função do número de rotas para um reposicionamento e para cada fator de desbalanceamento 


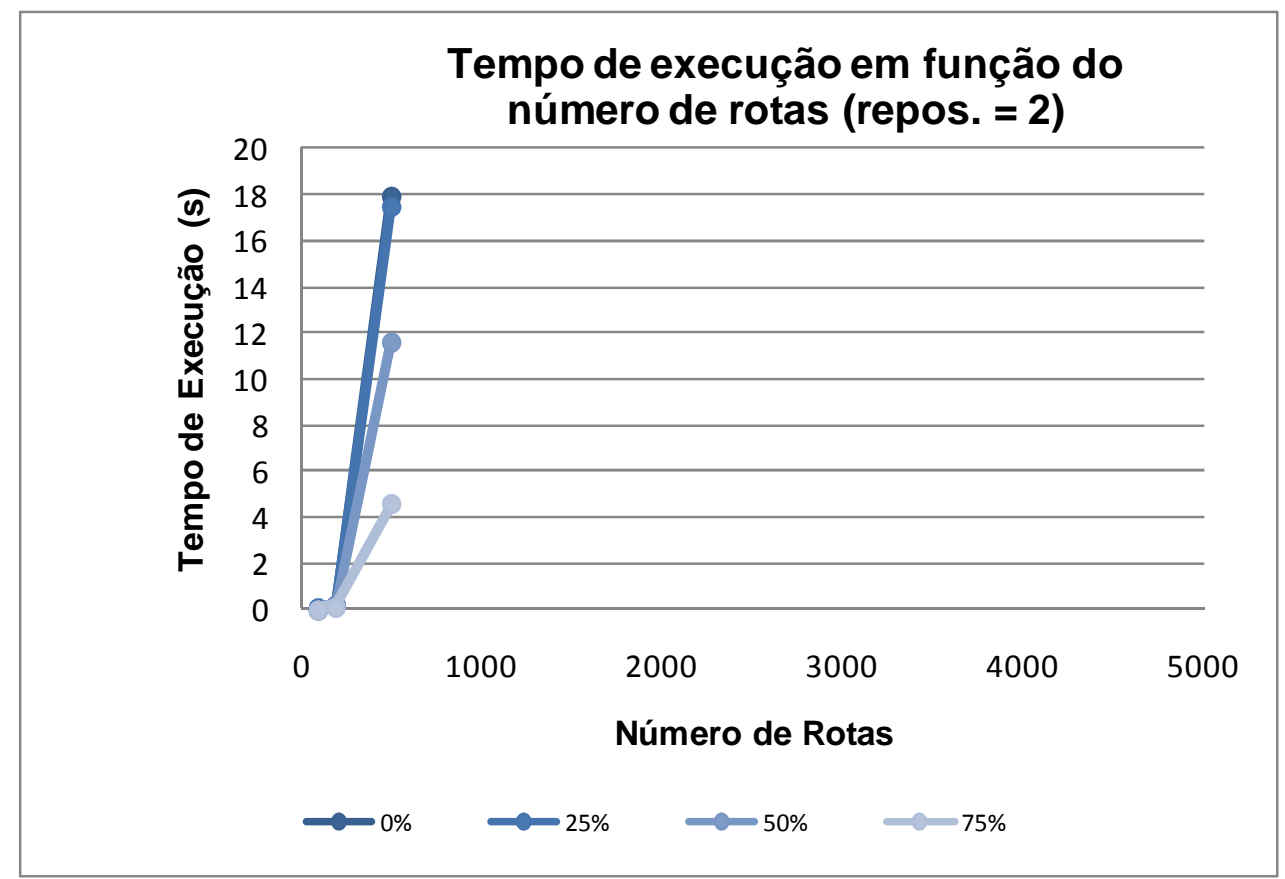

Figura 4-7: Tempos de execução em função do número de rotas para dois reposicionamentos e para cada fator de desbalanceamento

Comparando-se os tempos de execução obtidos para os problemas balanceados com os resultados obtidos por (ERGUN et al, 2007b) observa-se que para os problemas com um único reposicionamento existe uma diferença muito pequena, principalmente para os problemas com 1500 rotas. Porém, não se pode realmente afirmar que a diferença existe, uma vez que nota-se que os tempos foram arredondados para números inteiros.

Para os problemas com dois reposicionamentos, existe uma diferença para os problemas com 500 rotas. Os autores obtiveram uma média aproximada de $115 \mathrm{~s}$, enquanto neste trabalho obteve-se 17s. É provável que tenham utilizado uma parametrização diferente do otimizador, porém isso não está explícito em (ERGUN et al, 2007b). Por outro lado, também se observa uma característica exponencial em seus resultados. Não é possível comparar os resultados obtidos, pois não foi possível obter as mesmas instâncias utilizadas pelos autores. 
Tabela 4-11: Comparação dos tempos de execução da aplicação de PLI com (ERGUN et al, 2007b) para problemas balanceados

\begin{tabular}{|c|c|c|c|c|}
\hline \multirow[b]{2}{*}{ REPOS. } & \multirow[b]{2}{*}{ DÍGRAFO } & \multirow[b]{2}{*}{ ROTAS } & \multicolumn{2}{|c|}{ TEMPO EXECUÇÃO (s) } \\
\hline & & & $\begin{array}{c}\text { (ERGUN et al, } \\
2007 b)\end{array}$ & (FERRI, 2009) \\
\hline 1 & 1 & 100 & 0,00 & 0,02 \\
\hline 1 & 1 & 200 & 0,00 & 0,02 \\
\hline 1 & 1 & 500 & 0,00 & 0,05 \\
\hline 1 & 1 & 1000 & 0,00 & 0,38 \\
\hline 1 & 1 & 1500 & 0,00 & 9,66 \\
\hline 1 & 2 & 100 & 0,00 & 0,02 \\
\hline 1 & 2 & 200 & 0,00 & 0,03 \\
\hline 1 & 2 & 500 & 0,00 & 0,04 \\
\hline 1 & 2 & 1000 & 0,00 & 0,41 \\
\hline 1 & 2 & 1500 & 0,00 & 9,63 \\
\hline 1 & 3 & 100 & 0,00 & 0,02 \\
\hline 1 & 3 & 200 & 0,00 & 0,02 \\
\hline 1 & 3 & 500 & 0,00 & 0,04 \\
\hline 1 & 3 & 1000 & 0,00 & 0,37 \\
\hline 1 & 3 & 1500 & 0,00 & 8,18 \\
\hline 2 & 1 & 100 & 0,00 & 0,06 \\
\hline 2 & 1 & 200 & 0,00 & 0,26 \\
\hline 2 & 1 & 500 & 115,00 & 17,91 \\
\hline 2 & 1 & 1000 & $5.719,00$ & \\
\hline 2 & 1 & 1500 & & \\
\hline 2 & 2 & 100 & 0,00 & 0,06 \\
\hline 2 & 2 & 200 & 0,00 & 0,24 \\
\hline 2 & 2 & 500 & 132,00 & 17,20 \\
\hline 2 & 2 & 1000 & $5.784,00$ & \\
\hline 2 & 2 & 1500 & & \\
\hline 2 & 3 & 100 & 0,00 & 0,06 \\
\hline 2 & 3 & 200 & 0,00 & 0,33 \\
\hline 2 & 3 & 500 & 104,00 & 17,25 \\
\hline 2 & 3 & 1000 & $8.244,00$ & \\
\hline 2 & 3 & 1500 & & \\
\hline
\end{tabular}




\subsection{Aplicação do Algoritmo GH}

O Algoritmo $\mathrm{GH}$ foi aplicado e os resultados para cada um dos dígrafos gerados para os problemas de 100, 200, 500, 1000, 1500, 3000 e 5000 rotas e fator de desbalanceamento de $0 \%, 25 \%, 50 \%$ e $75 \%$ sendo permitido um ou dois reposicionamentos estão mostrados, respectivamente, em Tabela 4-12 e Tabela 4-13. Os valores exibidos são uma média simples das soluções geradas por cada instância.

Tabela 4-12: Solução gerada por GH para problemas com um reposicionamento

SOLUÇÃO GERADA POR GH (\#)

\begin{tabular}{|c|c|c|c|c|c|c|}
\hline \multirow[b]{2}{*}{ REPOS. } & \multirow[b]{2}{*}{ DÍGRAFO } & \multirow[b]{2}{*}{ ROTAS } & \multicolumn{4}{|c|}{ FATOR DESBALANCEAMENTO } \\
\hline & & & $0 \%$ & $25 \%$ & $50 \%$ & $75 \%$ \\
\hline 1 & 1 & 100 & 97.111 & 96.154 & 98.594 & 96.073 \\
\hline 1 & 1 & 200 & 171.765 & 173.684 & 176.721 & 184.161 \\
\hline 1 & 1 & 500 & 358.778 & 356.634 & 405.567 & 456.684 \\
\hline 1 & 1 & 1000 & 686.026 & 676.179 & 779.621 & 824.257 \\
\hline 1 & 1 & 1500 & 918.722 & 1.030 .182 & 1.082 .759 & 1.281 .899 \\
\hline 1 & 1 & 3000 & 1.805 .524 & 1.978 .999 & 2.089 .210 & 2.524 .064 \\
\hline 1 & 1 & 5000 & 3.049 .304 & 3.220 .047 & 3.471 .315 & 4.390 .573 \\
\hline 1 & 2 & 100 & 94.315 & 84.740 & 102.313 & 103.400 \\
\hline 1 & 2 & 200 & 159.176 & 157.725 & 166.474 & 185.090 \\
\hline 1 & 2 & 500 & 328.042 & 340.653 & 353.732 & 437.037 \\
\hline 1 & 2 & 1000 & 608.978 & 645.679 & 702.136 & 845.176 \\
\hline 1 & 2 & 1500 & 889.441 & 894.997 & 1.128 .278 & 1.214 .440 \\
\hline 1 & 2 & 3000 & 1.858 .356 & 1.831 .875 & 2.026 .233 & 2.540 .562 \\
\hline 1 & 2 & 5000 & 2.776 .382 & 3.121 .231 & 3.468 .697 & 4.087 .316 \\
\hline 1 & 3 & 100 & 81.024 & 71.822 & 73.535 & 91.434 \\
\hline 1 & 3 & 200 & 151.118 & 148.799 & 138.202 & 158.605 \\
\hline 1 & 3 & 500 & 332.513 & 305.288 & 334.291 & 380.937 \\
\hline 1 & 3 & 1000 & 546.748 & 610.690 & 664.511 & 764.572 \\
\hline 1 & 3 & 1500 & 850.096 & 873.831 & 927.868 & 1.125 .388 \\
\hline 1 & 3 & 3000 & 1.514 .192 & 1.501 .597 & 1.850 .770 & 2.297 .121 \\
\hline 1 & 3 & 5000 & 2.843 .777 & 2.732 .532 & 3.597.342 & 4.004 .458 \\
\hline
\end{tabular}

Todos os problemas com um reposicionamento foram executados, porém não acontece o mesmo para os problemas com mais de 3000 rotas e dois reposicionamentos. Isso ocorreu, pois o gerador de ciclos não conseguiu gerar o 
conjunto $C_{k}$ para esses problemas e, dessa forma, o Algoritmo $\mathrm{GH}$ não pôde ser executado.

Tabela 4-13: Solução gerada por GH para problemas com dois reposicionamentos

SOLUÇÃO GERADA POR GH (\#)

\begin{tabular}{|c|c|c|c|c|c|c|}
\hline \multirow[b]{2}{*}{ REPOS. } & \multirow[b]{2}{*}{ DÍGRAFO } & \multirow[b]{2}{*}{ ROTAS } & \multicolumn{4}{|c|}{ FATOR DESBALANCEAMENTO } \\
\hline & & & $0 \%$ & $25 \%$ & $50 \%$ & $75 \%$ \\
\hline 2 & 1 & 100 & 61.298 & 60.698 & 67.333 & 70.431 \\
\hline 2 & 1 & 200 & 116.696 & 128.094 & 130.126 & 142.018 \\
\hline 2 & 1 & 500 & 263.046 & 277.279 & 317.937 & 347.994 \\
\hline 2 & 1 & 1000 & 542.223 & 529.182 & 619.792 & 731.748 \\
\hline 2 & 1 & 1500 & 834.578 & 825.615 & 935.251 & 1.060 .550 \\
\hline 2 & 1 & 3000 & & & & \\
\hline 2 & 1 & 5000 & & & & \\
\hline 2 & 2 & 100 & 57.481 & 61.116 & 61.831 & 73.741 \\
\hline 2 & 2 & 200 & 102.686 & 105.094 & 126.978 & 138.944 \\
\hline 2 & 2 & 500 & 257.563 & 260.918 & 316.898 & 358.540 \\
\hline 2 & 2 & 1000 & 477.794 & 584.864 & 641.805 & 723.082 \\
\hline 2 & 2 & 1500 & 757.614 & 844.160 & 957.058 & 1.159 .750 \\
\hline 2 & 2 & 3000 & & & & \\
\hline 2 & 2 & 5000 & & & & \\
\hline 2 & 3 & 100 & 53.164 & 46.015 & 54.802 & 61.446 \\
\hline 2 & 3 & 200 & 99.915 & 92.483 & 116.394 & 139.839 \\
\hline 2 & 3 & 500 & 252.073 & 231.553 & 298.194 & 320.065 \\
\hline 2 & 3 & 1000 & 489.139 & 528.979 & 647.135 & 722.692 \\
\hline 2 & 3 & 1500 & 621.364 & 798.754 & 878.806 & 1.094 .442 \\
\hline 2 & 3 & 3000 & & & & \\
\hline 2 & 3 & 5000 & & & & \\
\hline
\end{tabular}

A Tabela 4-14 e a Tabela 4-15 a seguir mostram os tempos de execução do Algoritmo GH para os problemas com um e dois reposicionamento, respectivamente. Esses tempos não possuem os tempos de geração de ciclos viáveis somados. Da mesma forma que para o número de ciclos gerados, também foi feita uma média dos tempos das instâncias. 
Tabela 4-14: Tempo de execução para problemas com um reposicionamento

TEMPO DE EXECUÇÃO (s)

\begin{tabular}{|c|c|c|c|c|c|c|}
\hline \multirow[b]{2}{*}{ REPOS. } & \multirow[b]{2}{*}{ DÍGRAFO } & \multirow[b]{2}{*}{ ROTAS } & \multicolumn{4}{|c|}{ FATOR DESBALANCEAMENTO } \\
\hline & & & $0 \%$ & $25 \%$ & $50 \%$ & $75 \%$ \\
\hline 1 & 1 & 100 & 0,00 & 0,01 & 0,01 & 0,01 \\
\hline 1 & 1 & 200 & 0,02 & 0,00 & 0,02 & 0,01 \\
\hline 1 & 1 & 500 & 0,03 & 0,03 & 0,04 & 0,04 \\
\hline 1 & 1 & 1000 & 0,26 & 0,23 & 0,16 & 0,11 \\
\hline 1 & 1 & 1500 & 1,58 & 1,32 & 0,74 & 0,28 \\
\hline 1 & 1 & 3000 & 47,99 & 38,69 & 20,01 & 4,74 \\
\hline 1 & 1 & 5000 & 632,09 & 494,96 & 262,33 & 55,34 \\
\hline 1 & 2 & 100 & 0,01 & 0,01 & 0,01 & 0,01 \\
\hline 1 & 2 & 200 & 0,01 & 0,01 & 0,02 & 0,01 \\
\hline 1 & 2 & 500 & 0,04 & 0,04 & 0,03 & 0,03 \\
\hline 1 & 2 & 1000 & 0,28 & 0,22 & 0,17 & 0,11 \\
\hline 1 & 2 & 1500 & 1,57 & 1,24 & 0,76 & 0,29 \\
\hline 1 & 2 & 3000 & 47,49 & 36,73 & 21,10 & 5,35 \\
\hline 1 & 2 & 5000 & 631,64 & 473,41 & 258,14 & 53,62 \\
\hline 1 & 3 & 100 & 0,01 & 0,01 & 0,01 & 0,00 \\
\hline 1 & 3 & 200 & 0,01 & 0,01 & 0,01 & 0,02 \\
\hline 1 & 3 & 500 & 0,04 & 0,03 & 0,03 & 0,04 \\
\hline 1 & 3 & 1000 & 0,27 & 0,22 & 0,17 & 0,11 \\
\hline 1 & 3 & 1500 & 1,50 & 1,25 & 0,72 & 0,31 \\
\hline 1 & 3 & 3000 & 45,96 & 37,28 & 18,20 & 5,35 \\
\hline 1 & 3 & 5000 & 615,52 & 480,75 & 226,41 & 61,27 \\
\hline
\end{tabular}

O tempo de execução do Algoritmo $\mathrm{GH}$ aumenta com o número de rotas. $\mathrm{O}$ crescimento é relevante para os problemas com um reposicionamento e com mais de 1500 rotas, passado a necessitar mais de dez minutos para sua conclusão. Não existe diferença significativa ou uma tendência clara entre os dígrafos para um mesmo problema. Porém os tempos decrescem significativamente com o aumento do desbalanceamento do problema. Isso ocorre devido ao número de ciclos viáveis gerados para esses problemas serem menores.

A Figura 4-8 a seguir mostra um gráfico do tempo de execução do Algoritmo GH em função do número de ciclos do problema. Foi ajustada uma curva de tendência exponencial e seu $R^{2}$ foi de $87,14 \%$. 
Tabela 4-15: Tempo de execução para problemas com dois reposicionamentos

TEMPO DE EXECUÇÃO (s)

\begin{tabular}{|c|c|c|c|c|c|c|}
\hline \multirow[b]{2}{*}{ REPOS. } & \multirow[b]{2}{*}{ DÍGRAFO } & \multirow[b]{2}{*}{ ROTAS } & \multicolumn{4}{|c|}{ FATOR DESBALANCEAMENTO } \\
\hline & & & $0 \%$ & $25 \%$ & $50 \%$ & $75 \%$ \\
\hline 2 & 1 & 100 & 0,02 & 0,01 & 0,02 & 0,01 \\
\hline 2 & 1 & 200 & 0,08 & 0,07 & 0,07 & 0,07 \\
\hline 2 & 1 & 500 & 3,02 & 2,98 & 2,62 & 1,86 \\
\hline 2 & 1 & 1000 & 41,46 & 39,86 & 34,71 & 25,08 \\
\hline 2 & 1 & 1500 & 198,50 & 190,68 & 164,58 & 111,13 \\
\hline 2 & 1 & 3000 & & & & \\
\hline 2 & 1 & 5000 & & & & \\
\hline 2 & 2 & 100 & 0,01 & 0,01 & 0,01 & 0,01 \\
\hline 2 & 2 & 200 & 0,08 & 0,07 & 0,07 & 0,06 \\
\hline 2 & 2 & 500 & 3,03 & 2,72 & 2,40 & 1,86 \\
\hline 2 & 2 & 1000 & 41,74 & 38,18 & 32,71 & 24,31 \\
\hline 2 & 2 & 1500 & 198,55 & 184,28 & 156,01 & 111,16 \\
\hline 2 & 2 & 3000 & & & & \\
\hline 2 & 2 & 5000 & & & & \\
\hline 2 & 3 & 100 & 0,01 & 0,01 & 0,01 & 0,02 \\
\hline 2 & 3 & 200 & 0,08 & 0,08 & 0,07 & 0,06 \\
\hline 2 & 3 & 500 & 2,83 & 2,67 & 2,30 & 1,72 \\
\hline 2 & 3 & 1000 & 39,90 & 36,51 & 31,57 & 23,05 \\
\hline 2 & 3 & 1500 & 190,01 & 173,39 & 147,54 & 105,38 \\
\hline 2 & 3 & 3000 & & & & \\
\hline 2 & 3 & 5000 & & & & \\
\hline
\end{tabular}

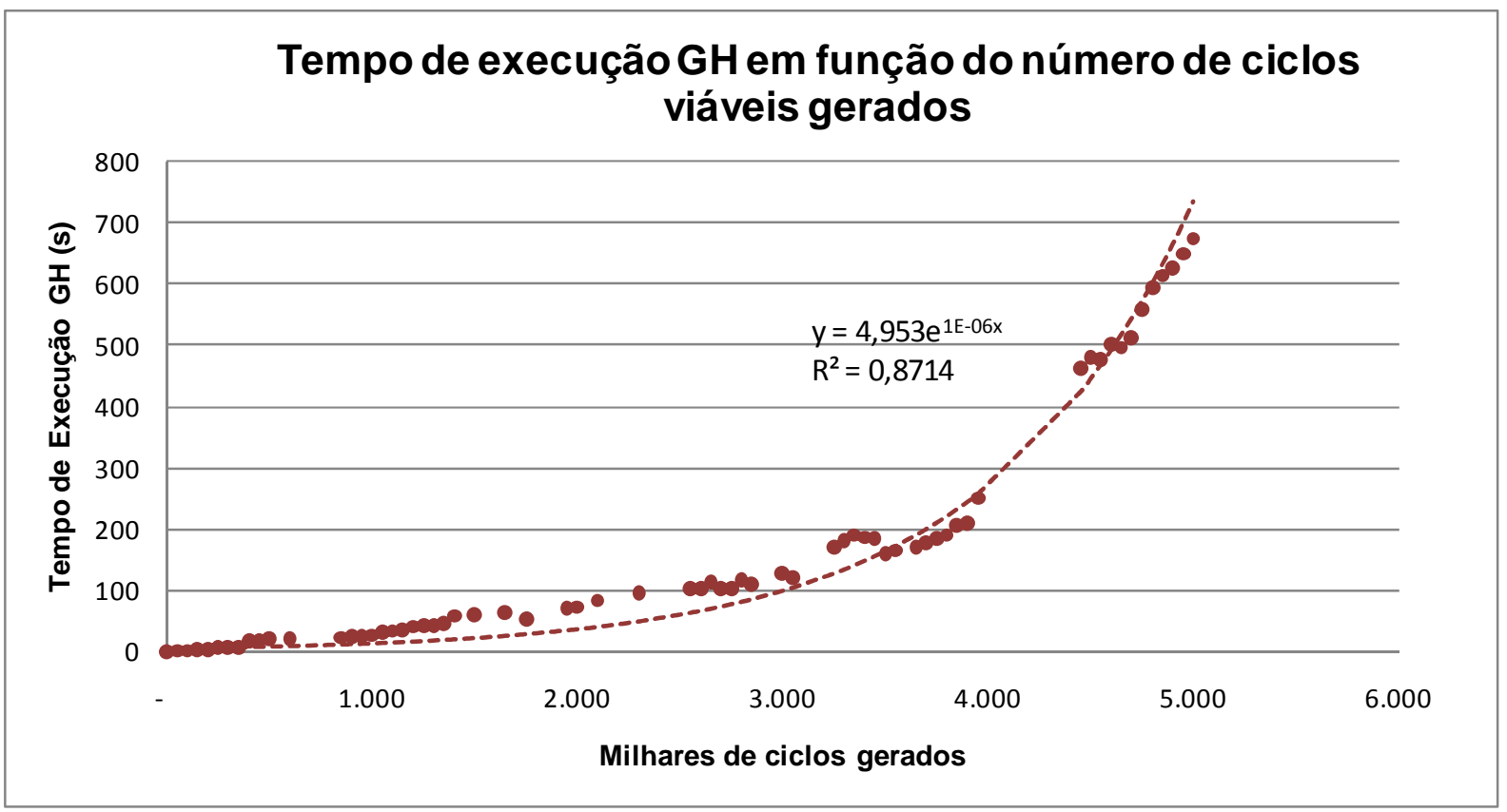

Figura 4-8: Tempo de execução do Algoritmo GH em função do número de ciclos gerados 
A Figura 4-10 e a Figura 4-10 mostram a taxa de crescimento do tempo de execução por fator de desbalanceamento em função do número rotas para os problemas de um e dois reposicionamentos, respectivamente. Utilizou-se o dígrafo 1 como exemplo. É importante ressaltar que a escala da segunda figura é diferente da primeira para facilitar a visualização.

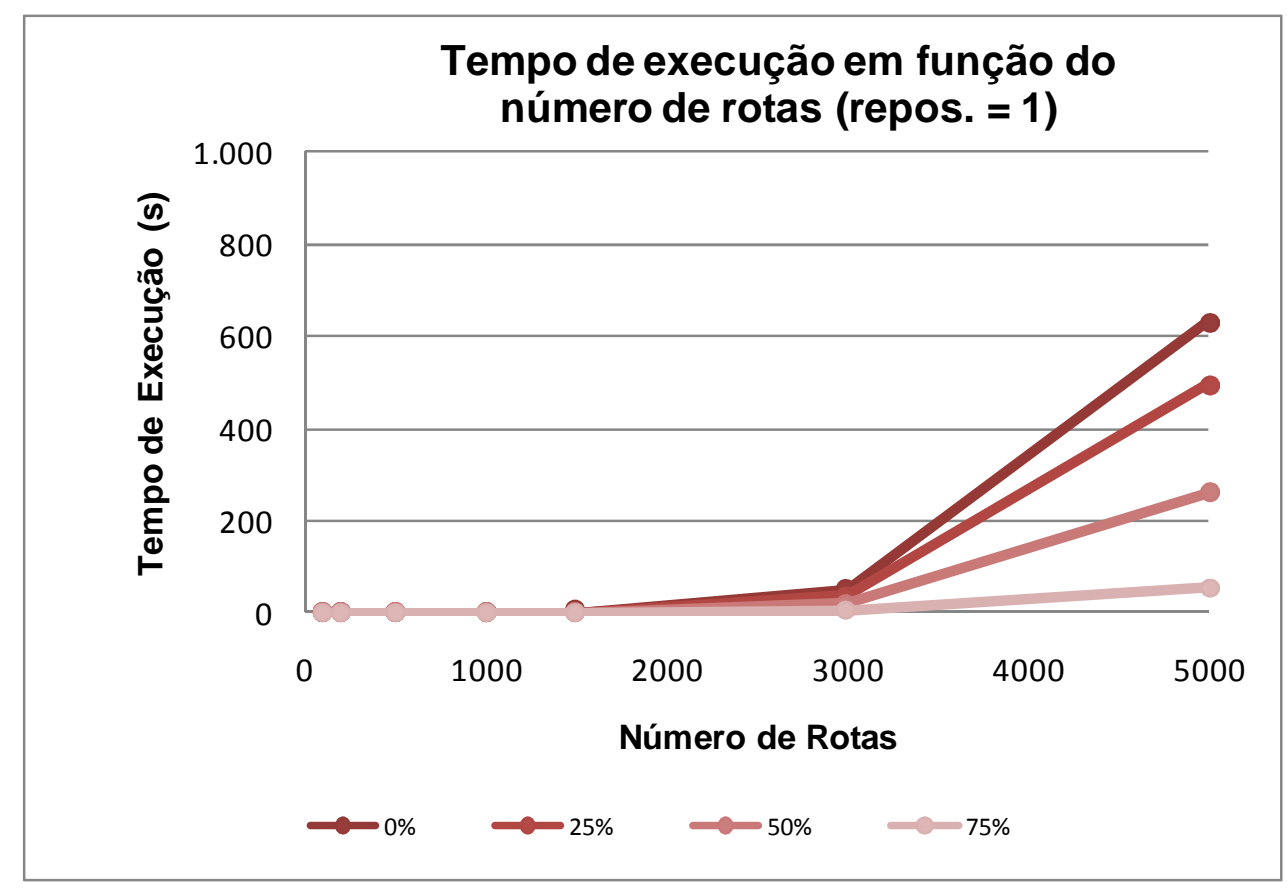

Figura 4-9: Tempos de execução em função do número de rotas para um reposicionamento e para cada fator de desbalanceamento 


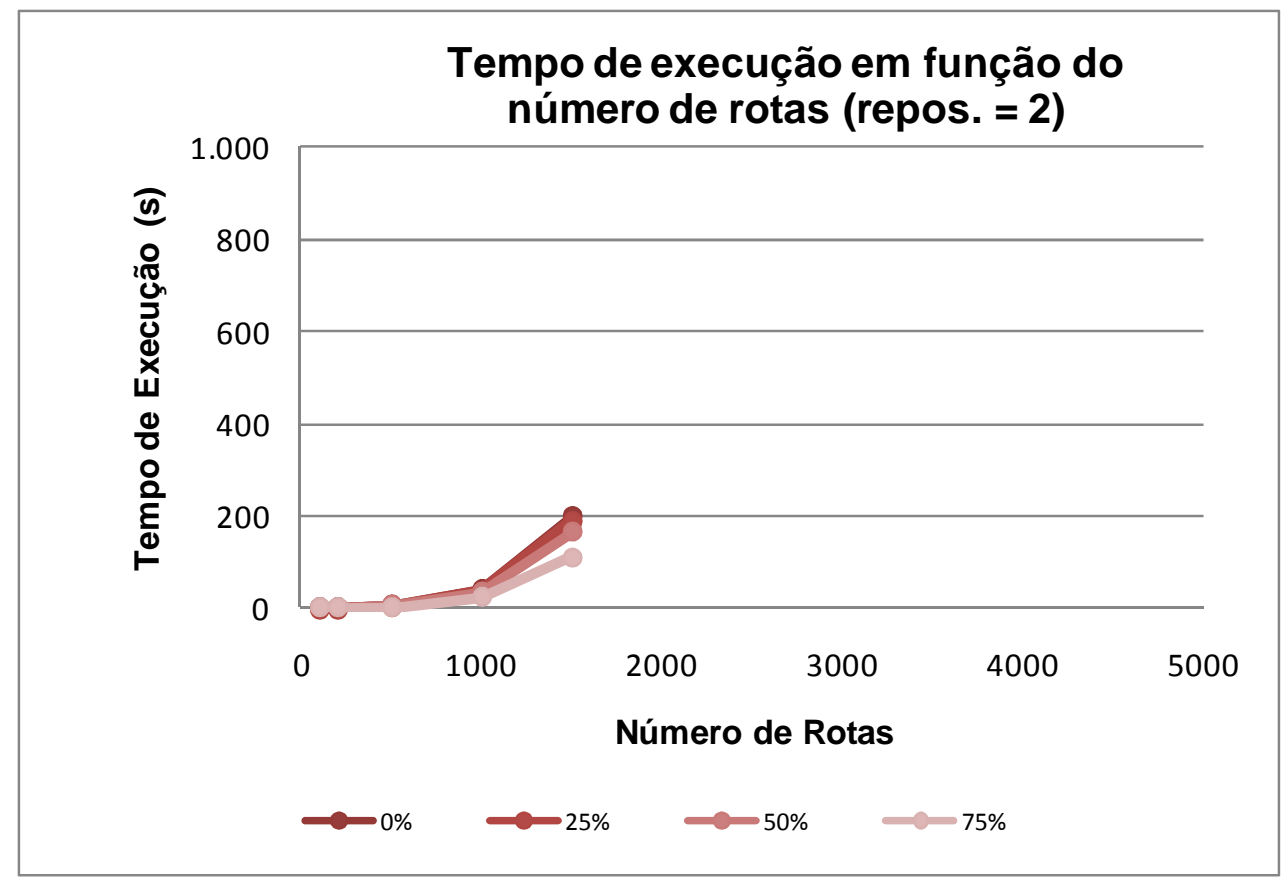

Figura 4-10: Tempos de execução em função do número de rotas para dois reposicionamento e para cada fator de desbalanceamento

Comparando-se os tempos de execução obtidos para os problemas balanceados com os resultados obtidos por (ERGUN et al, 2007b) na Tabela 4-16 observa-se que para os problemas com um único reposicionamento existe uma diferença nos tempos encontrados. Para problemas com 1500 rotas, por exemplo, os autores obtiveram valores aproximadamente instantâneos para a solução, enquanto neste trabalho o valor foi de, aproximadamente, $2 \mathrm{~s}$.

Para os problemas com dois reposicionamentos, essa diferença é mais acentuada. Por exemplo, para o mesmo caso de 1500 rotas, (ERGUN et al, 2007b) obtiveram uma média de 1650s (sempre considerando o tempo de geração de ciclos) enquanto obteve-se uma média de 205s aproximadamente. 
Tabela 4-16: Comparação dos tempos de execução da aplicação de GH com (ERGUN et al, 2007b) para problemas balanceados

\begin{tabular}{|c|c|c|c|c|}
\hline \multirow[b]{2}{*}{ REPOS. } & \multirow[b]{2}{*}{ DÍGRAFO } & \multirow[b]{2}{*}{ ROTAS } & \multicolumn{2}{|c|}{ TEMPO EXECUÇÃO (s) } \\
\hline & & & $\begin{array}{c}\text { (ERGUN et al, } \\
2007 b)\end{array}$ & (FERRI, 2009) \\
\hline 1 & 1 & 100 & 0,00 & 0,00 \\
\hline 1 & 1 & 200 & 0,00 & 0,02 \\
\hline 1 & 1 & 500 & 0,00 & 0,03 \\
\hline 1 & 1 & 1000 & 0,00 & 0,26 \\
\hline 1 & 1 & 1500 & 0,01 & 1,58 \\
\hline 1 & 2 & 100 & 0,00 & 0,01 \\
\hline 1 & 2 & 200 & 0,00 & 0,01 \\
\hline 1 & 2 & 500 & 0,00 & 0,04 \\
\hline 1 & 2 & 1000 & 0,00 & 0,28 \\
\hline 1 & 2 & 1500 & 0,02 & 1,57 \\
\hline 1 & 3 & 100 & 0,00 & 0,01 \\
\hline 1 & 3 & 200 & 0,00 & 0,01 \\
\hline 1 & 3 & 500 & 0,00 & 0,04 \\
\hline 1 & 3 & 1000 & 0,00 & 0,27 \\
\hline 1 & 3 & 1500 & 0,03 & 1,50 \\
\hline 2 & 1 & 100 & 0,00 & 0,02 \\
\hline 2 & 1 & 200 & 0,02 & 0,08 \\
\hline 2 & 1 & 500 & 0,44 & 3,02 \\
\hline 2 & 1 & 1000 & 4,22 & 41,46 \\
\hline 2 & 1 & 1500 & 15,72 & 198,50 \\
\hline 2 & 2 & 100 & 0,00 & 0,01 \\
\hline 2 & 2 & 200 & 0,03 & 0,08 \\
\hline 2 & 2 & 500 & 0,44 & 3,03 \\
\hline 2 & 2 & 1000 & 4,44 & 41,74 \\
\hline 2 & 2 & 1500 & 16,98 & 198,55 \\
\hline 2 & 3 & 100 & 0,00 & 0,01 \\
\hline 2 & 3 & 200 & 0,02 & 0,08 \\
\hline 2 & 3 & 500 & 0,36 & 2,83 \\
\hline 2 & 3 & 1000 & 3,63 & 39,90 \\
\hline 2 & 3 & 1500 & 14,75 & 190,01 \\
\hline
\end{tabular}




\subsection{Aplicação da Heurística CD}

A Heurística CD possui cinco parâmetros de entrada (sendo dois deles opcionais) que podem ser configurados para fazer com que o algoritmo responda de formas diferentes. Esses parâmetros possuem a flexibilidade de regular o trade-off entre melhores resultados ou melhores tempos de execução. Normalmente, para obter resultados melhores, é necessário um tempo de execução maior.

A seguir, realizou-se a calibração destes parâmetros obtendo bons resultados de modo que o tempo de execução não fosse prejudicado, mantendo, assim, valores de tempo semelhantes aos outros métodos.

\subsubsection{Calibração da Heurística CD para um reposicionamento}

Os cinco parâmetros da Heurística CD, que foram apresentados no capítulo anterior, são:

- $\quad p_{\min }$ que é a menor proporção $p$ que um ciclo deve possuir para não ser destruído.

- $\quad p_{\text {incr }}$ que é o quanto a proporção $p_{\min }$ deve ser incrementada após todas as rotas serem inspecionadas.

- $\quad j_{\max }$ que é o número máximo de ciclos que são construídos em paralelo.

- $I_{\min }$ que é a proporção mínima de rotas que devem ser alocadas em ciclos antes de $p_{\min }$ ser incrementado.

- $p_{\text {mult }}$ que é o multiplicador que será aplicado a $p_{\text {incr, }}$ caso a proporção mínima de rotas $I_{\min }$ não seja atingida.

Os dois últimos parâmetros são opcionais e são utilizados para reduzir o tempo de execução da heurística CD.

A calibração foi feita utilizando-se um conjunto de problemas diferentes dos que foram utilizados como problema de teste (conforme explicado em 4.3), porém 
que possuem as mesmas características. Também foram utilizadas cinco instâncias para um mesmo problema.

Para a calibração, o conjunto de problemas foi executado várias vezes alterando-se, a cada vez, um parâmetro da heurística de modo a identificar a tendência de cada um deles. Não foi possível fazer uma busca exaustiva, já que todos os parâmetros aceitam números reais não negativos.

Dado isso, verificou-se que, o comportamento dos parâmetros ocorre de maneira distinta para os problemas com um ou dois reposicionamentos. Além disso, o parâmetro $j_{\max }$ é o único que influencia problemas de dígrafos diferentes. Em função disso, esses problemas foram estudados separadamente.

A Tabela 4-17 a seguir, é um exemplo dos resultados gerados para o dígrafo 1 com um reposicionamento permitido. Para cada conjunto de parâmetros, gerou-se a soma de todos os resultados dos problemas e a soma dos tempos de execução. A última coluna da tabela possui a diferença entre o valor obtido por aqueles parâmetros em relação ao conjunto de parâmetros que possui melhor resultado.

O objetivo é que se selecione um conjunto de parâmetros que possuíssem um valor de resultado baixo (comparado com os demais da calibração), porém que possuísse um tempo não muito elevado. 
Tabela 4-17: Resultados da calibração para os problemas com um reposicionamento

\begin{tabular}{|c|c|c|c|c|c|c|c|}
\hline$j_{\max }$ & $p_{\min }$ & $p_{\text {incr }}$ & $p_{\text {mult }}$ & $I_{\min }$ & RESULTADO (\#) & TEMPO (s) & DIF (\%) \\
\hline 2 & 6 & 2 & 3 & 6 & 10.852 .614 & 117,08 & $0,85 \%$ \\
\hline 25 & 6 & 2 & 3 & 6 & 10.815 .366 & 360,29 & $0,51 \%$ \\
\hline 25 & 5 & 10 & 2 & 6 & 10.807 .174 & 160,02 & $0,43 \%$ \\
\hline 30 & 1 & 10 & 2 & 10 & 10.804 .834 & 309,16 & $0,41 \%$ \\
\hline 30 & 5 & 10 & 3 & 10 & 10.809 .014 & 133,13 & $0,45 \%$ \\
\hline 60 & 5 & 10 & 5 & 10 & 10.792 .364 & 172,45 & $0,29 \%$ \\
\hline 50 & 5 & 10 & 4 & 10 & 10.792 .364 & 172,42 & $0,29 \%$ \\
\hline 50 & 5 & 10 & 5 & 10 & 10.793 .587 & 159,36 & $0,30 \%$ \\
\hline 50 & 5 & 10 & 3 & 10 & 10.785 .220 & 197,59 & $0,23 \%$ \\
\hline 50 & 5 & 10 & 1 & 10 & 10.782 .020 & 417,10 & $0,20 \%$ \\
\hline 50 & 5 & 10 & 2 & 20 & 10.779 .956 & 246,76 & $0,18 \%$ \\
\hline 50 & 3 & 10 & 3 & 20 & 10.784 .480 & 233,58 & $0,22 \%$ \\
\hline 1000 & 5 & 10 & 3 & 20 & 10.760 .937 & $1.578,55$ & $0,00 \%$ \\
\hline 150 & 5 & 10 & 3 & 20 & 10.762 .694 & 481,32 & $0,02 \%$ \\
\hline 100 & 5 & 10 & 3 & 20 & 10.765 .276 & 335,91 & $0,04 \%$ \\
\hline 75 & 5 & 10 & 3 & 20 & 10.770 .468 & 259,60 & $0,09 \%$ \\
\hline 50 & 5 & 10 & 3 & 20 & 10.783 .366 & 187,66 & $0,21 \%$ \\
\hline 75 & 5 & 10 & 3 & 30 & 10.769 .901 & 258,15 & $0,08 \%$ \\
\hline 75 & 5 & 10 & 2 & 40 & 10.770 .805 & 339,02 & $0,09 \%$ \\
\hline 75 & 5 & 10 & 2 & 50 & 10.769 .193 & 335,70 & $0,08 \%$ \\
\hline 75 & 5 & 15 & 2 & 50 & 10.770 .598 & 249,93 & $0,09 \%$ \\
\hline 75 & 5 & 15 & 3 & 50 & 10.779 .507 & 194,56 & $0,17 \%$ \\
\hline 75 & 5 & 20 & 2 & 40 & 10.775 .028 & 211,14 & $0,13 \%$ \\
\hline 80 & 5 & 25 & 2 & 50 & 10.772 .080 & 192,32 & $0,10 \%$ \\
\hline 100 & 5 & 30 & 2 & 50 & 10.783 .604 & 211,32 & $0,21 \%$ \\
\hline 90 & 5 & 30 & 2 & 40 & 10.775 .611 & 196,14 & $0,14 \%$ \\
\hline 90 & 5 & 30 & 2 & 60 & 10.774 .634 & 173,88 & $0,13 \%$ \\
\hline 90 & 5 & 30 & 2 & 80 & 10.774 .634 & 173,51 & $0,13 \%$ \\
\hline 90 & 5 & 40 & 2 & 60 & 10.786 .588 & 148,71 & $0,24 \%$ \\
\hline 80 & 5 & 30 & 2 & 60 & 10.781 .792 & 157,01 & $0,19 \%$ \\
\hline 100 & 5 & 30 & 2 & 60 & 10.778 .160 & 191,25 & $0,16 \%$ \\
\hline 85 & 5 & 30 & 2 & 60 & 10.775 .988 & 168,38 & $0,14 \%$ \\
\hline 85 & 5 & 25 & 2 & 60 & 10.770 .614 & 187,98 & $0,09 \%$ \\
\hline 85 & 5 & 25 & 2 & 80 & 10.770 .614 & 187,45 & $0,09 \%$ \\
\hline 85 & 5 & 26 & 2 & 80 & 10.769 .628 & 184,58 & $0,08 \%$ \\
\hline 85 & 5 & 27 & 2 & 80 & 10.772 .051 & 182,08 & $0,10 \%$ \\
\hline 85 & 5 & 28 & 2 & 80 & 10.768 .809 & 179,33 & $0,07 \%$ \\
\hline 85 & 5 & 29 & 2 & 80 & 10.768 .817 & 176,33 & $0,07 \%$ \\
\hline 85 & 5 & 30 & 2 & 80 & 10.775 .988 & 164,35 & $0,14 \%$ \\
\hline 57 & 5 & 29 & 2 & 80 & 10.777 .194 & 157,93 & $0,15 \%$ \\
\hline
\end{tabular}


A partir desse teste, chegara-se às seguintes conclusões:

- Quanto maior o valor de $j_{\max }$, melhor será o resultado. Como essa variável apresenta comportamento diferente por dígrafo, foi feita uma análise adicional a seguir.

- Quanto menor o valor de $p_{\min }$, melhor será o resultado, porém um valor muito baixo gera um tempo de processamento muito elevado.

- Quanto menor o valor de $p_{i n c r}$, melhor será o resultado, porém, da mesma forma que $p_{\min }$, ao se selecionar um valor muito baixo de $p_{i n c r} 0$ tempo de processamento será muito elevado.

- Quanto maior o valor de $p_{\text {mult, }}$ mais rápido é o tempo de execução, porém o resultado é prejudicado. Para valores baixos, a redução do tempo é significativa (observou-se de $20 \%$ a $50 \%$ de redução no tempo) sem alterar o resultado significativamente.

- Quanto maior o valor de $I_{\min }$, mais rápido é o tempo de execução. Notou-se que este parâmetro não afeta significativamente o resultado.

A fim de deixar mais claro o comportamento do parâmetro $p_{\text {mult, }}$ foram geradas a Figura 4-11, a Figura 4-12 e a Figura 4-13 que são os gráficos do número de rotas utilizadas em função do tempo para $p_{\text {mul }}$ com os valores de 1,2 e 3 , respectivamente. Foi utilizado como base para este exemplo um problema do dígrafo 1 com um reposicionamento permitido e 1500 rotas.

Nota-se que, para o caso de $p_{\text {mult }}=1$ (que faz com que este parâmetro não tenha efeito sobre a solução), o número de rotas utilizadas nos primeiros segundos de execução é alto porém ele decresce a valores muito baixos ficando neste patamar até quase o final da execução. Isso ocorre devido á característica construtivo-destrutiva da heurística, uma vez que as melhores rotas são alocadas no início do processo. Conclui-se que é mais difícil gerar um ciclo com fator $p$ bom o suficiente para que o ciclo não seja destruído. Ao final da execução, são permitidos valores de $\mathrm{p}$ mais elevado de modo que as últimas rotas são consumidas mais rapidamente. 


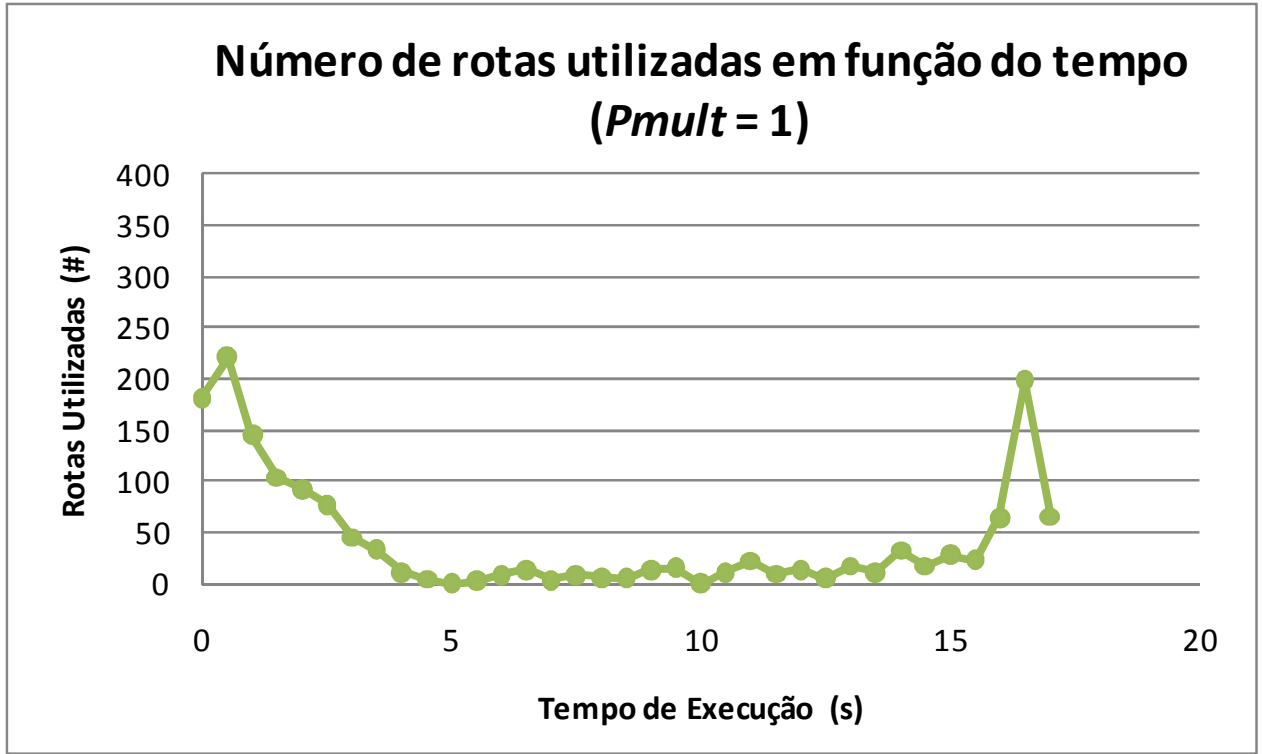

Figura 4-11: Número de rotas utilizadas em função do tempo para $p_{\text {mult }}=1$

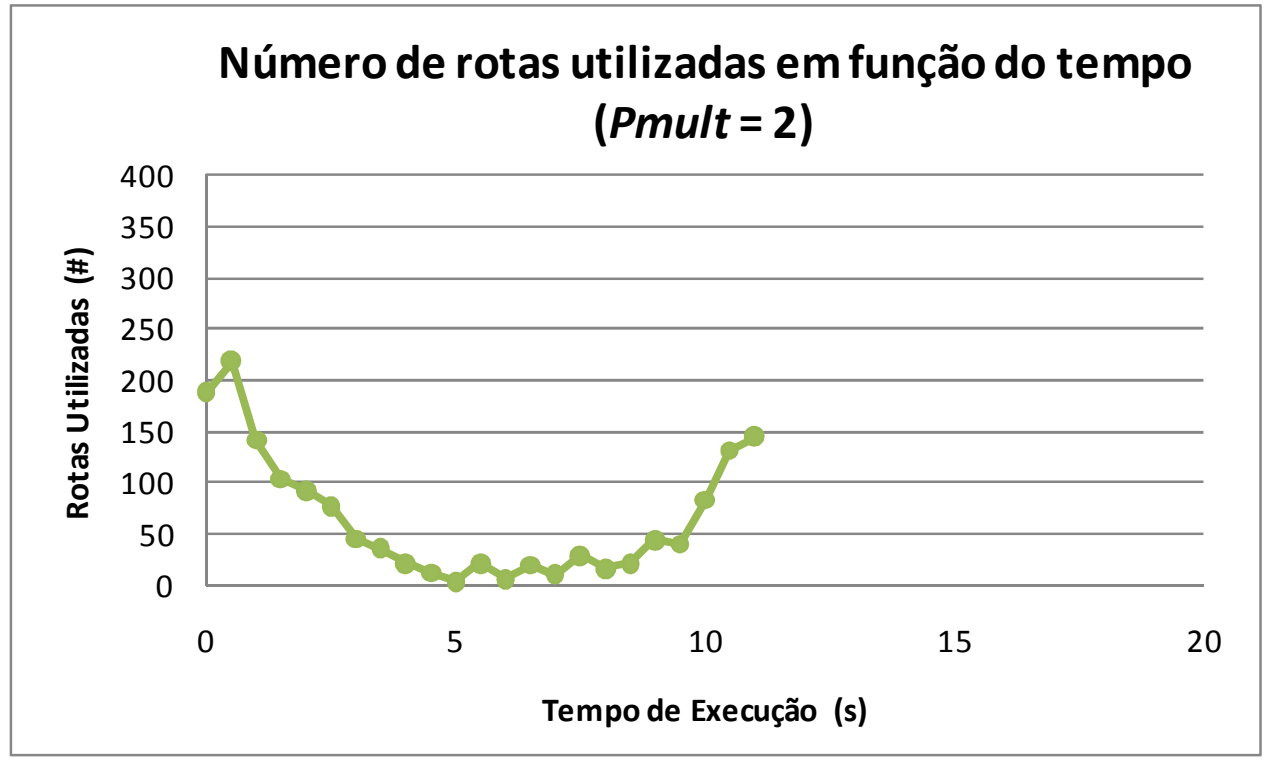

Figura 4-12: Número de rotas utilizadas em função do tempo para $p_{\text {mult }}=2$ 


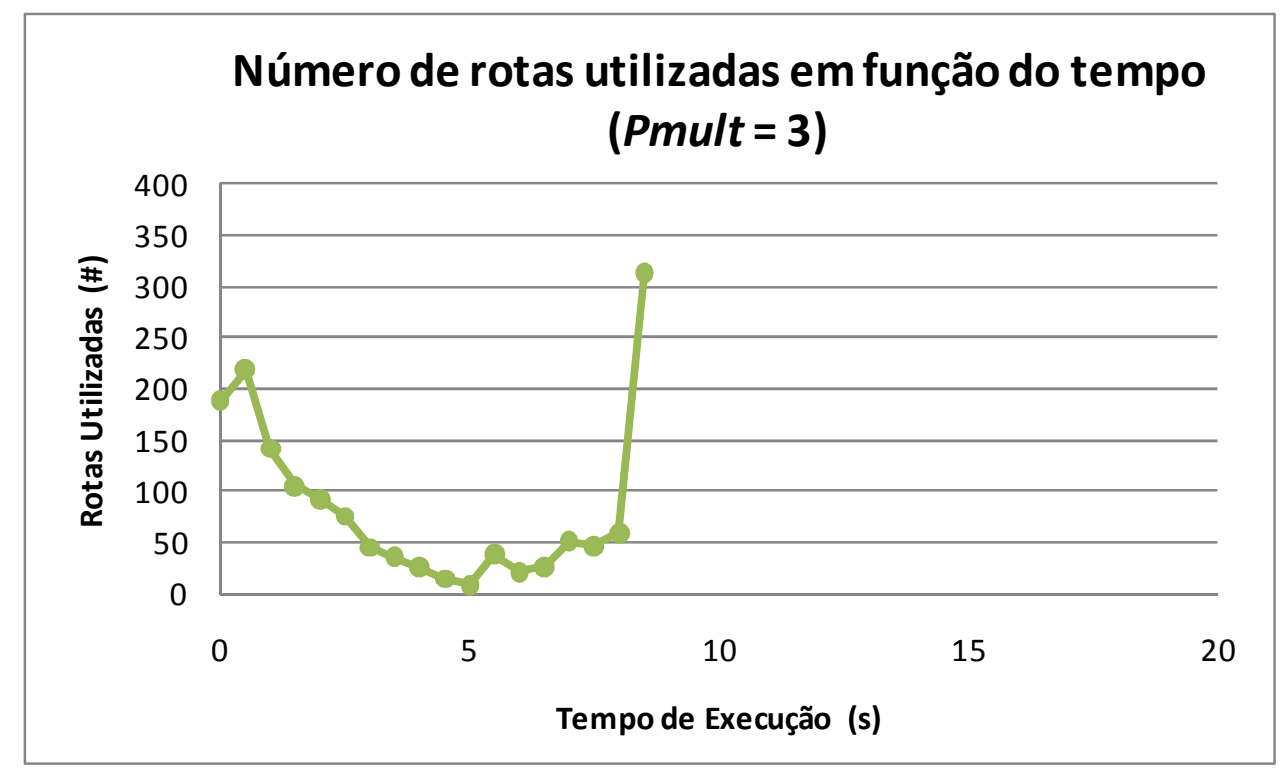

Figura 4-13: Número de rotas utilizadas em função do tempo para $p_{\text {mult }}=3$

Com a utilização de $p_{\text {mult }}$ mais elevado, nota-se que a característica da utilização das rotas no tempo se mantém, porém seu tempo de execução cai para $35 \%$ e $50 \%$ respectivamente. Este mesmo comportamento é observado em todos os problemas sendo, assim, característico da Heurística CD.

A partir dessas informações, escolheu-se a configuração que possui o quinto melhor resultado da Tabela 4-17, pois a diferença do valor total é de apenas 0,07\%, mas seu tempo é $89 \%$ menor. Dado isso, os parâmetros selecionados para os problemas com um reposicionamento são:

- $p_{\min }=5$

- $p_{\text {incr }}=29$

- $p_{\text {mult }}=2$

- $I_{\min }=80$

O parâmetro $j_{\max }$ foi estudado mais detalhadamente para cada dígrafo. Fixando-se os parâmetros já selecionados anteriormente, alterou-se $j_{\max }$ de 0 a 200 e foram gerados gráficos dos resultados obtidos. Dado o número de combinações de gráficos, foram selecionados os do problema de 1500 rotas (um para cada dígrafo), pois possuem o mesmo padrão dos demais, porém visualmente possuem 
características mais evidentes. Os demais gráficos estão disponíveis no Anexo A. Os problemas menores (100 e 200 rotas) apresentam resultados constantes para valores de $j_{\max }$ pequenos (maiores que 5, aproximadamente). A Figura 4-14, a Figura 4-15 e a Figura 4-16 estão representadas a seguir:

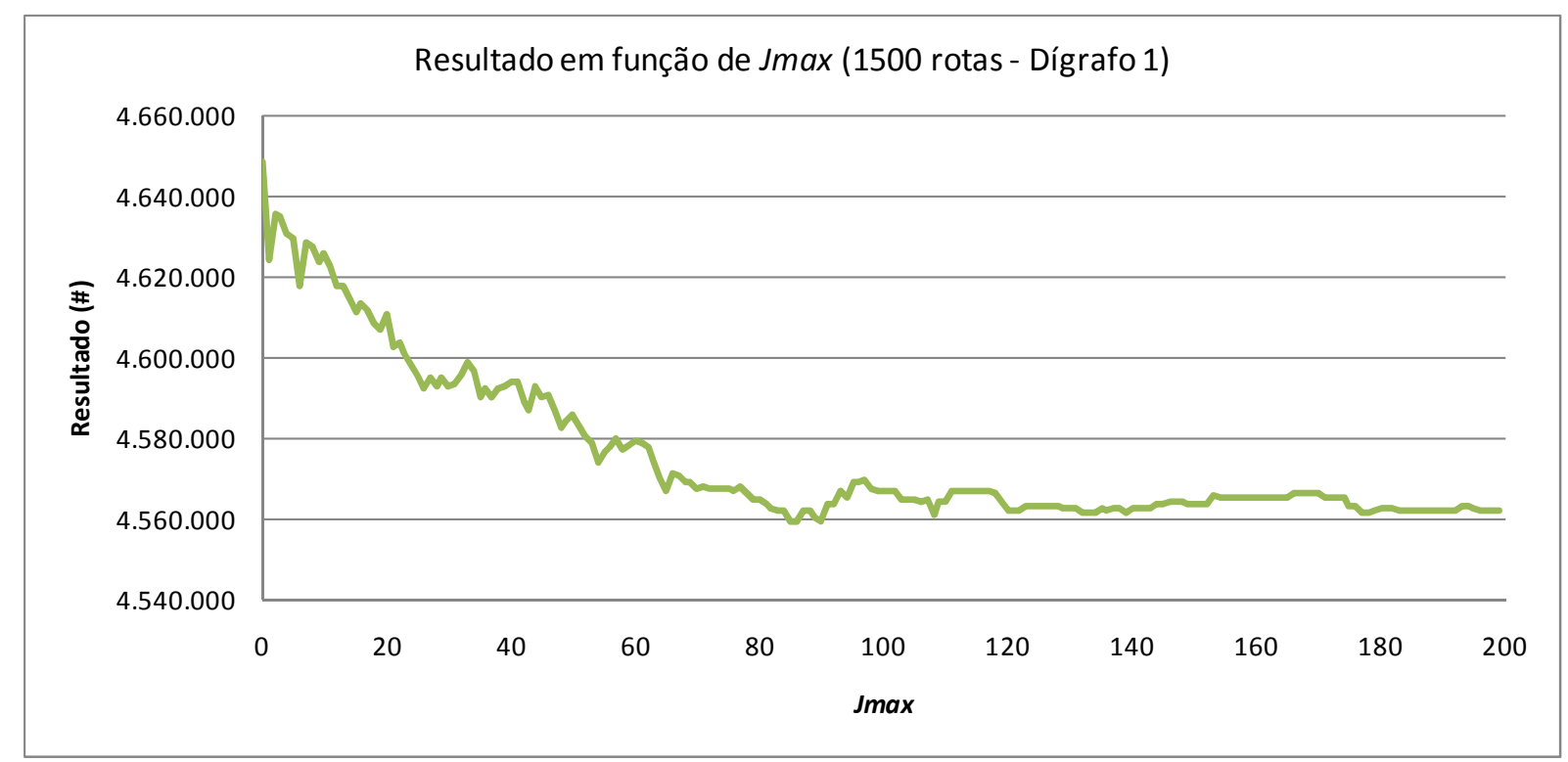

Figura 4-14: Resultado em função de $j_{\max }$ para problema de 1500 rotas e dígrafo 1

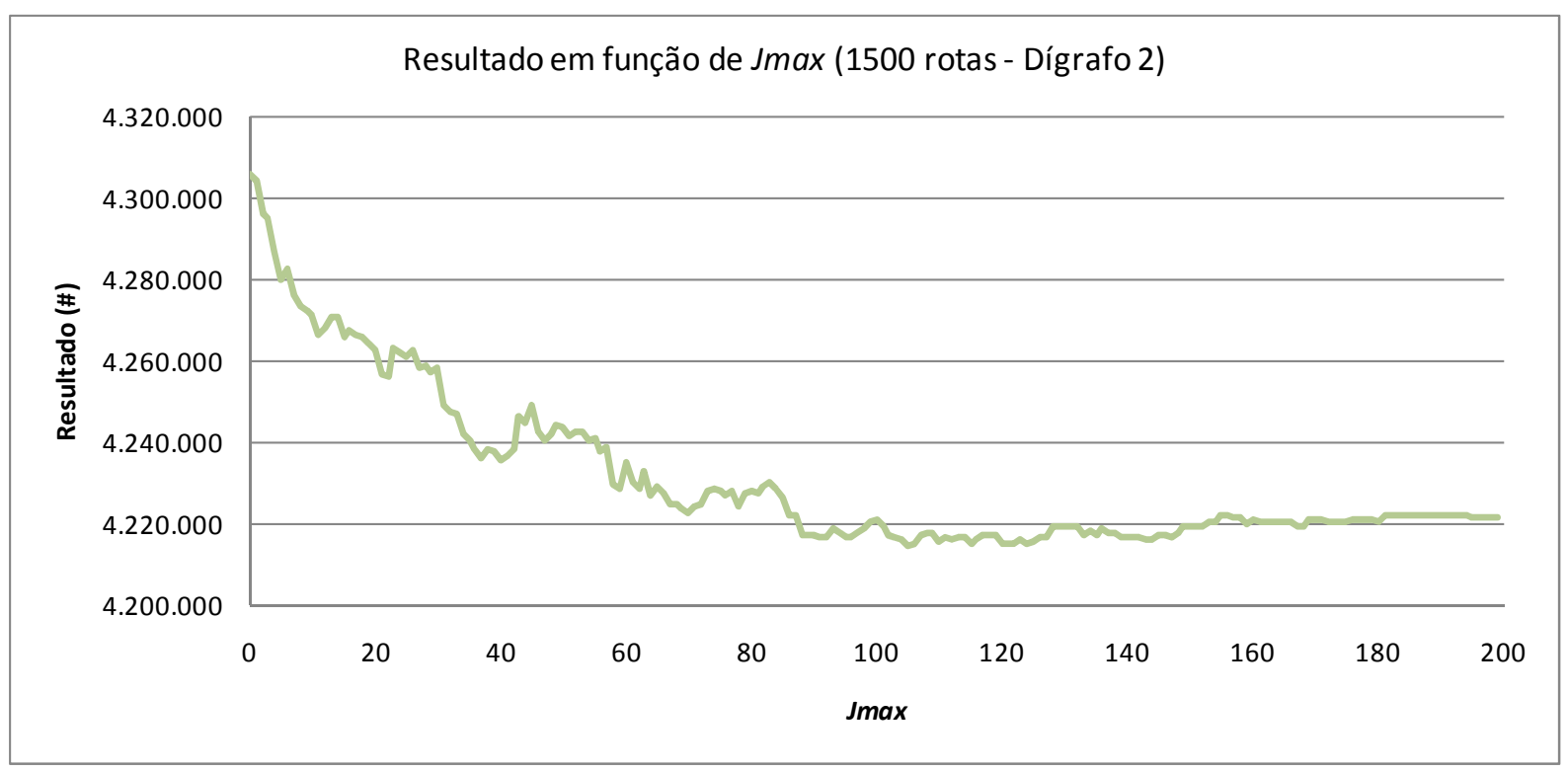

Figura 4-15: Resultado em função de jmax para problema de 1500 rotas e dígrafo 2 


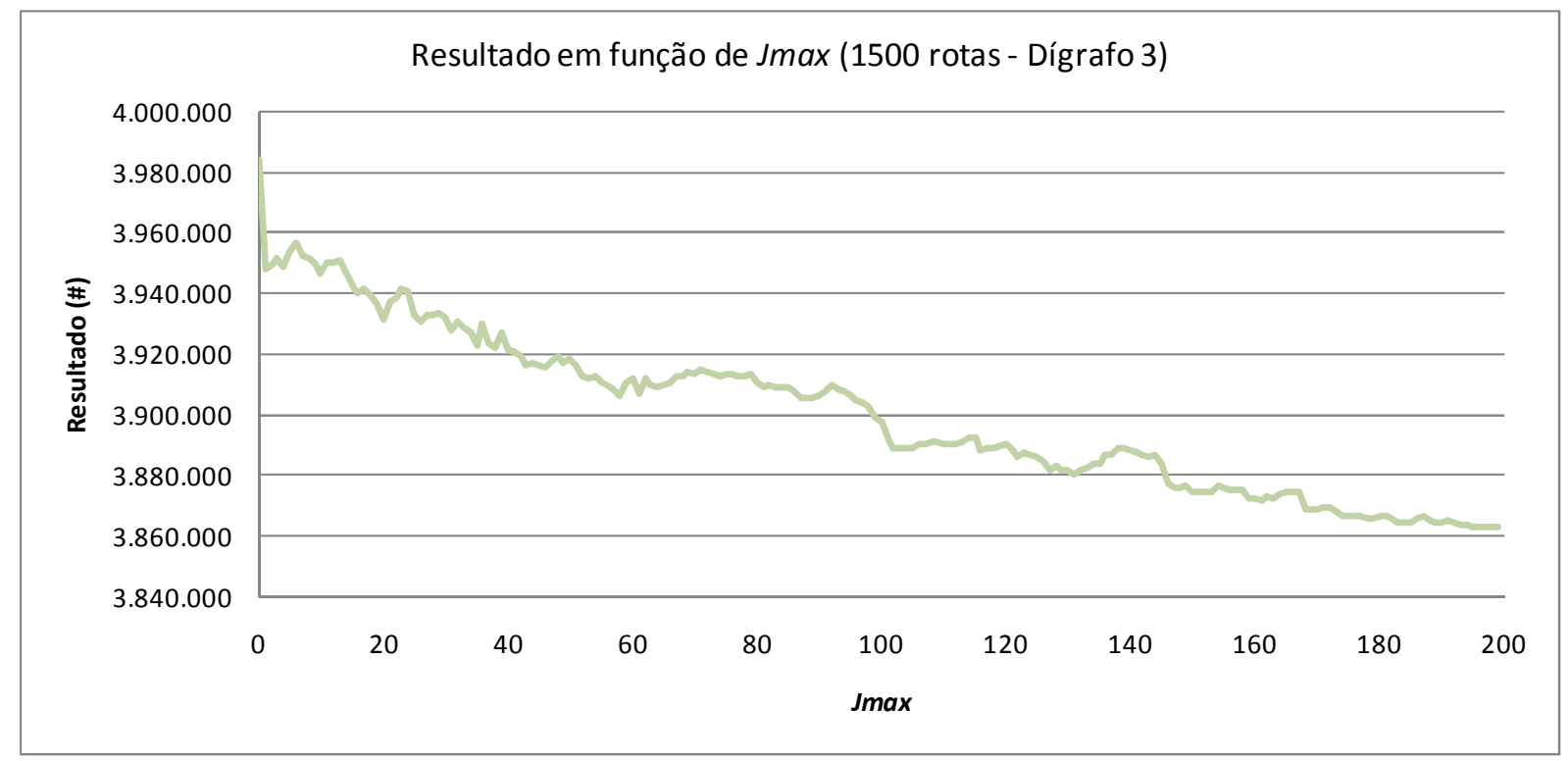

Figura 4-16: Resultado em função de $j_{\max }$ para problema de 1500 rotas e dígrafo 3

Notas-se que para o dígrafo 1, o resultado melhora proporcionalmente com o aumento de $j_{\max }$ até atingir um patamar aproximadamente constante a partir de $j_{\max }=90$, aproximadamente. O mesmo ocorre para o dígrafo 2 , porém o resultado atinge o patamar para $j_{\max }=110$, aproximadamente. $O$ problema do dígrafo 3 não apresentou patamar constante para esta faixa de $j_{\max }$ analisada.

O tempo de execução apresentado na Figura 4-17 mostra que o tempo de execução é linear em função de $j_{\max }$.

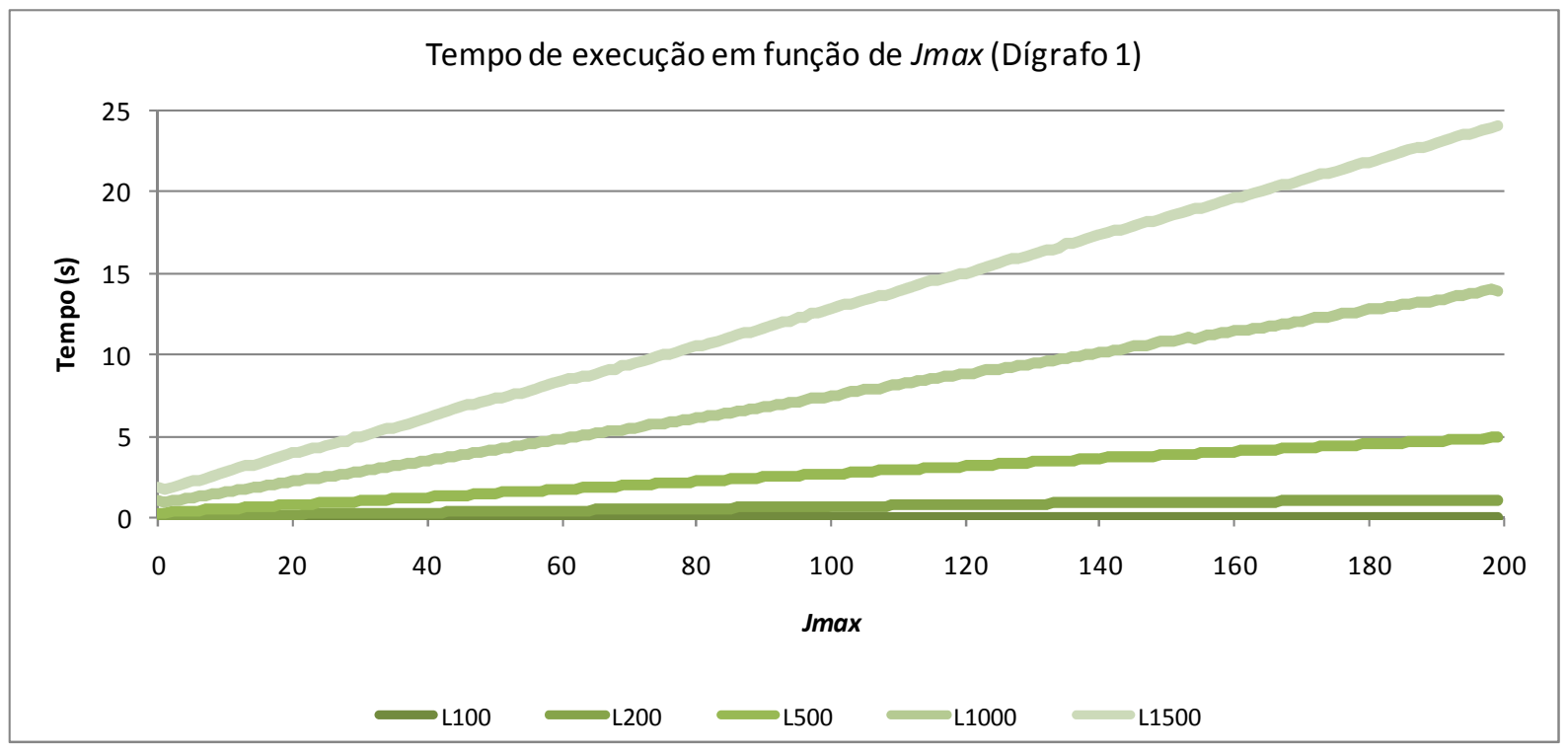

Figura 4-17: Tempo de execução em função de $j_{\max }$ para os problemas do dígrafo 1 
Dado isso, a Tabela 4-18 abaixo apresenta o valor do parâmetro $j_{\max }$ selecionado para cada tipo de rota e por dígrafo para os problemas de um reposicionamento. Para problemas com 100 e 200 rotas, foram selecionados valores diferentes, pois seus comportamentos são aproximadamente constantes para $j_{\max }$ maiores.

Tabela 4-18: $j_{\max }$ por número de rotas por dígrafo

\begin{tabular}{cccc} 
& \multicolumn{3}{c}{$\boldsymbol{j}_{\max }$} \\
\cline { 3 - 5 } ROTAS & D1 & D2 & D3 \\
\cline { 1 - 4 } 100 & 2 & 70 & 30 \\
200 & 5 & 105 & 15 \\
500 & 86 & 105 & 183 \\
1000 & 86 & 105 & 183 \\
1500 & 86 & 105 & 183 \\
3000 & 86 & 105 & 183 \\
5000 & 86 & 105 & 183 \\
\hline
\end{tabular}

\subsubsection{Calibração da Heurística CD para dois reposicionamentos}

O mesmo processo foi feito para os problemas com dois reposicionamentos.

Gerou-se a Tabela 4-19 com um exemplo dos resultados obtidos pela calibração semelhante à apresentada em 4.7.1.

Nota-se que as mesmas conclusões obtidas na calibração dos problemas com um reposicionamento são válidas. Além disso, verificou-se que, para uma mesma configuração da Heurística CD, os tempos de execução foram menores. Esse comportamento já era esperado uma vez que o reposicionamento adicional facilita a construção de ciclos que também pode ser observado pelo número de ciclos viáveis gerados em 4.3 que é muito superior do que para problemas com apenas um reposicionamento. 
Tabela 4-19: Resultados da calibração para os problemas com dois reposicionamentos

\begin{tabular}{|c|c|c|c|c|c|c|c|}
\hline$j_{\max }$ & $p_{\min }$ & $\boldsymbol{p}_{\text {incr }}$ & $p_{\text {mult }}$ & $I_{\min }$ & RESULTADO (\#) & TEMPO (s) & DIF (\%) \\
\hline 10 & 5 & 40 & 1 & 10 & 8.774 .226 & 11,53 & $0,54 \%$ \\
\hline 85 & 5 & 40 & 1 & 10 & 8.745 .959 & 55,31 & $0,21 \%$ \\
\hline 85 & 1 & 10 & 1 & 10 & 8.731 .484 & 143,40 & $0,05 \%$ \\
\hline 85 & 1 & 20 & 1 & 10 & 8.731 .484 & 144,75 & $0,05 \%$ \\
\hline 85 & 1 & 5 & 1 & 10 & 8.728 .774 & 453,96 & $0,01 \%$ \\
\hline 85 & 1 & 21 & 1 & 80 & 8.730 .867 & 139,43 & $0,04 \%$ \\
\hline 85 & 1 & 23 & 1 & 80 & 8.732 .325 & 131,07 & $0,06 \%$ \\
\hline 85 & 1 & 25 & 1 & 80 & 8.731 .883 & 124,26 & $0,05 \%$ \\
\hline 85 & 1 & 27 & 1 & 80 & 8.731 .705 & 118,35 & $0,05 \%$ \\
\hline 85 & 1 & 29 & 1 & 80 & 8.732 .031 & 112,46 & $0,05 \%$ \\
\hline 85 & 1 & 31 & 1 & 80 & 8.732 .566 & 106,88 & $0,06 \%$ \\
\hline 85 & 1 & 33 & 1 & 80 & 8.732 .833 & 103,15 & $0,06 \%$ \\
\hline 85 & 1 & 35 & 1 & 80 & 8.734 .928 & 99,59 & $0,09 \%$ \\
\hline 85 & 1 & 37 & 1 & 80 & 8.735 .787 & 96,11 & $0,09 \%$ \\
\hline 85 & 1 & 39 & 1 & 80 & 8.734 .026 & 92,68 & $0,07 \%$ \\
\hline 85 & 1 & 27 & 2 & 10 & 8.733 .187 & 86,09 & $0,07 \%$ \\
\hline 85 & 1 & 27 & 2 & 30 & 8.737 .486 & 82,68 & $0,11 \%$ \\
\hline 85 & 1 & 27 & 2 & 50 & 8.736 .516 & 82,42 & $0,10 \%$ \\
\hline 85 & 1 & 27 & 2 & 70 & 8.737 .217 & 82,42 & $0,11 \%$ \\
\hline 85 & 1 & 32 & 2 & 10 & 8.735 .451 & 80,57 & $0,09 \%$ \\
\hline 85 & 1 & 32 & 2 & 9 & 8.735 .795 & 81,65 & $0,10 \%$ \\
\hline 85 & 1 & 32 & 2 & 8 & 8.736 .243 & 83,31 & $0,10 \%$ \\
\hline 85 & 1 & 32 & 2 & 7 & 8.735 .213 & 84,76 & $0,09 \%$ \\
\hline 85 & 1 & 32 & 2 & 6 & 8.734 .805 & 86,79 & $0,08 \%$ \\
\hline 85 & 1 & 32 & 2 & 5 & 8.733 .975 & 89,82 & $0,07 \%$ \\
\hline 85 & 1 & 32 & 2 & 4 & 8.734 .079 & 92,00 & $0,08 \%$ \\
\hline 85 & 1 & 32 & 2 & 3 & 8.732 .383 & 96,94 & $0,06 \%$ \\
\hline 85 & 1 & 32 & 2 & 2 & 8.733.332 & 99,20 & $0,07 \%$ \\
\hline 85 & 1 & 32 & 2 & 1 & 8.733 .405 & 100,70 & $0,07 \%$ \\
\hline 43 & 1 & 32 & 2 & 3 & 8.729 .844 & 52,08 & $0,03 \%$ \\
\hline 43 & 1 & 25 & 2 & 3 & 8.730 .657 & 57,88 & $0,04 \%$ \\
\hline 43 & 1 & 10 & 2 & 3 & 8.728 .260 & 94,77 & $0,01 \%$ \\
\hline 43 & 1 & 11 & 2 & 3 & 8.730 .911 & 89,29 & $0,04 \%$ \\
\hline 43 & 1 & 12 & 2 & 3 & 8.730 .125 & 84,48 & $0,03 \%$ \\
\hline 43 & 1 & 13 & 2 & 3 & 8.729 .772 & 80,88 & $0,03 \%$ \\
\hline 43 & 1 & 9 & 2 & 3 & 8.728 .554 & 100,03 & $0,01 \%$ \\
\hline 43 & 1 & 8 & 2 & 3 & 8.727 .502 & 108,15 & $0,00 \%$ \\
\hline 43 & 1 & 7 & 2 & 3 & 8.727.962 & 117,41 & $0,01 \%$ \\
\hline 43 & 1 & 6 & 2 & 3 & 8.729.198 & 131,70 & $0,02 \%$ \\
\hline
\end{tabular}


Dado isso, foi escolhida a melhor configuração da Tabela 4-19, já que seu tempo possui ordem de grandeza semelhante à configuração de um reposicionamento.

- $\quad p_{\min }=1$

- $p_{\text {incr }}=8$

- $p_{\text {mult }}=2$

- $I_{\min }=3$

Da mesma forma que os problemas com um reposicionamento, o parâmetro $j_{\max }$ foi estudado separadamente para cada dígrafo. Fixando-se os parâmetros já selecionados anteriormente, alterou-se $j_{\max }$ de 0 a 200 e foram geradas gráficos do resultado obtido em função de $j_{\max }$. Dado o número de combinações de gráficos gerados foram selecionados os gráficos do problema de 1500 rotas (um para cada dígrafo), pois possuem o mesmo padrão dos demais, porém são graficamente mais evidentes. Os demais gráficos estão disponíveis no Anexo B. A Figura 4-18, a Figura 4-19 e a Figura 4-20 estão representadas a seguir:

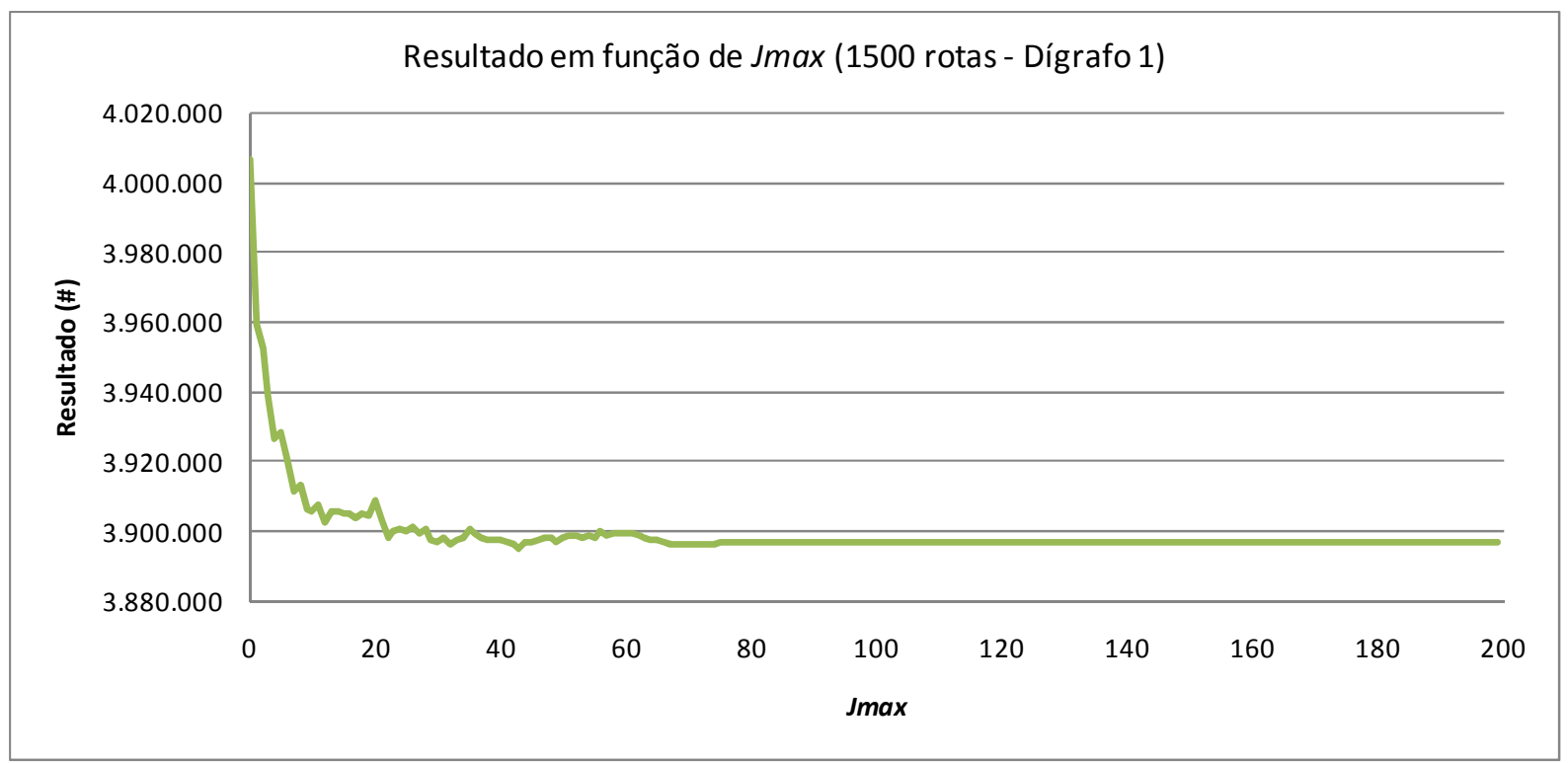

Figura 4-18: Resultado em função de $j_{\max }$ para problema de 1500 rotas e dígrafo 1 


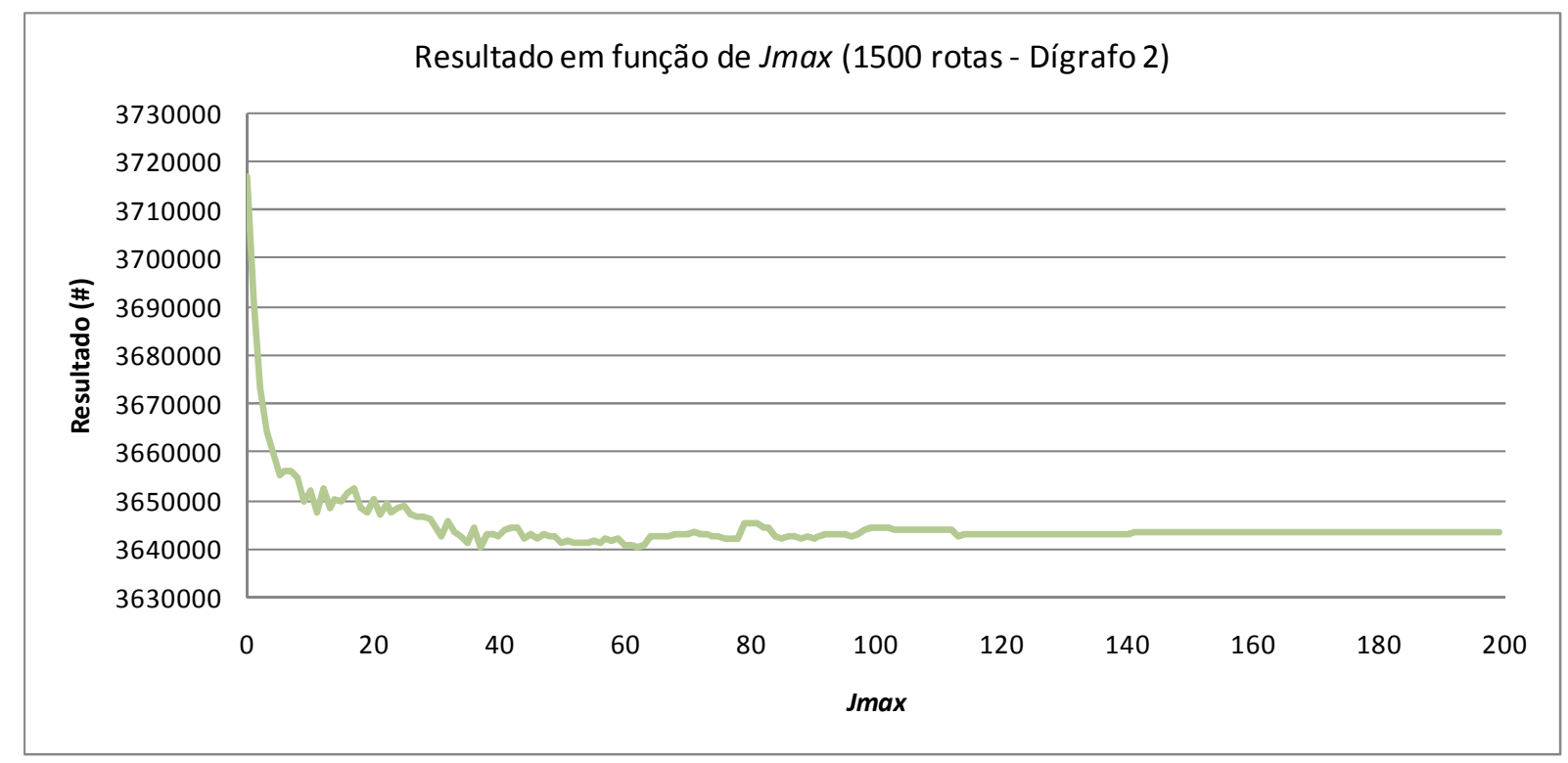

Figura 4-19: Resultado em função de $j_{\max }$ para problema de 1500 rotas e dígrafo 2

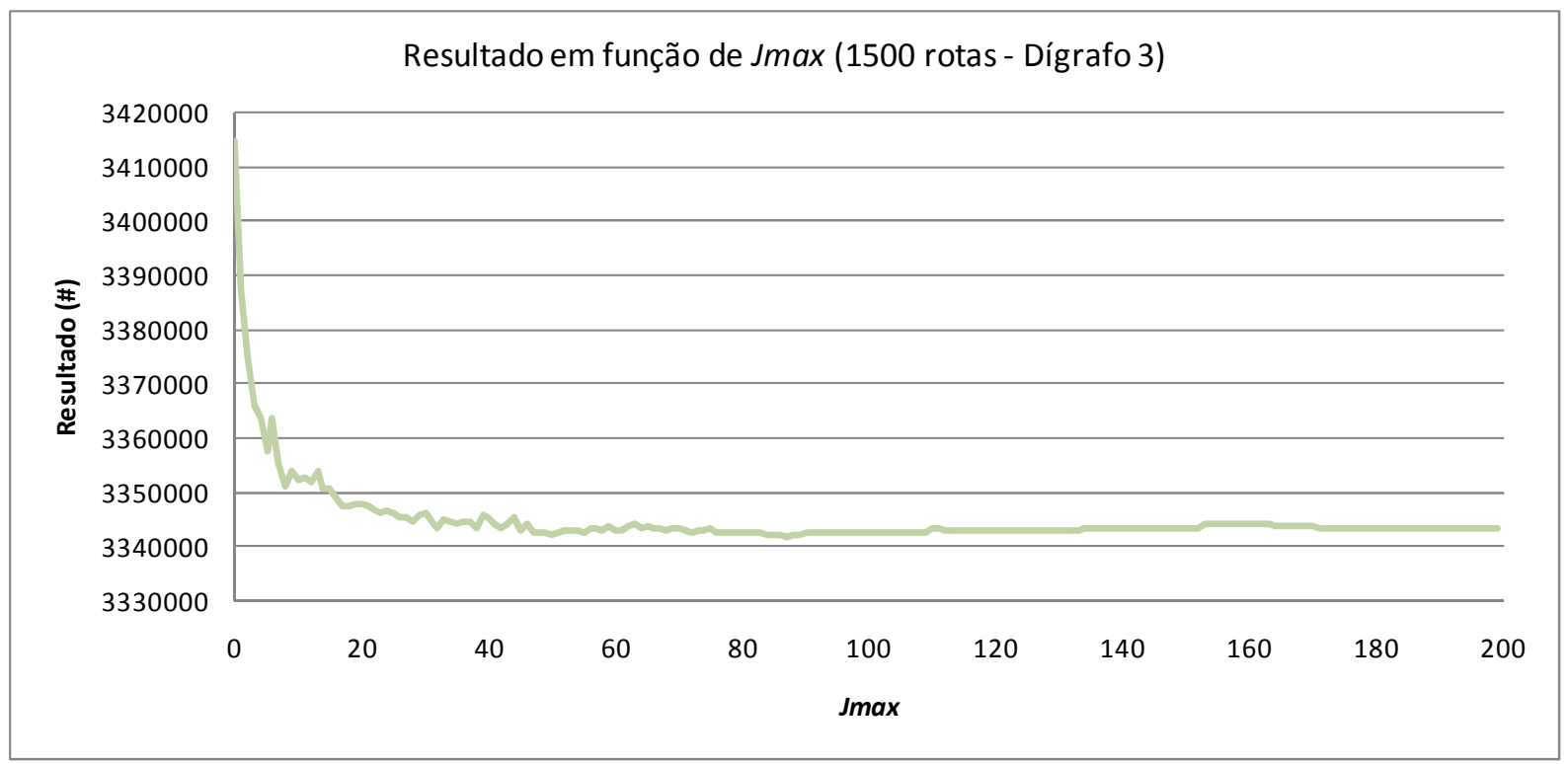

Figura 4-20: Resultado em função de $j_{\max }$ para problema de 1500 rotas e dígrafo 3

Notas-se que para o dígrafo 1, o resultado melhora proporcionalmente com o aumento de $j_{\max }$ até atingir um patamar aproximadamente constante a partir de $j_{\max }=50$, aproximadamente. 0 mesmo ocorre para o dígrafo 2 , porém o resultado atinge o patamar para $j_{\max }=65$, aproximadamente. Enquanto que o dígrafo 3 atingiu patamar em $j_{\max }=90$, aproximadamente. Comparando-se com os resultados obtidos 
para os problemas com um reposicionamento, nota-se que o comportamento é muito semelhante, porém os patamares são atingidos para valores de $j_{\max }$ menores.

O tempo de execução apresentado na Figura 4-21 mostra que o tempo de execução decresce para $j_{\max }$ menor que 5 e cresce linearmente a partir deste ponto.

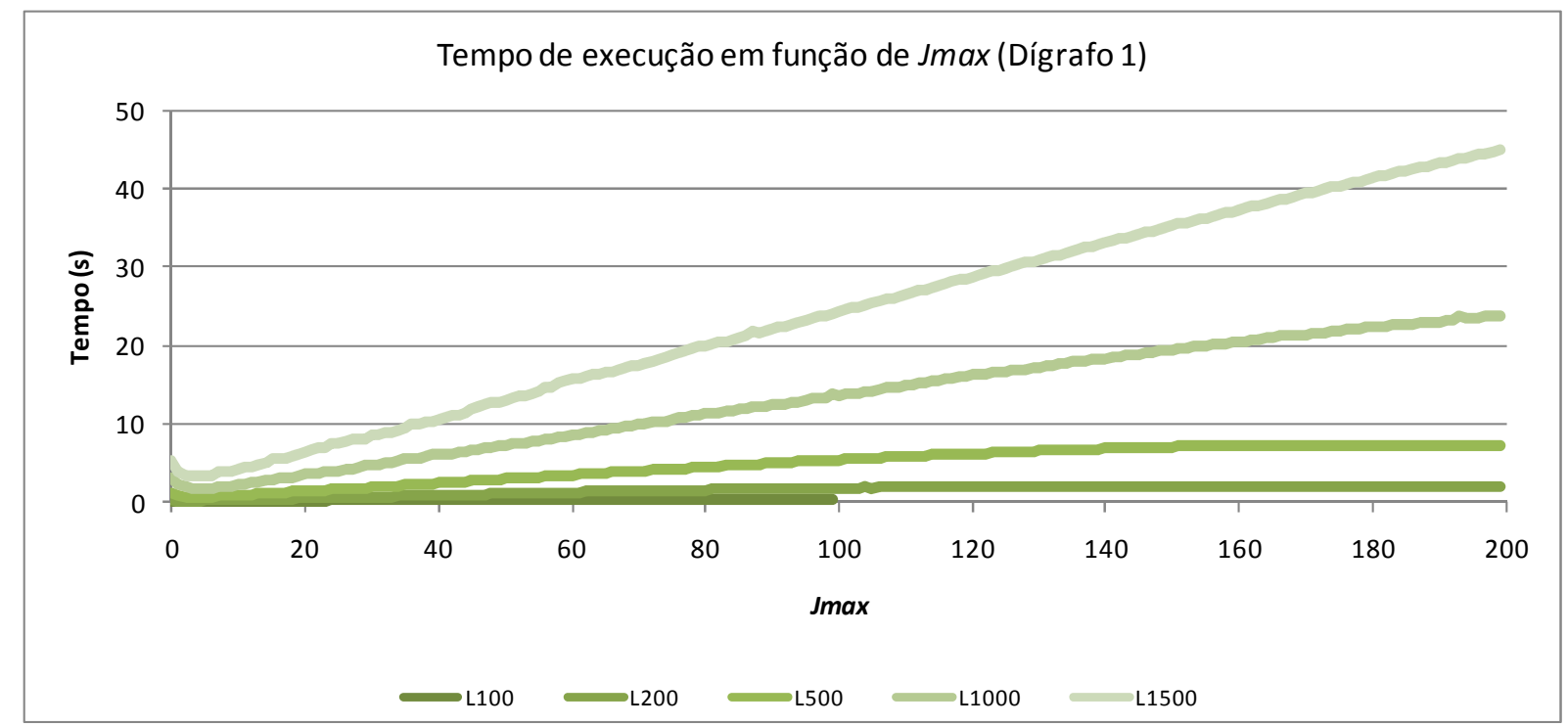

Figura 4-21: Tempo de execução em função de $j_{\max }$ para os problemas do dígrafo 1

A partir disso, a Tabela 4-20 a seguir mostra o valor do parâmetro $j_{\max }$ selecionado para cada tipo de rota e por dígrafo para os problemas de um reposicionamento.

Tabela 4-20: $j_{\max }$ por número de rotas por dígrafo

\begin{tabular}{cccc} 
& \multicolumn{3}{c}{$\boldsymbol{j}_{\max }$} \\
\cline { 2 - 4 } ROTAS & D1 & D2 & D3 \\
\cline { 3 - 4 } \cline { 3 - 4 } 100 & 15 & 17 & 15 \\
200 & 31 & 25 & 20 \\
500 & 33 & 42 & 68 \\
1000 & 43 & 62 & 87 \\
1500 & 43 & 62 & 87 \\
3000 & 43 & 62 & 87 \\
5000 & 43 & 62 & 87 \\
\hline
\end{tabular}




\subsubsection{Resultados da Heurística CD}

Utilizando-se os parâmetros obtidos na etapa de calibração, foram geradas as soluções para os problemas de teste.

Da mesma forma que os demais, a Heurística CD foi aplicada e os resultados para cada um dos dígrafos gerados para os problemas de 100, 200, 500, 1000, 1500,3000 e 5000 rotas e fator de desbalanceamento de $0 \%, 25 \%, 50 \%$ e $75 \%$ sendo permitido um ou dois reposicionamentos estão mostrados, respectivamente, em Tabela 4-21 e Tabela 4-22. Os valores exibidos são uma média simples das soluções geradas por cada instância.

Tabela 4-21: Solução gerada por CD para problemas com um reposicionamento

SOLUÇÃO GERADA POR CD (\#)

\begin{tabular}{cccrrrr}
\hline & & & \multicolumn{4}{c}{ FATOR DESBALANCEAMENTO } \\
\cline { 5 - 8 } REPOS. DÍGRAFO & ROTAS & \multicolumn{1}{c}{$\mathbf{0} \%$} & \multicolumn{2}{c}{$\mathbf{2 5 \%}$} & \multicolumn{1}{c}{$\mathbf{5 0 \%}$} & \multicolumn{1}{c}{$\mathbf{7 5 \%}$} \\
\hline 1 & 1 & 100 & 96.976 & 96.139 & 98.594 & 96.057 \\
1 & 1 & 200 & 171.135 & 173.540 & 176.742 & 184.049 \\
1 & 1 & 500 & 357.333 & 355.400 & 404.515 & 455.818 \\
1 & 1 & 1000 & 683.449 & 672.437 & 776.287 & 823.002 \\
1 & 1 & 1500 & 910.723 & 1.020 .103 & 1.077 .020 & 1.275 .628 \\
1 & 1 & 3000 & 1.761 .072 & 1.924 .528 & 2.057 .832 & 2.506 .030 \\
1 & 1 & 5000 & 2.938 .458 & 3.109 .944 & 3.391 .172 & 4.345 .638 \\
\hline 1 & 2 & 100 & 94.315 & 84.612 & 102.303 & 103.195 \\
1 & 2 & 200 & 158.972 & 157.600 & 166.352 & 184.799 \\
1 & 2 & 500 & 326.172 & 338.635 & 353.727 & 436.253 \\
1 & 2 & 1000 & 600.711 & 639.654 & 698.512 & 842.069 \\
1 & 2 & 1500 & 872.138 & 881.849 & 1.113 .654 & 1.205 .966 \\
1 & 2 & 3000 & 1.792 .328 & 1.772 .440 & 1.980 .246 & 2.509 .830 \\
1 & 2 & 5000 & 2.659 .818 & 2.987 .054 & 3.367 .586 & 4.025 .824 \\
\hline 1 & 3 & 100 & 81.019 & 71.822 & 73.421 & 91.428 \\
1 & 3 & 200 & 150.836 & 148.643 & 138.083 & 158.606 \\
1 & 3 & 500 & 331.576 & 301.201 & 332.587 & 379.822 \\
1 & 3 & 1000 & 534.086 & 601.420 & 654.554 & 761.762 \\
1 & 3 & 1500 & 818.112 & 856.504 & 912.387 & 1.117 .491 \\
1 & 3 & 3000 & 1.439 .456 & 1.444 .106 & 1.803 .258 & 2.268 .764 \\
1 & 3 & 5000 & 2.672 .684 & 2.604 .074 & 3.493 .006 & 3.937 .014 \\
\hline
\end{tabular}


Tabela 4-22: Solução gerada por CD para problemas com dois reposicionamentos

SOLUÇÃO GERADA POR CD (\#)

\begin{tabular}{|c|c|c|c|c|c|c|}
\hline \multirow[b]{2}{*}{ REPOS. } & \multirow[b]{2}{*}{ DÍGRAFO } & \multirow[b]{2}{*}{ ROTAS } & \multicolumn{4}{|c|}{ FATOR DESBALANCEAMENTO } \\
\hline & & & $0 \%$ & $25 \%$ & $50 \%$ & $75 \%$ \\
\hline 2 & 1 & 100 & 61.049 & 60.357 & 67.050 & 70.320 \\
\hline 2 & 1 & 200 & 115.929 & 127.528 & 129.810 & 141.458 \\
\hline 2 & 1 & 500 & 261.924 & 275.951 & 317.141 & 347.852 \\
\hline 2 & 1 & 1000 & 542.133 & 528.163 & 619.504 & 733.787 \\
\hline 2 & 1 & 1500 & 833.767 & 825.635 & 937.306 & 1.065 .695 \\
\hline 2 & 1 & 3000 & 1.543 .930 & 1.511 .850 & 1.989 .400 & 2.175 .520 \\
\hline 2 & 1 & 5000 & 2.565 .374 & 2.543 .600 & 3.300 .980 & 3.679 .480 \\
\hline 2 & 2 & 100 & 56.989 & 60.849 & 61.287 & 73.674 \\
\hline 2 & 2 & 200 & 101.914 & 104.901 & 126.689 & 138.869 \\
\hline 2 & 2 & 500 & 256.715 & 260.807 & 317.011 & 358.323 \\
\hline 2 & 2 & 1000 & 477.748 & 584.446 & 642.064 & 724.602 \\
\hline 2 & 2 & 1500 & 757.932 & 845.185 & 958.296 & 1.165 .808 \\
\hline 2 & 2 & 3000 & 1.481 .806 & 1.621 .550 & 1.582 .770 & 1.852 .990 \\
\hline 2 & 2 & 5000 & 2.479 .096 & 2.706 .700 & 2.618 .980 & 3.100 .400 \\
\hline 2 & 3 & 100 & 53.132 & 45.769 & 54.810 & 61.413 \\
\hline 2 & 3 & 200 & 98.914 & 92.064 & 116.326 & 139.491 \\
\hline 2 & 3 & 500 & 252.037 & 231.582 & 297.822 & 320.059 \\
\hline 2 & 3 & 1000 & 489.070 & 529.058 & 647.415 & 723.068 \\
\hline 2 & 3 & 1500 & 622.082 & 798.918 & 880.113 & 1.094 .504 \\
\hline 2 & 3 & 3000 & 1.484 .356 & 1.197 .000 & 1.421 .480 & 1.641 .170 \\
\hline 2 & 3 & 5000 & 2.500 .852 & 2.023 .570 & 2.361 .800 & 2.776 .630 \\
\hline
\end{tabular}

Tabela 4-23: Tempo de execução para problemas com um reposicionamento

Nota-se que tanto os problemas com um reposicionamento permitido quanto para aqueles com dois reposicionamentos foram executados sem nenhum tipo de restrição, diferentemente de PLI e GH.

A Tabela 4-24 e a Tabela 4-25 a seguir mostram os tempos de execução da Heurística CD para os problemas com um e dois reposicionamento, respectivamente. Como a heurística independe da geração de todos os ciclos viáveis do problema, o tempo de geração desses não deve ser somado ao tempo de execução. Da mesma forma que os demais métodos, também foi feita uma média dos tempos das instâncias. 
Tabela 4-24: Tempo de execução para problemas com um reposicionamento

TEMPO DE EXECUÇÃO (s)

\begin{tabular}{|c|c|c|c|c|c|c|}
\hline \multirow[b]{2}{*}{ REPOS. } & \multirow[b]{2}{*}{ DÍGRAFO } & \multirow[b]{2}{*}{ ROTAS } & \multicolumn{4}{|c|}{ FATOR DESBALANCEAMENTO } \\
\hline & & & $0 \%$ & $25 \%$ & $50 \%$ & $75 \%$ \\
\hline 1 & 1 & 100 & 0,03 & 0,03 & 0,03 & 0,03 \\
\hline 1 & 1 & 200 & 0,11 & 0,12 & 0,12 & 0,14 \\
\hline 1 & 1 & 500 & 2,33 & 2,58 & 3,16 & 4,00 \\
\hline 1 & 1 & 1000 & 6,33 & 8,13 & 11,22 & 15,47 \\
\hline 1 & 1 & 1500 & 11,07 & 14,80 & 22,55 & 33,07 \\
\hline 1 & 1 & 3000 & 29,54 & 44,50 & 80,58 & 124,30 \\
\hline 1 & 1 & 5000 & 58,43 & 102,22 & 198,13 & 330,79 \\
\hline 1 & 2 & 100 & 0,16 & 0,16 & 0,16 & 0,17 \\
\hline 1 & 2 & 200 & 0,72 & 0,76 & 0,78 & 0,85 \\
\hline 1 & 2 & 500 & 2,58 & 3,06 & 3,76 & 4,76 \\
\hline 1 & 2 & 1000 & 6,74 & 9,42 & 12,72 & 17,82 \\
\hline 1 & 2 & 1500 & 12,15 & 18,02 & 27,08 & 40,70 \\
\hline 1 & 2 & 3000 & 30,78 & 57,98 & 102,31 & 160,82 \\
\hline 1 & 2 & 5000 & 68,23 & 119,39 & 244,56 & 409,69 \\
\hline 1 & 3 & 100 & 0,08 & 0,07 & 0,08 & 0,09 \\
\hline 1 & 3 & 200 & 0,16 & 0,19 & 0,18 & 0,21 \\
\hline 1 & 3 & 500 & 4,05 & 5,05 & 6,44 & 8,49 \\
\hline 1 & 3 & 1000 & 10,72 & 16,28 & 23,63 & 31,90 \\
\hline 1 & 3 & 1500 & 19,64 & 31,20 & 46,79 & 64,60 \\
\hline 1 & 3 & 3000 & 48,77 & 84,00 & 164,77 & 248,12 \\
\hline 1 & 3 & 5000 & 101,29 & 195,93 & 441,99 & 664,89 \\
\hline
\end{tabular}

Como esperado e da mesma forma que os demais métodos, o tempo de execução da Heurística CD aumenta com o número de rotas. Porém, diferentemente dos demais, o tempo cresce com o aumento de desbalanceamento e também para os dígrafos mais concentrados. Isso ocorre devido à natureza da heurística que é construtivo-destrutiva. Por exemplo, em um problema mais desbalanceado, o número de combinações possíveis (conforme visto em 4.3) é menor do que em um problema balanceado. Isso faz com que seja mais difícil construir um ciclo e, além disso, torna mais fácil que ele seja destruído fazendo com que o processo seja mais demorado.

Notou-se também que os tempos para os problemas com um e dois reposicionamentos possuem tempos da mesma ordem de grandeza, sendo que os com dois reposicionamentos são maiores em praticamente todos os problemas. 
Tabela 4-25: Tempo de execução para problemas com dois reposicionamentos

TEMPO DE EXECUÇÃO (s)

\begin{tabular}{|c|c|c|c|c|c|c|}
\hline \multirow[b]{2}{*}{ REPOS. } & \multirow[b]{2}{*}{ DÍGRAFO } & \multirow[b]{2}{*}{ ROTAS } & \multicolumn{4}{|c|}{ FATOR DESBALANCEAMENTO } \\
\hline & & & $0 \%$ & $25 \%$ & $50 \%$ & $75 \%$ \\
\hline 2 & 1 & 100 & 0,17 & 0,19 & 0,22 & 0,25 \\
\hline 2 & 1 & 200 & 0,71 & 0,79 & 1,01 & 1,37 \\
\hline 2 & 1 & 500 & 2,17 & 2,45 & 4,56 & 8,12 \\
\hline 2 & 1 & 1000 & 6,30 & 8,73 & 17,73 & 30,50 \\
\hline 2 & 1 & 1500 & 10,35 & 17,34 & 37,94 & 70,82 \\
\hline 2 & 1 & 3000 & 34,66 & 64,71 & 137,19 & 263,22 \\
\hline 2 & 1 & 5000 & 70,47 & 176,19 & 392,47 & 739,45 \\
\hline 2 & 2 & 100 & 0,16 & 0,16 & 0,17 & 0,23 \\
\hline 2 & 2 & 200 & 0,47 & 0,66 & 0,80 & 1,28 \\
\hline 2 & 2 & 500 & 2,29 & 3,02 & 5,49 & 8,67 \\
\hline 2 & 2 & 1000 & 8,96 & 9,05 & 19,98 & 33,74 \\
\hline 2 & 2 & 1500 & 14,85 & 18,22 & 43,37 & 77,42 \\
\hline 2 & 2 & 3000 & 41,90 & 47,89 & 200,31 & 334,47 \\
\hline 2 & 2 & 5000 & 95,87 & 133,62 & 536,90 & 921,12 \\
\hline 2 & 3 & 100 & 0,09 & 0,12 & 0,17 & 0,24 \\
\hline 2 & 3 & 200 & 0,30 & 0,52 & 0,82 & 1,18 \\
\hline 2 & 3 & 500 & 2,94 & 3,49 & 5,92 & 9,79 \\
\hline 2 & 3 & 1000 & 10,52 & 11,90 & 22,36 & 36,90 \\
\hline 2 & 3 & 1500 & 22,70 & 25,08 & 51,26 & 81,71 \\
\hline 2 & 3 & 3000 & 63,69 & 95,96 & 238,51 & 352,50 \\
\hline 2 & 3 & 5000 & 144,74 & 264,55 & 639,02 & $1.008,48$ \\
\hline
\end{tabular}

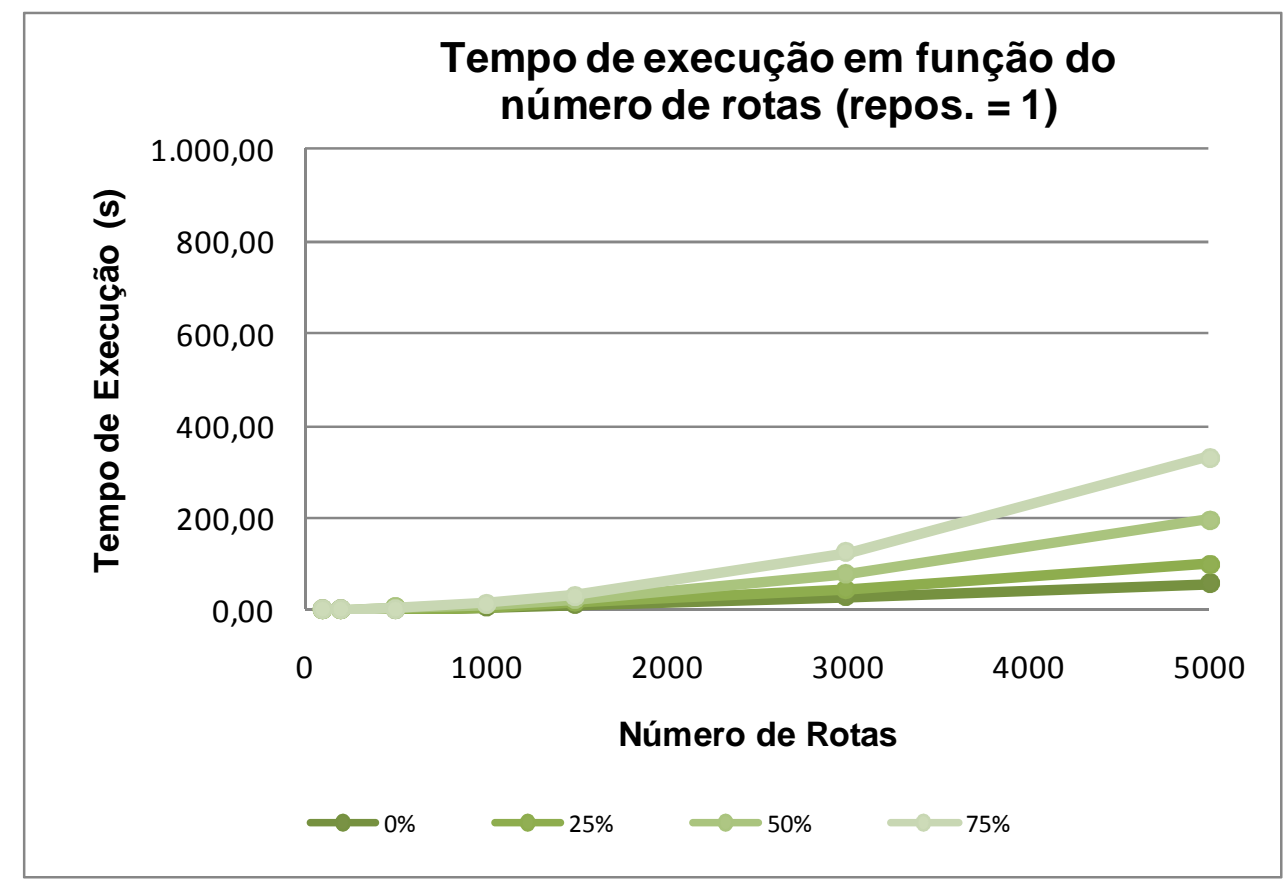

Figura 4-22: Tempos de execução em função do número de rotas para um reposicionamento e para cada fator de desbalanceamento 


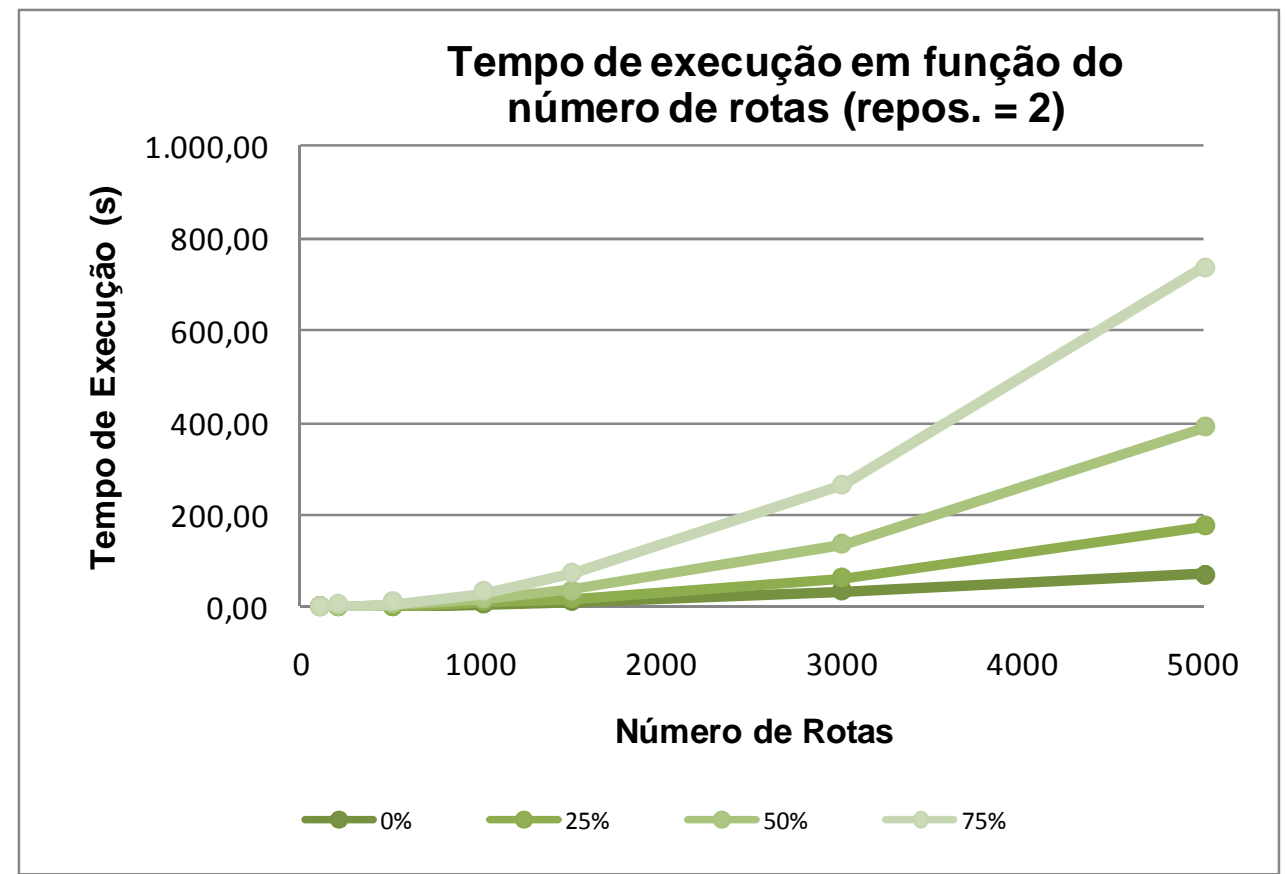

Figura 4-23: Tempos de execução em função do número de rotas para dois reposicionamentos e para cada fator de desbalanceamento

É possível observar por meio das figuras que o crescimento do tempo de execução da Heurística CD não é tão acentuado como os demais métodos.

\subsection{Comparação e Análise dos resultados}

Após analisar o resultado de cada método individualmente, foram comparados os três métodos tanto nos resultados obtidos por cada um como pelo tempo de execução.

\subsubsection{Análise dos problemas com um reposicionamento permitido}

A Tabela 4-26 a seguir mostra a comparação dos resultados dos três métodos (PLI, GH e CD) para os problemas balanceados e com um único reposicionamento. 
Tabela 4-26: Comparação das soluções para problemas balanceados e com um reposicionamento

\begin{tabular}{|c|c|c|c|c|c|c|c|c|}
\hline \multirow[b]{2}{*}{ DESBAL. } & \multirow[b]{2}{*}{ DÍGRAFO } & \multirow[b]{2}{*}{ ROTAS } & \multicolumn{3}{|c|}{ RESULTADOS (\#) } & \multicolumn{3}{|c|}{ DIFERENÇAS (\%) } \\
\hline & & & PLI & GH & CD & CD $\times$ GH & CD $\times$ PLI & GH x PLI \\
\hline $0 \%$ & 1 & 100 & $96.872,14$ & $97.110,76$ & $96.975,58$ & $-0,14 \%$ & $0,11 \%$ & $0,25 \%$ \\
\hline $0 \%$ & 1 & 200 & $169.442,99$ & $171.764,97$ & $171.135,20$ & $-0,37 \%$ & $1,00 \%$ & $1,37 \%$ \\
\hline $0 \%$ & 1 & 500 & $338.856,33$ & $358.777,58$ & $357.332,80$ & $-0,40 \%$ & $5,45 \%$ & $5,88 \%$ \\
\hline $0 \%$ & 1 & 1000 & $621.360,37$ & $686.025,76$ & $683.448,80$ & $-0,38 \%$ & $9,99 \%$ & $10,41 \%$ \\
\hline $0 \%$ & 1 & 1500 & $828.851,60$ & $918.721,56$ & $910.723,00$ & $-0,87 \%$ & $9,88 \%$ & $10,84 \%$ \\
\hline $0 \%$ & 1 & 3000 & $1.603 .193,08$ & $1.805 .524,28$ & $1.761 .072,00$ & $-2,46 \%$ & $9,85 \%$ & $12,62 \%$ \\
\hline $0 \%$ & 1 & 5000 & & $3.049 .304,03$ & $2.938 .458,00$ & $-3,64 \%$ & & \\
\hline \multicolumn{3}{|c|}{ SUBTOTAL DÍGRAFO 1} & & & & $-2,37 \%$ & $8,80 \%$ & $10,37 \%$ \\
\hline $0 \%$ & 2 & 100 & $94.153,69$ & $94.315,11$ & $94.315,10$ & $0,00 \%$ & $0,17 \%$ & $0,17 \%$ \\
\hline $0 \%$ & 2 & 200 & $157.752,13$ & $159.175,92$ & $158.972,40$ & $-0,13 \%$ & $0,77 \%$ & $0,90 \%$ \\
\hline $0 \%$ & 2 & 500 & $309.631,20$ & $328.042,02$ & $326.172,20$ & $-0,57 \%$ & $5,34 \%$ & $5,95 \%$ \\
\hline $0 \%$ & 2 & 1000 & $546.413,84$ & $608.978,00$ & $600.711,00$ & $-1,36 \%$ & $9,94 \%$ & $11,45 \%$ \\
\hline $0 \%$ & 2 & 1500 & $789.015,56$ & $889.440,60$ & $872.138,00$ & $-1,95 \%$ & $10,53 \%$ & $12,73 \%$ \\
\hline $0 \%$ & 2 & 3000 & $1.654 .982,77$ & $1.858 .356,37$ & $1.792 .328,00$ & $-3,55 \%$ & $8,30 \%$ & $12,29 \%$ \\
\hline $0 \%$ & 2 & 5000 & & $2.776 .382,20$ & $2.659 .818,00$ & $-4,20 \%$ & & \\
\hline \multicolumn{3}{|c|}{ SUBTOTAL DÍGRAFO 2} & & & & $-3,13 \%$ & $8,24 \%$ & $10,88 \%$ \\
\hline $0 \%$ & 3 & 100 & $81.018,44$ & $81.024,10$ & $81.019,18$ & $-0,01 \%$ & $0,00 \%$ & $0,01 \%$ \\
\hline $0 \%$ & 3 & 200 & $150.130,76$ & $151.117,65$ & $150.835,60$ & $-0,19 \%$ & $0,47 \%$ & $0,66 \%$ \\
\hline $0 \%$ & 3 & 500 & $314.158,93$ & $332.513,16$ & $331.576,20$ & $-0,28 \%$ & $5,54 \%$ & $5,84 \%$ \\
\hline $0 \%$ & 3 & 1000 & $479.838,33$ & $546.747,99$ & $534.086,40$ & $-2,32 \%$ & $11,31 \%$ & $13,94 \%$ \\
\hline $0 \%$ & 3 & 1500 & $738.953,22$ & $850.096,26$ & $818.111,60$ & $-3,76 \%$ & $10,71 \%$ & $15,04 \%$ \\
\hline $0 \%$ & 3 & 3000 & $1.339 .474,40$ & $1.514 .192,25$ & $1.439 .456,00$ & $-4,94 \%$ & $7,46 \%$ & $13,04 \%$ \\
\hline $0 \%$ & 3 & 5000 & & $2.843 .777,17$ & $2.672 .684,00$ & $-6,02 \%$ & & \\
\hline \multicolumn{3}{|c|}{ SUBTOTAL DÍGRAFO 3} & & & & $-4,62 \%$ & $8,10 \%$ & $11,99 \%$ \\
\hline \multicolumn{3}{|c|}{ TOTAL } & & & & $-3,33 \%$ & $8,40 \%$ & $11,03 \%$ \\
\hline
\end{tabular}


Comparando-se os três métodos, nota-se que a Heurística CD possui resultados melhores para todos os casos, se comparados com o Algoritmo GH. Além disso, quanto maior a concentração do dígrafo, melhor foi o desempenho da Heurística tanto em relação ao GH quanto ao PLI. Esse comportamento não ocorreu comparando-se GH com PLI, já que a diferença aumenta com o a concentração dos dígrafos.

O ganho da Heurística CD em relação ao Algoritmo $\mathrm{GH}$ variou de $-0,01 \%$ a $-6,02 \%$, sendo que na média, ficou em $-3,33 \%$. Comparando os resultados de CD com PLI, a diferença ficou, na média, em $8,40 \%$ enquanto que a diferença entre $\mathrm{GH}$ e PLI ficou em 11,03\%.

A Tabela 4-27, a Tabela 4-28 e a Tabela 4-29 mostram as comparações dos três métodos para os problemas desbalanceados (com 25\%, 50\% e 75\% de fator de desbalanceamento) com um reposicionamento.

A mesma tendência que os problemas balanceados foi observada para os desbalanceados: quanto maior a concentração dos agrupamentos, melhor o desempenho da heurística em relação a GH e PLI. Além disso, esse comportamento não é observado para GH em relação a PLI.

A Heurística CD obteve sempre melhor desempenho que o Algoritmo GH (exceto em um caso em que a diferença foi de centésimos). Porém observa-se que a diferença entre os dois métodos se reduz com o aumento do desbalanceamento: para os problemas com $25 \%$ de desbalanceamento a diferença média é de $-2,93 \%$, enquanto que para os problemas com $75 \%$, a diferença se reduz a uma média de 1,02\%. Diferentemente, comparando-se CD com PLI, a diferença se reduz com o aumento do desbalanceamento: se reduz de $7,86 \%$ para os problemas com $25 \%$ para apenas uma média de 2,64\% para os problemas mais desbalanceados. 
Tabela 4-27: Comparação das soluções para problemas desbalanceados (25\%) e com um reposicionamento

\begin{tabular}{|c|c|c|c|c|c|c|c|c|}
\hline \multirow[b]{2}{*}{ DESBAL. } & \multirow[b]{2}{*}{ DÍGRAFO } & \multirow[b]{2}{*}{ ROTAS } & \multicolumn{3}{|c|}{ RESULTADOS (\#) } & \multicolumn{3}{|c|}{ DIFERENÇAS (\%) } \\
\hline & & & PLI & GH & CD & CD $\times$ GH & CD x PLI & GH x PLI \\
\hline $25 \%$ & 1 & 100 & $96.089,14$ & $96.153,55$ & $96.138,78$ & $-0,02 \%$ & $0,05 \%$ & $0,07 \%$ \\
\hline $25 \%$ & 1 & 200 & $172.256,47$ & $173.683,70$ & $173.540,00$ & $-0,08 \%$ & $0,75 \%$ & $0,83 \%$ \\
\hline $25 \%$ & 1 & 1000 & $619.281,55$ & $676.178,69$ & $672.437,40$ & $-0,55 \%$ & $8,58 \%$ & $9,19 \%$ \\
\hline $25 \%$ & 1 & 1500 & $923.947,14$ & $1.030 .181,92$ & $1.020 .102,80$ & $-0,98 \%$ & $10,41 \%$ & $11,50 \%$ \\
\hline \multicolumn{3}{|c|}{ SUBTOTAL DÍGRAFO 1} & & & & $-2,39 \%$ & $8,71 \%$ & $10,49 \%$ \\
\hline $25 \%$ & 2 & 100 & $84.563,86$ & $84.740,07$ & $84.611,68$ & $-0,15 \%$ & $0,06 \%$ & $0,21 \%$ \\
\hline $25 \%$ & 2 & 200 & $156.558,38$ & $157.724,93$ & $157.599,60$ & $-0,08 \%$ & $0,67 \%$ & $0,75 \%$ \\
\hline $25 \%$ & 2 & 500 & $323.818,20$ & $340.653,36$ & $338.635,00$ & $-0,59 \%$ & $4,58 \%$ & $5,20 \%$ \\
\hline $25 \%$ & 2 & 1000 & $586.106,14$ & $645.678,82$ & $639.654,40$ & $-0,93 \%$ & $9,14 \%$ & $10,16 \%$ \\
\hline \multicolumn{3}{|c|}{ SUBTOTAL DÍGRAFO 2} & & & & $-3,04 \%$ & $8,25 \%$ & $10,51 \%$ \\
\hline $25 \%$ & 3 & 100 & $71.773,92$ & $71.822,08$ & $71.822,06$ & $0,00 \%$ & $0,07 \%$ & $0,07 \%$ \\
\hline $25 \%$ & 3 & 200 & $147.863,62$ & $148.798,71$ & $148.642,60$ & $-0,10 \%$ & $0,53 \%$ & $0,63 \%$ \\
\hline $25 \%$ & 3 & 500 & $289.424,44$ & $305.287,70$ & $301.201,40$ & $-1,34 \%$ & $4,07 \%$ & $5,48 \%$ \\
\hline $25 \%$ & 3 & 1000 & $552.270,31$ & $610.689,87$ & $601.420,00$ & $-1,52 \%$ & $8,90 \%$ & $10,58 \%$ \\
\hline $25 \%$ & 3 & 1500 & $784.489,79$ & $873.830,71$ & $856.504,20$ & $-1,98 \%$ & $9,18 \%$ & $11,39 \%$ \\
\hline $25 \%$ & 3 & 3000 & $1.371 .506,07$ & $1.501 .597,35$ & $1.444 .106,00$ & $-3,83 \%$ & $5,29 \%$ & $9,49 \%$ \\
\hline $25 \%$ & 3 & 5000 & & $2.732 .532,23$ & $2.604 .074,00$ & $-4,70 \%$ & & \\
\hline \multicolumn{3}{|c|}{ SUBTOTAL DÍGRAFO 3} & & & & $-3,47 \%$ & $6,41 \%$ & $9,16 \%$ \\
\hline \multicolumn{3}{|c|}{ TOTAL } & & & & $-2,93 \%$ & $7,86 \%$ & $10,10 \%$ \\
\hline
\end{tabular}


Tabela 4-28: Comparação das soluções para problemas desbalanceados $(50 \%)$ e com um reposicionamento

\begin{tabular}{|c|c|c|c|c|c|c|c|c|}
\hline \multirow[b]{2}{*}{ DESBAL. } & \multirow[b]{2}{*}{ DÍGRAFO } & \multirow[b]{2}{*}{ ROTAS } & \multicolumn{3}{|c|}{ RESULTADOS (\#) } & \multicolumn{3}{|c|}{ DIFERENÇAS (\%) } \\
\hline & & & PLI & GH & CD & CD $\times$ GH & CD $\times$ PLI & GH $\times$ PLI \\
\hline $50 \%$ & 1 & 100 & $98.522,13$ & $98.593,88$ & $98.593,68$ & $0,00 \%$ & $0,07 \%$ & $0,07 \%$ \\
\hline $50 \%$ & 1 & 200 & $175.179,34$ & $176.720,74$ & $176.742,40$ & $0,01 \%$ & $0,89 \%$ & $0,88 \%$ \\
\hline $50 \%$ & 1 & 500 & $393.514,32$ & $405.566,70$ & $404.514,60$ & $-0,26 \%$ & $2,80 \%$ & $3,06 \%$ \\
\hline $50 \%$ & 1 & 1000 & $732.749,02$ & $779.620,94$ & $776.287,00$ & $-0,43 \%$ & $5,94 \%$ & $6,40 \%$ \\
\hline $50 \%$ & 1 & 1500 & $1.001 .653,78$ & $1.082 .759,30$ & $1.077 .020,00$ & $-0,53 \%$ & $7,52 \%$ & $8,10 \%$ \\
\hline $50 \%$ & 1 & 3000 & $1.888 .528,39$ & 2.089.209,93 & $2.057 .832,00$ & $-1,50 \%$ & $8,96 \%$ & $10,63 \%$ \\
\hline $50 \%$ & 1 & 5000 & & $3.471 .315,38$ & $3.391 .172,00$ & $-2,31 \%$ & & \\
\hline \multicolumn{3}{|c|}{ SUBTOTAL DÍGRAFO 1} & & & & $-1,50 \%$ & $7,01 \%$ & $7,98 \%$ \\
\hline $50 \%$ & 2 & 100 & $102.191,75$ & $102.312,82$ & $102.303,06$ & $-0,01 \%$ & $0,11 \%$ & $0,12 \%$ \\
\hline $50 \%$ & 2 & 200 & $165.210,18$ & $166.474,09$ & $166.351,60$ & $-0,07 \%$ & $0,69 \%$ & $0,77 \%$ \\
\hline $50 \%$ & 2 & 500 & $342.358,07$ & $353.731,55$ & $353.727,40$ & $0,00 \%$ & $3,32 \%$ & $3,32 \%$ \\
\hline $50 \%$ & 2 & 1000 & $657.094,65$ & $702.136,30$ & $698.512,40$ & $-0,52 \%$ & $6,30 \%$ & $6,85 \%$ \\
\hline $50 \%$ & 2 & 1500 & $1.043 .284,22$ & $1.128 .278,35$ & $1.113 .654,40$ & $-1,30 \%$ & $6,75 \%$ & $8,15 \%$ \\
\hline $50 \%$ & 2 & 3000 & $1.836 .830,91$ & $2.026 .233,35$ & $1.980 .246,00$ & $-2,27 \%$ & $7,81 \%$ & $10,31 \%$ \\
\hline $50 \%$ & 2 & 5000 & & $3.468 .697,27$ & $3.367 .586,00$ & $-2,91 \%$ & & \\
\hline \multicolumn{3}{|c|}{ SUBTOTAL DÍGRAFO 2} & & & & $-2,08 \%$ & $6,46 \%$ & $8,01 \%$ \\
\hline $50 \%$ & 3 & 100 & $73.417,86$ & $73.535,08$ & $73.421,20$ & $-0,15 \%$ & $0,00 \%$ & $0,16 \%$ \\
\hline $50 \%$ & 3 & 200 & $137.100,10$ & $138.202,22$ & $138.082,60$ & $-0,09 \%$ & $0,72 \%$ & $0,80 \%$ \\
\hline $50 \%$ & 3 & 500 & $323.130,44$ & $334.291,20$ & $332.586,80$ & $-0,51 \%$ & $2,93 \%$ & $3,45 \%$ \\
\hline $50 \%$ & 3 & 1000 & $623.184,68$ & $664.511,03$ & $654.554,00$ & $-1,50 \%$ & $5,03 \%$ & $6,63 \%$ \\
\hline $50 \%$ & 3 & 1500 & $863.017,57$ & $927.867,51$ & $912.387,40$ & $-1,67 \%$ & $5,72 \%$ & $7,51 \%$ \\
\hline $50 \%$ & 3 & 3000 & $1.717 .237,88$ & $1.850 .769,54$ & $1.803 .258,00$ & $-2,57 \%$ & $5,01 \%$ & $7,78 \%$ \\
\hline $50 \%$ & 3 & 5000 & & $3.597 .342,37$ & $3.493 .006,00$ & $-2,90 \%$ & & \\
\hline \multicolumn{3}{|c|}{ SUBTOTAL DÍGRAFO 3} & & & & $-2,36 \%$ & $4,74 \%$ & $6,75 \%$ \\
\hline \multicolumn{3}{|c|}{ TOTAL } & & & & $-1,97 \%$ & $6,13 \%$ & $7,61 \%$ \\
\hline
\end{tabular}


Tabela 4-29: Comparação das soluções para problemas desbalanceados $(75 \%)$ e com um reposicionamento

\begin{tabular}{|c|c|c|c|c|c|c|c|c|}
\hline \multirow[b]{2}{*}{ DESBAL. } & \multirow[b]{2}{*}{ DÍGRAFO } & \multirow[b]{2}{*}{ ROTAS } & \multicolumn{3}{|c|}{ RESULTADOS (\#) } & \multicolumn{3}{|c|}{ DIFERENÇAS (\%) } \\
\hline & & & PLI & GH & CD & $\mathrm{CD} \times \mathrm{GH}$ & CD $\times$ PLI & GH $x$ PLI \\
\hline $75 \%$ & 1 & 100 & $96.044,08$ & $96.073,07$ & $96.057,16$ & $-0,02 \%$ & $0,01 \%$ & $0,03 \%$ \\
\hline $75 \%$ & 1 & 200 & $183.478,37$ & $184.161,18$ & $184.049,20$ & $-0,06 \%$ & $0,31 \%$ & $0,37 \%$ \\
\hline $75 \%$ & 1 & 500 & $449.747,03$ & $456.684,18$ & $455.818,00$ & $-0,19 \%$ & $1,35 \%$ & $1,54 \%$ \\
\hline $75 \%$ & 1 & 1000 & $804.719,77$ & $824.257,31$ & $823.001,60$ & $-0,15 \%$ & $2,27 \%$ & $2,43 \%$ \\
\hline $75 \%$ & 1 & 1500 & $1.238 .229,01$ & $1.281 .898,82$ & $1.275 .628,00$ & $-0,49 \%$ & $3,02 \%$ & $3,53 \%$ \\
\hline $75 \%$ & 1 & 3000 & $2.412 .726,49$ & $2.524 .063,98$ & $2.506 .030,00$ & $-0,71 \%$ & $3,87 \%$ & $4,61 \%$ \\
\hline $75 \%$ & 1 & 5000 & & $4.390 .573,16$ & $4.345 .638,00$ & $-1,02 \%$ & & \\
\hline \multicolumn{3}{|c|}{ SUBTOTAL DÍGRAFO 1} & & & & $-0,73 \%$ & $3,00 \%$ & $3,51 \%$ \\
\hline $75 \%$ & 2 & 100 & $103.157,80$ & $103.400,13$ & $103.194,94$ & $-0,20 \%$ & $0,04 \%$ & $0,23 \%$ \\
\hline $75 \%$ & 2 & 200 & $184.439,74$ & $185.090,29$ & $184.799,20$ & $-0,16 \%$ & $0,19 \%$ & $0,35 \%$ \\
\hline $75 \%$ & 2 & 500 & $430.666,91$ & $437.036,63$ & $436.253,20$ & $-0,18 \%$ & $1,30 \%$ & $1,48 \%$ \\
\hline $75 \%$ & 2 & 1000 & $822.530,83$ & $845.175,60$ & $842.069,40$ & $-0,37 \%$ & $2,38 \%$ & $2,75 \%$ \\
\hline $75 \%$ & 2 & 1500 & $1.172 .947,76$ & $1.214 .440,12$ & $1.205 .966,00$ & $-0,70 \%$ & $2,81 \%$ & $3,54 \%$ \\
\hline $75 \%$ & 2 & 3000 & $2.422 .984,79$ & $2.540 .562,39$ & $2.509 .830,00$ & $-1,21 \%$ & $3,58 \%$ & $4,85 \%$ \\
\hline $75 \%$ & 2 & 5000 & & 4.087.316,35 & $4.025 .824,00$ & $-1,50 \%$ & & \\
\hline \multicolumn{3}{|c|}{ SUBTOTAL DÍGRAFO 2} & & & & $-1,12 \%$ & $2,83 \%$ & $3,68 \%$ \\
\hline $75 \%$ & 3 & 100 & $91.426,37$ & $91.433,68$ & $91.428,18$ & $-0,01 \%$ & $0,00 \%$ & $0,01 \%$ \\
\hline $75 \%$ & 3 & 200 & $158.352,52$ & $158.604,87$ & $158.605,80$ & $0,00 \%$ & $0,16 \%$ & $0,16 \%$ \\
\hline $75 \%$ & 3 & 500 & $374.736,51$ & $380.937,05$ & $379.822,40$ & $-0,29 \%$ & $1,36 \%$ & $1,65 \%$ \\
\hline $75 \%$ & 3 & 1000 & $746.580,32$ & $764.571,69$ & $761.762,20$ & $-0,37 \%$ & $2,03 \%$ & $2,41 \%$ \\
\hline $75 \%$ & 3 & 1500 & $1.094 .550,86$ & $1.125 .387,92$ & $1.117 .491,20$ & $-0,70 \%$ & $2,10 \%$ & $2,82 \%$ \\
\hline $75 \%$ & 3 & 3000 & $2.216 .555,97$ & 2.297.121,04 & $2.268 .764,00$ & $-1,23 \%$ & $2,36 \%$ & $3,63 \%$ \\
\hline $75 \%$ & 3 & 5000 & & $4.004 .458,26$ & $3.937 .014,00$ & $-1,68 \%$ & & \\
\hline \multicolumn{3}{|c|}{ SUBTOTAL DÍGRAFO 3} & & & & $-1,22 \%$ & $2,04 \%$ & $2,90 \%$ \\
\hline \multicolumn{3}{|c|}{ TOTAL } & & & & $-1,02 \%$ & $2,64 \%$ & $3,38 \%$ \\
\hline
\end{tabular}


A Tabela 4-30 a seguir, mostra a comparação dos tempos de execução dos três métodos para os problemas balanceados com permissão de um reposicionamento. Para PLI e GH, os tempos de geração de ciclos viáveis estão somados aos tempos dos métodos, uma vez que faz parte do processo de solução.

Tabela 4-30: Comparação dos tempos de execução para problemas balanceados e com um reposicionamento

\begin{tabular}{|c|c|c|c|c|c|}
\hline \multirow[b]{2}{*}{ DESBAL. } & \multirow[b]{2}{*}{ DÍGRAFO } & \multirow[b]{2}{*}{ ROTAS } & \multicolumn{3}{|c|}{ TEMPOS DE EXECUÇÃO (s) } \\
\hline & & & PLI & GH & CD \\
\hline $0 \%$ & 1 & 100 & 0,02 & 0,00 & 0,03 \\
\hline $0 \%$ & 1 & 200 & 0,02 & 0,02 & 0,11 \\
\hline $0 \%$ & 1 & 500 & 0,05 & 0,04 & 2,33 \\
\hline $0 \%$ & 1 & 1000 & 0,45 & 0,33 & 6,33 \\
\hline $0 \%$ & 1 & 1500 & 9,99 & 1,92 & 11,07 \\
\hline $0 \%$ & 1 & 3000 & $4.507,56$ & 53,34 & 29,54 \\
\hline $0 \%$ & 1 & 5000 & & 680,58 & 58,43 \\
\hline $0 \%$ & 2 & 100 & 0,02 & 0,01 & 0,16 \\
\hline $0 \%$ & 2 & 200 & 0,03 & 0,01 & 0,72 \\
\hline $0 \%$ & 2 & 500 & 0,06 & 0,05 & 2,58 \\
\hline $0 \%$ & 2 & 1000 & 0,48 & 0,36 & 6,74 \\
\hline $0 \%$ & 2 & 1500 & 9,96 & 1,91 & 12,15 \\
\hline $0 \%$ & 2 & 3000 & $4.823,14$ & 52,87 & 30,78 \\
\hline $0 \%$ & 2 & 5000 & & 680,12 & 68,23 \\
\hline $0 \%$ & 3 & 100 & 0,02 & 0,01 & 0,08 \\
\hline $0 \%$ & 3 & 200 & 0,03 & 0,01 & 0,16 \\
\hline $0 \%$ & 3 & 500 & 0,05 & 0,05 & 4,05 \\
\hline $0 \%$ & 3 & 1000 & 0,45 & 0,35 & 10,72 \\
\hline $0 \%$ & 3 & 1500 & 8,50 & 1,83 & 19,64 \\
\hline $0 \%$ & 3 & 3000 & $4.356,73$ & 51,29 & 48,77 \\
\hline $0 \%$ & 3 & 5000 & & 663,97 & 101,29 \\
\hline
\end{tabular}

A Heurística CD possui tempos de execução maiores que GH e PLI para os problemas com rotas menores que 3000 , porém o crescimento de seu tempo é menos acentuado. Isso faz com que para problemas grandes (3000 e 5000 rotas) seu tempo seja menor. Por exemplo, para os problemas com 5000 rotas, a heurística executa um problema de 1 a 2 minutos, dependendo do dígrafo. Por outro lado, GH necessita mais de 11 minutos. Esse comportamento fica claro na Figura 
4-24 e Figura 4-25 que são os gráficos desses tempos de execução em função do número de rotas para problemas do dígrafo 1 e 3 , respectivamente.

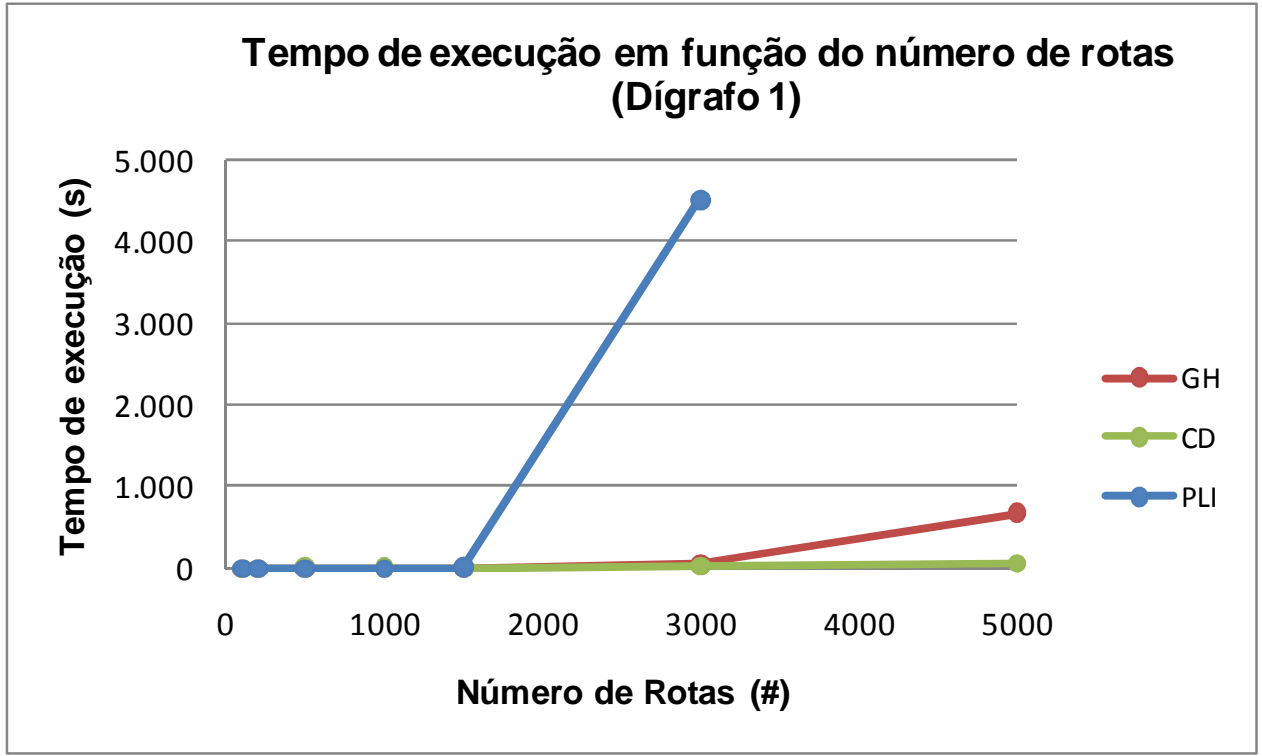

Figura 4-24: Gráfico do tempo de execução dos problemas balanceados com um reposicionamento (dígrafo 1 )

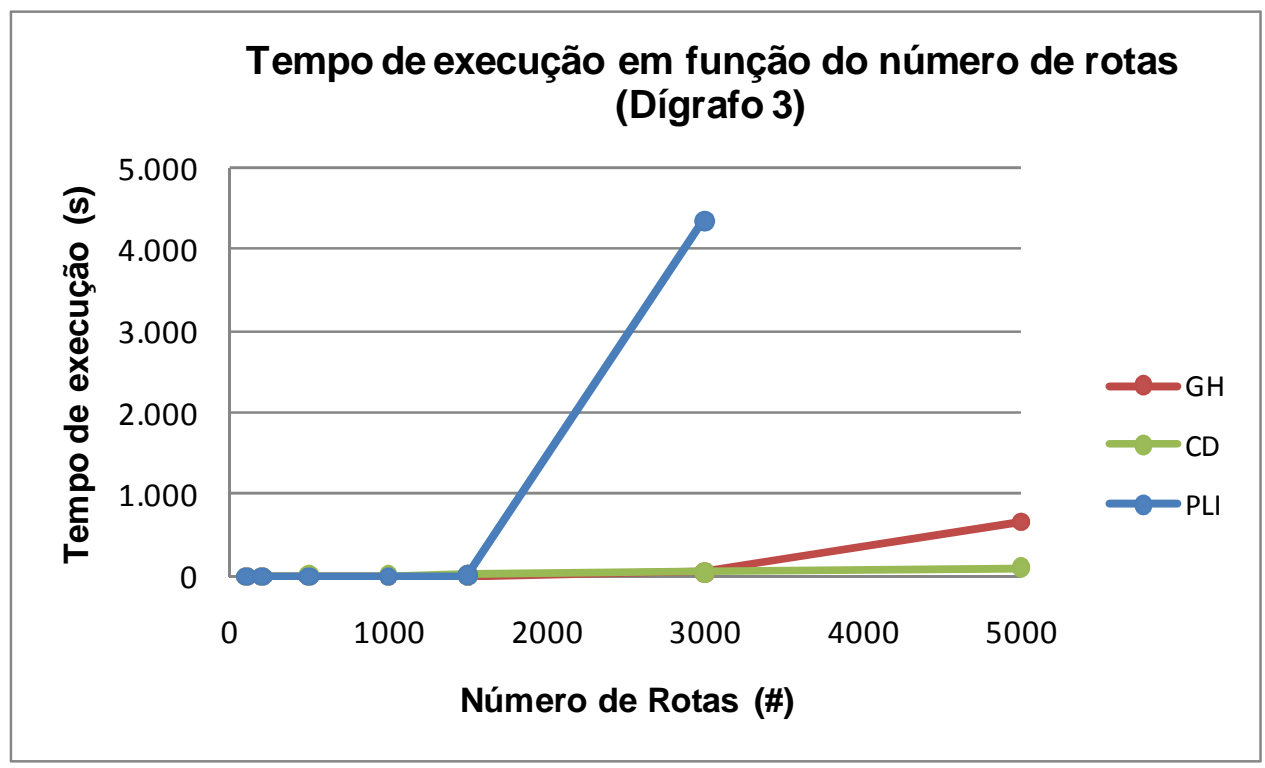

Figura 4-25: Gráfico do tempo de execução dos problemas balanceados com um reposicionamento (dígrafo 3 ) 
A Tabela 4-31, a Tabela 4-32 e a Tabela 4-33 a seguir, mostra a comparação dos tempos de execução dos três métodos, porém para os problemas desbalanceados (com 25\%, 50\% e 75\% de fator de desbalanceamento) com permissão para apenas um reposicionamento. Para PLI e GH, os tempos de geração de ciclos viáveis também estão somados aos tempos dos métodos.

Tabela 4-31: Comparação dos tempos de execução para problemas desbalanceados (25\%) e com um reposicionamento

TEMPOS DE EXECUÇÃO (s)

\begin{tabular}{|c|c|c|c|c|c|}
\hline DESBAL. & DÍGRAFO & ROTAS & PLI & GH & CD \\
\hline $25 \%$ & 1 & 100 & 0,02 & 0,01 & 0,03 \\
\hline $25 \%$ & 1 & 200 & 0,03 & 0,00 & 0,12 \\
\hline $25 \%$ & 1 & 500 & 0,05 & 0,04 & 2,58 \\
\hline $25 \%$ & 1 & 1000 & 0,39 & 0,30 & 8,13 \\
\hline $25 \%$ & 1 & 1500 & 5,14 & 1,66 & 14,80 \\
\hline $25 \%$ & 1 & 3000 & $1.407,59$ & 43,83 & 44,50 \\
\hline $25 \%$ & 1 & 5000 & & 540,82 & 102,22 \\
\hline $25 \%$ & 2 & 100 & 0,03 & 0,01 & 0,16 \\
\hline $25 \%$ & 2 & 200 & 0,02 & 0,01 & 0,76 \\
\hline $25 \%$ & 2 & 500 & 0,05 & 0,05 & 3,06 \\
\hline $25 \%$ & 2 & 1000 & 0,35 & 0,30 & 9,42 \\
\hline $25 \%$ & 2 & 1500 & 3,82 & 1,55 & 18,02 \\
\hline $25 \%$ & 2 & 3000 & $1.194,97$ & 41,89 & 57,98 \\
\hline $25 \%$ & 2 & 5000 & & 518,38 & 119,39 \\
\hline $25 \%$ & 3 & 100 & 0,02 & 0,01 & 0,07 \\
\hline $25 \%$ & 3 & 200 & 0,03 & 0,01 & 0,19 \\
\hline $25 \%$ & 3 & 500 & 0,06 & 0,04 & 5,05 \\
\hline $25 \%$ & 3 & 1000 & 0,32 & 0,29 & 16,28 \\
\hline $25 \%$ & 3 & 1500 & 4,19 & 1,58 & 31,20 \\
\hline $25 \%$ & 3 & 3000 & $1.576,01$ & 42,46 & 84,00 \\
\hline $25 \%$ & 3 & 5000 & & 526,65 & 195,93 \\
\hline
\end{tabular}


Tabela 4-32: Comparação dos tempos de execução para problemas desbalanceados (50\%) e com um reposicionamento

\begin{tabular}{|c|c|c|c|c|c|}
\hline \multirow[b]{2}{*}{ DESBAL. } & \multirow[b]{2}{*}{ DÍGRAFO } & \multirow[b]{2}{*}{ ROTAS } & \multicolumn{3}{|c|}{ TEMPOS DE EXECUÇÃO (s) } \\
\hline & & & PLI & GH & CD \\
\hline $50 \%$ & 1 & 100 & 0,02 & 0,01 & 0,03 \\
\hline $50 \%$ & 1 & 200 & 0,03 & 0,02 & 0,12 \\
\hline $50 \%$ & 1 & 500 & 0,05 & 0,05 & 3,16 \\
\hline $50 \%$ & 1 & 1000 & 0,24 & 0,22 & 11,22 \\
\hline $50 \%$ & 1 & 1500 & 1,60 & 0,99 & 22,55 \\
\hline $50 \%$ & 1 & 3000 & 201,41 & 23,83 & 80,58 \\
\hline $50 \%$ & 1 & 5000 & & 297,15 & 198,13 \\
\hline $50 \%$ & 2 & 100 & 0,02 & 0,01 & 0,16 \\
\hline $50 \%$ & 2 & 200 & 0,03 & 0,02 & 0,78 \\
\hline $50 \%$ & 2 & 500 & 0,05 & 0,05 & 3,76 \\
\hline $50 \%$ & 2 & 1000 & 0,27 & 0,24 & 12,72 \\
\hline $50 \%$ & 2 & 1500 & 1,36 & 1,03 & 27,08 \\
\hline $50 \%$ & 2 & 3000 & 196,14 & 25,17 & 102,31 \\
\hline $50 \%$ & 2 & 5000 & & 293,95 & 244,56 \\
\hline $50 \%$ & 3 & 100 & 0,02 & 0,01 & 0,08 \\
\hline $50 \%$ & 3 & 200 & 0,02 & 0,01 & 0,18 \\
\hline $50 \%$ & 3 & 500 & 0,05 & 0,05 & 6,44 \\
\hline $50 \%$ & 3 & 1000 & 0,24 & 0,24 & 23,63 \\
\hline $50 \%$ & 3 & 1500 & 1,05 & 0,98 & 46,79 \\
\hline $50 \%$ & 3 & 3000 & 131,50 & 22,03 & 164,77 \\
\hline $50 \%$ & 3 & 5000 & & 260,75 & 441,99 \\
\hline
\end{tabular}


Tabela 4-33: Comparação dos tempos de execução para problemas desbalanceados (75\%) e com um reposicionamento

\begin{tabular}{|c|c|c|c|c|c|}
\hline \multirow[b]{2}{*}{ DESBAL. } & \multirow[b]{2}{*}{ DÍGRAFO } & \multirow[b]{2}{*}{ ROTAS } & \multicolumn{3}{|c|}{ TEMPOS DE EXECUÇÃO (s) } \\
\hline & & & PLI & GH & CD \\
\hline $75 \%$ & 1 & 100 & 0,02 & 0,01 & 0,03 \\
\hline $75 \%$ & 1 & 200 & 0,02 & 0,01 & 0,14 \\
\hline $75 \%$ & 1 & 500 & 0,03 & 0,04 & 4,00 \\
\hline $75 \%$ & 1 & 1000 & 0,12 & 0,14 & 15,47 \\
\hline $75 \%$ & 1 & 1500 & 0,45 & 0,42 & 33,07 \\
\hline $75 \%$ & 1 & 3000 & 9,43 & 6,52 & 124,30 \\
\hline $75 \%$ & 1 & 5000 & & 70,28 & 330,79 \\
\hline $75 \%$ & 2 & 100 & 0,02 & 0,01 & 0,17 \\
\hline $75 \%$ & 2 & 200 & 0,02 & 0,01 & 0,85 \\
\hline $75 \%$ & 2 & 500 & 0,04 & 0,04 & 4,76 \\
\hline $75 \%$ & 2 & 1000 & 0,13 & 0,14 & 17,82 \\
\hline $75 \%$ & 2 & 1500 & 0,42 & 0,42 & 40,70 \\
\hline $75 \%$ & 2 & 3000 & 9,75 & 7,41 & 160,82 \\
\hline $75 \%$ & 2 & 5000 & & 69,76 & 409,69 \\
\hline $75 \%$ & 3 & 100 & 0,02 & 0,00 & 0,09 \\
\hline $75 \%$ & 3 & 200 & 0,02 & 0,02 & 0,21 \\
\hline $75 \%$ & 3 & 500 & 0,04 & 0,04 & 8,49 \\
\hline $75 \%$ & 3 & 1000 & 0,14 & 0,14 & 31,90 \\
\hline $75 \%$ & 3 & 1500 & 0,49 & 0,47 & 64,60 \\
\hline $75 \%$ & 3 & 3000 & 9,72 & 7,59 & 248,12 \\
\hline $75 \%$ & 3 & 5000 & & 80,40 & 664,89 \\
\hline
\end{tabular}

Nota-se que 0 os problemas desbalanceados possuem as mesmas tendências que os balanceados. Porém, com o aumento do desbalanceamento, o tempo de CD aumenta enquanto para os outros métodos, diminui. Por exemplo, para os problemas com $75 \%$ de desbalanceamento os tempos de execução de CD são sempre maiores. Isso passa a ocorrer a partir do segundo dígrafo dos problemas com $50 \%$ de desbalanceamento.

A Figura 4-26, a Figura 4-27 e a Figura 4-28 ilustram os tempos de execução em função do número de rotas para os problemas com $25 \%, 50 \%$ e $75 \%$ de desbalanceamento, respectivamente, e um único reposicionamento. 

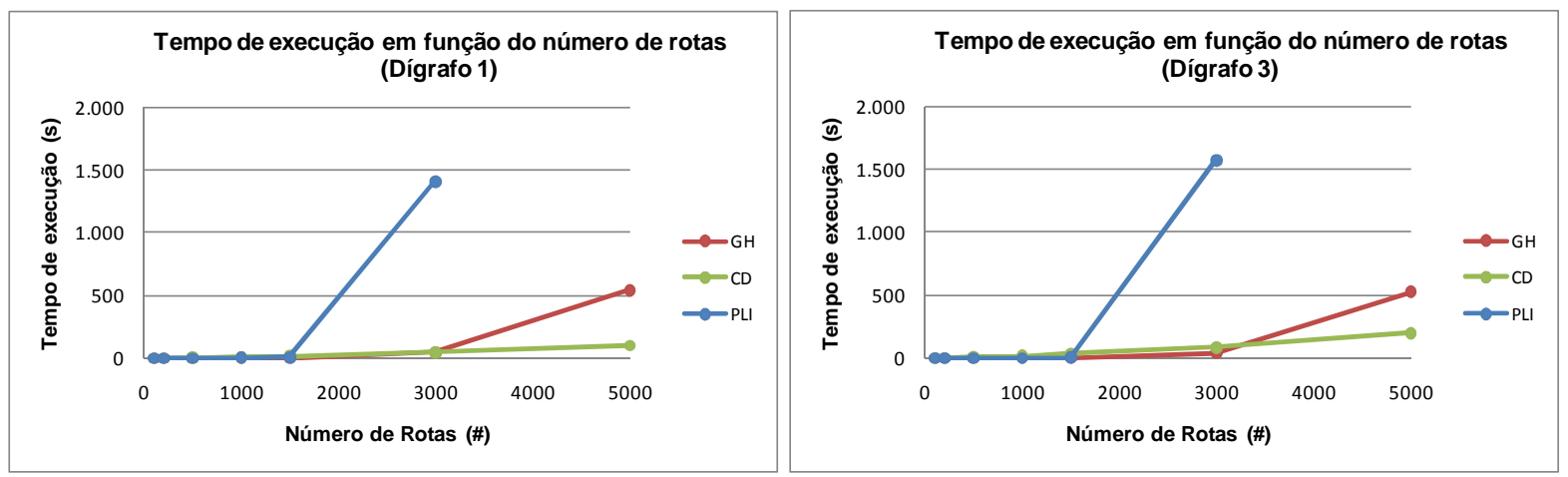

Figura 4-26: Gráfico do tempo de execução dos problemas desbalanceados (25\%) com um reposicionamento (dígrafo 1 e 3 )
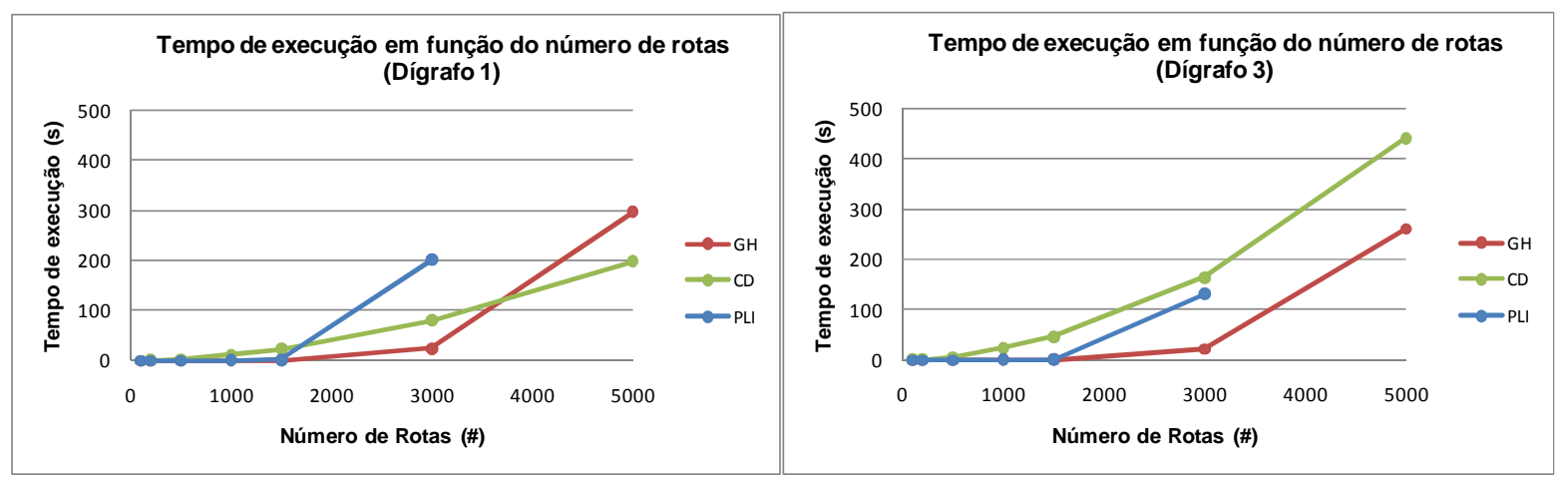

Figura 4-27: Gráfico do tempo de execução dos problemas desbalanceados (50\%) com um reposicionamento (dígrafo 1 e 3 )
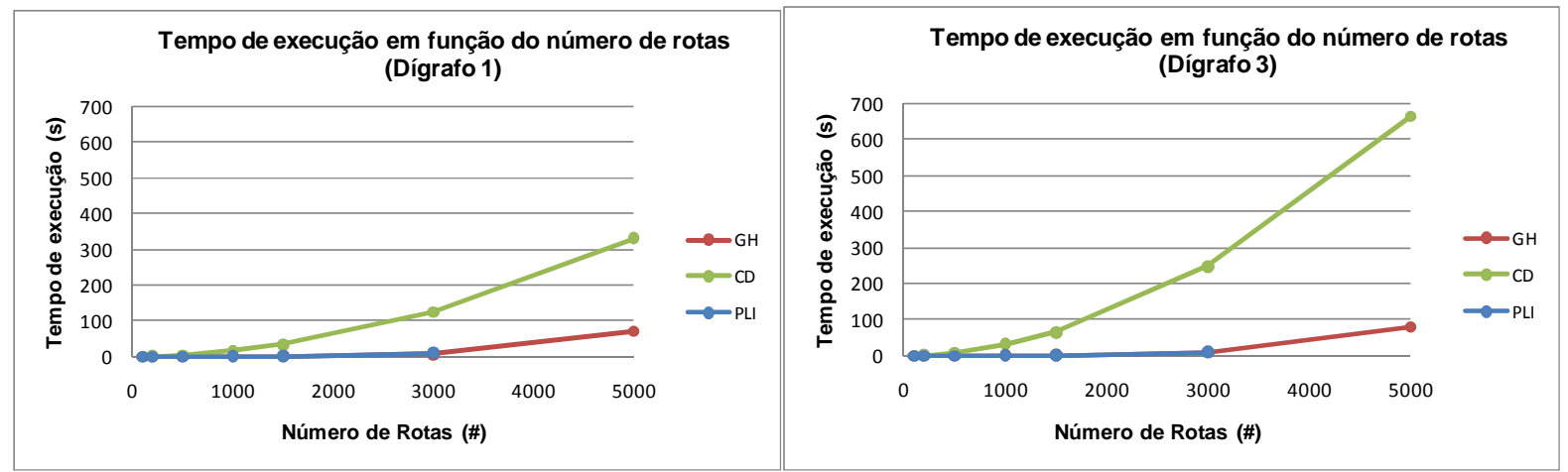

Figura 4-28: Gráfico do tempo de execução dos problemas desbalanceados (75\%) com um reposicionamento (dígrafo 1 e 3) 


\subsubsection{Análise dos problemas com dois reposicionamentos permitidos}

A Tabela 4-34 a seguir mostra a comparação dos resultados dos três métodos (PLI, GH e CD) para os problemas balanceados e com dois reposicionamentos permitidos.

Comparando-se os resultados obtidos, nota-se que a Heurística CD possui resultados melhores para praticamente todos os casos, se comparados com 0 Algoritmo $\mathrm{GH}$, perdendo apenas para os problemas de 1500 rotas para os dígrafos 2 e 3. Ao contrário do que ocorreu para os problemas com um reposicionamento, quanto menor a concentração do dígrafo, melhor foi o desempenho de CD em relação a $\mathrm{GH}$. Por sua vez, quanto maior a concentração do dígrafo, melhor foi o resultado em relação a PLI gerando uma diferença muito pequena $(0,39 \%)$ para o dígrafo 3.

O ganho da Heurística CD em relação ao Algoritmo GH variou de $-1,00 \%$ a $0,12 \%$, sendo que na média, ficou em $-0,11 \%$. Comparando-se os resultados de CD com PLI, a diferença ficou entre $0,32 \%$ e $2,17 \%$, com uma média de $1,10 \%$. A diferença entre GH e PLI entre 0,33\% e 2,59\%, com uma média de 1,53\%.

É importante enfatizar o fato de CD ter conseguido executar todos os problemas sem exceção. Enquanto isso, PLI executou apenas os problemas menores (100 a 500 rotas) e GH não executou os problemas maiores (com mais de 1500 rotas). 
Tabela 4-34: Comparação das soluções para problemas balanceados e com dois reposicionamentos

\begin{tabular}{|c|c|c|c|c|c|c|c|c|}
\hline \multirow[b]{2}{*}{ DESBAL. } & \multirow[b]{2}{*}{ DÍGRAFO } & \multirow[b]{2}{*}{ ROTAS } & \multicolumn{3}{|c|}{ RESULTADOS (\#) } & \multicolumn{3}{|c|}{ DIFERENÇAS (\%) } \\
\hline & & & PLI & GH & CD & CD $\times$ GH & CD $\times$ PLI & GH $\times$ PLI \\
\hline $0 \%$ & 1 & 100 & $59.751,44$ & $61.297,89$ & $61.049,20$ & $-0,41 \%$ & $2,17 \%$ & $2,59 \%$ \\
\hline $0 \%$ & 1 & 200 & $114.033,55$ & $116.695,76$ & $115.929,20$ & $-0,66 \%$ & $1,66 \%$ & $2,33 \%$ \\
\hline $0 \%$ & 1 & 500 & $257.593,37$ & $263.045,72$ & $261.924,40$ & $-0,43 \%$ & $1,68 \%$ & $2,12 \%$ \\
\hline $0 \%$ & 1 & 1000 & & $542.223,43$ & $542.132,80$ & $-0,02 \%$ & & \\
\hline $0 \%$ & 1 & 1500 & & $834.578,42$ & $833.766,60$ & $-0,10 \%$ & & \\
\hline $0 \%$ & 1 & 3000 & & & $1.543 .930,00$ & & & \\
\hline $0 \%$ & 1 & 5000 & & & $2.565 .374,00$ & & & \\
\hline \multicolumn{3}{|c|}{ SUBTOTAL DÍGRAFO 1} & & & & $-0,17 \%$ & $1,74 \%$ & $2,24 \%$ \\
\hline $0 \%$ & 2 & 100 & $56.052,07$ & $57.481,30$ & $56.989,06$ & $-0,86 \%$ & $1,67 \%$ & $2,55 \%$ \\
\hline $0 \%$ & 2 & 200 & $100.763,85$ & $102.686,13$ & $101.913,50$ & $-0,75 \%$ & $1,14 \%$ & $1,91 \%$ \\
\hline $0 \%$ & 2 & 500 & $254.204,86$ & $257.562,58$ & $256.715,20$ & $-0,33 \%$ & $0,99 \%$ & $1,32 \%$ \\
\hline $0 \%$ & 2 & 1000 & & $477.793,62$ & $477.747,80$ & $-0,01 \%$ & & \\
\hline $0 \%$ & 2 & 1500 & & $757.613,50$ & $757.932,40$ & $0,04 \%$ & & \\
\hline $0 \%$ & 2 & 3000 & & & $1.481 .806,00$ & & & \\
\hline $0 \%$ & 2 & 5000 & & & $2.479 .096,00$ & & & \\
\hline \multicolumn{3}{|c|}{ SUBTOTAL DÍGRAFO 2} & & & & $-0,11 \%$ & $1,12 \%$ & $1,63 \%$ \\
\hline $0 \%$ & 3 & 100 & $52.854,45$ & $53.163,76$ & $53.132,30$ & $-0,06 \%$ & $0,53 \%$ & $0,59 \%$ \\
\hline $0 \%$ & 3 & 200 & $98.424,45$ & $99.914,85$ & $98.914,20$ & $-1,00 \%$ & $0,50 \%$ & $1,51 \%$ \\
\hline $0 \%$ & 3 & 500 & $251.236,56$ & $252.073,47$ & $252.037,00$ & $-0,01 \%$ & $0,32 \%$ & $0,33 \%$ \\
\hline $0 \%$ & 3 & 1000 & & $489.138,50$ & $489.070,20$ & $-0,01 \%$ & & \\
\hline $0 \%$ & 3 & 1500 & & $621.364,35$ & $622.081,80$ & $0,12 \%$ & & \\
\hline $0 \%$ & 3 & 3000 & & & $1.484 .356,00$ & & & \\
\hline $0 \%$ & 3 & 5000 & & & $2.500 .852,00$ & & & \\
\hline \multicolumn{3}{|c|}{ SUBTOTAL DÍGRAFO 3} & & & & $-0,03 \%$ & $0,39 \%$ & $0,66 \%$ \\
\hline \multicolumn{3}{|c|}{ TOTAL } & & & & $-0,11 \%$ & $1,10 \%$ & $1,53 \%$ \\
\hline
\end{tabular}


A Tabela 4-35, a Tabela 4-36 e a Tabela 4-37 mostram as comparações dos três métodos para os problemas desbalanceados (com $25 \%, 50 \%$ e $75 \%$ de fator de desbalanceamento) com dois reposicionamentos permitidos.

Da mesma forma que para os problemas com um reposicionamento, verificouse a mesma tendência para os problemas desbalanceados que a dos balanceados: quanto maior a concentração dos agrupamentos, melhor o desempenho da heurística em relação a PLI e pior em relação a $\mathrm{GH}$.

A Heurística $\mathrm{CD}$ obteve melhor desempenho que o Algoritmo $\mathrm{GH}$ para quase todos os problemas com $25 \%$ de desbalanceamento. Nota-se que, com o aumento do desbalanceamento, essa diferença se reduz de uma média de $-0,07 \%$ para problemas com $p_{\text {desb }}=25 \%$ para $0,19 \%$, para problemas com $p_{\text {desb }}=75 \%$.

Comparando-se CD com PLI, a diferença se reduz com o aumento do desbalanceamento, de $1,11 \%$ para os problemas menos desbalanceados, para $0,94 \%$ para os mais desbalanceados. O mesmo ocorre entre GH e PLI, variando de $1,39 \%$ para $1,04 \%$, para os problemas com menos e mais desbalanceamento, respectivamente.

Nota-se que quanto maior o desbalanceamento, menor é a diferença entre os três métodos. Além disso, nota-se na Tabela 4-3 que o número de ciclos viáveis diminui com o aumento de $p_{\text {desb }}$ indicando que existe uma quantidade de soluções possíveis menor. Isso faz com que a diferença dos resultados obtidos entre os métodos seja menor. 
Tabela 4-35: Comparação das soluções para problemas desbalanceados (25\%) e com dois reposicionamentos

\begin{tabular}{|c|c|c|c|c|c|c|c|c|}
\hline \multirow[b]{2}{*}{ DESBAL. } & \multirow[b]{2}{*}{ DÍGRAFO } & \multirow[b]{2}{*}{ ROTAS } & \multicolumn{3}{|c|}{ RESULTADOS (\#) } & \multicolumn{3}{|c|}{ DIFERENÇAS (\%) } \\
\hline & & & PLI & GH & CD & CD $\times$ GH & CD x PLI & GH $\times$ PLI \\
\hline $25 \%$ & 1 & 100 & $58.979,72$ & $60.697,81$ & $60.356,76$ & $-0,56 \%$ & $2,33 \%$ & $2,91 \%$ \\
\hline $25 \%$ & 1 & 200 & $125.249,87$ & $128.093,58$ & $127.528,40$ & $-0,44 \%$ & $1,82 \%$ & $2,27 \%$ \\
\hline $25 \%$ & 1 & 500 & $271.827,82$ & $277.278,74$ & $275.951,40$ & $-0,48 \%$ & $1,52 \%$ & $2,01 \%$ \\
\hline $25 \%$ & 1 & 1000 & & $529.182,31$ & $528.162,60$ & $-0,19 \%$ & & \\
\hline $25 \%$ & 1 & 1500 & & $825.614,92$ & $825.635,40$ & $0,00 \%$ & & \\
\hline $25 \%$ & 1 & 3000 & & & $1.511 .850,00$ & & & \\
\hline $25 \%$ & 1 & 5000 & & & $2.543 .600,00$ & & & \\
\hline \multicolumn{3}{|c|}{ SUBTOTAL DÍGRAFO 1} & & & & $-0,18 \%$ & $1,71 \%$ & $2,20 \%$ \\
\hline $25 \%$ & 2 & 100 & $59.693,21$ & $61.115,87$ & $60.849,04$ & $-0,44 \%$ & $1,94 \%$ & $2,38 \%$ \\
\hline $25 \%$ & 2 & 200 & $103.758,14$ & $105.094,20$ & $104.900,68$ & $-0,18 \%$ & $1,10 \%$ & $1,29 \%$ \\
\hline $25 \%$ & 2 & 500 & $258.835,18$ & $260.917,79$ & $260.806,80$ & $-0,04 \%$ & $0,76 \%$ & $0,80 \%$ \\
\hline $25 \%$ & 2 & 1000 & & $584.863,83$ & $584.445,80$ & $-0,07 \%$ & & \\
\hline $25 \%$ & 2 & 1500 & & $844.160,03$ & $845.184,80$ & $0,12 \%$ & & \\
\hline $25 \%$ & 2 & 3000 & & & $1.621 .550,00$ & & & \\
\hline $25 \%$ & 2 & 5000 & & & $2.706 .700,00$ & & & \\
\hline \multicolumn{3}{|c|}{ SUBTOTAL DÍGRAFO 2} & & & & $0,00 \%$ & $1,01 \%$ & $1,15 \%$ \\
\hline $25 \%$ & 3 & 100 & $45.424,38$ & $46.014,73$ & $45.769,30$ & $-0,53 \%$ & $0,76 \%$ & $1,30 \%$ \\
\hline $25 \%$ & 3 & 200 & $91.602,43$ & $92.482,54$ & $92.063,88$ & $-0,45 \%$ & $0,50 \%$ & $0,96 \%$ \\
\hline $25 \%$ & 3 & 500 & $230.619,41$ & $231.552,55$ & $231.581,80$ & $0,01 \%$ & $0,42 \%$ & $0,40 \%$ \\
\hline $25 \%$ & 3 & 1000 & & $528.979,41$ & $529.058,40$ & $0,01 \%$ & & \\
\hline $25 \%$ & 3 & 1500 & & $798.754,35$ & $798.918,20$ & $0,02 \%$ & & \\
\hline $25 \%$ & 3 & 3000 & & & $1.197 .000,00$ & & & \\
\hline $25 \%$ & 3 & 5000 & & & $2.023 .570,00$ & & & \\
\hline \multicolumn{3}{|c|}{ SUBTOTAL DÍGRAFO 3} & & & & $-0,02 \%$ & $0,48 \%$ & $0,65 \%$ \\
\hline \multicolumn{3}{|c|}{ TOTAL } & & & & $-0,07 \%$ & $1,11 \%$ & $1,39 \%$ \\
\hline
\end{tabular}


Tabela 4-36: Comparação das soluções para problemas desbalanceados $(50 \%)$ e com dois reposicionamentos

\begin{tabular}{|c|c|c|c|c|c|c|c|c|}
\hline \multirow[b]{2}{*}{ DESBAL. } & \multirow[b]{2}{*}{ DÍGRAFO } & \multirow[b]{2}{*}{ ROTAS } & \multicolumn{3}{|c|}{ RESULTADOS (\#) } & \multicolumn{3}{|c|}{ DIFERENÇAS (\%) } \\
\hline & & & PLI & GH & CD & $\mathrm{CD} \times \mathrm{GH}$ & CD x PLI & GH $\times$ PLI \\
\hline $50 \%$ & 1 & 100 & $66.006,22$ & $67.332,66$ & $67.049,88$ & $-0,42 \%$ & $1,58 \%$ & $2,01 \%$ \\
\hline $50 \%$ & 1 & 200 & $126.834,86$ & $130.125,67$ & $129.809,60$ & $-0,24 \%$ & $2,35 \%$ & $2,59 \%$ \\
\hline $50 \%$ & 1 & 500 & $312.874,72$ & $317.936,79$ & $317.140,80$ & $-0,25 \%$ & $1,36 \%$ & $1,62 \%$ \\
\hline $50 \%$ & 1 & 1000 & & $619.791,98$ & $619.503,80$ & $-0,05 \%$ & & \\
\hline $50 \%$ & 1 & 1500 & & $935.250,58$ & $937.306,20$ & $0,22 \%$ & & \\
\hline $50 \%$ & 1 & 3000 & & & $1.989 .400,00$ & & & \\
\hline $50 \%$ & 1 & 5000 & & & $3.300 .980,00$ & & & \\
\hline \multicolumn{3}{|c|}{ SUBTOTAL DÍGRAFO 1} & & & & $0,02 \%$ & $1,64 \%$ & $1,91 \%$ \\
\hline $50 \%$ & 2 & 100 & $60.347,70$ & $61.831,35$ & $61.286,72$ & $-0,88 \%$ & $1,56 \%$ & $2,46 \%$ \\
\hline $50 \%$ & 2 & 200 & $125.662,03$ & $126.977,80$ & $126.689,00$ & $-0,23 \%$ & $0,82 \%$ & $1,05 \%$ \\
\hline $50 \%$ & 2 & 500 & $314.886,48$ & $316.898,03$ & $317.011,00$ & $0,04 \%$ & $0,67 \%$ & $0,64 \%$ \\
\hline $50 \%$ & 2 & 1000 & & $641.805,06$ & $642.064,00$ & $0,04 \%$ & & \\
\hline $50 \%$ & 2 & 1500 & & $957.058,15$ & $958.296,00$ & $0,13 \%$ & & \\
\hline $50 \%$ & 2 & 3000 & & & $1.582 .770,00$ & & & \\
\hline $50 \%$ & 2 & 5000 & & & $2.618 .980,00$ & & & \\
\hline \multicolumn{3}{|c|}{ SUBTOTAL DÍGRAFO 2} & & & & $0,04 \%$ & $0,82 \%$ & $0,96 \%$ \\
\hline $50 \%$ & 3 & 100 & $54.571,74$ & $54.802,43$ & $54.809,62$ & $0,01 \%$ & $0,44 \%$ & $0,42 \%$ \\
\hline $50 \%$ & 3 & 200 & $115.919,43$ & $116.394,28$ & $116.326,08$ & $-0,06 \%$ & $0,35 \%$ & $0,41 \%$ \\
\hline $50 \%$ & 3 & 500 & $296.690,92$ & $298.193,53$ & $297.822,20$ & $-0,12 \%$ & $0,38 \%$ & $0,51 \%$ \\
\hline $50 \%$ & 3 & 1000 & & $647.135,34$ & $647.415,00$ & $0,04 \%$ & & \\
\hline $50 \%$ & 3 & 1500 & & $878.805,82$ & $880.113,00$ & $0,15 \%$ & & \\
\hline $50 \%$ & 3 & 3000 & & & $1.421 .480,00$ & & & \\
\hline $50 \%$ & 3 & 5000 & & & $2.361 .800,00$ & & & \\
\hline \multicolumn{3}{|c|}{ SUBTOTAL DÍGRAFO 3} & & & & $0,06 \%$ & $0,38 \%$ & $0,47 \%$ \\
\hline \multicolumn{3}{|c|}{ TOTAL } & & & & $0,04 \%$ & $0,96 \%$ & $1,13 \%$ \\
\hline
\end{tabular}


Tabela 4-37: Comparação das soluções para problemas desbalanceados $(75 \%)$ e com dois reposicionamentos

\begin{tabular}{|c|c|c|c|c|c|c|c|c|}
\hline \multirow[b]{2}{*}{ DESBAL. } & \multirow[b]{2}{*}{ DÍGRAFO } & \multirow[b]{2}{*}{ ROTAS } & \multicolumn{3}{|c|}{ RESULTADOS (\#) } & \multicolumn{3}{|c|}{ DIFERENÇAS (\%) } \\
\hline & & & PLI & GH & CD & CD x GH & CD x PLI & GH $x$ PLI \\
\hline $75 \%$ & 1 & 100 & $69.258,52$ & $70.431,38$ & $70.320,46$ & $-0,16 \%$ & $1,53 \%$ & $1,69 \%$ \\
\hline $75 \%$ & 1 & 200 & $138.828,16$ & $142.018,45$ & $141.458,00$ & $-0,39 \%$ & $1,89 \%$ & $2,30 \%$ \\
\hline $75 \%$ & 1 & 500 & $342.942,38$ & $347.994,43$ & $347.851,60$ & $-0,04 \%$ & $1,43 \%$ & $1,47 \%$ \\
\hline $75 \%$ & 1 & 1000 & & $731.747,89$ & $733.786,60$ & $0,28 \%$ & & \\
\hline $75 \%$ & 1 & 1500 & & $1.060 .549,88$ & $1.065 .695,40$ & $0,49 \%$ & & \\
\hline $75 \%$ & 1 & 3000 & & & $2.175 .520,00$ & & & \\
\hline $75 \%$ & 1 & 5000 & & & $3.679 .480,00$ & & & \\
\hline \multicolumn{3}{|c|}{ SUBTOTAL DÍGRAFO 1} & & & & $0,27 \%$ & $1,56 \%$ & $1,71 \%$ \\
\hline $75 \%$ & 2 & 100 & $73.146,63$ & $73.740,74$ & $73.673,72$ & $-0,09 \%$ & $0,72 \%$ & $0,81 \%$ \\
\hline $75 \%$ & 2 & 200 & $137.755,12$ & $138.943,54$ & $138.869,00$ & $-0,05 \%$ & $0,81 \%$ & $0,86 \%$ \\
\hline $75 \%$ & 2 & 500 & $355.387,52$ & $358.540,49$ & $358.322,60$ & $-0,06 \%$ & $0,83 \%$ & $0,89 \%$ \\
\hline $75 \%$ & 2 & 1000 & & $723.082,39$ & $724.602,40$ & $0,21 \%$ & & \\
\hline $75 \%$ & 2 & 1500 & & $1.159 .750,27$ & $1.165 .807,60$ & $0,52 \%$ & & \\
\hline $75 \%$ & 2 & 3000 & & & $1.852 .990,00$ & & & \\
\hline $75 \%$ & 2 & 5000 & & & $3.100 .400,00$ & & & \\
\hline \multicolumn{3}{|c|}{ SUBTOTAL DÍGRAFO 2} & & & & $0,29 \%$ & $0,81 \%$ & $0,87 \%$ \\
\hline $75 \%$ & 3 & 100 & $61.212,05$ & $61.445,59$ & $61.413,34$ & $-0,05 \%$ & $0,33 \%$ & $0,38 \%$ \\
\hline $75 \%$ & 3 & 200 & $138.848,15$ & $139.838,78$ & $139.490,70$ & $-0,25 \%$ & $0,46 \%$ & $0,71 \%$ \\
\hline $75 \%$ & 3 & 500 & $318.656,08$ & $320.065,38$ & $320.059,00$ & $0,00 \%$ & $0,44 \%$ & $0,44 \%$ \\
\hline $75 \%$ & 3 & 1000 & & $722.691,93$ & $723.068,40$ & $0,05 \%$ & & \\
\hline $75 \%$ & 3 & 1500 & & $1.094 .442,30$ & $1.094 .503,80$ & $0,01 \%$ & & \\
\hline $75 \%$ & 3 & 3000 & & & $1.641 .170,00$ & & & \\
\hline $75 \%$ & 3 & 5000 & & & $2.776 .630,00$ & & & \\
\hline \multicolumn{3}{|c|}{ SUBTOTAL DÍGRAFO 3} & & & & $0,00 \%$ & $0,43 \%$ & $0,51 \%$ \\
\hline \multicolumn{3}{|c|}{ TOTAL } & & & & $0,19 \%$ & $0,94 \%$ & $1,04 \%$ \\
\hline
\end{tabular}


A Tabela 4-38 a seguir, apresenta a comparação dos tempos de execução dos três métodos para os problemas balanceados com permissão de dois reposicionamentos. Para $\mathrm{PLI}$ e $\mathrm{GH}$, os tempos de geração de ciclos viáveis estão somados aos tempos dos métodos.

Tabela 4-38: Comparação dos tempos de execução para problemas balanceados e com dois reposicionamentos

\begin{tabular}{|c|c|c|c|c|c|}
\hline \multirow[b]{2}{*}{ DESBAL. } & \multirow[b]{2}{*}{ DÍGRAFO } & \multirow[b]{2}{*}{ ROTAS } & \multicolumn{3}{|c|}{ TEMPOS DE EXECUÇÃO (s) } \\
\hline & & & PLI & GH & CD \\
\hline $0 \%$ & 1 & 100 & 0,07 & 0,03 & 0,17 \\
\hline $0 \%$ & 1 & 200 & 0,30 & 0,12 & 0,71 \\
\hline $0 \%$ & 1 & 500 & 18,37 & 3,48 & 2,17 \\
\hline $0 \%$ & 1 & 1000 & & 44,98 & 6,30 \\
\hline $0 \%$ & 1 & 1500 & & 210,65 & 10,35 \\
\hline $0 \%$ & 1 & 3000 & & & 34,66 \\
\hline $0 \%$ & 1 & 5000 & & & 70,47 \\
\hline $0 \%$ & 2 & 100 & 0,07 & 0,02 & 0,16 \\
\hline $0 \%$ & 2 & 200 & 0,28 & 0,12 & 0,47 \\
\hline $0 \%$ & 2 & 500 & 17,68 & 3,50 & 2,29 \\
\hline $0 \%$ & 2 & 1000 & & 45,34 & 8,96 \\
\hline $0 \%$ & 2 & 1500 & & 210,72 & 14,85 \\
\hline $0 \%$ & 2 & 3000 & & & 41,90 \\
\hline $0 \%$ & 2 & 5000 & & & 95,87 \\
\hline $0 \%$ & 3 & 100 & 0,07 & 0,02 & 0,09 \\
\hline $0 \%$ & 3 & 200 & 0,37 & 0,12 & 0,30 \\
\hline $0 \%$ & 3 & 500 & 17,73 & 3,31 & 2,94 \\
\hline $0 \%$ & 3 & 1000 & & 43,44 & 10,52 \\
\hline $0 \%$ & 3 & 1500 & & 202,25 & 22,70 \\
\hline $0 \%$ & 3 & 3000 & & & 63,69 \\
\hline $0 \%$ & 3 & 5000 & & & 144,74 \\
\hline
\end{tabular}

Ao contrário do que foi observado para os problemas com um reposicionamento, a Heurística CD possui tempos de execução maiores que GH e PLI apenas para os problemas pequenos (100 e 200 rotas). Além disso, o crescimento de seu tempo é sempre menos acentuado. Isso faz com que, por exemplo, para os problemas com 1500 rotas, a heurística executa uma instância em 10 a 20 segundos, dependendo do dígrafo. Por outro lado, GH necessita mais de 200 segundos. Esse comportamento fica mais evidente na Figura 4-29 e Figura 4-30 
que são os gráficos desses tempos de execução em função do número de rotas para problemas do dígrafo 1 e 3 , respectivamente.

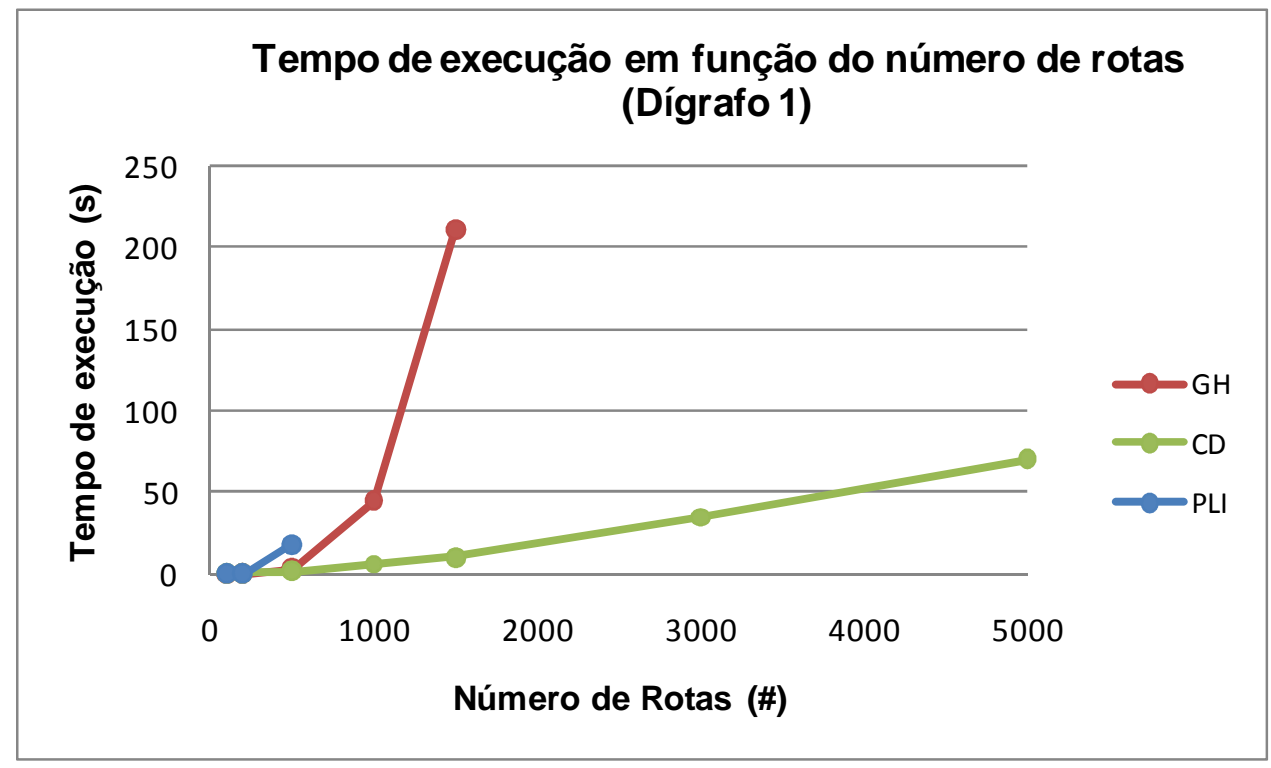

Figura 4-29: Gráfico do tempo de execução dos problemas balanceados com dois reposicionamentos (dígrafo 1 )

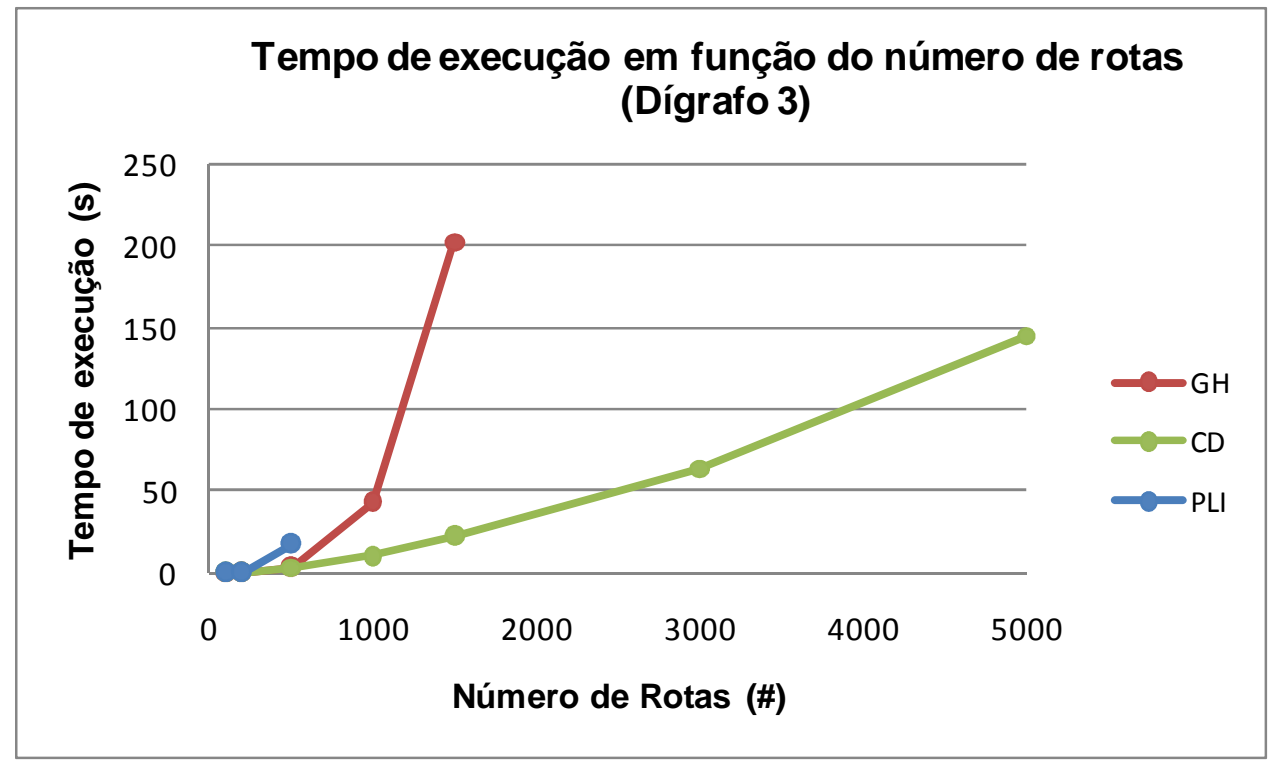

Figura 4-30: Gráfico do tempo de execução dos problemas balanceados com um reposicionamento (dígrafo 3 )

É importante salientar que o tempo originalmente obtido para $\mathrm{GH}$ por (ERGUN et al, 2007b) para os problemas de 1500 rotas do dígrafo 1 e dois 
reposicionamentos, por exemplo, foi de 1670,71 segundos, que é aproximadamente 8 vezes maior do o valor obtido por este estudo. Apesar da configuração dos computadores utilizados não ser exatamente a mesma, a diferença é significativa. Dado isso, a diferença entre CD e GH seria muito mais expressiva.

A Tabela 4-39, a Tabela 4-40 e a Tabela 4-41 a seguir, mostram a comparação dos tempos de execução dos três métodos, porém para os problemas desbalanceados (com 25\%, 50\% e 75\% de fator de desbalanceamento) com permissão para dois reposicionamentos. Para PLI e $\mathrm{GH}$, os tempos de geração de ciclos viáveis também estão somados aos tempos dos métodos.

Tabela 4-39: Comparação dos tempos de execução para problemas desbalanceados (25\%) e com dois reposicionamentos

\begin{tabular}{|c|c|c|c|c|c|}
\hline \multirow[b]{2}{*}{ DESBAL. } & \multirow[b]{2}{*}{ DÍGRAFO } & \multirow[b]{2}{*}{ ROTAS } & \multicolumn{3}{|c|}{ TEMPOS DE EXECUÇÃO (s) } \\
\hline & & & PLI & GH & CD \\
\hline $25 \%$ & 1 & 100 & 0,06 & 0,02 & 0,19 \\
\hline $25 \%$ & 1 & 200 & 0,26 & 0,10 & 0,79 \\
\hline $25 \%$ & 1 & 500 & 17,97 & 3,45 & 2,45 \\
\hline $25 \%$ & 1 & 1000 & & 43,35 & 8,73 \\
\hline $25 \%$ & 1 & 1500 & & 202,72 & 17,34 \\
\hline $25 \%$ & 1 & 3000 & & & 64,71 \\
\hline $25 \%$ & 1 & 5000 & & & 176,19 \\
\hline $25 \%$ & 2 & 100 & 0,06 & 0,01 & 0,16 \\
\hline $25 \%$ & 2 & 200 & 0,29 & 0,11 & 0,66 \\
\hline $25 \%$ & 2 & 500 & 14,51 & 3,18 & 3,02 \\
\hline $25 \%$ & 2 & 1000 & & 41,60 & 9,05 \\
\hline $25 \%$ & 2 & 1500 & & 196,24 & 18,22 \\
\hline $25 \%$ & 2 & 3000 & & & 47,89 \\
\hline $25 \%$ & 2 & 5000 & & & 133,62 \\
\hline $25 \%$ & 3 & 100 & 0,06 & 0,01 & 0,12 \\
\hline $25 \%$ & 3 & 200 & 0,26 & 0,12 & 0,52 \\
\hline $25 \%$ & 3 & 500 & 15,19 & 3,13 & 3,49 \\
\hline $25 \%$ & 3 & 1000 & & 39,89 & 11,90 \\
\hline $25 \%$ & 3 & 1500 & & 185,04 & 25,08 \\
\hline $25 \%$ & 3 & 3000 & & & 95,96 \\
\hline $25 \%$ & 3 & 5000 & & & 264,55 \\
\hline
\end{tabular}


Tabela 4-40: Comparação dos tempos de execução para problemas desbalanceados (50\%) e com dois reposicionamentos

\begin{tabular}{|c|c|c|c|c|c|}
\hline \multirow[b]{2}{*}{ DESBAL. } & \multirow[b]{2}{*}{ DÍGRAFO } & \multirow[b]{2}{*}{ ROTAS } & \multicolumn{3}{|c|}{ TEMPOS DE EXECUÇÃO (s) } \\
\hline & & & PLI & GH & CD \\
\hline $50 \%$ & 1 & 100 & 0,09 & 0,03 & 0,22 \\
\hline $50 \%$ & 1 & 200 & 0,26 & 0,10 & 1,01 \\
\hline $50 \%$ & 1 & 500 & 12,02 & 3,04 & 4,56 \\
\hline $50 \%$ & 1 & 1000 & & 37,87 & 17,73 \\
\hline $50 \%$ & 1 & 1500 & & 175,50 & 37,94 \\
\hline $50 \%$ & 1 & 3000 & & & 137,19 \\
\hline $50 \%$ & 1 & 5000 & & & 392,47 \\
\hline $50 \%$ & 2 & 100 & 0,06 & 0,02 & 0,17 \\
\hline $50 \%$ & 2 & 200 & 0,40 & 0,11 & 0,80 \\
\hline $50 \%$ & 2 & 500 & 13,25 & 2,83 & 5,49 \\
\hline $50 \%$ & 2 & 1000 & & 35,86 & 19,98 \\
\hline $50 \%$ & 2 & 1500 & & 166,64 & 43,37 \\
\hline $50 \%$ & 2 & 3000 & & & 200,31 \\
\hline $50 \%$ & 2 & 5000 & & & 536,90 \\
\hline $50 \%$ & 3 & 100 & 0,06 & 0,01 & 0,17 \\
\hline $50 \%$ & 3 & 200 & 0,25 & 0,10 & 0,82 \\
\hline $50 \%$ & 3 & 500 & 15,98 & 2,74 & 5,92 \\
\hline $50 \%$ & 3 & 1000 & & 34,73 & 22,36 \\
\hline $50 \%$ & 3 & 1500 & & 158,18 & 51,26 \\
\hline $50 \%$ & 3 & 3000 & & & 238,51 \\
\hline $50 \%$ & 3 & 5000 & & & 639,02 \\
\hline
\end{tabular}


Tabela 4-41: Comparação dos tempos de execução para problemas desbalanceados (75\%) e com dois reposicionamentos

\begin{tabular}{|c|c|c|c|c|c|}
\hline \multirow[b]{2}{*}{ DESBAL. } & \multirow[b]{2}{*}{ DÍGRAFO } & \multirow[b]{2}{*}{ ROTAS } & \multicolumn{3}{|c|}{ TEMPOS DE EXECUÇÃO (s) } \\
\hline & & & PLI & GH & CD \\
\hline $75 \%$ & 1 & 100 & 0,06 & 0,02 & 0,25 \\
\hline $75 \%$ & 1 & 200 & 0,22 & 0,10 & 1,37 \\
\hline $75 \%$ & 1 & 500 & 4,89 & 2,19 & 8,12 \\
\hline $75 \%$ & 1 & 1000 & & 27,47 & 30,50 \\
\hline $75 \%$ & 1 & 1500 & & 118,79 & 70,82 \\
\hline $75 \%$ & 1 & 3000 & & & 263,22 \\
\hline $75 \%$ & 1 & 5000 & & & 739,45 \\
\hline $75 \%$ & 2 & 100 & 0,06 & 0,02 & 0,23 \\
\hline $75 \%$ & 2 & 200 & 0,21 & 0,09 & 1,28 \\
\hline $75 \%$ & 2 & 500 & 4,81 & 2,20 & 8,67 \\
\hline $75 \%$ & 2 & 1000 & & 26,73 & 33,74 \\
\hline $75 \%$ & 2 & 1500 & & 119,46 & 77,42 \\
\hline $75 \%$ & 2 & 3000 & & & 334,47 \\
\hline $75 \%$ & 2 & 5000 & & & 921,12 \\
\hline $75 \%$ & 3 & 100 & 0,06 & 0,02 & 0,24 \\
\hline $75 \%$ & 3 & 200 & 0,21 & 0,09 & 1,18 \\
\hline $75 \%$ & 3 & 500 & 4,65 & 2,09 & 9,79 \\
\hline $75 \%$ & 3 & 1000 & & 25,59 & 36,90 \\
\hline $75 \%$ & 3 & 1500 & & 113,74 & 81,71 \\
\hline $75 \%$ & 3 & 3000 & & & 352,50 \\
\hline $75 \%$ & 3 & 5000 & & & $1.008,48$ \\
\hline
\end{tabular}

Nota-se que o os problemas desbalanceados possuem as mesmas tendências que os balanceados. Da mesma forma que os problemas com um reposicionamento, com o aumento do desbalanceamento, o tempo de CD aumenta enquanto para os outros métodos, diminui. Porém os tempos de execução de CD são sempre menores para os problemas grandes (1500 rotas).

A Figura 4-31, a Figura 4-32 e a Figura 4-33 a seguir ilustram os tempos de execução em função do número de rotas para os problemas com $25 \%, 50 \%$ e $75 \%$ de desbalanceamento, respectivamente, e um único reposicionamento. 

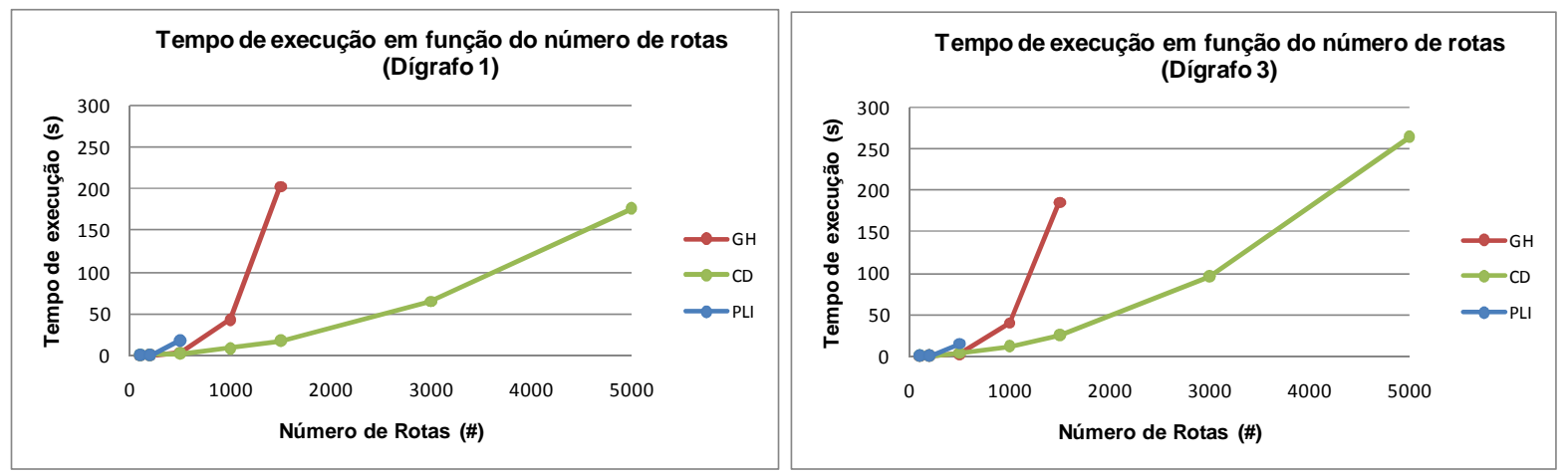

Figura 4-31: Gráfico do tempo de execução dos problemas desbalanceados (25\%) com dois reposicionamentos (dígrafo 1 e 3 )
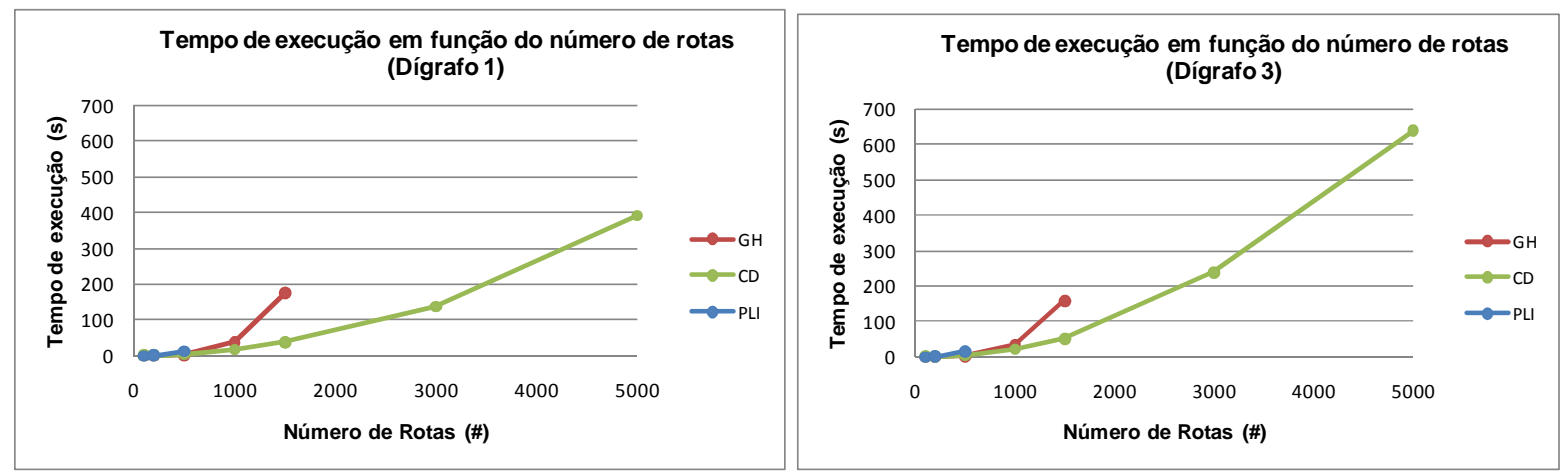

Figura 4-32: Gráfico do tempo de execução dos problemas desbalanceados (50\%) com dois reposicionamentos (dígrafo 1 e 3 )
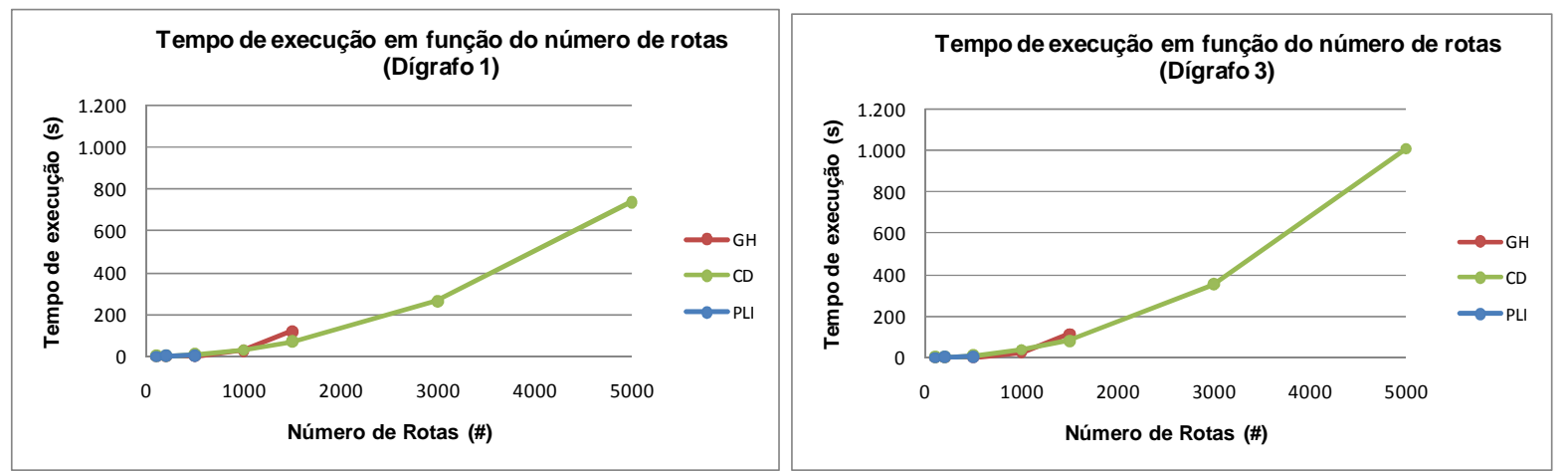

Figura 4-33: Gráfico do tempo de execução dos problemas desbalanceados (75\%) com dois reposicionamentos (dígrafo 1 e 3 ) 


\subsection{Análise dos tempos de execução}

Em função dos resultados dos tempos de execução obtidos, fez-se uma última análise para verificar a tendência de crescimento desses tempos em função do número de rotas. Para isso, gerou-se outro conjunto de problemas e, a partir de seu resultado, analisou-se o tempo de execução com gráficos e regressões.

Buscou-se utilizar, para esse novo conjunto de problemas, uma situação intermediária e, dessa forma, utilizou-se o dígrafo 2 como base. Além disso, buscouse gerar um número maior de problemas para não influenciar a regressão. Assim, foram gerados problemas com os seguintes números de rotas: 100, 500, 1000, $1500,2000,2500,3000,3500,4000,4500$ e 5000.

Por fim, optou-se por utilizar os problemas sem desbalanceamentos para utilizar o gerador original de (ERGUN et al, 2007b).

A Heurística CD foi aplicada utilizando-se os mesmo parâmetros utilizados para o dígrafo 2 apresentados em 4.6.1 e 4.6.2 para os problemas com um e dois reposicionamentos permitidos, respectivamente.

A análise foi feita separadamente para os problemas com um ou dois reposicionamentos.

\subsubsection{Regressão para os problemas com um reposicionamento}

Os tempos de execução para os problemas estão apresentados na Tabela 4-42 a seguir. Os tempos de geração de ciclos foram adicionados aos tempos de PLI e GH.

O problema com 5000 rotas não foi executado por PLI devido à restrição de memória do computador. Os demais problemas foram executados normalmente para os três métodos. 
Tabela 4-42: Tempos de execução para a regressão dos problemas com um reposicionamento

\begin{tabular}{|c|c|c|c|}
\hline \multirow[b]{2}{*}{ ROTAS } & \multicolumn{3}{|c|}{ TEMPOS DE EXECUÇÃO (s) } \\
\hline & PLI & GH & CD \\
\hline 100 & 0,03 & 0,01 & 0,20 \\
\hline 500 & 0,05 & 0,04 & 2,54 \\
\hline 1000 & 0,54 & 0,34 & 7,24 \\
\hline 1500 & 9,81 & 1,99 & 13,20 \\
\hline 2000 & 121,01 & 7,82 & 18,64 \\
\hline 2500 & 637,41 & 21,57 & 25,87 \\
\hline 3000 & $4.774,24$ & 51,93 & 32,28 \\
\hline 3500 & $13.716,90$ & 113,04 & 38,73 \\
\hline 4000 & $32.316,73$ & 210,95 & 47,40 \\
\hline 4500 & $67.307,83$ & 385,24 & 56,79 \\
\hline 5000 & & 667,84 & 68,09 \\
\hline
\end{tabular}

Nota-se que foram obtidas as mesmas ordens de grandeza para os tempos de execução dos problemas com a mesma característica apresentados na Tabela 4-30.

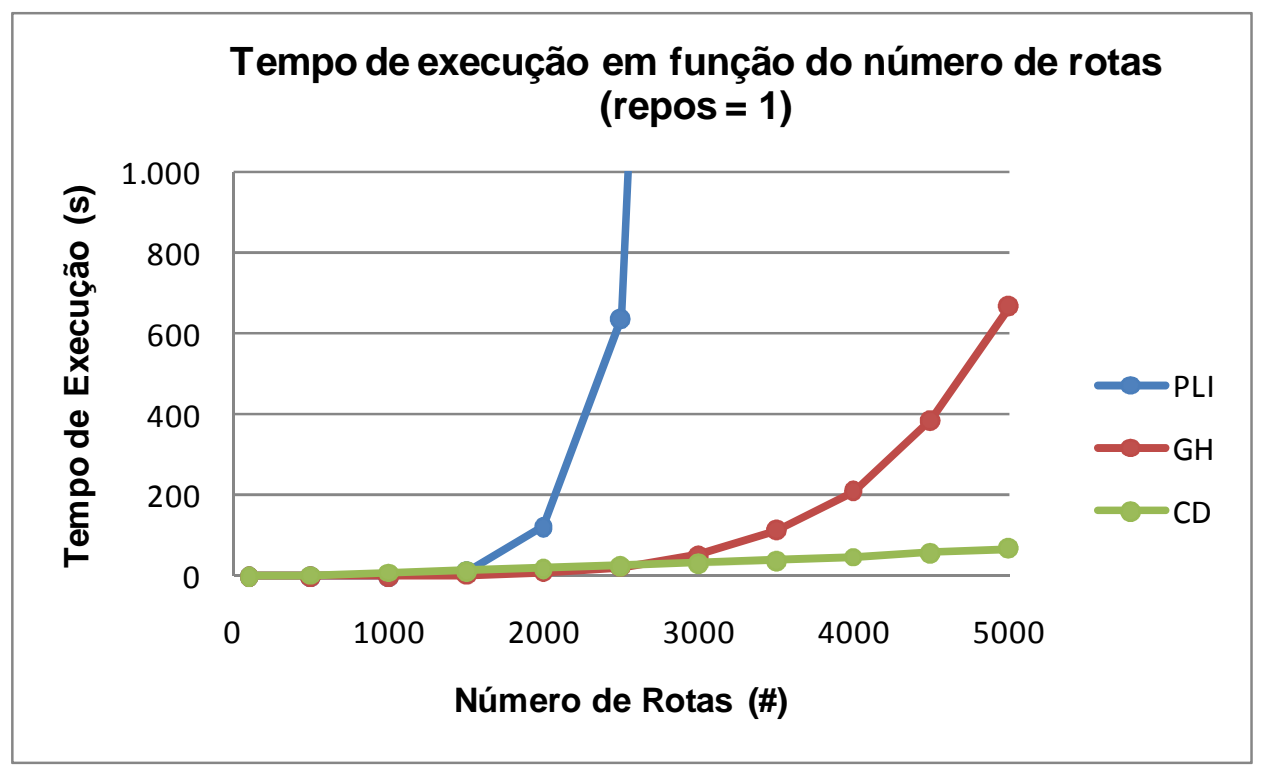

Figura 4-34: Gráfico do tempo de execução em função do número de rotas dos problemas com um reposicionamento

A Figura 4-34 mostra um gráfico com a comparação dos tempos dos três métodos. 
A partir desses tempos, foram gerados os gráficos a seguir com as regressões para cada método.

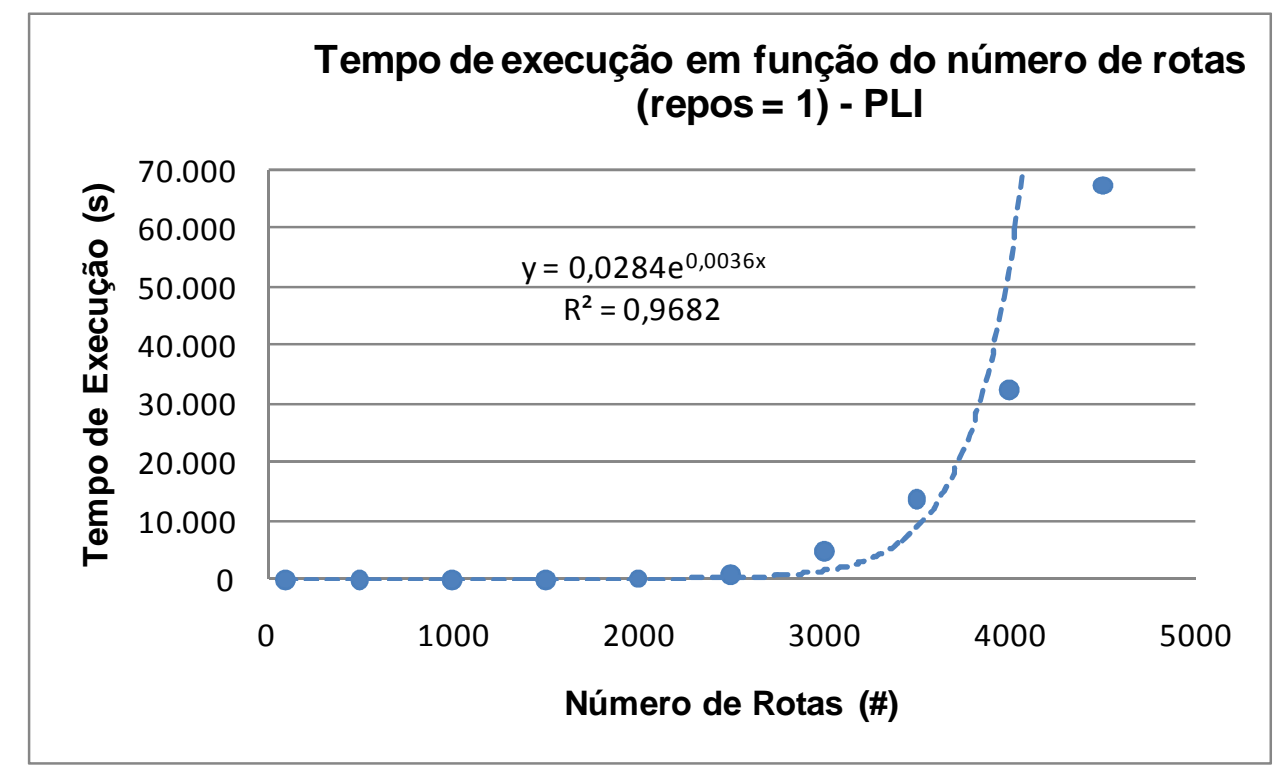

Figura 4-35: Gráfico e regressão do tempo de execução em função do número de rotas dos problemas com um reposicionamento para PLI

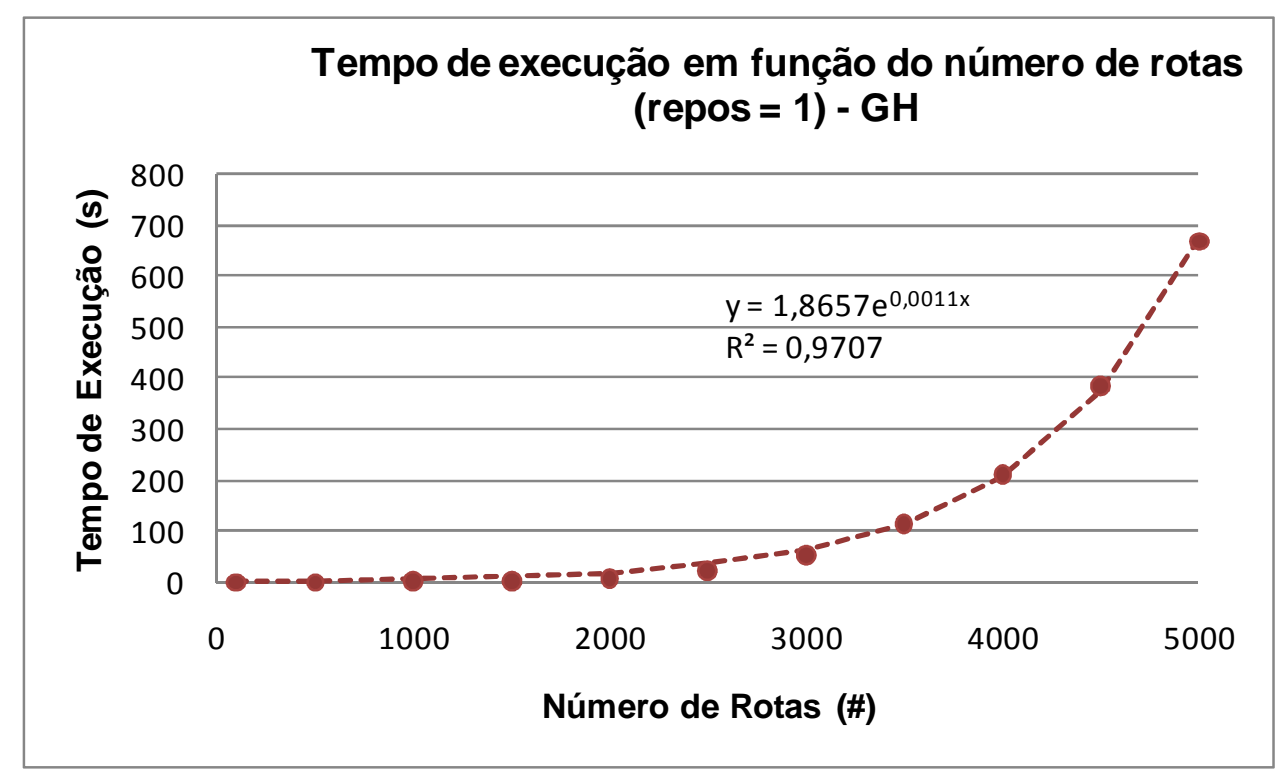

Figura 4-36: Gráfico e regressão do tempo de execução em função do número de rotas dos problemas com um reposicionamento para GH 


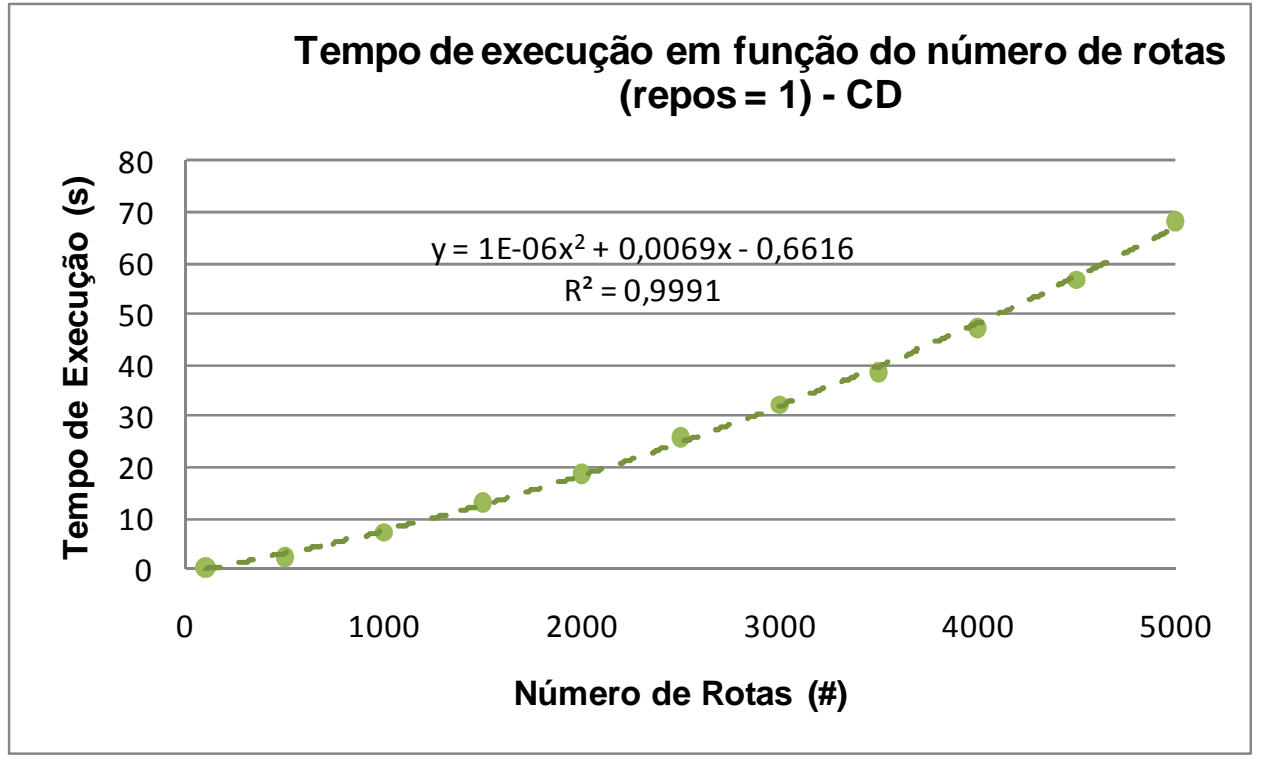

Figura 4-37: Gráfico e regressão do tempo de execução em função do número de rotas dos problemas com um reposicionamento para CD

Nota-se que tanto GH quanto PLI foram ajustadas pela regressão por uma curva exponencial com boa aderência (ambas com $\mathrm{R}^{2}$ superior a $95 \%$ ). A Heurística CD foi ajustada por uma curva polinomial de grau dois com excelente aderência $\left(R^{2}\right.$ $=99,91 \%$ ).

Dado isso, é possível estimar os tempos para qualquer tamanho de problema. Dessa forma, nota-se que para executar problemas maiores que 5000 rotas, os temos necessários para PLI e GH serão muito maiores se comparados com os de CD.

\subsubsection{Regressão para os problemas com dois reposicionamentos}

O mesmo processo foi feito para os problemas com dois reposicionamentos e os tempos de execução estão apresentados na Tabela 4-43 a seguir. Da mesma forma, os tempos de geração de ciclos foram adicionados aos tempos de PLI e GH. 
Tabela 4-43: Tempos de execução para a regressão dos problemas com dois reposicionamentos

\begin{tabular}{crrr} 
& \multicolumn{3}{c}{ TEMPOS DE EXECUÇÃO (s) } \\
\cline { 2 - 4 } ROTAS & \multicolumn{1}{c}{ PLI } & GH & \multicolumn{1}{c}{ CD } \\
\cline { 2 - 4 } 100 & 0,05 & 0,00 & 0,31 \\
500 & 18,92 & 3,60 & 2,33 \\
1000 & $32.736,99$ & 45,50 & 7,35 \\
1500 & & 211,74 & 12,07 \\
2000 & & 687,61 & 20,19 \\
2500 & & $1.692,47$ & 28,32 \\
3000 & & & 35,53 \\
3500 & & & 50,91 \\
4000 & & & \\
4500 & & & \\
5000 & & & \\
\hline
\end{tabular}

Os problemas com mais de 1000 rotas não foi executado por PLI e os com mais de 2500 não foram executados por $\mathrm{GH}$ devido à restrição de memória do computador. Todos os problemas foram executados normalmente para CD.

Nota-se que foram obtidas as mesmas ordens de grandeza para os tempos de execução dos problemas com a mesma característica apresentados na Tabela 4-38. Além disso, conseguiu-se executar o problema com 1000 rotas para PLI, porém o tempo necessário para isso foi superior a $9 \mathrm{~h}$.

A Figura 4-38 mostra um gráfico com a comparação dos tempos dos três métodos. 


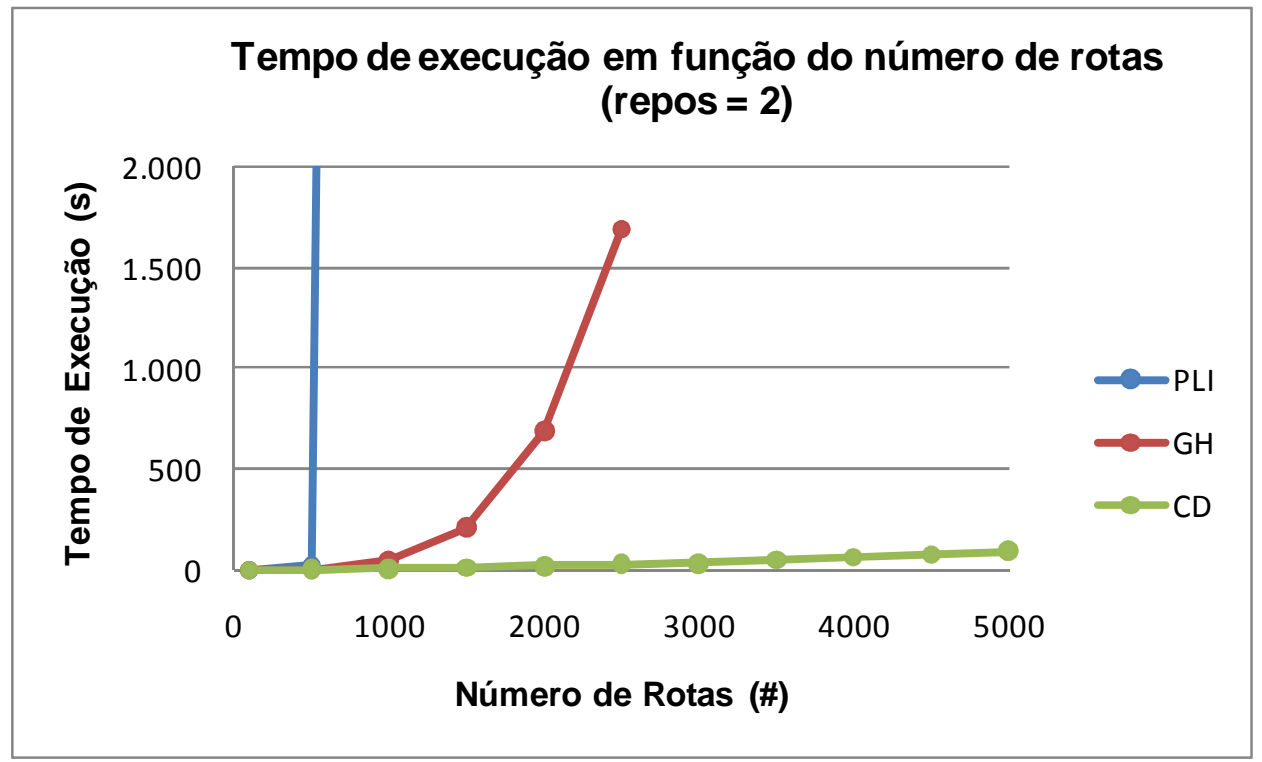

Figura 4-38: Gráfico do tempo de execução em função do número de rotas dos problemas com dois reposicionamentos

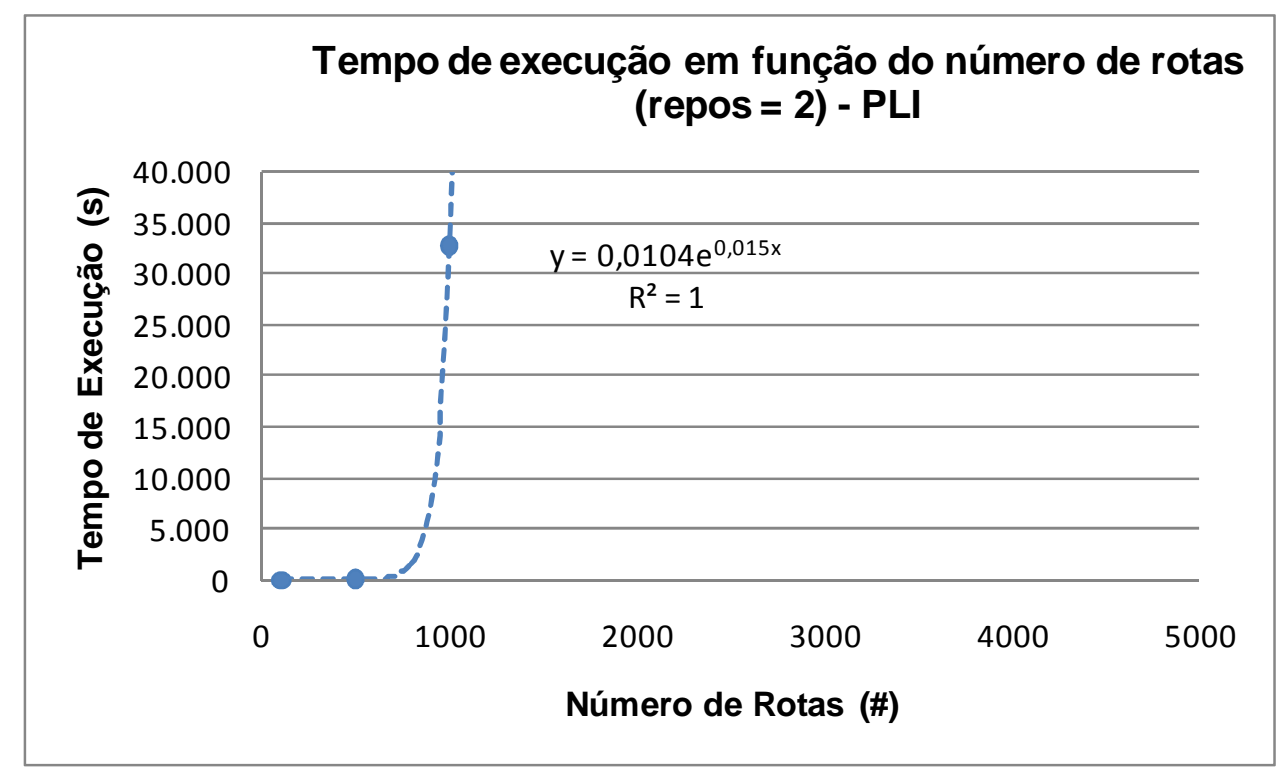

Figura 4-39: Gráfico e regressão do tempo de execução em função do número de rotas dos problemas com dois reposicionamentos para PLI 


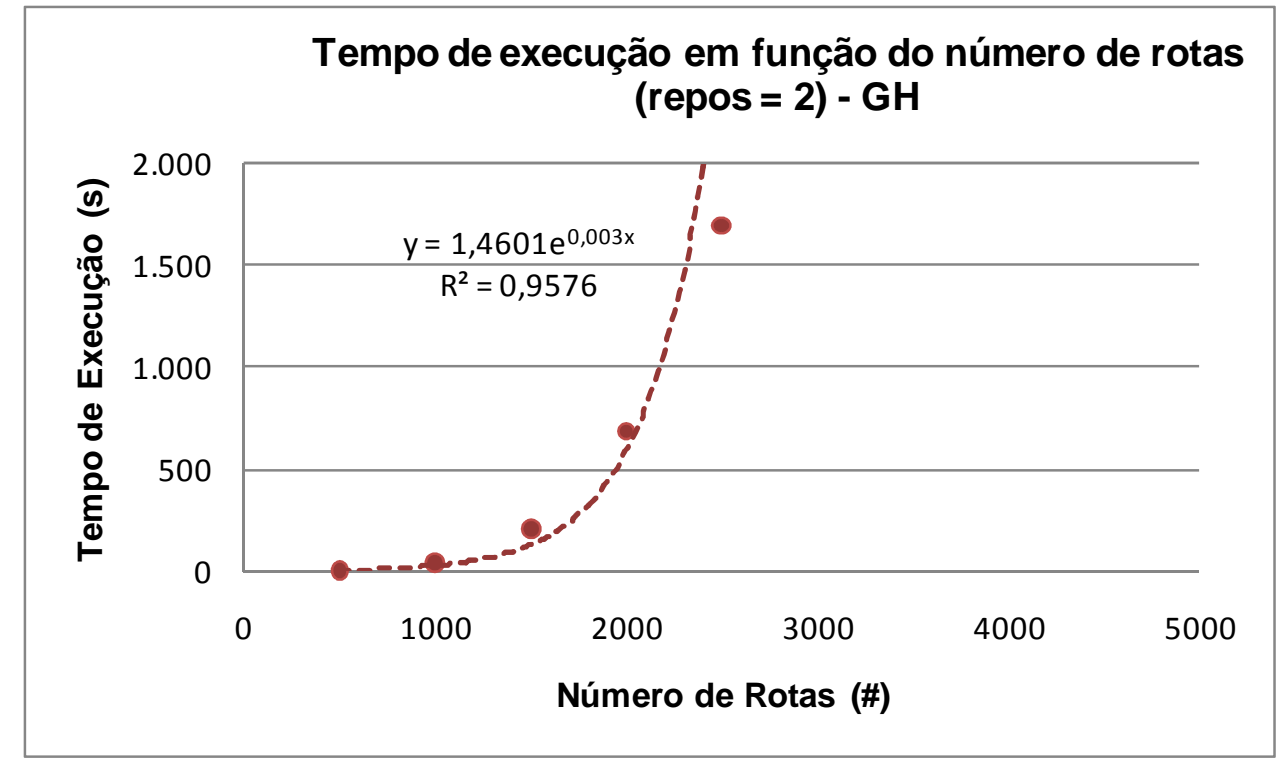

Figura 4-40: Gráfico e regressão do tempo de execução em função do número de rotas dos problemas com dois reposicionamentos para GH

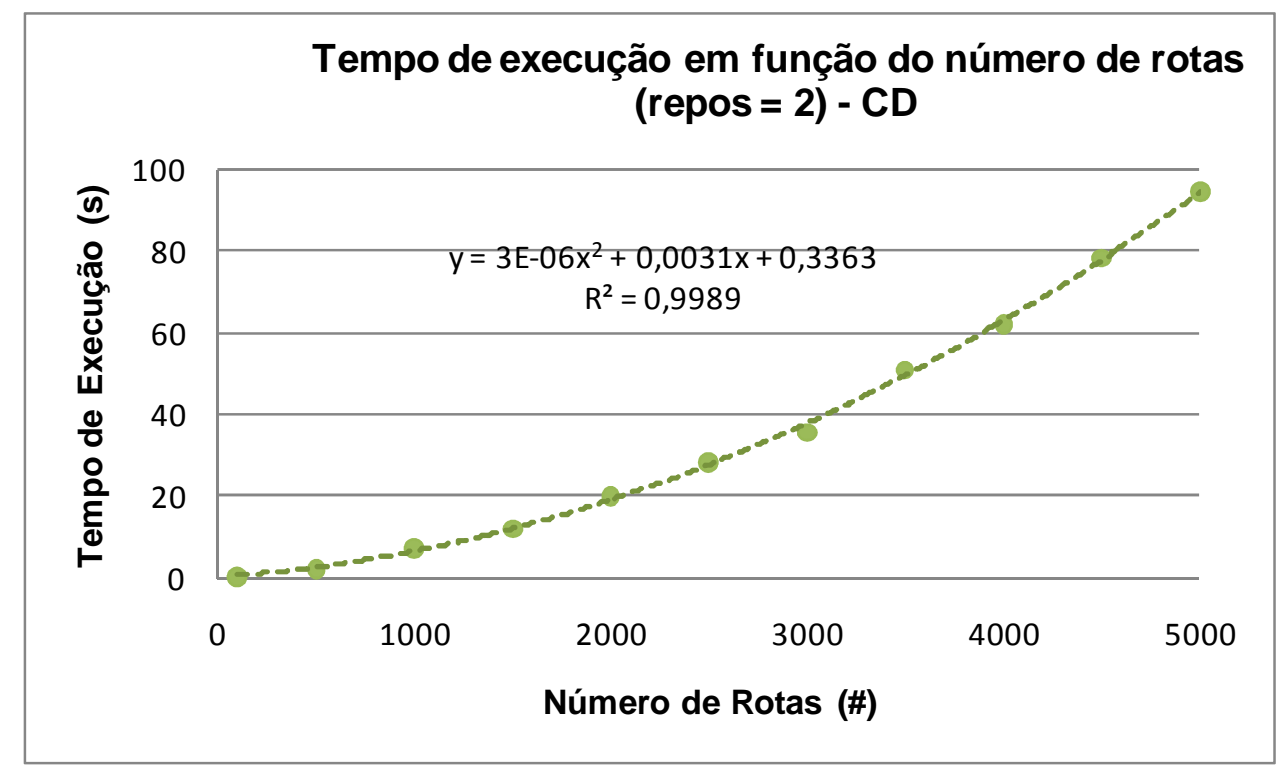

Figura 4-41: Gráfico e regressão do tempo de execução em função do número de rotas dos problemas com dois reposicionamentos para CD

Nota-se que GH e PLI foram ajustadas novamente pela regressão por uma curva exponencial com boa aderência (ambas com $\mathrm{R}^{2}$ superior a $95 \%$ ). O $\mathrm{R}^{2}$ obtido por PLI foi igual a 1, devido ao número pequeno de pontos obtidos (somente 3 pontos). 
A Heurística CD foi ajustada por uma curva polinomial de grau dois com excelente aderência $\left(R^{2}=99,89 \%\right)$. Isso permite conjecturar que seu tempo de execução pode ser realmente polinomial.

No próximo capítulo é feita a conclusão deste trabalho com base nos resultados apresentados neste capítulo, bem como a apresentação dos próximos passos. 


\section{CONCLUSÕES E PRÓXIMAS ETAPAS}

Este capítulo apresenta a conclusão do estudo e as sugestões para estudos futuros.

\subsection{Comentários sobre os resultados obtidos}

No capítulo anterior, foram apresentados os resultados de PLI, GH e CD para o problema de cobertura de rotas com cardinalidade restrita (PCRCR) que foram divididos em dois conjuntos: problemas em que eram permitidos ciclos com um único reposicionamento e com dois reposicionamentos. Os problemas foram separados para que seus resultados pudessem ser comparados com (ERGUN et al, 2007b).

Tabela 5-1: Média dos resultados de todos os problemas

\begin{tabular}{cccc} 
& \multicolumn{3}{c}{ DIFERENÇAS (\%) } \\
\cline { 3 - 4 } REPOS. & CD $\times$ GH & CD x PLI & GH x PLI \\
\hline 1 & $-2,19 \%$ & $5,91 \%$ & $7,58 \%$ \\
\hline 2 & $0,03 \%$ & $1,02 \%$ & $1,25 \%$ \\
\hline TOTAL & $-1,74 \%$ & $5,40 \%$ & $6,92 \%$ \\
\hline
\end{tabular}

A Heurística CD obteve um desempenho melhor, se comparado com 0 Algoritmo $\mathrm{GH}$, para os problemas com um único reposicionamento permitido. A diferença, para a média de todos os problemas (incluindo os balanceados e desbalanceados), ficou em $-2,19 \%$. Em relação a PLI, CD ficou com uma diferença de $5,91 \%$, enquanto que $\mathrm{GH}$ ficou com $7,58 \%$.

Para os problemas com dois reposicionamentos, a diferença de CD com GH, em relação à média de todos os problemas, ficou em $0,03 \%$. Em relação a $P L I, C D$ obteve uma diferença de $1,02 \%$ e GH, 1,25\%.

Ao considerar todos os problemas, $\mathrm{CD}$ obteve um ganho em relação a $\mathrm{GH}$ de -1,74\%. Comparando com PLI, CD obteve uma diferença de 5,40\% e GH, 6,92\%. Além disso, observa-se que a Heurística CD obteve melhores resultados que GH para $85 \%$ dos problemas executados. 
Observando-se os problemas em que CD obteve pior desempenho, que foi o caso dos problemas do dígrafo 2 com dois reposicionamentos com $75 \%$ de desbalanceamento, CD obteve diferença de 0,29\% em relação a $\mathrm{GH}$, porém ficou a 0,81\% de PLI. Observando também os problemas semelhantes em que 0 desempenho de CD foi pior em relação a $\mathrm{GH}$, nota-se a diferença em relação a PLI foi sempre relativamente pequena, indicando uma convergência dos resultados.

A Figura 5-1 a seguir, mostra a média geral dos tempos de execução para os problemas com um reposicionamento em função do número de rotas. Nota-se que, na média, a Heurística CD é mais rápida somente para aqueles de 5000 rotas. Para os demais problemas a heurística apresenta tempos maiores sendo que para aquele com 3000 rotas a diferença é maior chegando a, aproximadamente, 1 minuto.

Individualmente, o pior caso é obtido para as instâncias com $75 \%$ de desbalanceamento, chegando a aproximadamente 10 minutos, para a instância de 5000 rotas do dígrafo 3 , conforme a Tabela 4-33. Porém, para este mesmo caso, a diferença de resultado obtida é significativa, gerando um ganho de $-1,68 \%$ entre CD e $\mathrm{GH}$.

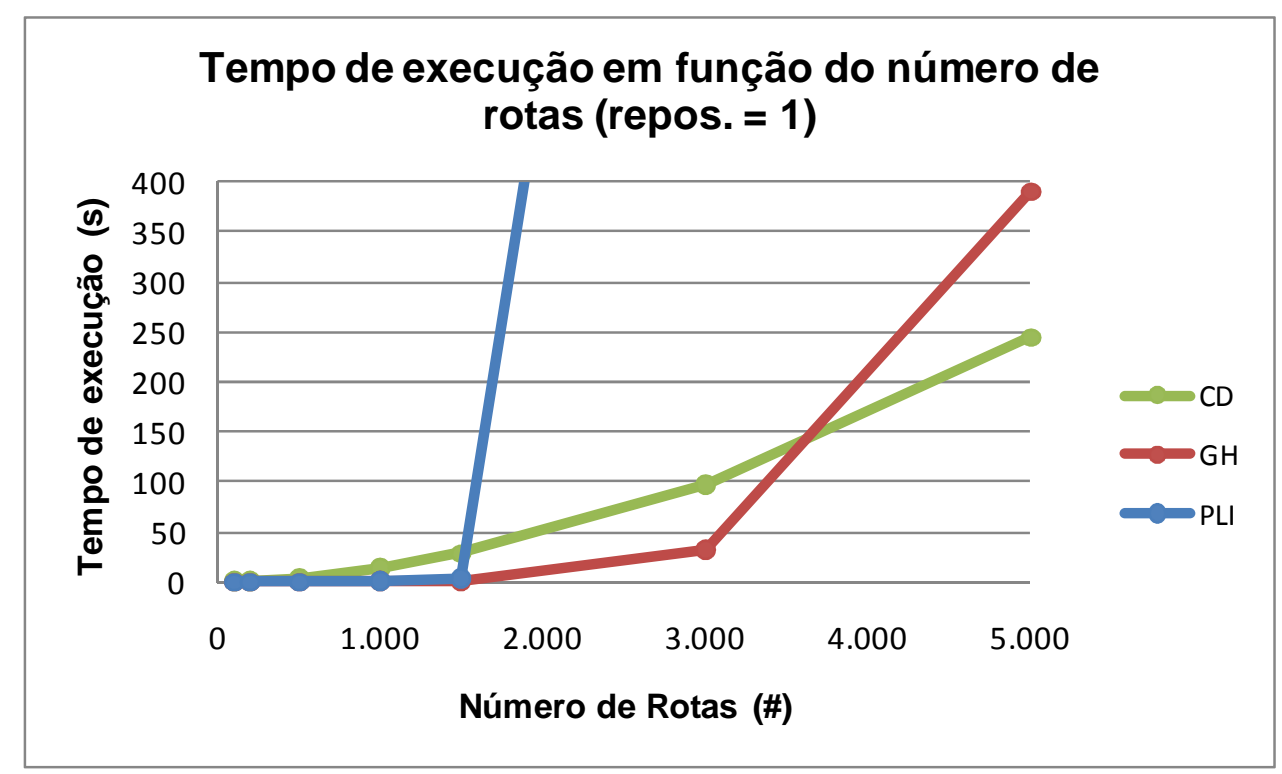

Figura 5-1: Média dos tempos de execução em função do número de rotas para problemas com um reposicionamento 
Para os problemas com dois reposicionamentos, a Figura 5-2 a seguir mostra a média global em função do número de rotas. A Heurística CD obtém melhores médias para problemas maiores que 500 rotas. Nota-se que os tempos médios obtidos por CD para aqueles com um e dois reposicionamentos são muito semelhantes.

O pior resultado individual obtido foi para a instância de $75 \%$ de desbalanceamento do dígrafo 3 com 1000 rotas, cuja diferença foi de apenas 10 segundos, aproximadamente, conforme a Tabela 4-41.

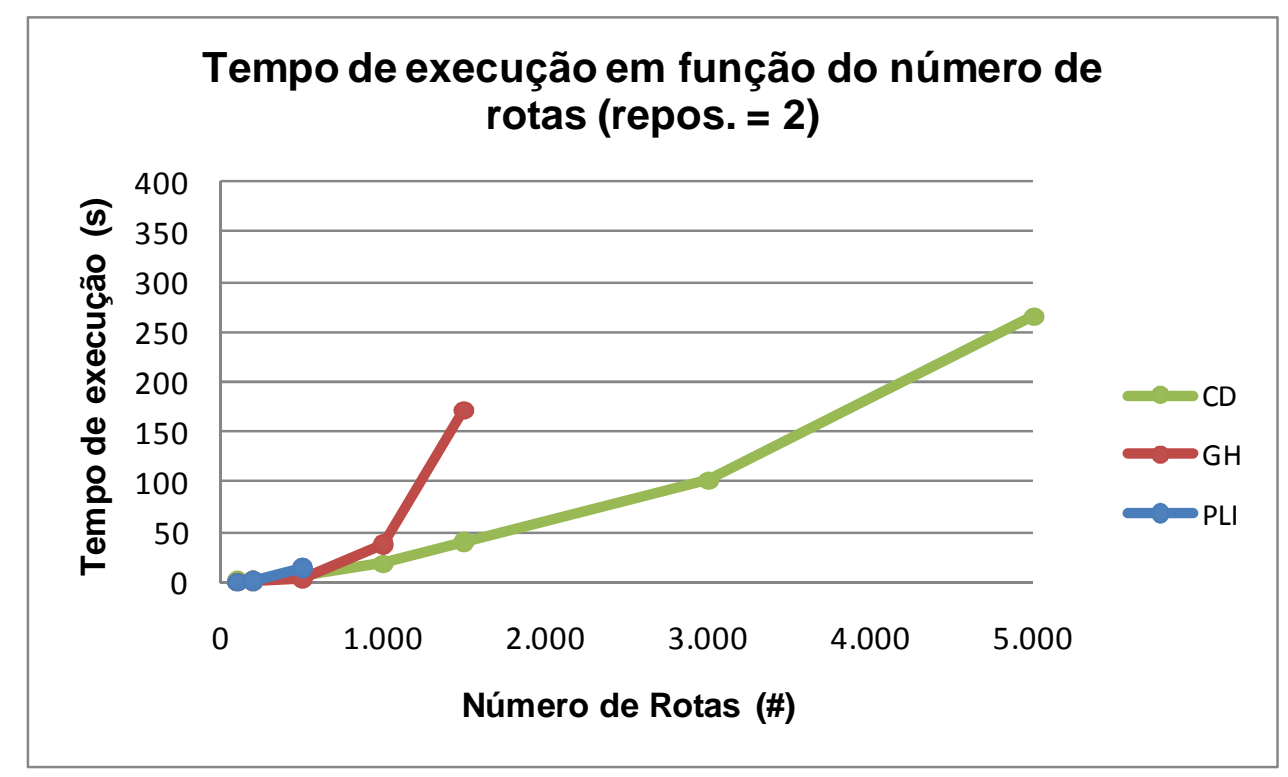

Figura 5-2: Média dos tempos de execução em função do número de rotas para problemas com dois reposicionamentos

Comparando-se os problemas executados, a Heurística CD foi o único método que conseguiu uma solução para todas as instâncias. O Algoritmo GH e PLI foram penalizados, já que o gerador de ciclos viáveis que não conseguiu gerar o conjunto de ciclos necessários para serem executados. Entretanto, é importante relembrar, conforme explicado em 3.1.2, que Ergun et al (2007b) separaram os problemas para um ou dois reposicionamentos pela dificuldade obtida na execução de GH e PLI devido ao número de combinações fornecidas pelo gerador de ciclos. Porém, conforme apontado em 4.4, a permissão de dois reposicionamentos é muito relevante, reduzindo o resultado de $10 \%$ a $40 \%$ melhores, em relação ao problema com um único reposicionamento. Além disso, aqueles em que são permitidos até 
dois reposicionamentos incluem, em seus conjuntos de ciclos viáveis, os ciclos para o caso de até um reposicionamento.

Dado isso, acredita-se que será difícil fazer com que GH e PLI consigam executar problemas maiores, como, por exemplo, de cardinalidade 6 e mais de 1500 , caso seja necessário, uma vez que o crescimento do número de ciclos viáveis gerados é exponencial.

\subsection{Comentários finais}

O problema de transporte colaborativo para embarcadores de carga lotação pode ser representado pelo problema de cobertura de rotas (PCR) e suas variações, como é o caso do problema de cobertura de rotas com cardinalidade restrita (PCRCR).

Este trabalho propôs uma heurística construtivo-destrutiva para solucionar o problema PCRCR que fosse independente da geração de todas as combinações de ciclos que respeitam as restrições de cardinalidade e número máximo de reposicionamentos.

Comparou-se a heurística proposta com os métodos disponíveis na literatura atual. Verificou-se que obteve melhores resultados que o Algoritmo $\mathrm{GH}$ proposto por (ERGUN et al, 2007b) para 85\% dos problemas avaliados que incluem também problemas com características de desbalanceamento entre os agrupamentos de vértices. Além disso, obteve-se um ganho global médio de $-1,74 \%$ em relação a $\mathrm{GH}$ e uma diferença de 5,4\% em relação a PLI.

Constatou-se que o tempo de execução de CD é menor para os problemas maiores e mais complexos (por exemplo, aqueles que possuem dois reposicionamentos). Além do mais, o aumento do tempo de execução em função do número de rotas apresentou característica polinomial, ao contrário de GH e PLI que apresentaram comportamento exponencial.

Ademais, a Heurística CD demonstra necessitar de muito menos memória para ser processada, o que permite solucionar instâncias significativamente maiores 
que a literatura disponível atualmente, pois independe da geração de todos os ciclos viáveis.

Portanto, conclui-se que os objetivos deste trabalho foram cumpridos.

\subsection{Propostas de estudos futuros}

Durante a realização desta dissertação, verificaram-se algumas oportunidades que ficam como sugestões para a continuidade dos estudos iniciados neste trabalho:

- Aplicação da Heurística CD em casos reais

- Aplicação de CD em problemas com características diferentes como, por exemplo, com cardinalidade maior e/ou número de reposicionamentos permitidos maiores.

- Utilização da heurística proposta como uma solução inicial de uma metaheurística.

- Modificação de CD considerando buscas locais ou trocas de rotas entre ciclos explorando vizinhanças.

- Integração deste estudo a outras classes de problemas como, por exemplo, considerar cobertura de rotas e de localização de instalações.

- Adaptação da heurística proposta para os problemas PCRER, PCRJT e PCRMT.

- Aplicar o método de geração de colunas para a execução do PLI.

- Adaptação da Heurística CD para o problema de cobertura de rotas que considere simultaneamente restrição de cardinalidade e de extensão máxima do ciclo. Podem-se considerar também custos fixos para a formação de ciclos. 


\subsection{Propostas de abordagens que não devem ser realizadas}

Durante o desenvolvimento da Heurística CD, outras abordagens foram avaliadas antes da versão apresentada nesta dissertação, porém que não trouxeram benefícios. Desejou-se compartilhá-las para que os próximos estudos não sigam por esses caminhos:

- A heurística construtiva sem a destruição de ciclos não gera ganhos significativos.

- A seleção da primeira rota do ciclo (a rota base) não gera ganhos se os ciclos do conjunto $U$ estiverem ordenados em ordem crescente.

- A seleção da rota base utilizando uma distribuição aleatória deve ser evitada.

- A seleção da rota base como sendo a rota entre dois agrupamentos que o menor número de viagens entre si.

- A implementação de uma rotina estilo GRASP para a seleção da segunda rota de um ciclo não se mostrou efetiva. Criou-se uma lista com um número definido de rotas mais próximas à rota base. Em seguida, selecionava-se aleatoriamente uma para ser inserida ao ciclo.

- $\mathrm{O}$ incremento do parâmetro $p_{\min }$ feito pela soma de $p_{\text {incr, }}$ ao invés da multiplicação, não traz ganhos.

- A utilização de um critério absoluto, ao invés de relativo como $p$, para a destruição do ciclo não se mostrou eficaz.

- A heurística puramente construtiva sem a geração de ciclos em paralelo, destruição de ciclos ou utilização de parâmetros executa uma solução, independente do tamanho do problema, quase que instantaneamente (tempo menor que $0,1 \mathrm{~s}$ para problemas com 1500 rotas e 2 reposicionamentos). Porém não se obtém ganhos em relação aos demais métodos. 


\section{BIBLIOGRAFIA}

ALON, N.; TARSI, M. Covering multigraphs by simple circuits. SIAM Journal on Algorithmic and Discrete Methods, v. 6, n. 3, p.345-350, 1985.

BALLOU, R. H. Gerenciamento da cadeia de suprimentos/Logística empresarial. 5ª ed. Porto Alegre: Bookman, 2006.

BERMOND, J. C.; JACKSON, B.; JAEGER, F. Shortest covering of graphs with cycles. Journal of Combinatorial Theory, v. 35, p. 297-308, 1983.

BANG-JENSEN, J. e GUTIN, G. Digraphs: Theory, Algorithms and Applications. $3^{\text {a }}$ ed. Estados Unidos: Springer, 2002.

BOTTER, R. C.; TACLA D.; HINO C. M. Estudo e aplicação de transporte colaborativo para cargas de grande volume. Revista Pesquisa Operacional v.26 n.1, Rio de Janeiro, jan./abr. 2006.

CAPLICE, C.; SHEFFI, Y. Optimization Based Procurement for Transportation Services, Journal of Business Logistics 24:2, p. 109-128, 2003.

CAPLICE, C.; SHEFFI, Y. Combinatorial Auctions for Truckload Transportation. Combinatorial Auctions, MIT Press, Cambridge et al. p. 539-571, 2006.

CHRISTOFIDES, N.; MINGOZZI, A.; TOTH P. The vehicle routing problem, Combinatorial Optimization, p. 315-338, 1979.

CPFR. Collaborative Planning, Forecasting \& Replenishment (CPFR ${ }^{\circledR}$ ) Committee. Disponível em: <http://www.vics.org/committees/cpfr/>. Acessado em: 04/07/2008.

ERGUN, O.; KUYZU, G. \& SAVELSBERGH, M. Reducing Truckload Transportation Costs Through Collaboration. Transportation Science n. 41(2), p. 206-221, 2007. 
ERGUN, Ö.; KUYZU, G.; SAVELSBERGH, M. Shipper collaboration. Computers \& Operations Research, v. 34, p. 1551-1560, 2007.

ERGUN, O.; KUYZU, G. \& SAVELSBERGH, M. The Lane Covering Problem. ISYE, GeorgiaTechc, EUA, 2004. Disponível em: http://www2.isye.gatech.edu/ mwps/publications/ijoc030404.pdf. Acessado em: 20/03/2009.

FAN, G. Covering graphs by cycles. SIAM Journal on Discrete Mathematics, v. 5 , n. 4, p. 491-496, 1992.

FIGUEIREDO, R; EIRAS, J. Transporte colaborativo: conceituação, benefícios e práticas (parte 1). ILOS, Instituto de Logística e Supply Chain, 2007. Disponível em: <http://www.ilos.com.br/index.php?option=com_docman\&task= doc_details\&gid=14\&ltemid=44>. Acessado em: 11/08/2008.

FIPE. Fundação Instituto de Pesquisa Econômica. Disponível em: <http://www.fipe.org.br/web/indices/idet/indices.aspx?g=2\&s=26>. Acessado em: 24/01/2009.

FRAISSE, P. Cycle covering in bridgeless graphs. Journal of Combinatorial Theory, v. 39, p. 146-152, 1985.

IMMORLICA, N.; MAHDIAN, M.; MIRROKNI, V. S. Cycle cover with short cycles. Lecture Notes in Computer Science, v. 3404, p. 641-653, 2005.

ITAI, A.; LIPTON, R. J.; PAPADIMITRIOU, C. H.; RODEH, M. Covering graphs by simple circuits. SIAM Journal on Computing, v. 10, n. 4, p. 746-750, 1981.

JACKSON, B. Shortest circuit covers and postman tours in graphs with a nowhere zero 4-flows. SIAM Journal on Computing, v. 19, n. 4, p. 659-665, 1990.

KUYZU, G. Procurement in truckload transportation. Tese de Doutorado. Georgia Institute of Technology, Estados Unidos, 2007.

LABBE, M.; LAPORTE, G.; SORIANO, P. Covering a graph with cycles. Computers and Operations Research, v. 25, n. 6, p. 499-504, 1998. 
NASA. Visible Earth - A catalog of NASA images and animations of our planet. 2000. 1 mapa, color. Escala 1:47500000. Disponível em: <http://veimages.gsfc.nasa.gov/1438/earth_lights_Irg.jpg>. Acesso em: 14/05/2008.

NOVAES, A. G. Logística e Gerenciamento da Cadeia de Distribuição: Estratégia, Operação e Avaliação. $2^{a}$ ed. Rio de Janeiro: Campos, 2004.

PELED, U.; SIMEONE, B., Polynomial-time algorithms for regular setcovering and threshold synthesis. Discrete Applied Mathematics, n. 12, p. 57-69, 1985.

PELIZARO, C. Avaliação de desempenho do algoritmo de um programa comercial para roteirização de veículos. Dissertação de Mestrado. Escola de Engenharia de São Carlos da Universidade de São Carlos, Brasil, 2000.

SOLOMON, M. M. Algorithms for the vehicle routing and scheduling problems with time window constraints. Operational Research, v. 35, n. 2, p. 254265, 1987.

STRINGHER, F. G. Designação de rotas para frota dedicada em uma rede de distribuição de linha branca. Dissertação de Mestrado. Escola Politécnica da Universidade de São Paulo, Brasil, 2004.

ÖZENER, O; ERGUN, Ö. Allocating Costs in a Collaborative Transportation Procurement Network. Transportation Science, v. 42, n. 2, p. 146165, 2008.

ÖZENER, O. Collaboration in transportation. Tese de Doutorado. Georgia Institute of Technology, Estados Unidos, 2008.

VIEIRA, J. G. V. Avaliação do estado de colaboração logística entre indústria de bens de consumo e redes de varejo supermercadista. Tese de Doutorado. Escola Politécnica da Universidade de São Paulo, Brasil, 2006.

VICS. Voluntary Inter-Industry Commerce Standards Association. Disponível em: <http://www.vics.org/join/about-vics/>. Acessado em: 04/07/2008. 
SAVELSBERGH, M.; ERGUN, O. \& KUYZU, G. Collaborative Logistics. 35th Annual Conference of the Italian Operations Research Society, Lecce, Itália, 2004. 


\section{GLOSSÁRIO}

Carga lotação Ocorre quando o carregamento de um veículo é completo e o caminhão dirige-se da origem ao destino diretamente, sem paradas intermediárias.

Carga fracionada Ocorre quando o carregamento de um veículo é não completo e a carga deve ser enviada para centros concentradores onde é feita a consolidação de pequenas cargas a fim de completar um caminhão que as distribuirá para vários destinos.

Rota

Viagens de carga lotação com freqüência regular.

Reposicionamento Viagem sem carga útil.

Ciclo Um percurso fechado feito por um veículo. É composto por rotas e reposicionamentos.

Cardinalidade

Dígrafo
O número de arcos (rotas ou reposicionamentos) contidos dentro de um ciclo.

Grafo direcionado consiste em um conjunto finito não vazio de vértices e em um conjunto finito de pares ordenados de vértices distintos que são chamados de arcos. 
ANEXO A

A seguir estão listadas todas as figuras obtidas na calibração do parâmetro $j_{\max }$ da Heurística CD para os problemas de 100, 200, 500, 1000, 1500 rotas dos dígrafos 1, 2 e 3 com um reposicionamento permitido. Os gráficos mostram os resultados obtidos em função de $j_{\max }$ para um conjunto de parâmetros fixados em 4.6.1.

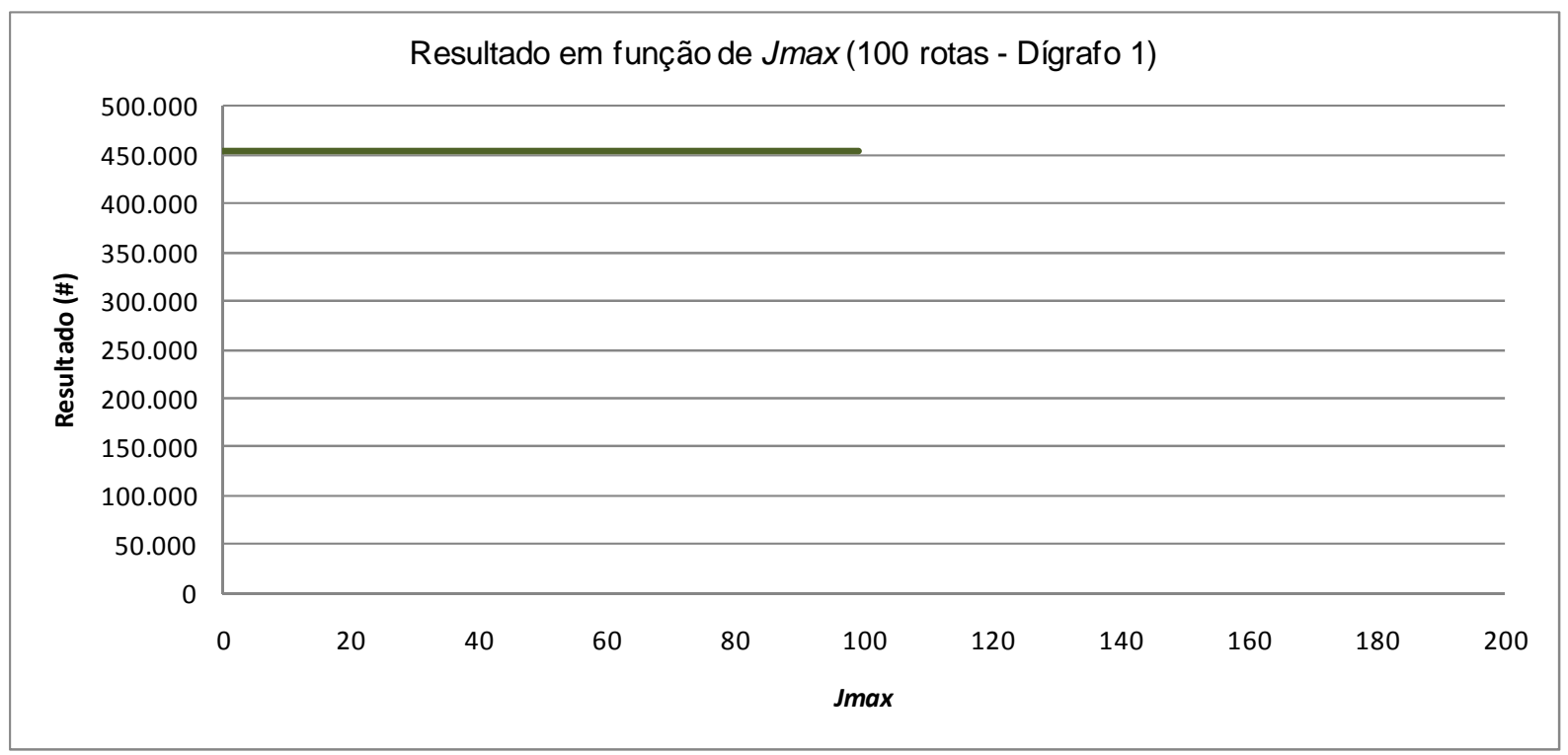

Figura A-1: Resultado em função de $j_{\max }$ para problema de 100 rotas e dígrafo 1 e um reposicionamento 


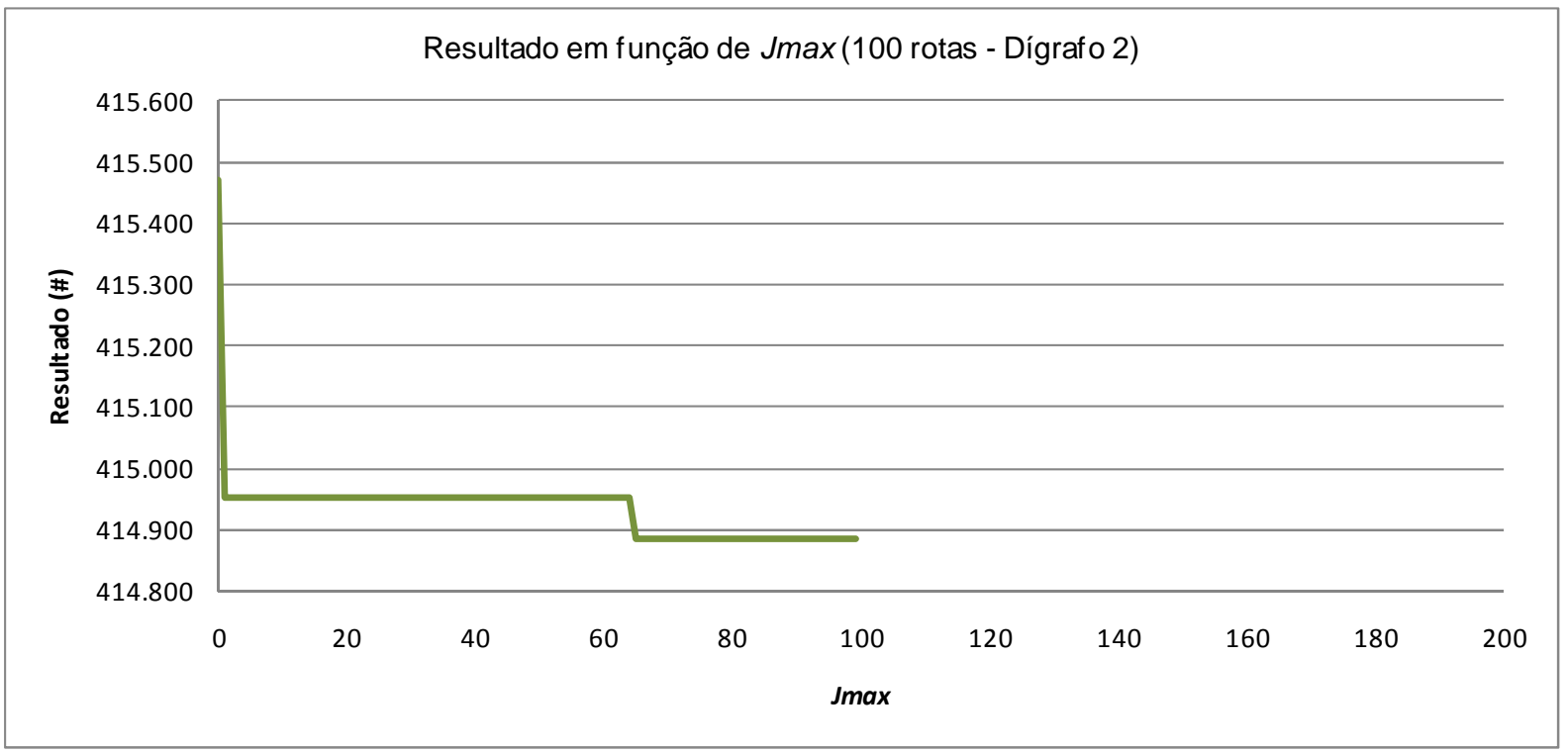

Figura A-2: Resultado em função de $j_{\max }$ para problema de 100 rotas e dígrafo 2 e um reposicionamento

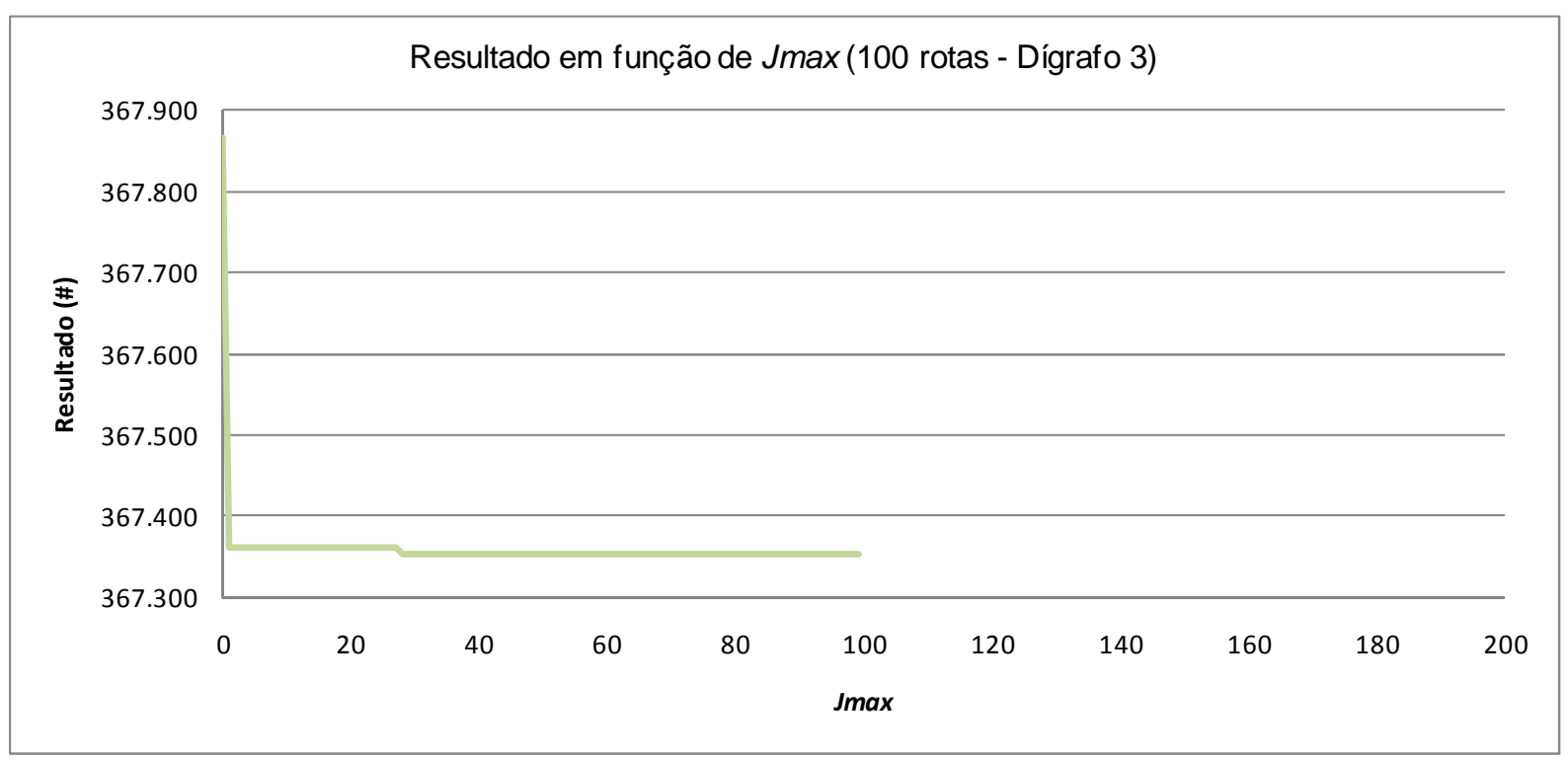

Figura A-3: Resultado em função de $j_{\max }$ para problema de 100 rotas e dígrafo 3 e um reposicionamento 


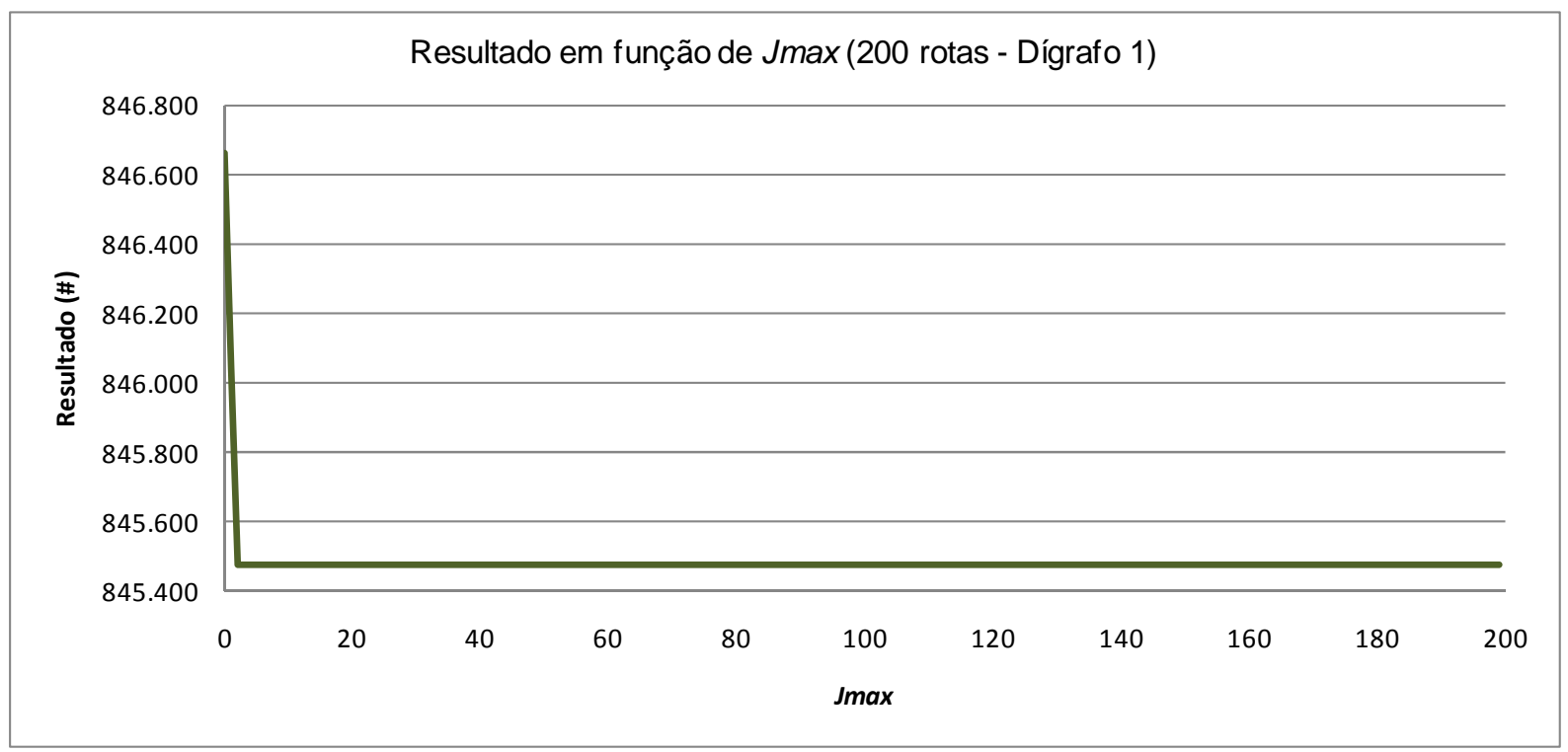

Figura A-4: Resultado em função de $j_{\max }$ para problema de 200 rotas e dígrafo 1 e um reposicionamento

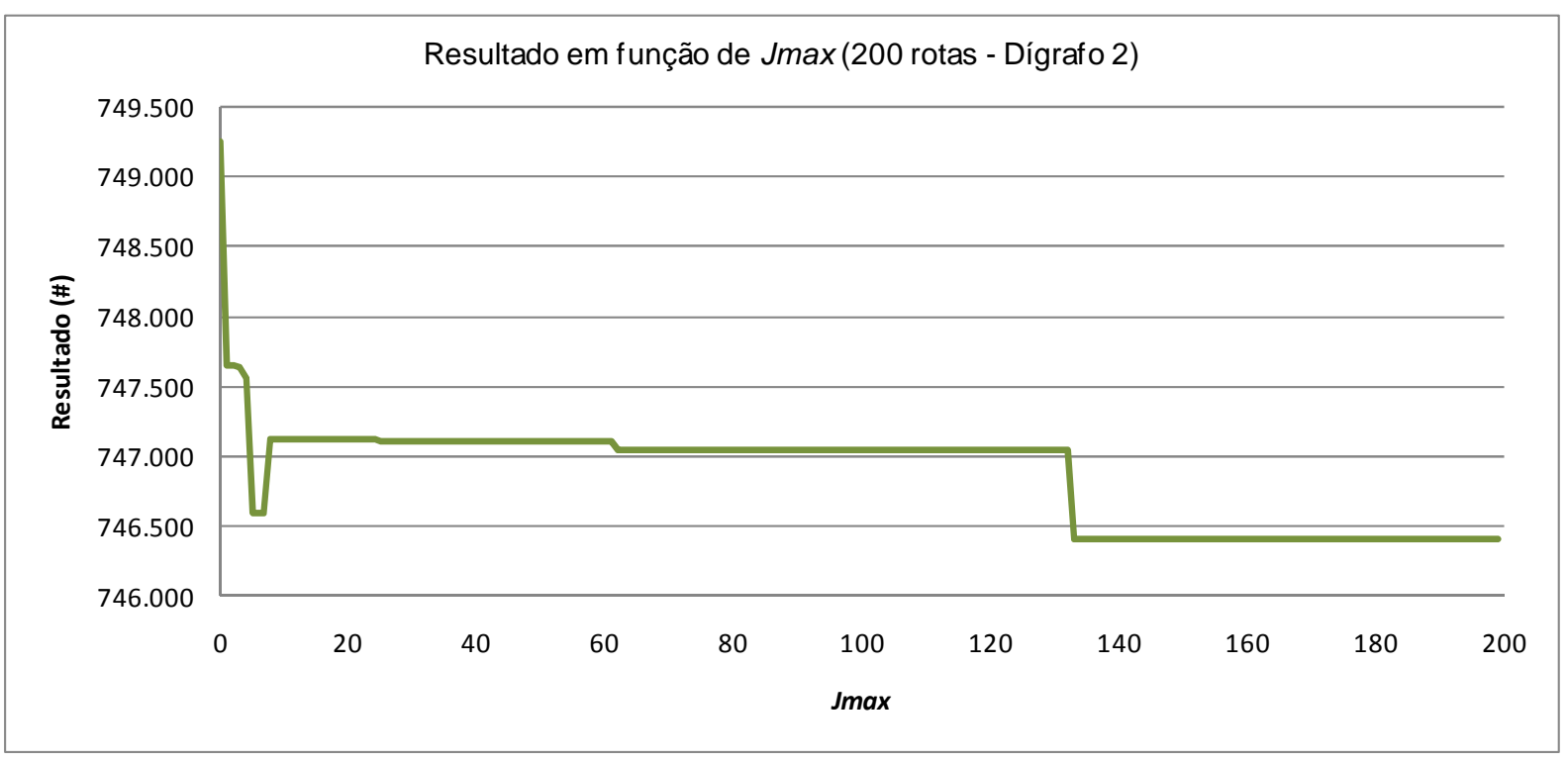

Figura A-5: Resultado em função de $j_{\max }$ para problema de 200 rotas e dígrafo 2 e um reposicionamento 


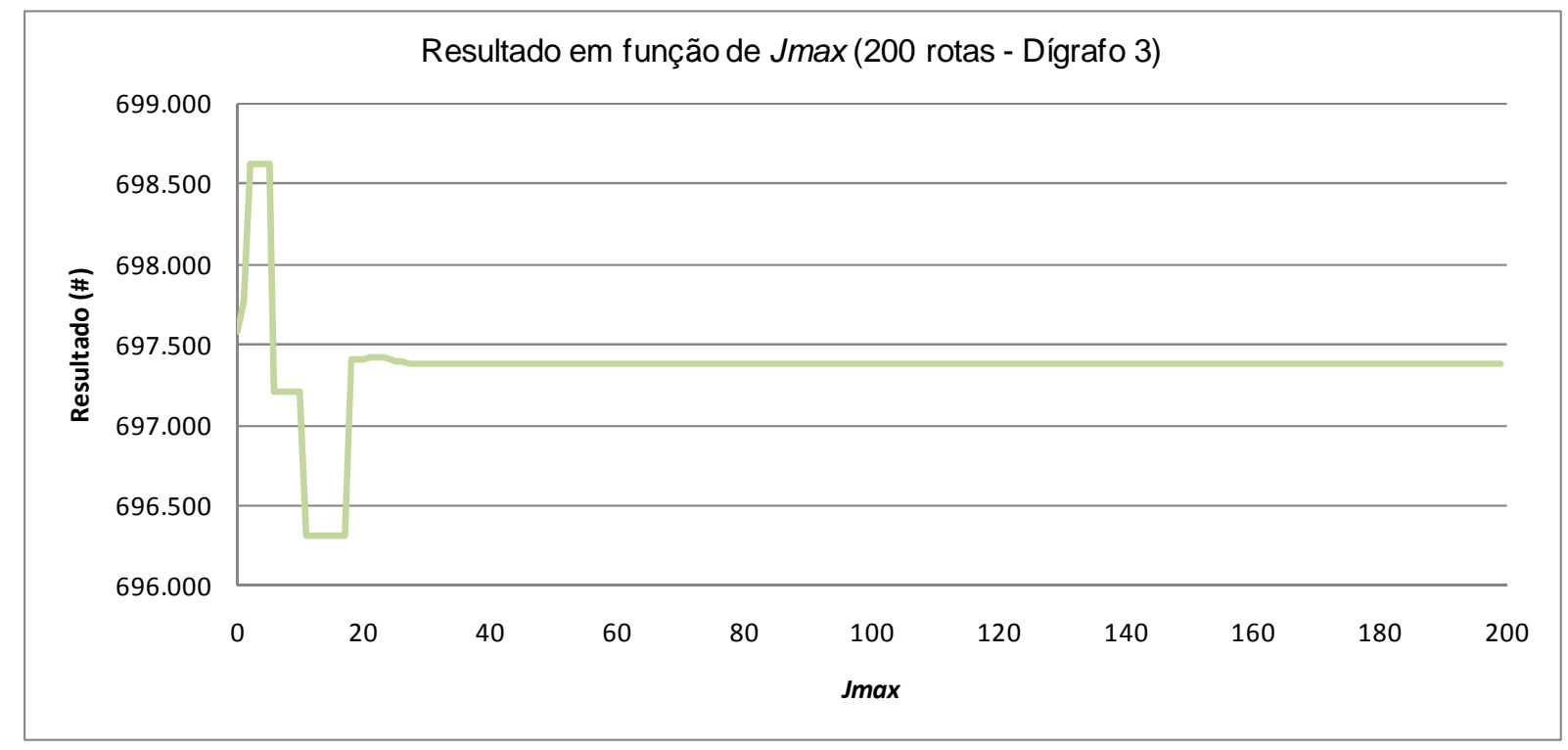

Figura A-6: Resultado em função de $j_{\max }$ para problema de 200 rotas e dígrafo 3 e um reposicionamento

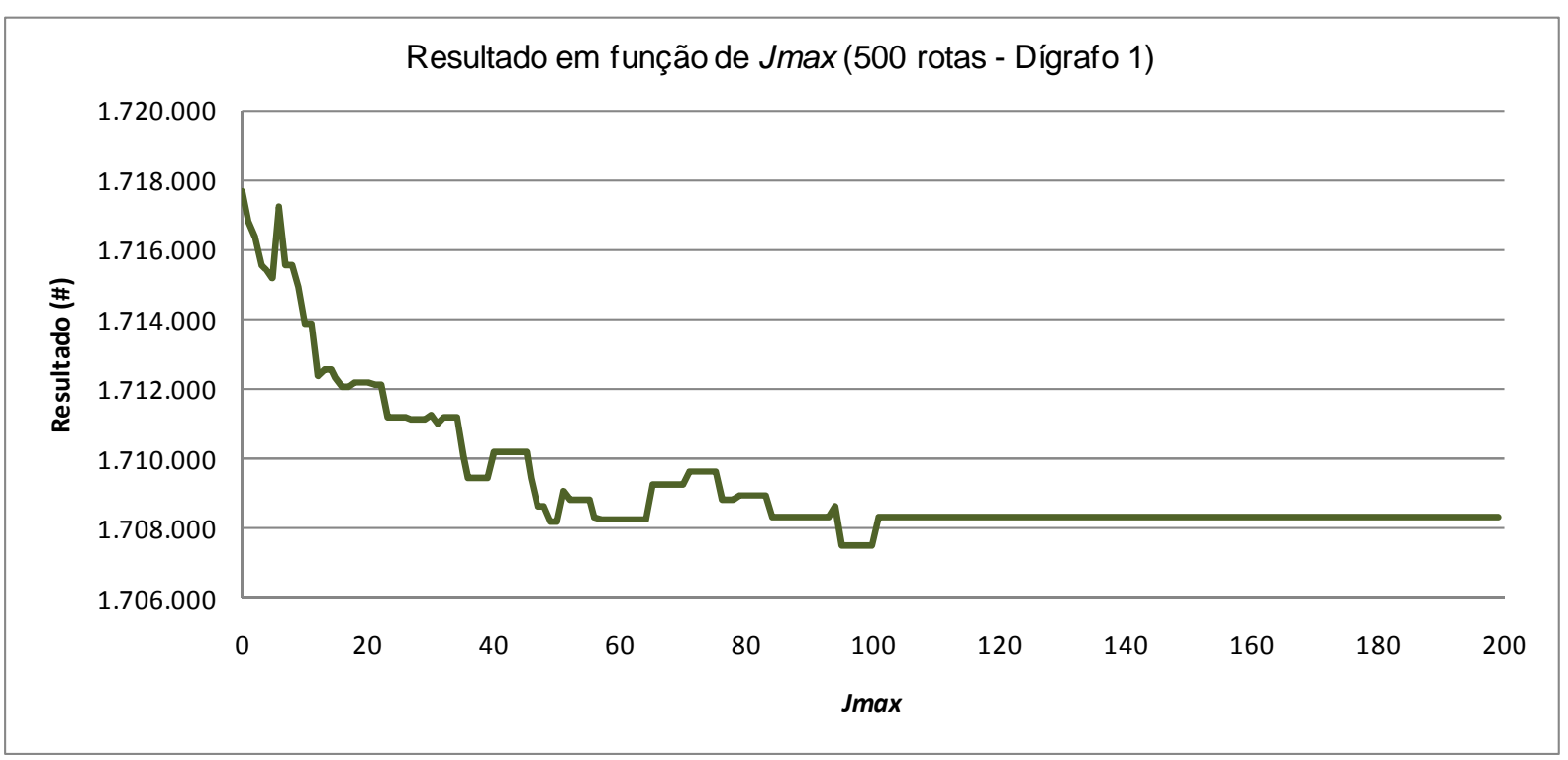

Figura A-7: Resultado em função de $j_{\max }$ para problema de 500 rotas e dígrafo 1 e um reposicionamento 


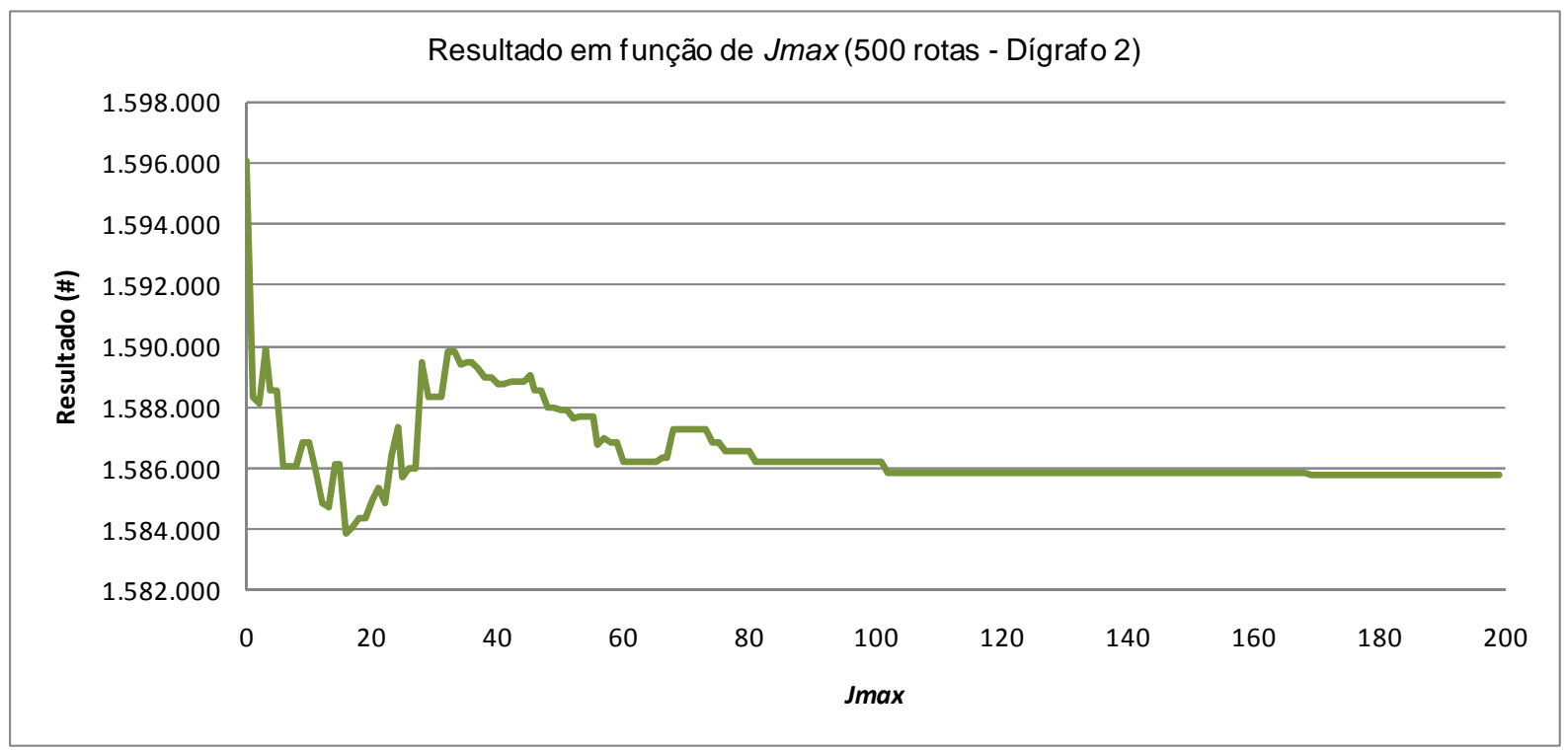

Figura A-8: Resultado em função de $j_{\max }$ para problema de 500 rotas e dígrafo 2 e um reposicionamento

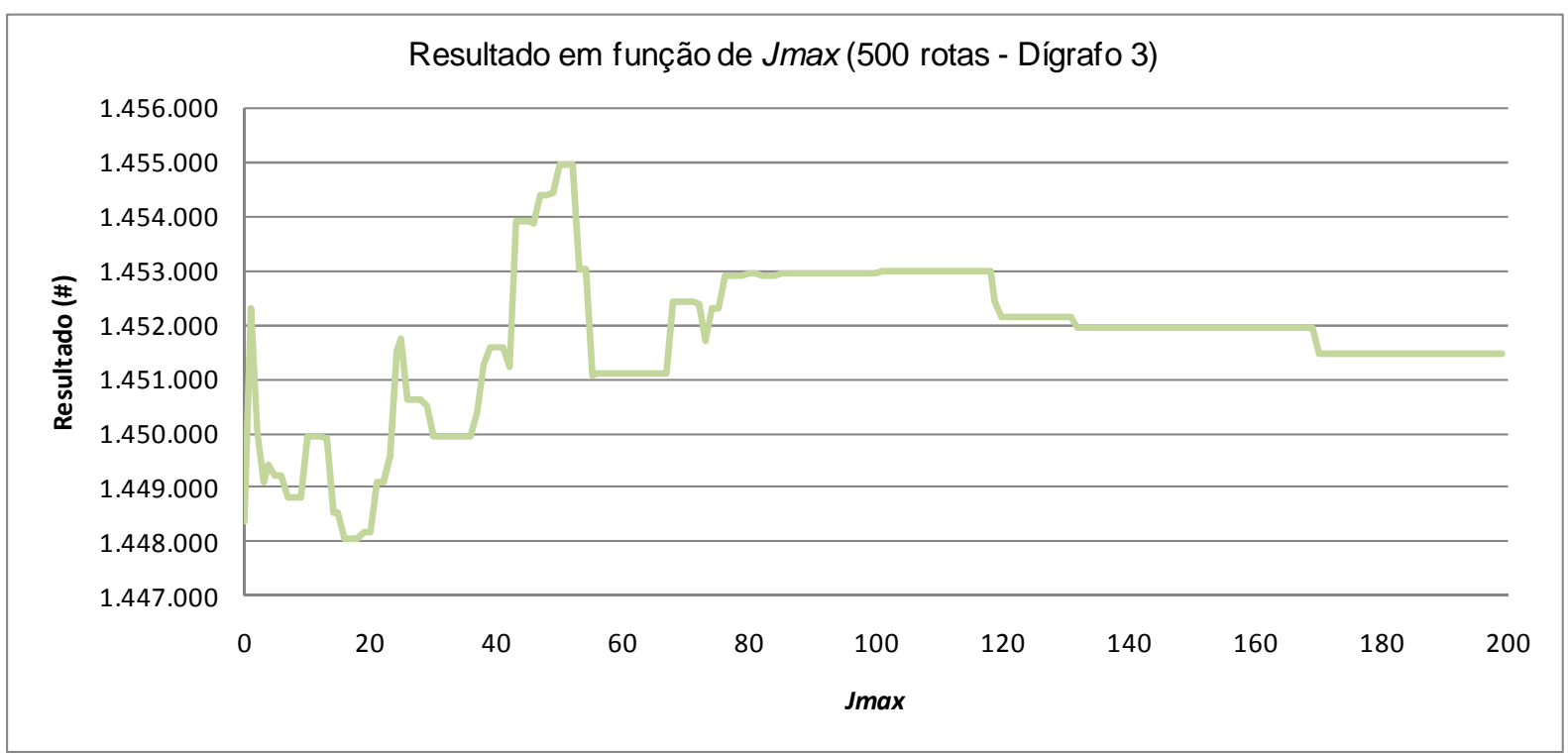

Figura A-9: Resultado em função de $j_{\max }$ para problema de 500 rotas e dígrafo 3 e um reposicionamento 


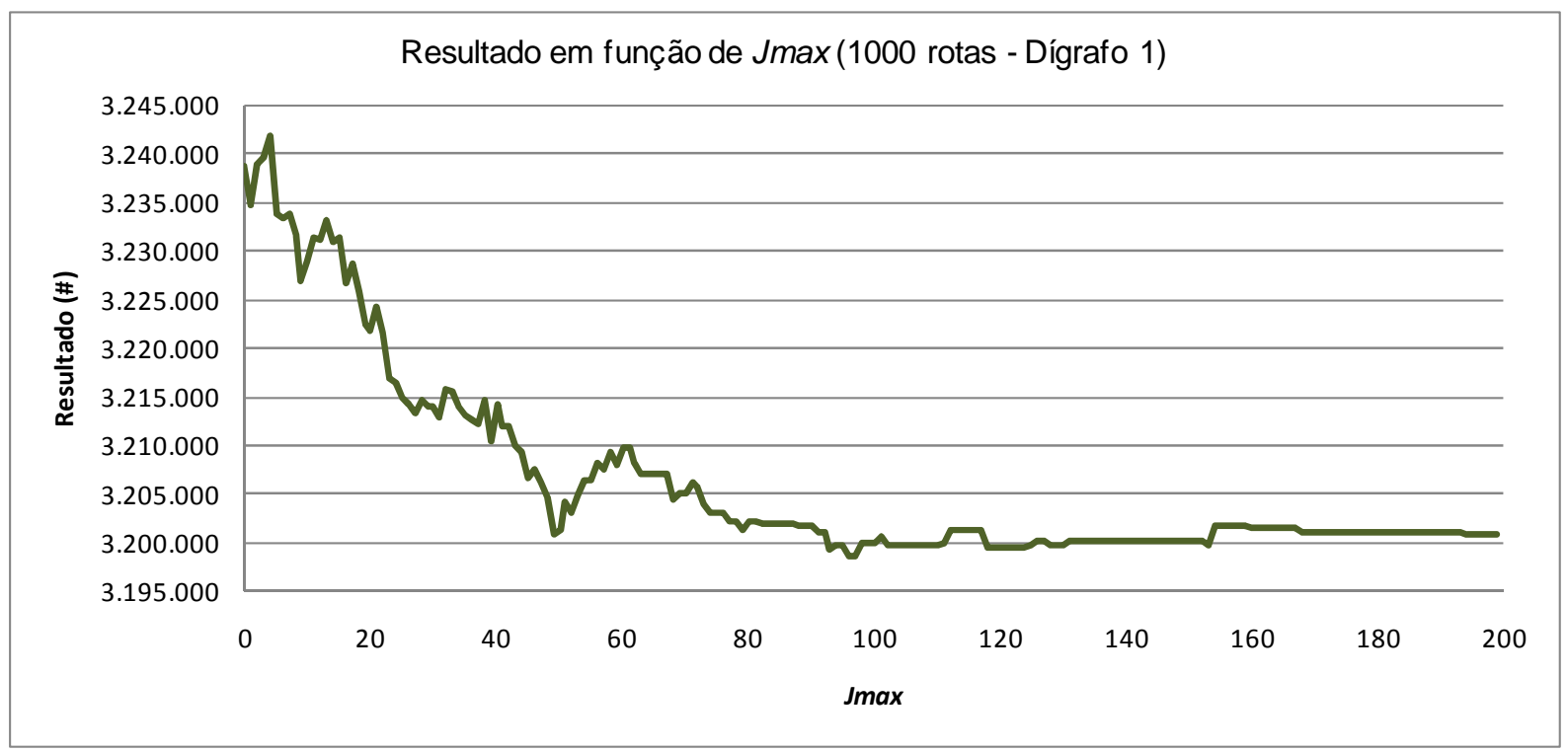

Figura A-10: Resultado em função de $j_{\max }$ para problema de 1000 rotas e dígrafo 1 e um reposicionamento

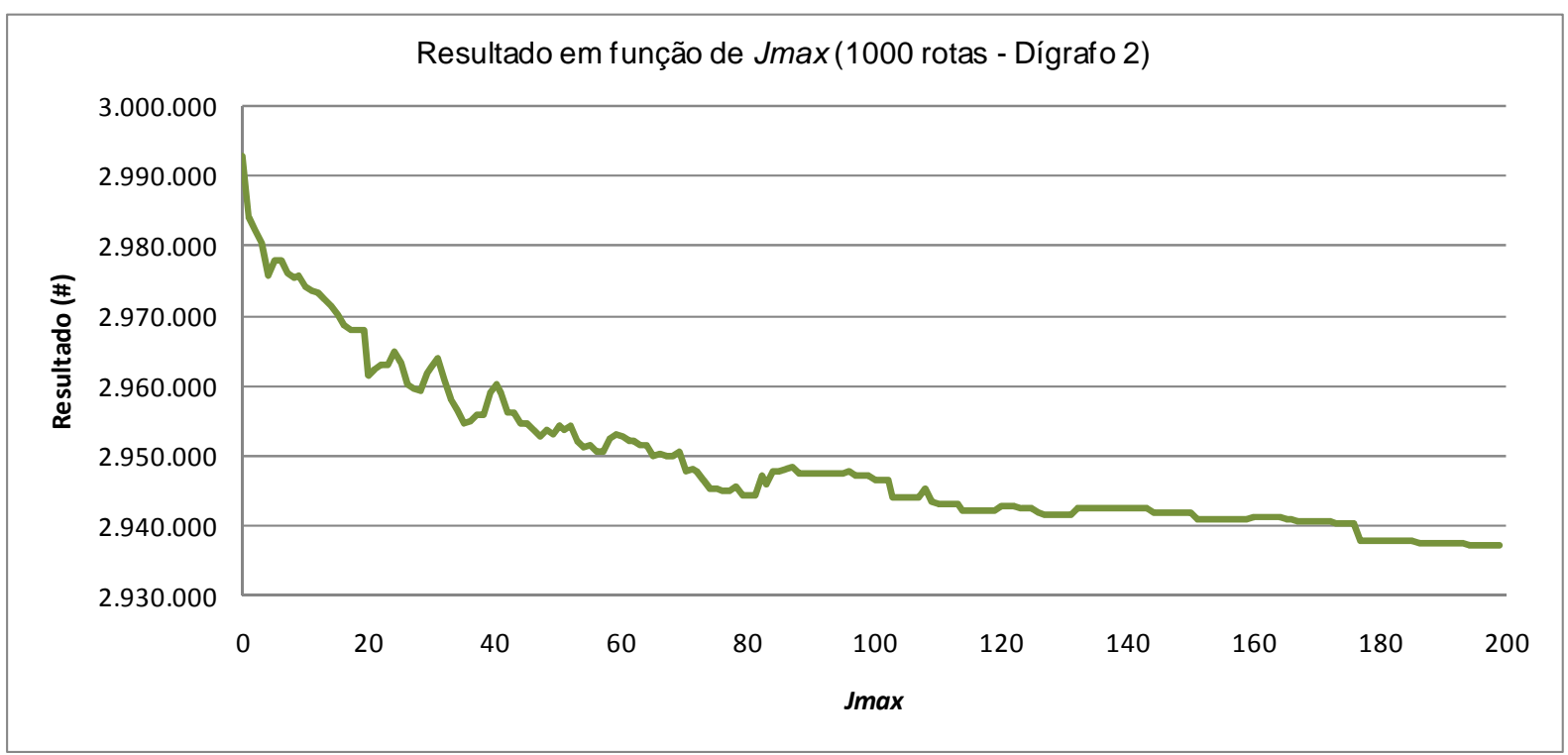

Figura A-11: Resultado em função de $j_{\max }$ para problema de 1000 rotas e dígrafo 2 e um reposicionamento 


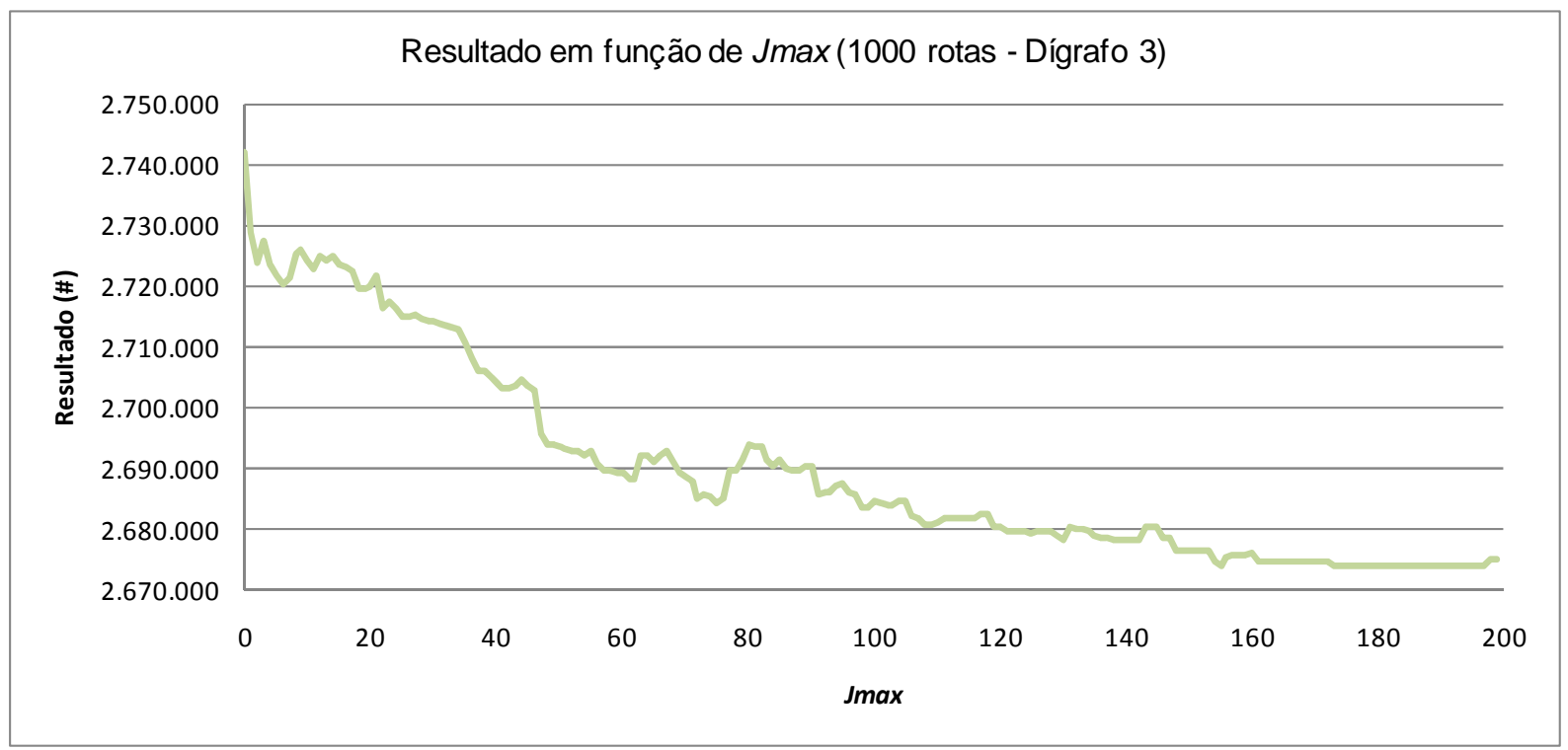

Figura A-12: Resultado em função de $j_{\max }$ para problema de 1000 rotas e dígrafo 3 e um reposicionamento

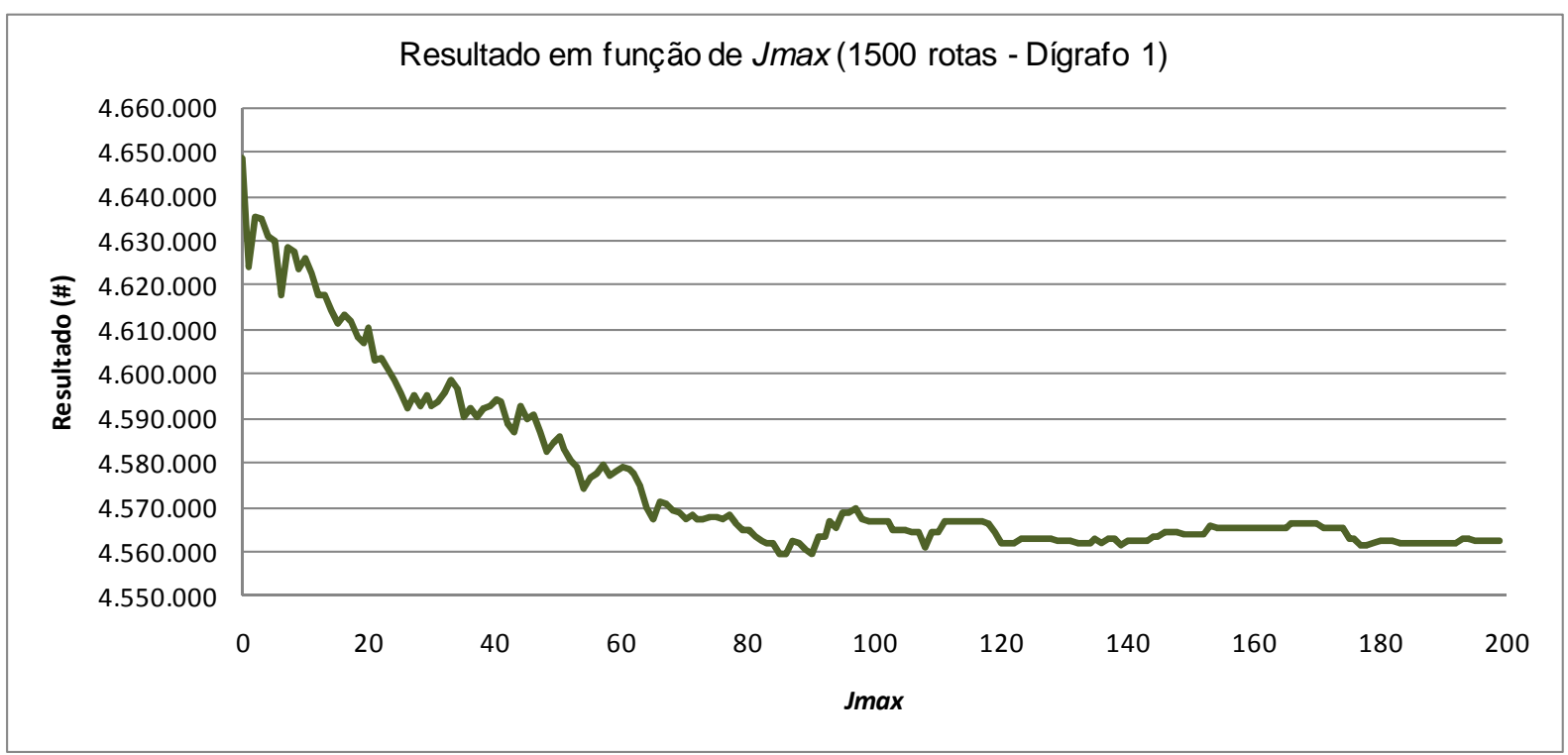

Figura A-13: Resultado em função de $j_{\max }$ para problema de 1500 rotas e dígrafo 1 e um reposicionamento 


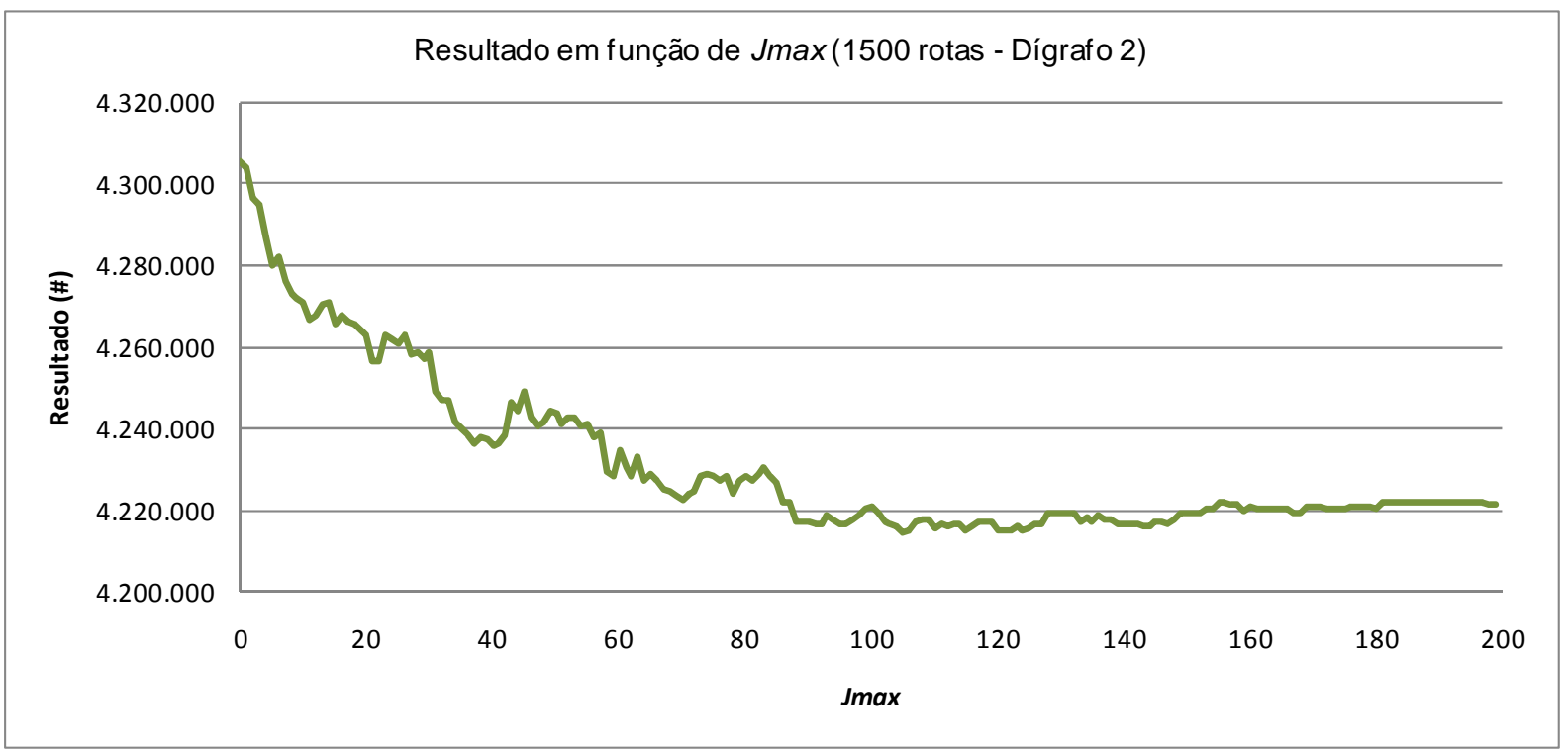

Figura A-14: Resultado em função de $j_{\max }$ para problema de 1500 rotas e dígrafo 2 e um reposicionamento

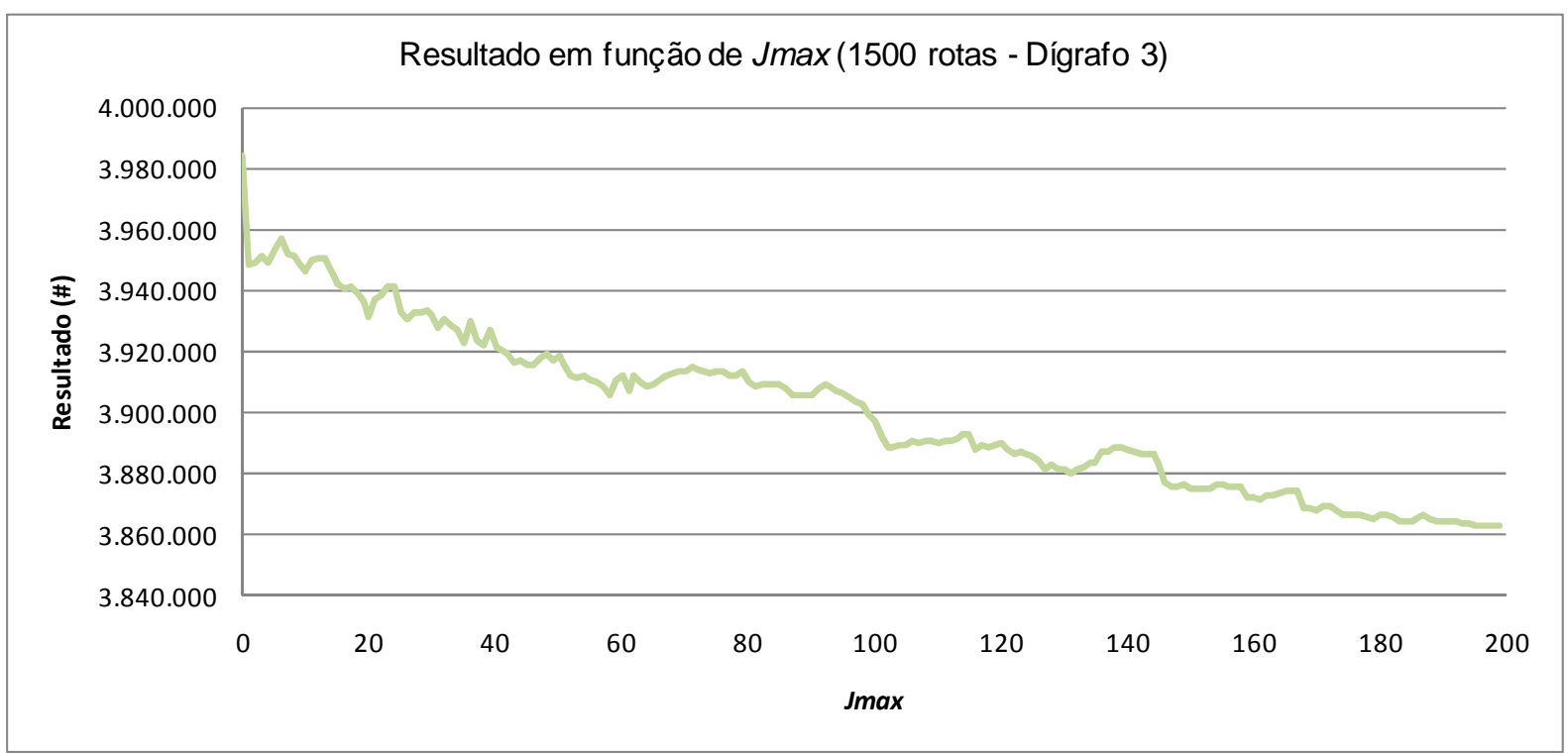

Figura A-15: Resultado em função de $j_{\max }$ para problema de 1500 rotas e dígrafo 3 e um reposicionamento 


\section{ANEXO B}

A seguir estão listadas todas as figuras obtidas na calibração do parâmetro $j_{\max }$ da Heurística CD para os problemas de 100, 200, 500, 1000, 1500 rotas dos dígrafos 1, 2 e 3 com dois reposicionamentos permitido. Os gráficos mostram os resultados obtidos em função de $j_{\max }$ para um conjunto de parâmetros fixados em 4.6.2.

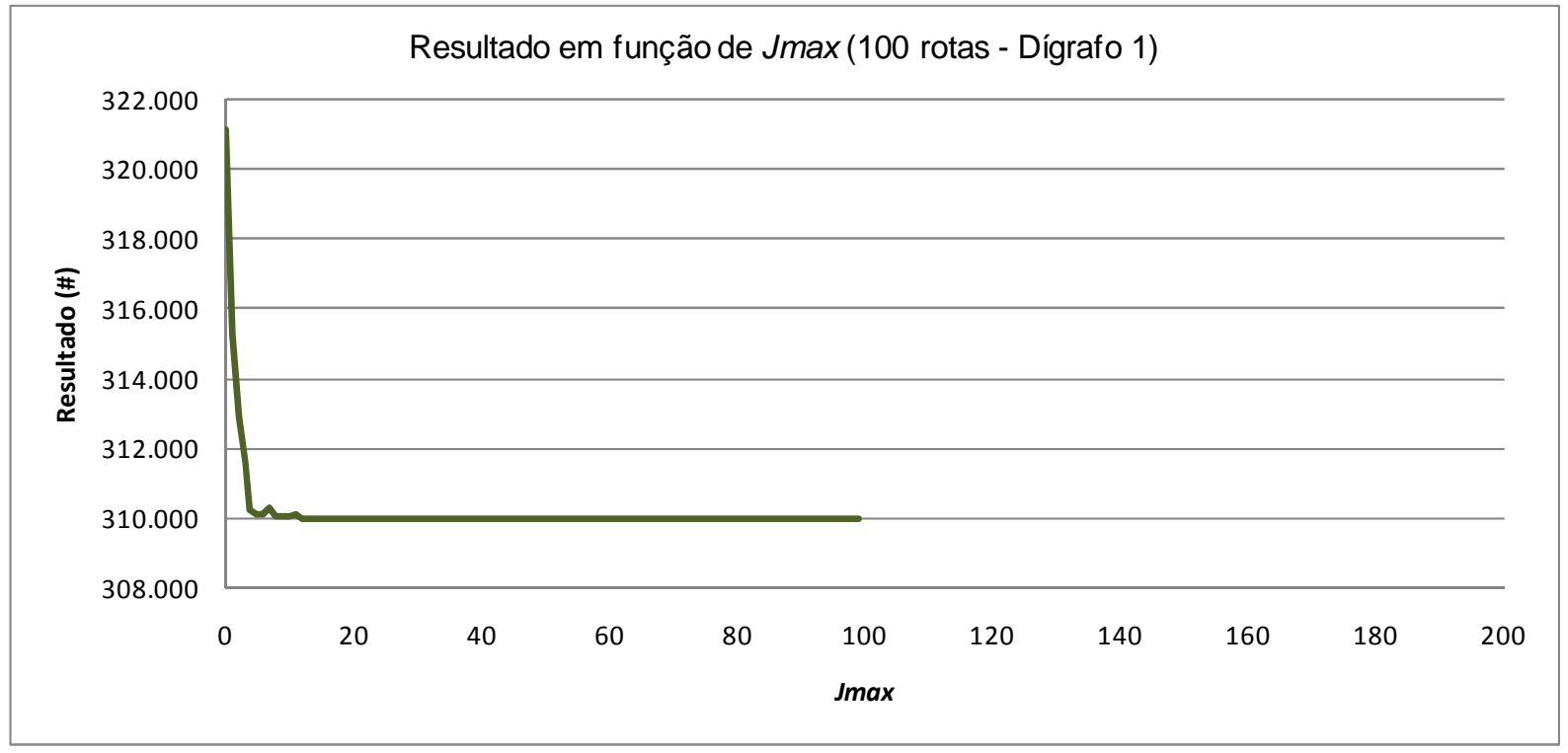

Figura B-1: Resultado em função de $j_{\max }$ para problema de 100 rotas e dígrafo 1 e dois reposicionamentos 


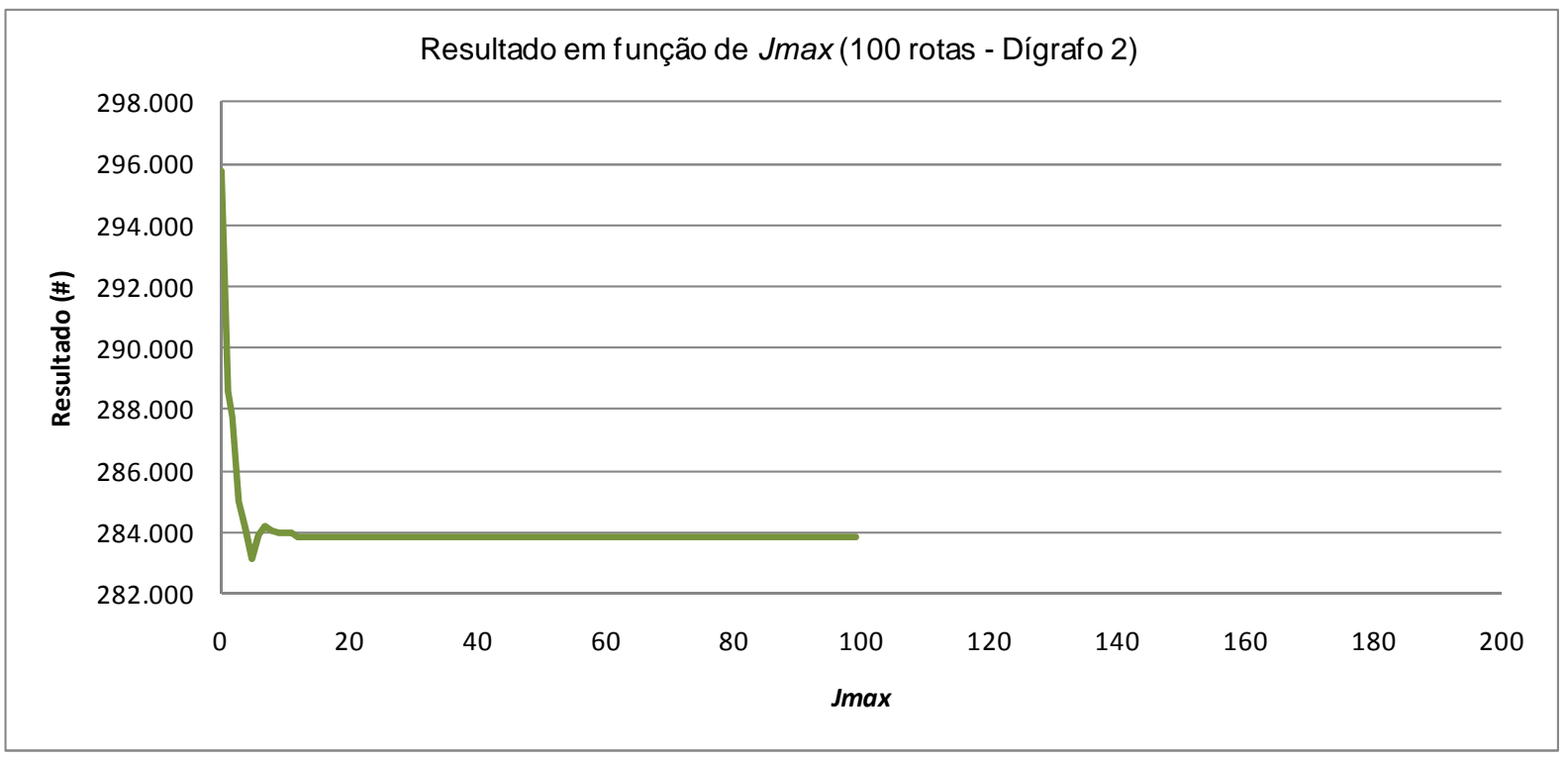

Figura B-2: Resultado em função de $j_{\max }$ para problema de 100 rotas e dígrafo 2 e dois reposicionamentos

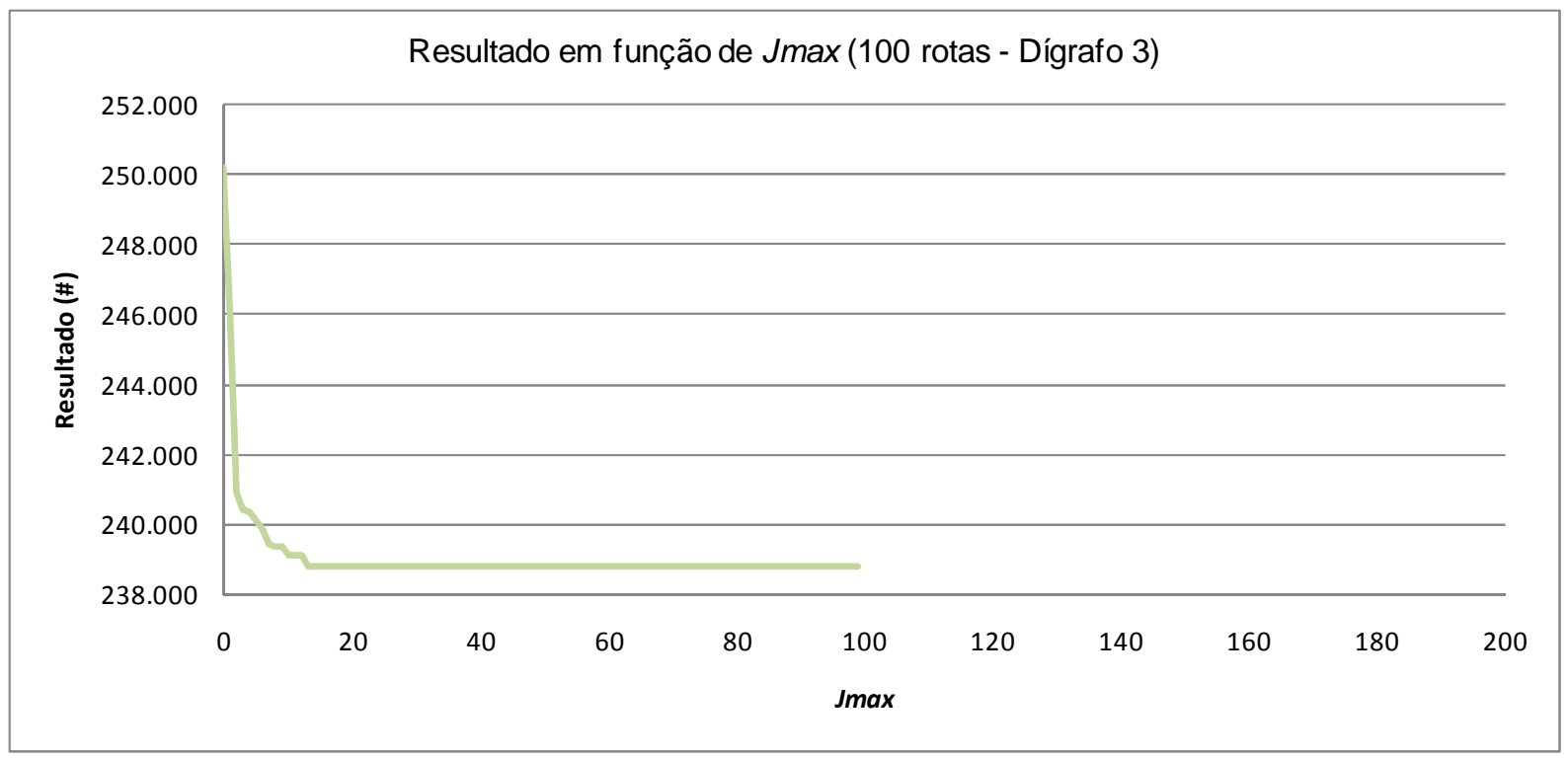

Figura B-3: Resultado em função de $j_{\max }$ para problema de 100 rotas e dígrafo 3 e dois reposicionamentos 


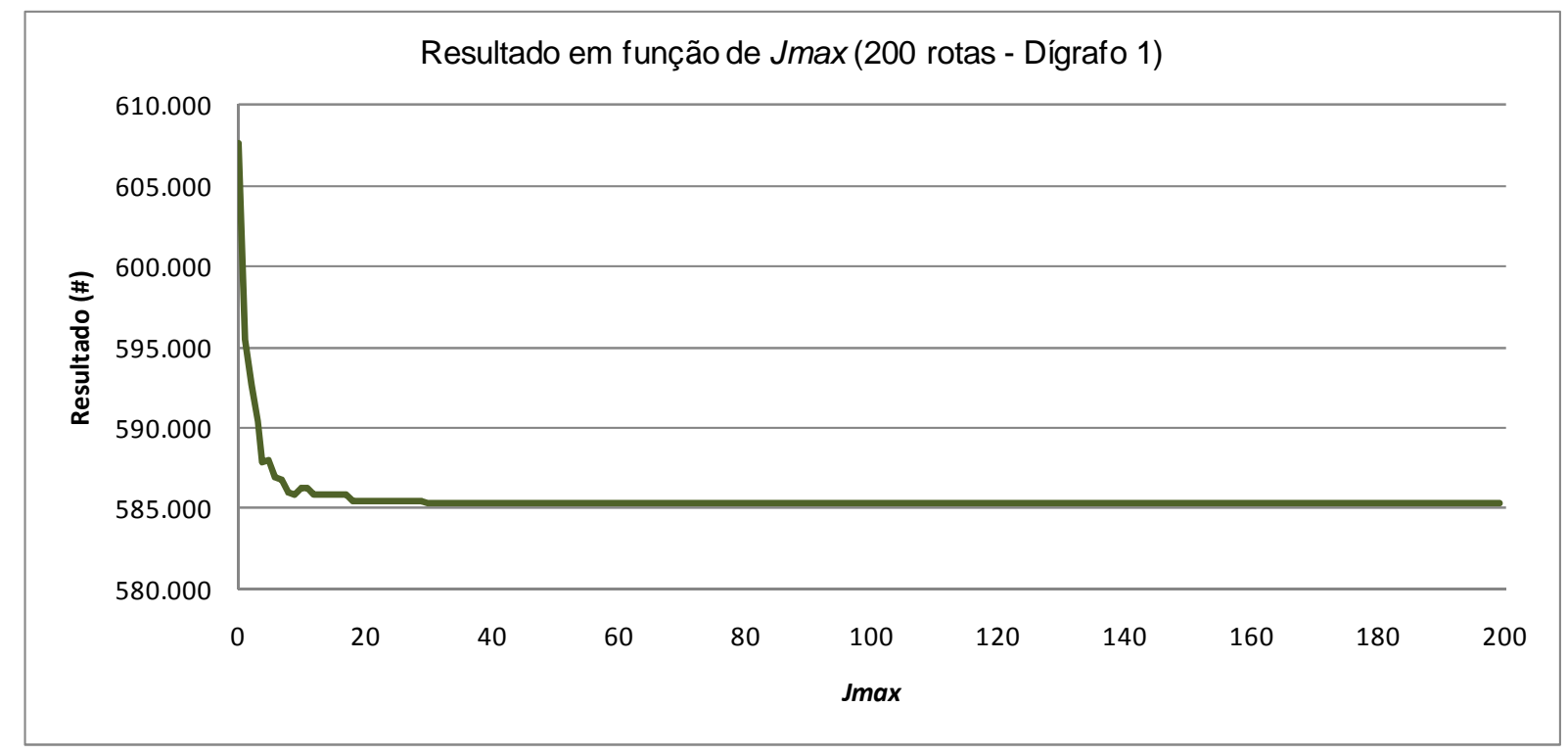

Figura B-4: Resultado em função de $j_{\max }$ para problema de 200 rotas e dígrafo 1 e dois reposicionamentos

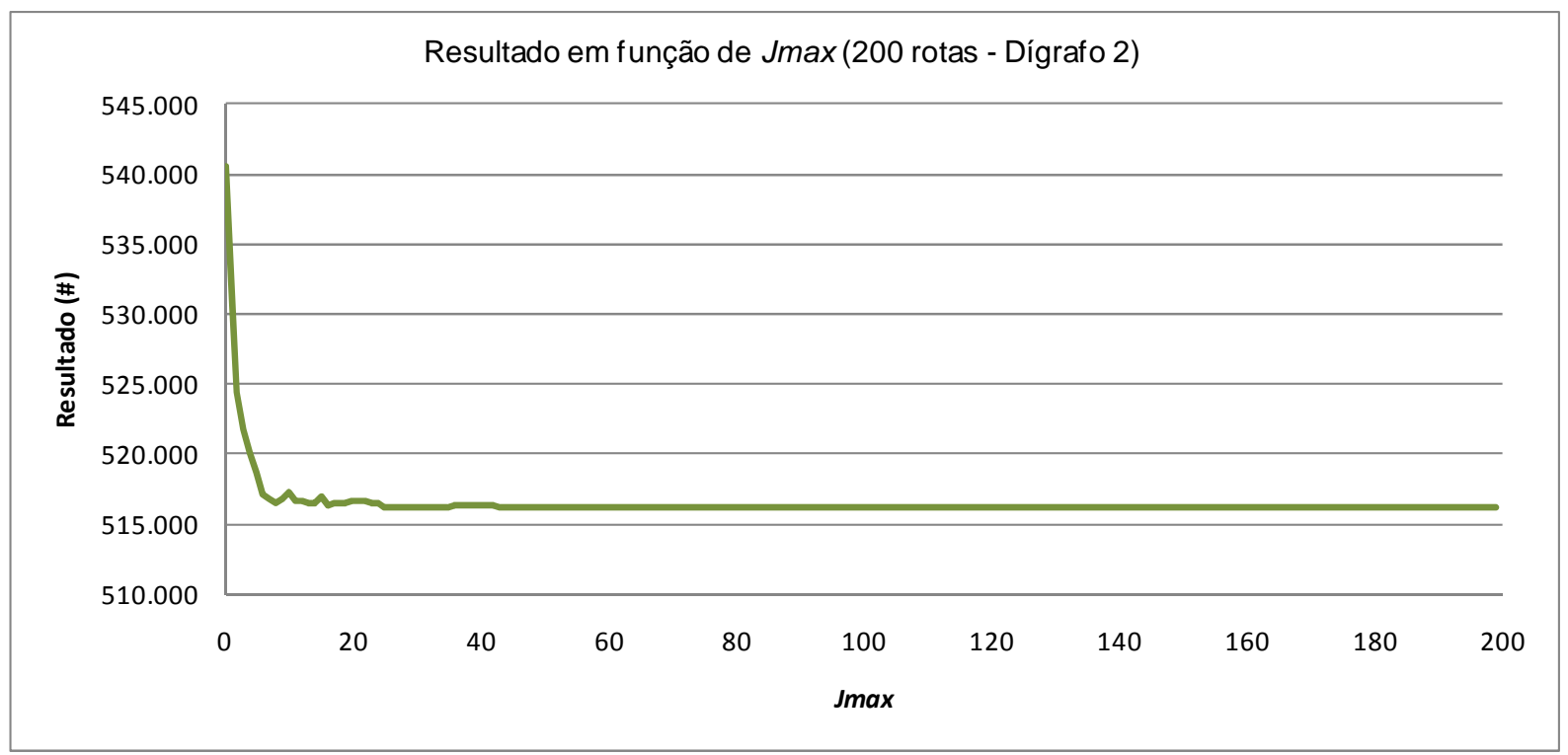

Figura B-5: Resultado em função de $j_{\max }$ para problema de 200 rotas e dígrafo 2 e dois reposicionamentos 


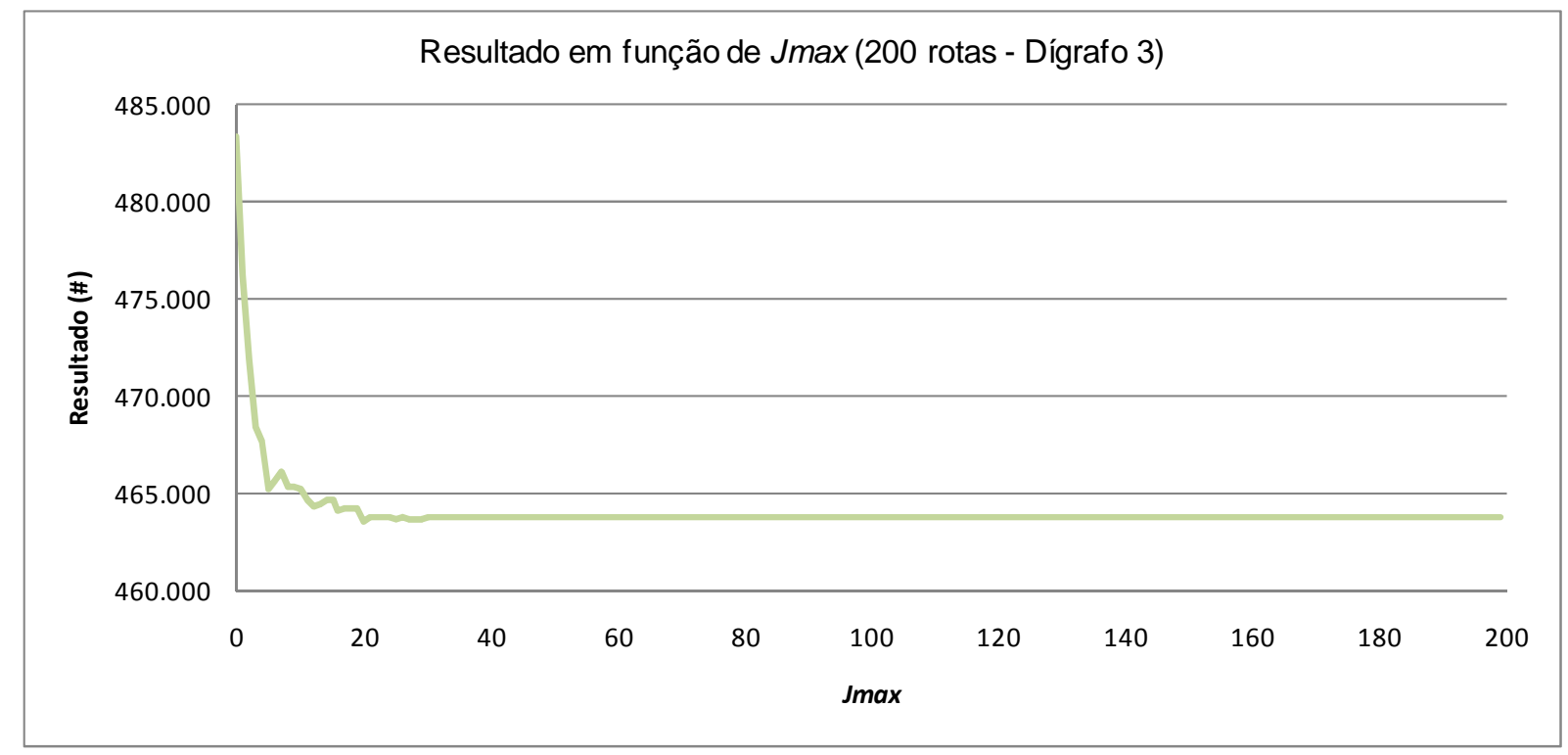

Figura B-6: Resultado em função de $j_{\max }$ para problema de 200 rotas e dígrafo 3 e dois reposicionamentos

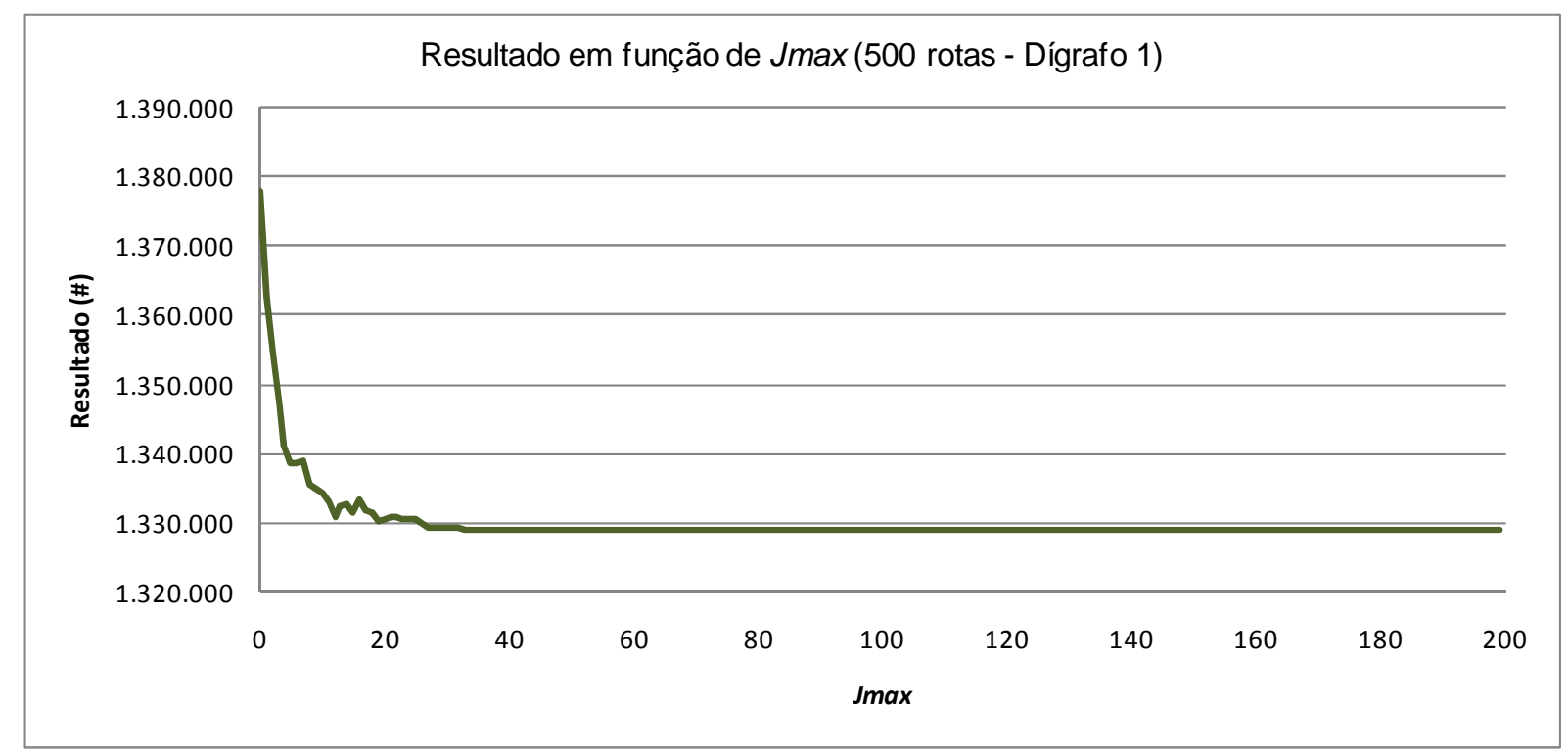

Figura B-7: Resultado em função de $j_{\max }$ para problema de 500 rotas e dígrafo 1 e dois reposicionamentos 


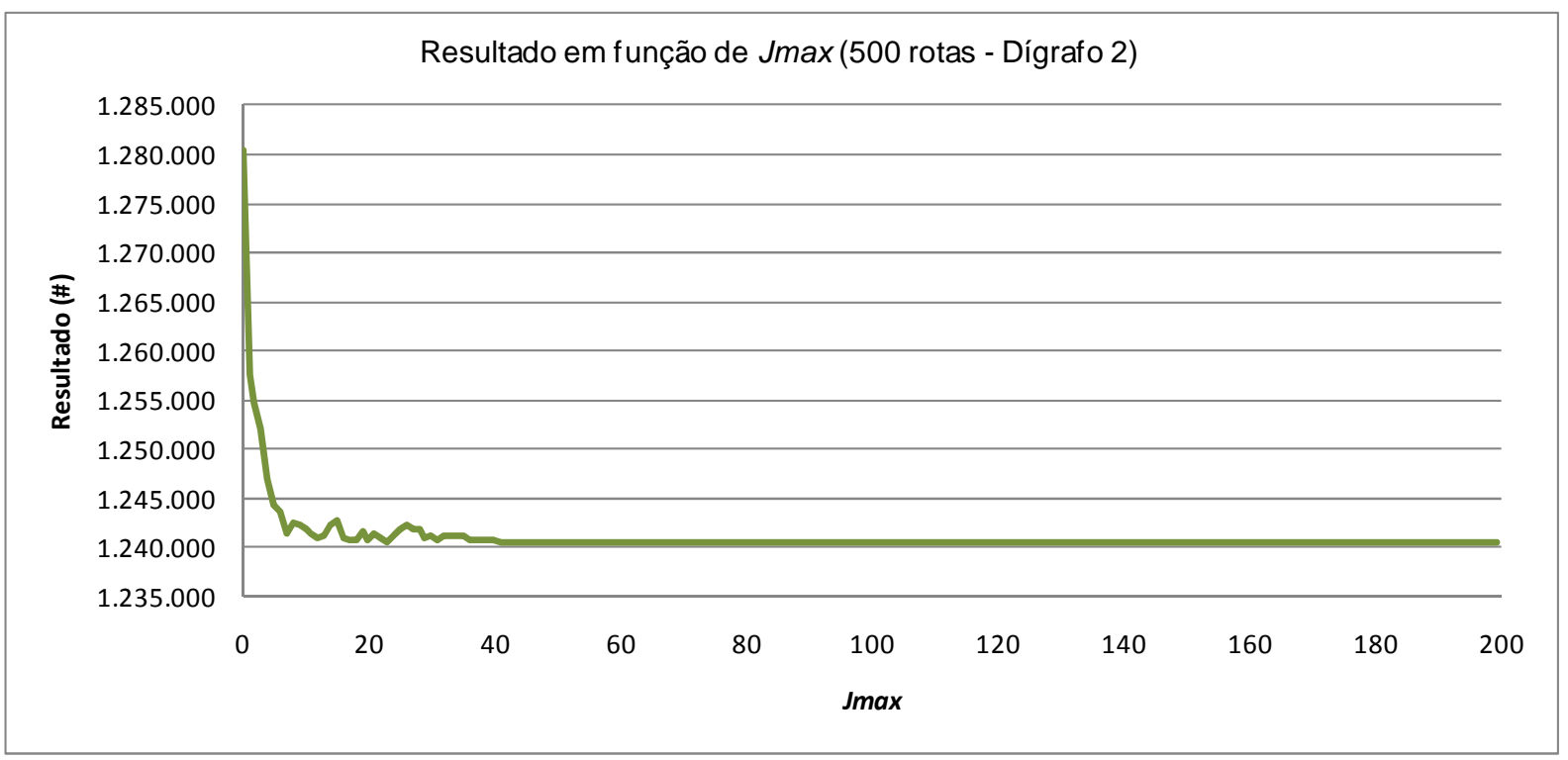

Figura B-8: Resultado em função de $j_{\max }$ para problema de 500 rotas e dígrafo 2 e dois reposicionamentos

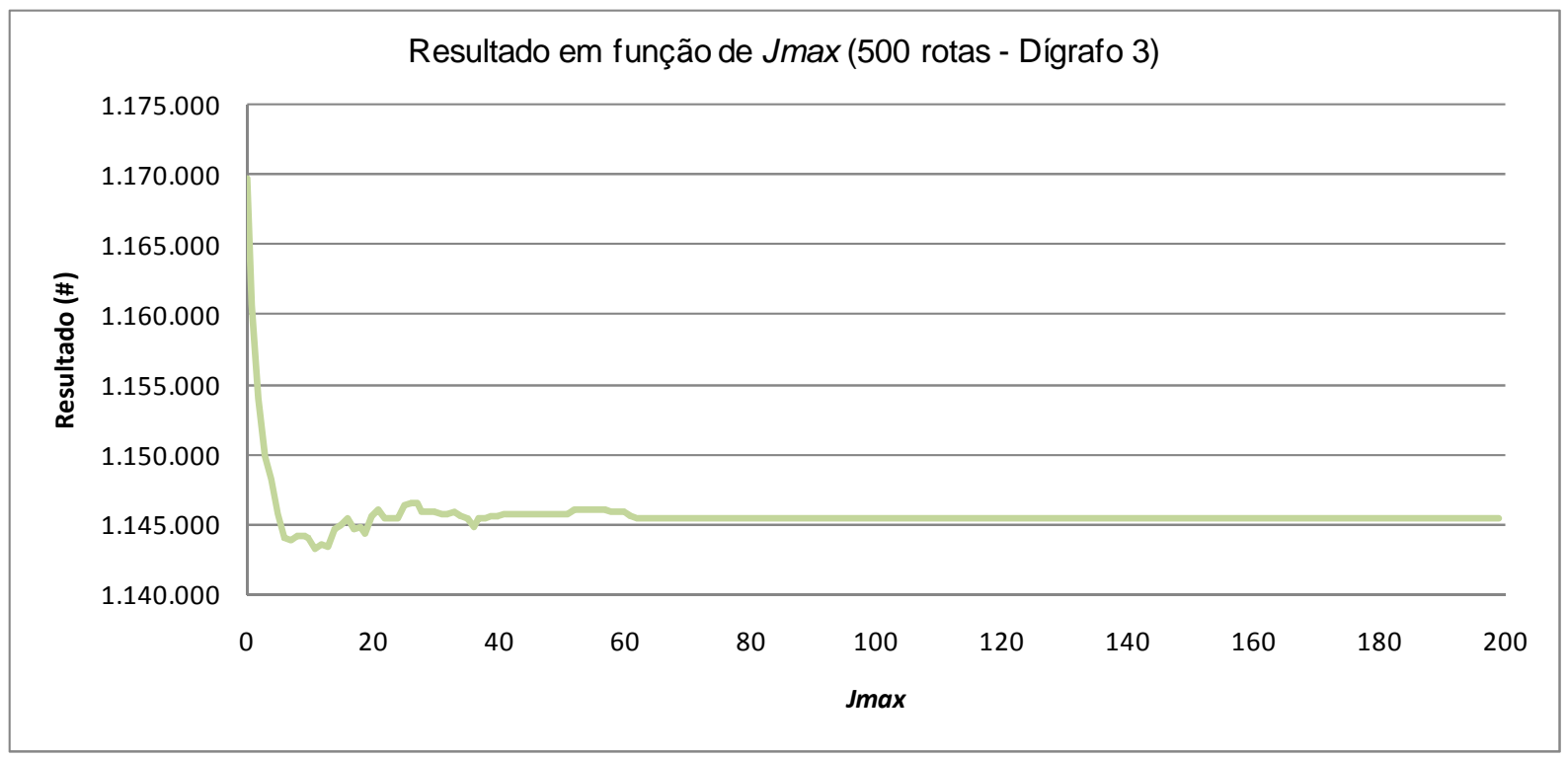

Figura B-9: Resultado em função de $j_{\max }$ para problema de 500 rotas e dígrafo 3 e dois reposicionamentos 


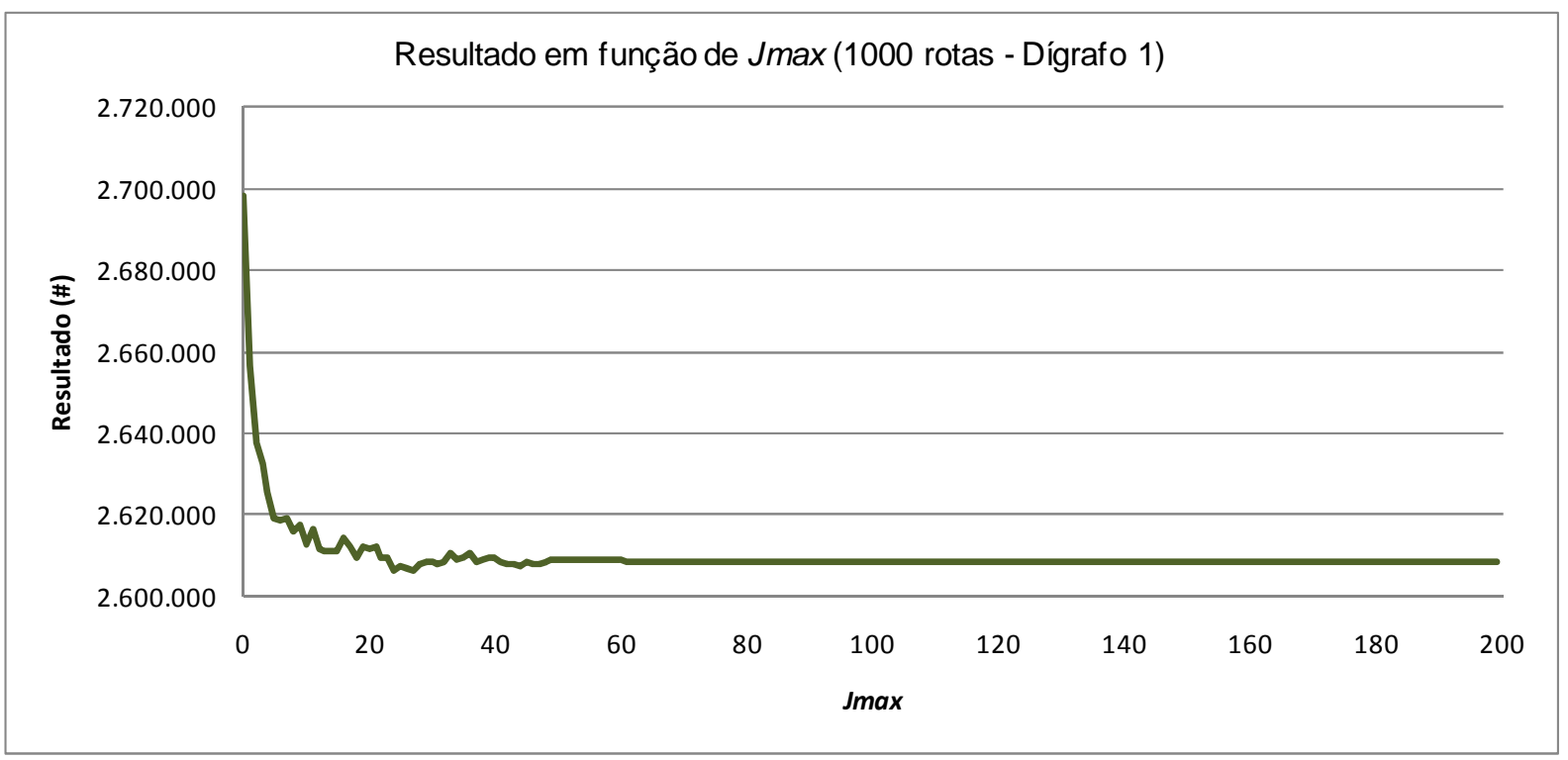

Figura B-10: Resultado em função de $j_{\max }$ para problema de 1000 rotas e dígrafo 1 e dois reposicionamentos

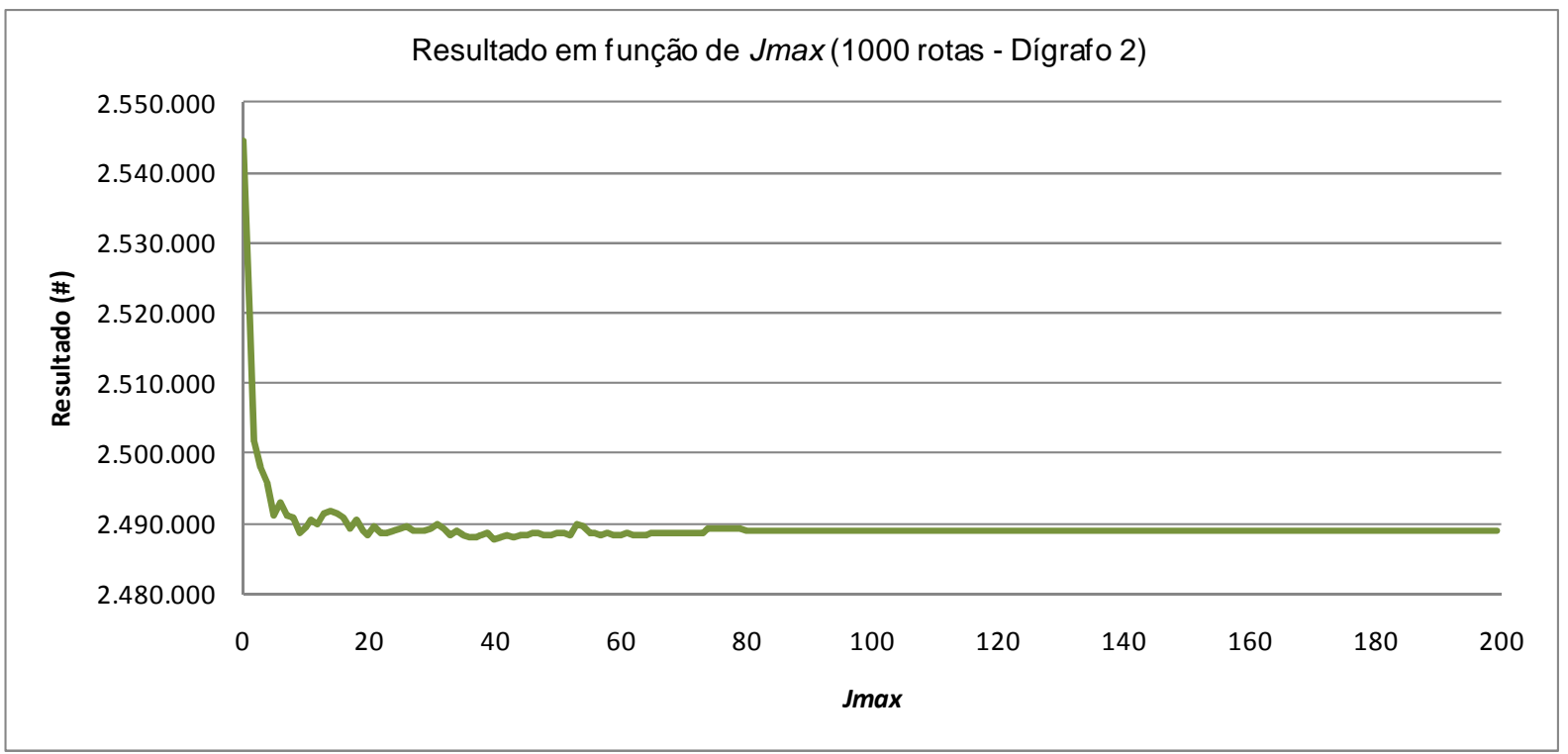

Figura B-11: Resultado em função de $j_{\max }$ para problema de 1000 rotas e dígrafo 2 e dois reposicionamentos 


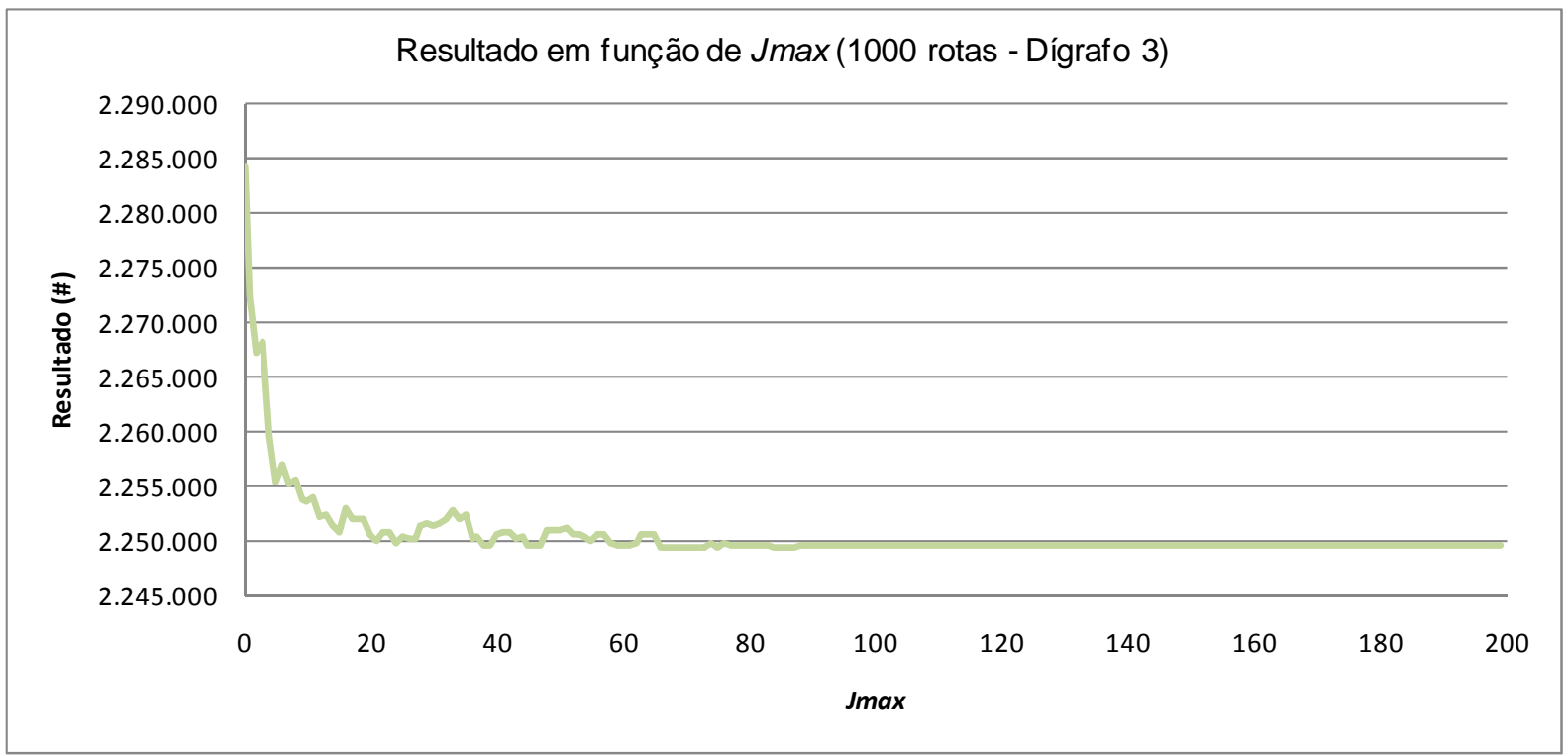

Figura B-12: Resultado em função de $j_{\max }$ para problema de 1000 rotas e dígrafo 3 e dois reposicionamentos

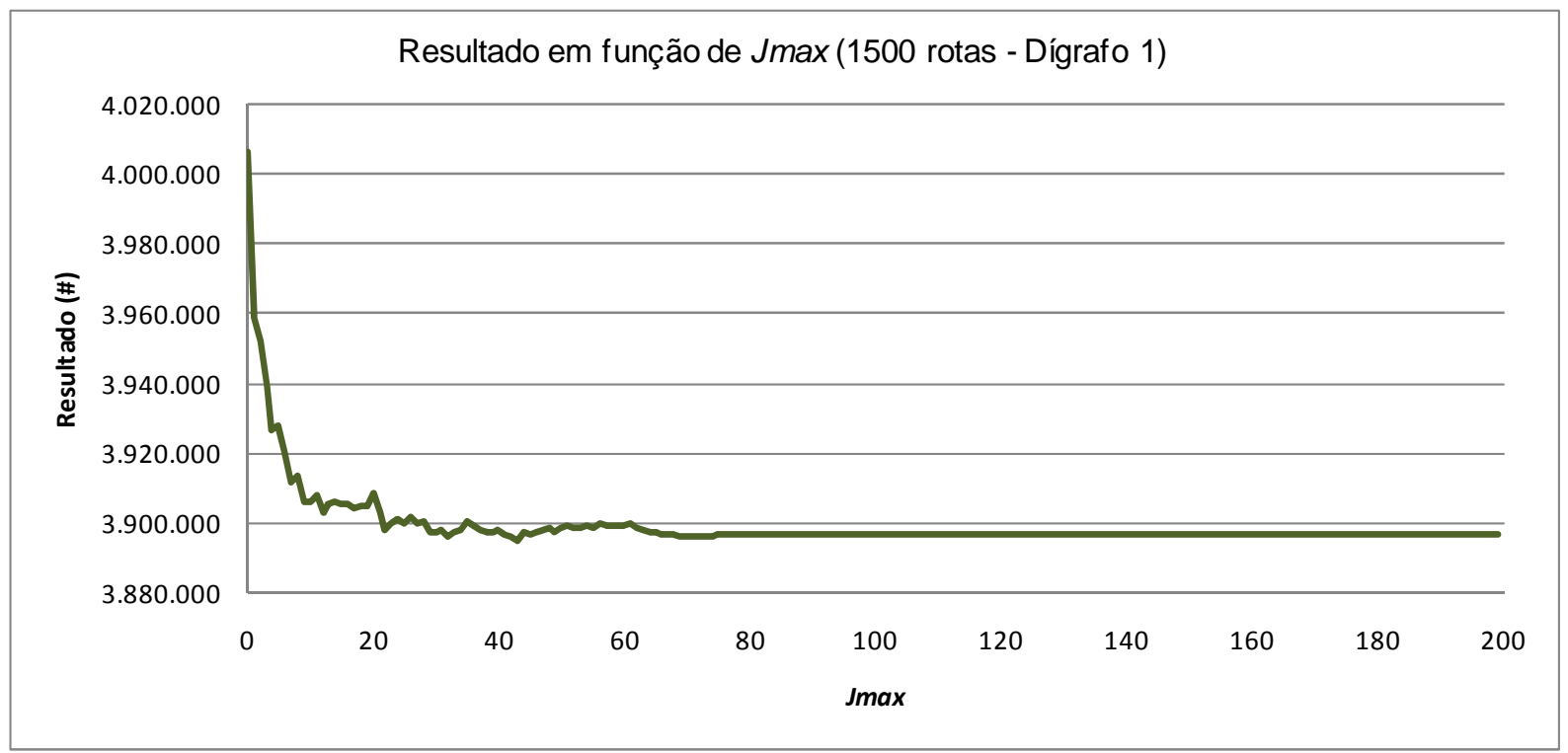

Figura B-13: Resultado em função de $j_{\max }$ para problema de 1500 rotas e dígrafo 1 e dois reposicionamentos 


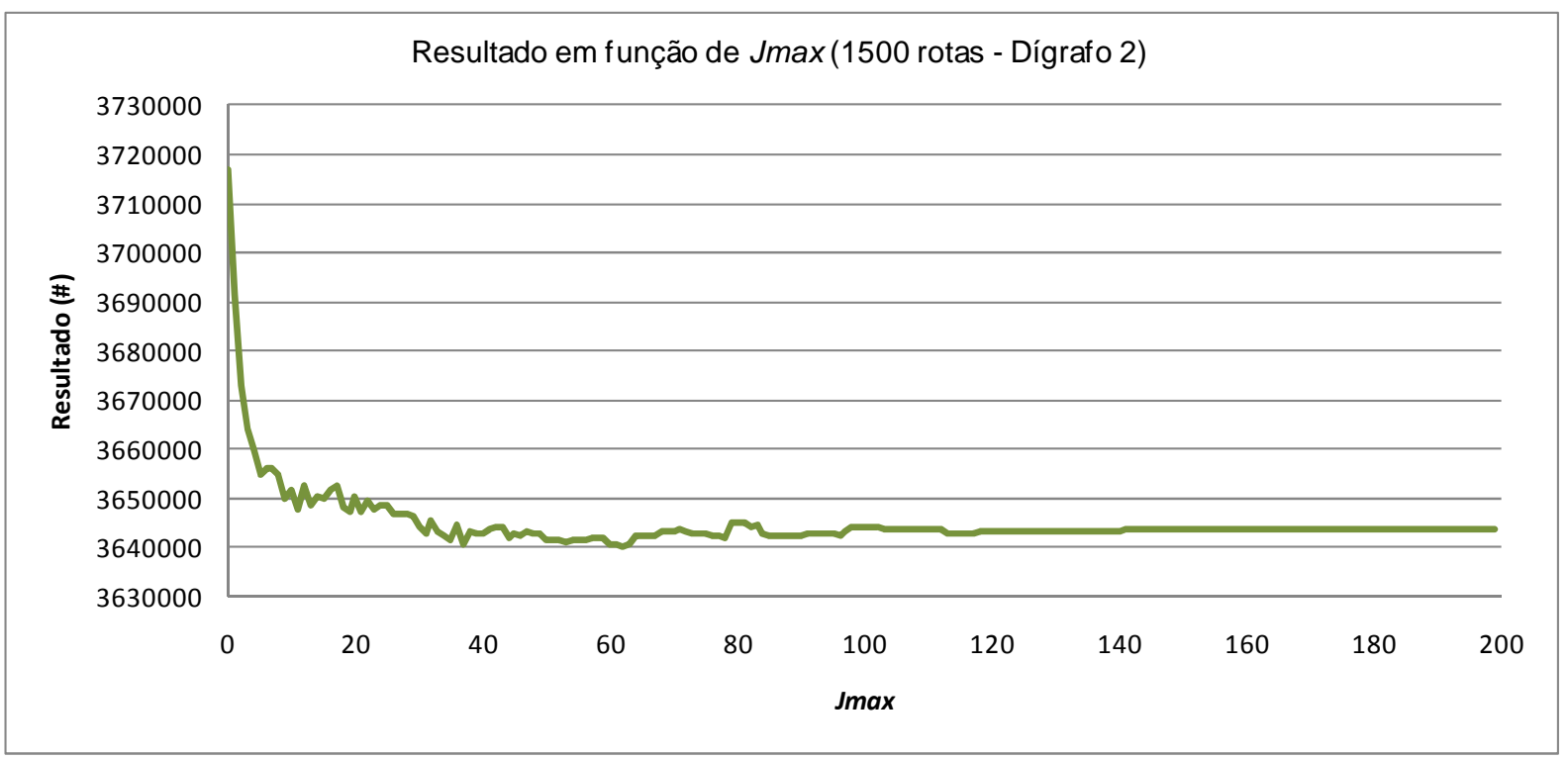

Figura B-14: Resultado em função de $j_{\max }$ para problema de 1500 rotas e dígrafo 2 e dois reposicionamentos

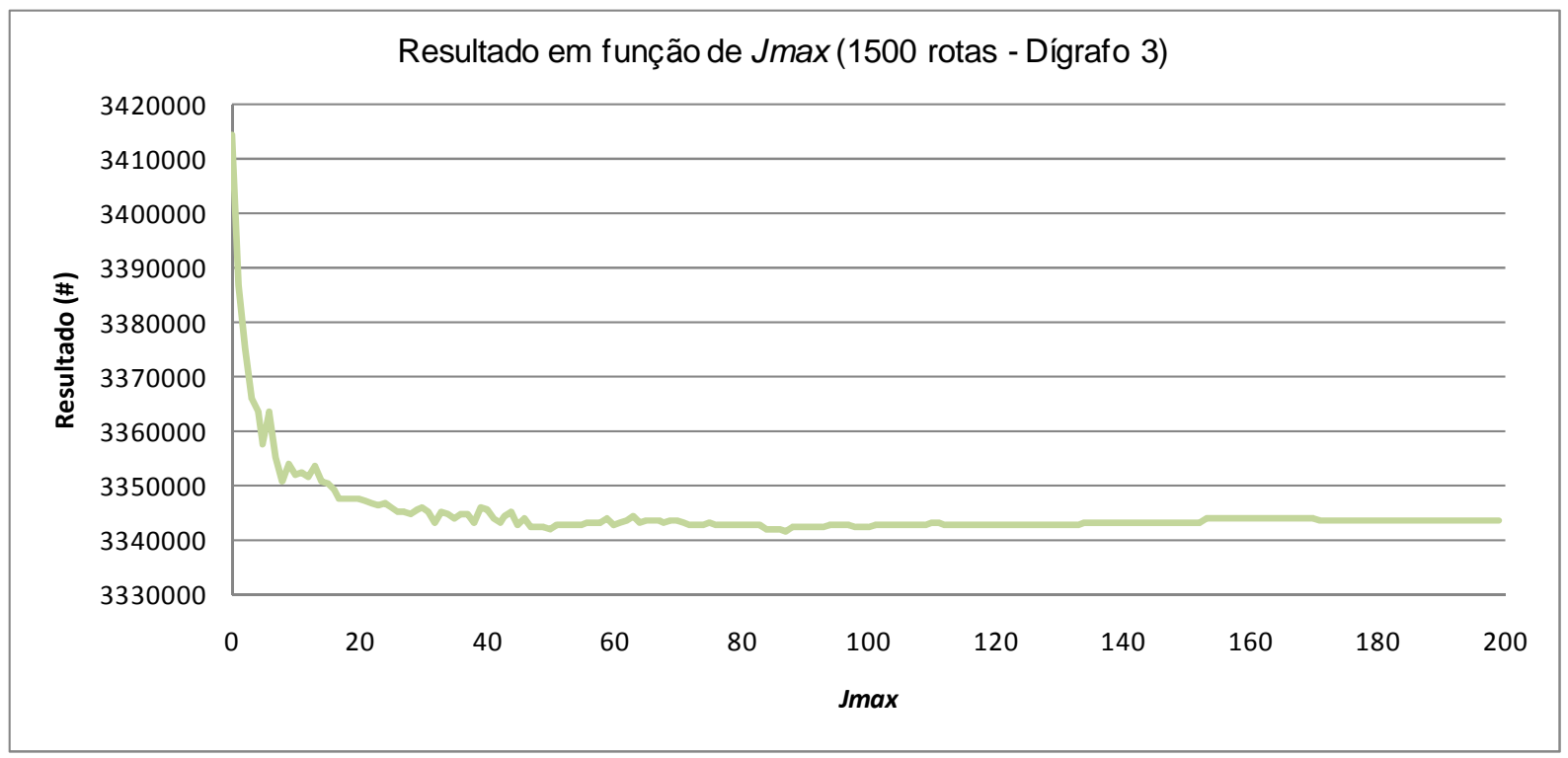

Figura B-15: Resultado em função de $j_{\max }$ para problema de 1500 rotas e dígrafo 3 e dois reposicionamentos 